UNIVERSIDADE DE SÃO PAULO

CENTRO DE ENERGIA NUCLEAR NA AGRICULTURA

DIEGO VENDRAMINI

Aspectos hidrogeoquímicos de uma microbacia reflorestada com Eucalyptus grandis no município de Angatuba - São Paulo 


\section{DIEGO VENDRAMINI}

Aspectos hidrogeoquímicos de uma microbacia reflorestada com Eucalyptus grandis no município de Angatuba - São Paulo

Dissertação apresentada ao Centro de Energia Nuclear na Agricultura da Universidade de São Paulo para obtenção do título de Mestre em Ciências.

Área de Concentração: Química na Agricultura e Ambiente

Orientador: Prof. Dr. Helder de Oliveira 
AUTORIZO A DIVULGAÇÃO TOTAL OU PARCIAL DESTE TRABALHO, POR QUALQUER MEIO CONVENCIONAL OU ELETRÔNICO, PARA FINS DE ESTUDO E PESQUISA, DESDE QUE CITADA A FONTE.

Dados Internacionais de Catalogação na Publicação (CIP)

Seção Técnica de Biblioteca - CENA/USP

Vendramini, Diego

Aspectos hidrogeoquímicos de uma microbacia reflorestada com Eucalyptus grandis no município de Angatuba - São Paulo / Diego Vendramini; orientador Helder de Oliveira. - - Piracicaba, 2009.

195 f.: il.

Dissertação (Mestrado - Programa de Pós-Graduação em Ciências. Área de Concentração: Química na Agricultura e no Ambiente) - Centro de Energia Nuclear na Agricultura da Universidade de São Paulo.

1. Água fluvial 2. Bacia hidrográfica 3. Hidrogeoquímica 4. Química aquática 5. Reflorestamento 6. Sedimentologia fluvial I. Título 
Aos meus pais

Paulo Roberto (in memorian) $e$ Rita de Cássia R. Vendramini, com muito amor e gratidão pelo grande incentivo

\section{Dedico}

Aos meus irmãos Rodrigo e Fernanda Vendramini, grandes companheiros e amigos e Viviane Cristina Blasqui pelo amor, respeito e incentivo 


\section{AGRADECIMENTOS}

Ao Prof. Dr. Helder de Oliveira, orientador, pela ótima convivência, paciência e amizade.

Ao Prof. Dr. Jefferson Mortatti, pela amizade, dedicação e ajuda na realização dos trabalhos.

Ao Prof. Dr. José Albertino Bendassoli e Prof. Dr. Paulo César Ocheuze Trivelin, pela amizade e apoio.

Ao Centro de Energia Nuclear na Agricultura (CENA/USP) pela possibilidade da realização do mestrado e a todo corpo docente pelos importantes ensinamentos.

Ao Conselho Nacional de Desenvolvimento Científico e Tecnológico pela bolsa de estudo concedida.

Aos amigos do Laboratório de Hidrogeoquímica Alexandre Martins Fernandes, Renato Alessandro Lopes, Murilo Basso Nolasco, Graziela Meneghel de Moraes e João Paulo R. Bibian pelo ótimo convívio e apoio nos trabalhos.

Aos técnicos José Aurélio Bonassi, Miguel Luiz Baldessin e Hugo Henrique Batagello pelo auxílio nas análises.

A todos os colegas do Laboratório de Isótopos Estáveis pelo apoio e amizade.

A todos os colegas do curso de Pós-graduação do Centro de Energia Nuclear na Agricultura (CENA-USP) pelos momentos de amizade e companheirismo.

A todos os amigos e parentes que contribuíram de alguma forma para realização deste importante trabalho.

À Marilia Ribeiro Garcia Henyei, pela ajuda na normatização das referências bibliográficas.

A todos aqueles que, embora não citados, foram importantes nessa etapa da minha vida. 


\section{RESUMO}

VENDRAMINI, D. Aspectos hidrogeoquímicos de uma microbacia reflorestada com Eucaliptus grandis no município de Angatuba - São Paulo. 2009. 195 f. Dissertação (Mestrado em Química na Agricultura e Ambiente) - Centro de Energia Nuclear na Agricultura, Universidade de São Paulo, Piracicaba, 2009.

O presente estudo objetivou a caracterização hidrogeoquímica da microbacia de drenagem Entre Rios, reflorestada com eucaliptos utilizando-se modelos de transporte de materiais nas fases dissolvidas e particuladas, em períodos de amostragens, antes e depois da realização da colheita de madeira. Na área experimental foram coletadas amostras de águas fluviais, material particulado em suspensão, águas de chuva, solos e sedimentos de fundo. Foram determinados importantes parâmetros e variáveis como vazão, concentração de íons majoritários e material particulado em suspensão, variabilidade temporal e transportes de material dissolvido e particulado, mecanismos de aporte difuso e pontual da carga dissolvida, separação das componentes superficial e subterrânea no escoamento total, concentração e biodisponibilidade dos principais metais pesados nos solos e sedimentos de fundo do córrego. As características hidroquímicas das águas fluviais mostraram que as espécies químicas $\mathrm{SiO}_{2}$, $\mathrm{HCO}_{3}{ }^{-}, \mathrm{Ca}^{2+}, \mathrm{Mg}^{2+}$ e $\mathrm{Na}^{+}$apresentaram comportamentos de diluição com o aumento da vazão e aportes de origem difusa, em todo período, relacionadas à formação geológica da região e mecanismos de recarga da bacia. A amostragem realizada cinco meses após a colheita de madeira evidenciou anomalias de $\mathrm{K}^{+}$e $\mathrm{Cl}^{-}$que apresentaram padrões de aumento de suas concentrações em relação ao aumento das respectivas vazões, associadas à aplicação de insumos agrícolas. O transporte específico de TDS na amostragem anterior à colheita foi de $35,81 \mathrm{~kg} \mathrm{~km}^{-2} \mathrm{~d}^{-1}$, e posterior à colheita foi de $23,53 \mathrm{~kg} \mathrm{~km}^{-2} \mathrm{~d}^{-1}$ pelo método estocástico. Tal transporte foi composto principalmente de $\mathrm{SiO}_{2}$ e $\mathrm{HCO}_{3}{ }^{-}$e a origem destas espécies estiveram associadas à alterações de rochas e aportes atmosféricos totais. Em termos de MPS, as concentrações obtidas se relacionaram positivamente com a vazão nas amostragens intensivas indicando maiores arrastes deste material nas maiores vazões, com concentrações máximas de 50,2 e 80,6 $\mathrm{mg} \mathrm{L}^{-1}$ antes e após a colheita, respectivamente. A erosão mecânica da microbacia mostrou-se com uma taxa de degradação física dos solos de $8,7 \mathrm{~m} \mathrm{Ma}^{-1}$.Em relação aos aportes atmosféricos, as espécies químicas mais representativas foram o $\mathrm{Ca}^{2+}$ e o $\mathrm{Na}^{+}$para os cátions e $\mathrm{HCO}_{3}{ }^{-}, \mathrm{NO}_{3}{ }^{-}$e $\mathrm{SO}_{4}{ }^{2-}$ para os ânions. O transporte específico do TDS nas águas de chuva foi de $4,10 \mathrm{t} \mathrm{km}^{-2} \mathrm{a}^{-1}$. Pelas razões dos transportes totais de águas pluviais e fluviais ficou evidenciado um controle dos aportes atmosféricos totais sobre as águas do córrego da microbacia. $\mathrm{Cr}, \mathrm{Cd}, \mathrm{Co}, \mathrm{Cu}, \mathrm{Zn}$ e Sc foram os metais pesados com maiores concentrações no solo LVd da microbacia. A especiação química dos solos revelou que o LVd foi solo que apresentou maior fração biodisponível para Cd e Zn e estiveram associados principalmente as frações óxidos de ferro cristalino e matéria orgânica, respectivamente. Os resultados dos fatores de enriquecimento para as camadas de $0-10 \mathrm{~cm}$ dos solos da microbacia de drenagem não evidenciaram influência antrópica causada pelos tratos culturais, exceto pelo $\mathrm{Cu}$ no solo LVAd na camada de $0-10 \mathrm{~cm}$.

Palavras-chave: Hidroquímica, mecanismos de transporte, metais pesados 


\begin{abstract}
VENDRAMINI, D. Hydrogeochemistry aspects of a Eucalyptus grandis reforested watershed in Angatuba - São Paulo. 2009. 195 f. Dissertação (Mestrado em Química na Agricultura e Ambiente) - Centro de Energia Nuclear na Agricultura, Universidade de São Paulo, Piracicaba, 2009.
\end{abstract}

This study aimed to characterize the Entre Rios stream small watershed hydrogeochemistry, reforested with eucalyptus using materials transport models in dissolved and particulate phases, in periods of sampling, before and after the clearcutting. In the experimental area were collected river water samples, suspended particulate material, rain water, soil and botton sediments. Were determined important parameters and variables such as discharge, major ions concentration, and suspended particulate material, temporal variability and dissolved and particulate transports, punctual and diffuse input mechanisms of the dissolved load, superficial and sub superficial components of the total discharge, concentration and bioavailability of the major heavy metals in soils and bottoms sediments. Hydrochemistry characteristics of the fluvial waters showed that chemical species $\mathrm{SiO}_{2}, \mathrm{HCO}_{3}^{-}, \mathrm{Ca}^{2+}, \mathrm{Mg}^{2+}$ and $\mathrm{Na}^{+}$presented dilution behavior with increasing of the discharge and diffuse input, in any period, related to the regional geological formation and watershed recharge mechanisms. Sampling performed five months after the clearcutting showed abnormalities of $\mathrm{K}^{+}$and $\mathrm{Cl}^{-}$ that showed increase of their concentrations with the discharge, associated with the agricultural inputs application. The TDS specific transport in the sample before clearcutting was $35.81 \mathrm{~kg} \mathrm{~km}^{-2} \mathrm{~d}^{-1}$, and after was $23.53 \mathrm{~kg} \mathrm{~km}^{-2} \mathrm{~d}^{-1}$ calculated by the stochastic method. This transport was composed mainly of the $\mathrm{SiO}_{2}$ and $\mathrm{HCO}_{3}{ }^{-}$and the origin of these species were associated with rock alterations and total atmospheric inputs. In terms of MPS, the concentrations were related positively with the discharge in intensive sampling indicating more haul of this material in the higher discharge with maximum concentrations of the 50.2 and $80.6 \mathrm{mg} \mathrm{L}^{-1}$ before and after clearcutting, respectively. The mechanical erosion showed a soil physical degradation tax of the $8.7 \mathrm{~m} \mathrm{Ma}^{-1}$. In relation of atmospherics inputs, the most representative chemical species were $\mathrm{Ca}^{2+}$ and $\mathrm{Na}^{+}$and $\mathrm{HCO}_{3}{ }^{-}, \mathrm{NO}_{3}{ }^{-}, \mathrm{SO}_{4}{ }^{2-}$. The TDS specific transport in rain waters was $4.10 \mathrm{t} \mathrm{km}^{-2} \mathrm{y}^{-1}$. The rations between rainwater and river transports demonstrated the control of the atmospheric total contributions in the watershed waters. $\mathrm{Cr}$, $\mathrm{Cd}, \mathrm{Co}, \mathrm{Cu}, \mathrm{Zn}$ and Sc were heavy metals with higher concentrations LVd in soil. The soils chemical speciation showed to the LVd soil higher bioavailable fraction for Cd and $\mathrm{Zn}$ and were associated mainly with crystalline iron oxides and organic matter, respectively. The enrichment factors results for the $0-10 \mathrm{~cm}$ soil layer in the watershed showed no anthropogenic influence caused by cultural treatments, except for the $\mathrm{Cu}$ in 0-10 cm LVAd soil layer.

Keywords: Hydrochemistry, transport mechanisms, heavy metals 


\section{LISTA DE FIGURAS}

Figura

Legenda

$\mathrm{Pg}$.

1 Localização geográfica da fazenda Entre Rios e microbacia de drenagem, distribuição dos talhões e ponto de coleta de águas fluviais em Angatuba, São Paulo. Fonte: Suzano Bahia Sul Papel e Celulose S.A.

2 Figura 2. Localização do ponto de amostragem, áreas plantadas e de colheita da microbacia do córrego Entre Rios. Fonte: Suzano Bahia Sul Papel e Celulose S.A. ..

3 Esquema da batimetria realizada no ponto de coleta.

4 Esquema de um vertedouro triangular de $90^{\circ}$ e adotado no presente estudo. Fonte: extraído de Cruciani (1993).

5 Esquema utilizado para construção do vertedouro empregado para as medidas de vazões do córrego Entre Rios, Angatuba, São Paulo.

6 Esquema do coletor de águas de chuva instalado na estação meteorológica da empresa (desenvolvido por Mortatti, 1995).

7 Pontos de amostragem dos solos CXbd, LVAd, LVd e RQo na microbacia Entre Rios, Angatuba, São Paulo. Fonte: Suzano Bahia Sul Papel e Celulose S.A.

8 Instalação do vertedouro na microbacia do córrego Entre Rios, Angatuba, São Paulo.

9 Detalhe da instalação do pluviômetro utilizado para amostragens de águas pluviais e medidas dos volumes de chuva na estação meteorológica da Fazenda Entre Rios. ..

10 Variação sazonal da precipitação total mensal $(\mathrm{mm})$, durante os meses de janeiro a dezembro no período de 1995 a 2007, na microbacia Entre Rios.

11 Variação da precipitação total mensal $(\mathrm{mm})$, durante os meses de janeiro a dezembro de 2006 e 2007, na microbacia Entre Rios, Angatuba, São Paulo.

12 Precipitações diárias (mm) e vazões $\left(\mathrm{L} \mathrm{s}^{-1}\right)$ medidas no período de 26/09/2006 a 05/12/2007, na microbacia do córrego Entre Rios, Angatuba, São Paulo.

13 Hidrograma de cheia referente ao período de amostragem da primeira intensiva de águas fluviais, realizada no período de 17/03/2007 a 18/07/2007 na microbacia Entre Rios.

14 Hidrograma de cheia referente ao período de amostragem da segunda intensiva de águas fluvais, realizada em 05/12/2007 na microbacia Entre Rios, Angatuba, São Paulo.

15 Separação dos hidrogramas de cheia nos reservatórios superficial rápido (Qr) e (Qn) pelo método de filtros numéricos, correspondentes respectivamente a primeira e segunda amostragem intensiva no córrego Entre Rios.

16 Erro analítico relativo (\%) ao equilíbrio iônico entre cátions e ânions referente a 14 excursões de amostras de águas fluviais da microbacia.

17 Razão entre a soma de cátions e de ânions nas amostras de águas do córrego Entre Rios, Angatuba, São Paulo, no período de 26/09/2006 a 05/12/2007.

18 Porcentagem das principais espécies químicas dissolvidas no córrego Entre Rios, Angatuba, São Paulo em função do TDS no período de 26/09/2006 a 05/12/2007. ... 
19 Variabilidade temporal da concentração $\left(\mathrm{mg} \mathrm{L}^{-1}\right)$ de cátions além de $\mathrm{SiO}_{2}$ em função das vazões $\left(\mathrm{L} \mathrm{s}^{-1}\right)$ para as amostras de águas do córrego Entre Rios, Angatuba, São Paulo, para as amostragens extensivas.

20 Variabilidade temporal da concentração $\left(\mathrm{mg} \mathrm{L}^{-1}\right)$ de ânions e TDS em função das vazões $\left(\mathrm{L} \mathrm{s}^{-1}\right)$ para as amostras de águas do córrego Entre Rios, Angatuba, São Paulo, para as amostragens extensivas.

21 Variabilidade temporal da concentração $\left(\mathrm{mg} \mathrm{L}^{-1}\right)$ de ânions e TDS em função das vazões $\left(\mathrm{L} \mathrm{s}^{-1}\right)$ para as amostras de águas do córrego Entre Rios, Angatuba, São Paulo, para a amostragem intensiva 1 .

22 Variabilidade temporal da concentração $\left(\mathrm{mg} \mathrm{L}^{-1}\right)$ de ânions e TDS em função das vazões $\left(\mathrm{L} \mathrm{s}^{-1}\right)$ para as amostras de águas do córrego Entre Rios, Angatuba, São Paulo, para a amostragem intensiva 1 .

23 Variabilidade temporal da concentração $\left(\mathrm{mg} \mathrm{L}^{-1}\right)$ de ânions e TDS em função das vazões $\left(\mathrm{L} \mathrm{s}^{-1}\right)$ para as amostras de águas do córrego Entre Rios, Angatuba, São Paulo, para a amostragem intensiva 2.

24 Variabilidade temporal da concentração $\left(\mathrm{mg} \mathrm{L}^{-1}\right)$ de ânions e TDS em função das vazões $\left(\mathrm{L} \mathrm{s}^{-1}\right)$ para as amostras de águas do córrego Entre Rios, Angatuba, São Paulo, para a amostragem intensiva 2.

25 Relacionamento entre a concentração de $\mathrm{Ca}^{2+}\left(\mathrm{mg} \mathrm{L}^{-1}\right)$ e a vazão $\left(\mathrm{L} \mathrm{s}^{-1}\right)$, dissolvidos no córrego Entre Rios, Angatuba, São Paulo, para as amostragens total, intensiva 1 e 2 .

26 Relacionamento entre a concentração de $\mathrm{Mg}^{2+}\left(\mathrm{mg} \mathrm{L}^{-1}\right)$ e a vazão $\left(\mathrm{L} \mathrm{s}^{-1}\right)$, dissolvidos no córrego Entre Rios, Angatuba, São Paulo, para as amostragens total, intensiva 1 e 2 .

27 Relacionamento entre a concentração de $\mathrm{Mg}^{2+}\left(\mathrm{mg} \mathrm{L}^{-1}\right)$ e a vazão $\left(\mathrm{L} \mathrm{s}^{-1}\right)$, dissolvidos no córrego Entre Rios, Angatuba, São Paulo, para as amostragens total, intensiva 1 e 2 .

28 Relacionamento entre a concentração de $\mathrm{K}^{+}\left(\mathrm{mg} \mathrm{L}^{-1}\right)$ e a vazão $\left(\mathrm{L} \mathrm{s}^{-1}\right)$, dissolvidos no córrego Entre Rios, Angatuba, São Paulo, para as amostragens total, intensiva 1 e 2 .

29 Relacionamento entre a concentração de $\mathrm{Cl}^{-}\left(\mathrm{mg} \mathrm{L}^{-1}\right)$ e a vazão $\left(\mathrm{L} \mathrm{s}^{-1}\right)$, dissolvidos no córrego Entre Rios, Angatuba, São Paulo, para as amostragens total, intensiva 1 e 2 .

30 Relacionamento entre a concentração de $\mathrm{NO}_{3}{ }^{-}\left(\mathrm{mg} \mathrm{L}^{-1}\right)$ e a vazão $\left(\mathrm{L} \mathrm{s}^{-1}\right)$, dissolvidos no córrego Entre Rios, Angatuba, São Paulo, para as amostragens total, intensiva 1 e 2 .

31 Relacionamento entre a concentração de $\mathrm{SO}_{4}{ }^{2-}\left(\mathrm{mg} \mathrm{L}^{-1}\right)$ e a vazão $\left(\mathrm{L} \mathrm{s}^{-1}\right)$, dissolvidos no córrego Entre Rios, Angatuba, São Paulo, para as amostragens total, intensiva 1 e 2 .

32 Relacionamento entre a concentração de $\mathrm{HCO}_{3}^{-}\left(\mathrm{mg} \mathrm{L}^{-1}\right)$ e a vazão $\left(\mathrm{L} \mathrm{s}^{-1}\right)$, dissolvidos no córrego Entre Rios, Angatuba, São Paulo, para as amostragens total, intensiva 1 e 2 .

33 Relacionamento entre a concentração de $\mathrm{SiO}_{2}\left(\mathrm{mg} \mathrm{L}^{-1}\right)$ e a vazão $\left(\mathrm{L} \mathrm{s}^{-1}\right)$, dissolvidos no córrego Entre Rios, Angatuba, São Paulo, para as amostragens total, intensiva 1 e 2 . 
34 Relacionamento entre a concentração de TDS $\left(\mathrm{mg} \mathrm{L}^{-1}\right)$ e a vazão $\left(\mathrm{L} \mathrm{s}^{-1}\right)$, dissolvidos no córrego Entre Rios, Angatuba, São Paulo, para as amostragens total, intensiva 1 e 2 .

35 Diagramas ternários de cátions e ânions dissolvidos nas águas fluviais do córrego Entre Rios, Angatuba, São Paulo, nos períodos estudados.

36 Relacionamento entre as vazões nos respectivos intervalos de tempo e as taxas de transportes parciais para o TDS nos períodos de coletas intensiva 1 e 2 , na microbacia do córrego Entre Rios.

37 Variabilidade temporal das concentrações de material particulado em suspensão (MPS) e vazões (Q) na microbacia Entre Rios, durante o período de 26/09/2006 a 05/12/2007.

38 Valores de vazão e concentração de MPS em função do tempo da primeira amostragem intensiva, realizada no período de 17 e 18/03/2007 no córrego Entre Rios.

39 Valores de vazão e concentração de MPS em função do tempo da segunda amostragem intensiva, realizada no período de 17 e 18/03/2007 no córrego Entre Rios.

40 Variabilidade das concentrações do material particulado em suspensão (MPS) em função da vazão $(\mathrm{Q})$ para o córrego Entre Rios na amostragem intensiva 1.

41 Variabilidade das concentrações do material particulado em suspensão (MPS) em função da vazão $(\mathrm{Q})$ para o córrego Entre Rios na amostragem intensiva 2.

42 Relacionamento entre a soma de cátions $\left(\Sigma^{+}\right)$e a soma de ânions $\left(\Sigma^{-}\right)$nas amostras de água de chuva na microbacia de drenagem Entre Rios no período de 13/10/2006 a $17 / 02 / 2008$.

43 Abundância relativa em porcentagem das principais espécies químicas nas águas pluviais da microbacia de drenagem Entre Rios referente ao período de 13/10/2006 a $17 / 02 / 2008$.

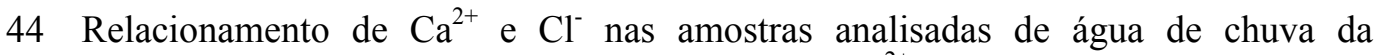
microbacia de drenagem Entre Rios com a razão $\mathrm{Ca}^{2+} / \mathrm{Cl}^{-}$dos sais cíclicos na chuva marinha, durante o período estudado.

45 Relacionamento de $\mathrm{Mg}^{2+}$ e $\mathrm{Cl}^{-}$nas amostras analisadas de água de chuva da microbacia de drenagem Entre Rios com a razão $\mathrm{Mg}^{2+} / \mathrm{Cl}^{-}$dos sais cíclicos na chuva marinha, durante o período estudado.

46 Relacionamento de $\mathrm{Na}^{+}$e $\mathrm{Cl}^{-}$nas amostras analisadas de água de chuva da microbacia de drenagem Entre Rios com a razão $\mathrm{Na}^{+} / \mathrm{Cl}^{-}$dos sais cíclicos na chuva marinha, durante o período estudado.

47 Relacionamento de $\mathrm{K}^{+}$e $\mathrm{Cl}^{-}$nas amostras analisadas de água de chuva da microbacia de drenagem Entre Rios com a razão $\mathrm{K}^{+} / \mathrm{Cl}^{-}$dos sais cíclicos na chuva marinha, durante o período estudado.

48 Relacionamento de $\mathrm{SO}_{4}{ }^{2-}$ e $\mathrm{Cl}^{-}$nas amostras analisadas de água de chuva da microbacia de drenagem Entre Rios com a razão $\mathrm{SO}_{4}{ }^{2-} / \mathrm{Cl}^{-}$dos sais cíclicos na chuva marinha, durante o período estudado.

49 Porcentagem de $\mathrm{Cr}$ lixiviado nas etapas de S1 a S7, frações biodisponível (Bio) e residual (Res) para o solo CXbd, na microbacia Entre Rios, Angatuba, São Paulo. ... 
50 Porcentagem de Cr lixiviado nas etapas de S1 a S7, frações biodisponível (Bio) e residual (Res) para o solo LVAd, na microbacia Entre Rios, Angatuba, São Paulo...

51 Porcentagem de Cr lixiviado nas etapas de S1 a S7, frações biodisponível (Bio) e residual (Res) para o solo LVd, na microbacia Entre Rios, Angatuba, São Paulo. .....

52 Porcentagem de Cr lixiviado nas etapas de S1 a S7, frações biodisponível (Bio) e residual (Res) para o solo RQo, na microbacia Entre Rios, Angatuba, São Paulo. .....

53 Porcentagem de Cr lixiviado nas etapas de S1 a S7, frações biodisponível (Bio) e residual (Res) para as amostras de sedimentos de fundo ITA1 e ITA10 coletadas no período chuvoso e seco, respectivamente, na microbacia Entre Rios, Angatuba. .......

54 Porcentagem de Cd lixiviado nas etapas de S1 a S7, frações biodisponível (Bio) e residual (Res) para o solo CXbd, na microbacia Entre Rios, Angatuba, São Paulo. ...

55 Porcentagem de Cd lixiviado nas etapas de S1 a S7, frações biodisponível (Bio) e residual (Res) para o solo LVAd, na microbacia Entre Rios, Angatuba, São Paulo...

56 Porcentagem de Cd lixiviado nas etapas de S1 a S7, frações biodisponível (Bio) e residual (Res) para o solo LVd, na microbacia Entre Rios, Angatuba, São Paulo. .....

57 Porcentagem de Cd lixiviado nas etapas de S1 a S7, frações biodisponível (Bio) e residual (Res) para o solo RQo, na microbacia Entre Rios, Angatuba, São Paulo. .....

58 Porcentagem de Cd lixiviado nas etapas de S1 a S7, frações biodisponível (Bio) e residual (Res) para as amostras de sedimentos de fundo ITA1 e ITA10 coletadas no período chuvoso e seco, respectivamente, na microbacia Entre Rios, Angatuba, São Paulo.

59 Porcentagem de $\mathrm{Pb}$ lixiviado nas etapas de $\mathrm{S} 1$ a $\mathrm{S} 7$, frações biodisponível (Bio) e residual (Res) para o solo LVd, na microbacia Entre Rios, Angatuba, São Paulo. .....

60 Porcentagem de Ni lixiviado nas etapas de S1 a S7, frações biodisponível (Bio) e residual (Res) para o solo LVd, na microbacia Entre Rios, Angatuba, São Paulo. .....

61 Porcentagem de Co lixiviado nas etapas de S1 a S7, frações biodisponível (Bio) e residual (Res) para o solo CXbd, na microbacia Entre Rios, Angatuba, São Paulo. ...

62 Porcentagem de Co lixiviado nas etapas de S1 a S7, frações biodisponível (Bio) e residual (Res) para o solo LVAd, na microbacia Entre Rios, Angatuba, São Paulo...

63 Porcentagem de Co lixiviado nas etapas de S1 a S7, frações biodisponível (Bio) e residual (Res) para o solo LVd, na microbacia Entre Rios, Angatuba, São Paulo. .....

64 Porcentagem de Co lixiviado nas etapas de S1 a S7, frações biodisponível (Bio) e residual (Res) para o solo RQo, na microbacia Entre Rios, Angatuba, São Paulo. .....

65 Porcentagem de Co lixiviado nas etapas de S1 a S7, frações biodisponível (Bio) e residual (Res) para as amostras de sedimentos de fundo ITA1 e ITA10 coletadas no período chuvoso e seco, respectivamente, na microbacia Entre Rios, Angatuba, São Paulo.

66 Porcentagem de $\mathrm{Cu}$ lixiviado nas etapas de S1 a S7, frações biodisponível (Bio) e residual (Res) para o solo CXbd, na microbacia Entre Rios, Angatuba, São Paulo. ...

67 Porcentagem de $\mathrm{Cu}$ lixiviado nas etapas de S1 a S7, frações biodisponível (Bio) e residual (Res) para o solo LVAd, na microbacia Entre Rios, Angatuba, São Paulo...

68 Porcentagem de $\mathrm{Cu}$ lixiviado nas etapas de S1 a S7, frações biodisponível (Bio) e residual (Res) para o solo LVd, na microbacia Entre Rios, Angatuba, São Paulo. ..... 
69 Porcentagem de $\mathrm{Cu}$ lixiviado nas etapas de S1 a S7, frações biodisponível (Bio) e residual (Res) para o solo RQo, na microbacia Entre Rios, Angatuba, São Paulo. .....

70 Porcentagem de $\mathrm{Cu}$ lixiviado nas etapas de $\mathrm{S} 1$ a S7, frações biodisponível (Bio) e residual (Res) para as amostras de sedimentos de fundo ITA1 e ITA10 coletadas no período chuvoso e seco, respectivamente, na microbacia Entre Rios, Angatuba, São Paulo.

71 Porcentagem de Zn lixiviado nas etapas de S1 a S7, frações biodisponível (Bio) e residual (Res) para o solo CXbd, na microbacia Entre Rios, Angatuba, São Paulo. ...

72 Porcentagem de Zn lixiviado nas etapas de S1 a S7, frações biodisponível (Bio) e residual (Res) para o solo LVAd, na microbacia Entre Rios, Angatuba, São Paulo. ..

73 Porcentagem de Zn lixiviado nas etapas de S1 a S7, frações biodisponível (Bio) e residual (Res) para o solo LVd, na microbacia Entre Rios, Angatuba, São Paulo. .....

74 Porcentagem de Zn lixiviado nas etapas de S1 a S7, frações biodisponível (Bio) e residual (Res) para as amostras de sedimentos de fundo ITA1 e ITA10 coletadas no período chuvoso e seco, respectivamente, na microbacia Entre Rios, Angatuba, São Paulo.

75 Porcentagem de Sc lixiviado nas etapas de S1 a S7, frações biodisponível (Bio) e residual (Res) para o solo CXbd, na microbacia Entre Rios, Angatuba, São Paulo. ...

76 Porcentagem de Sc lixiviado nas etapas de S1 a S7, frações biodisponível (Bio) e residual (Res) para o solo LVAd, na microbacia Entre Rios, Angatuba, São Paulo. ..

77 Porcentagem de Sc lixiviado nas etapas de S1 a S7, frações biodisponível (Bio) e residual (Res) para o solo LVd, na microbacia Entre Rios, Angatuba, São Paulo. .....

78 Figura 78. Porcentagem de Sc lixiviado nas etapas de S1 a S7, frações biodisponível (Bio) e residual (Res) para o solo RQo, na microbacia Entre Rios, Angatuba, São Paulo.

79 Figura 79. Porcentagem de Sc lixiviado nas etapas de S1 a S7, frações biodisponível (Bio) e residual (Res) para as amostras de sedimentos de fundo ITA1 e ITA10 coletadas no período chuvoso e seco, respectivamente, na microbacia Entre Rios, Angatuba, São Paulo. 


\section{LISTA DE TABELAS}

1 Informações gerais da área da microbacia e povoamento de árvores existentes na microbacia do córrego Entre Rios, Angatuba, São Paulo. Fonte: Suzano Bahia Sul Papel e Celulose S.A.

2 Tabela 2. Procedimento de extração sequencial em 7 etapas.

3 Resultados de vazão (Q), pH, condutividade elétrica (Cond.), oxigênio dissolvido (OD) e temperatura $(\mathrm{T})$ referentes às excursões realizadas na microbacia Entre Rios.

4 Resultados analíticos das principais espécies químicas dissolvidas (cátions e ânions) nas águas do córrego Entre Rios, Angatuba, São Paulo.

5 Matriz dos coeficientes de correlação entre as principais espécies químicas dissolvidas no córrego Entre Rios, Angatuba, São Paulo, no período de amostragem extensiva.

6 Matriz dos coeficientes de correlação entre as principais espécies químicas dissolvidas no córrego Entre Rios, Angatuba, São Paulo, no período de amostragem intensiva 1.

7 Matriz dos coeficientes de correlação entre as principais espécies químicas dissolvidas no córrego Entre Rios, Angatuba, São Paulo, no período de amostragem intensiva 2.

8 Vazões e concentrações dos metais dissolvidos nas amostras de águas fluviais do córrego Entre Rios durante o período de estudo.

9 Transporte total $\left(\mathrm{T}_{\mathrm{A}}\right.$ em t a $\left.\mathrm{a} \mathrm{kg} \mathrm{d}^{-1}\right)$ e transporte específico $\left(\mathrm{T}_{\mathrm{AE}}\right.$ em $\left.\mathrm{t} \mathrm{km}^{-2} \mathrm{a}^{-1} \mathrm{~kg} \mathrm{~km}^{-2} \mathrm{~d}^{-1}\right)$ das principais espécies químicas dissolvidas ocorridas no córrego Entre Rios, Angatuba, no período das amostragens extensivas.

10 Transporte total $\left(\mathrm{T}_{\mathrm{A}}\right.$ em $\left.\mathrm{kg} \mathrm{d}^{-1}\right)$ e transporte específico $\left(\mathrm{T}_{\mathrm{AE}}\right.$ em $\left.\mathrm{kg} \mathrm{km}^{-2} \mathrm{~d}^{-1}\right)$ das principais espécies químicas dissolvidas ocorridas no córrego Entre Rios, Angatuba, no período de amostragem intensiva 1.

11 Transporte total $\left(\mathrm{T}_{\mathrm{A}}\right.$ em kg d $\left.\mathrm{d}^{-1}\right)$ e transporte específico $\left(\mathrm{T}_{\mathrm{AE}}\right.$ em $\left.\mathrm{kg} \mathrm{km}^{-2} \mathrm{~d}^{-1}\right)$ das principais espécies químicas dissolvidas ocorridas no córrego Entre Rios, Angatuba, no período de amostragem intensiva 2.

12 Transporte total $\left(\mathrm{T}_{\mathrm{B}}\right.$ em $\left.\mathrm{kg} \mathrm{d}^{-1}\right)$ e transporte específico $\left(\mathrm{T}_{\mathrm{BE}}\right.$ em $\left.\mathrm{kg} \mathrm{km}^{-2} \mathrm{~d}^{-1}\right)$ das principais espécies químicas dissolvidas ocorridas no córrego Entre Rios, Angatuba, no período de amostragem intensiva 1 e 2, pelo método de integração de áreas.

13 Valores de vazão e MPS para o córrego Entre Rios, obtidos durante o período de estudo. ..

14 Resultados do transporte total ( $\mathrm{T}$ em t a $\mathrm{a}^{-1} \mathrm{~kg} \mathrm{~d}^{-1}$ ) e específico $\left(\mathrm{T}_{\mathrm{E}}\right.$ em $\mathrm{t} \mathrm{km}^{-2} \mathrm{a}^{-1}$ e kg km $\mathrm{kg}^{-2}$ $\mathrm{d}^{-1}$ ) para o MPS nas amostragens extensivas, intensiva 1 e 2 , calculados para a microbacia do córrego Entre Rios.

15 Resultados de precipitação, pH, TDS e concentrações de cátions e ânions das amostras de água de chuva ocorridas na microbacia de drenagem no período de 13/10/06 a 17/02/08.

16 Transporte pluvial total $\left(\mathrm{t} \mathrm{a}^{-1}\right)$ e específico $\left(\mathrm{t} \mathrm{km}^{2} \mathrm{a}^{-1}\right)$ das principais espécies químicas nas águas de chuva da microbacia Entre Rios relativas ao período de 01/01/2007 a 21/12/2007.

17 Análises granulométricas dos solos CXbd, LVAd, LVd, e RQo da microbacia Entre Rios, Angatuba, São Paulo.

18 Tabela 18. Composição química (\%) dos óxidos principais para as amostras de terra nas profundidades de 0-10, 10-20 e 20-40 cm dos solos CXbd, LVAd, LVd e RQo e sedimentos ITA1 e ITA10 na microbacia Entre Rios, Angatuba, São Paulo.

19 Tabela 19. Composição química $\left(\mu \mathrm{g} \mathrm{g}^{-1}\right)$ dos metais pesados principais nas amostras de solos da microbacia de drenagem Entre Rios.

20 Fatores de enriquecimento para os principais solos da microbacia de drenagem Entre Rios na profundidade de $0-10 \mathrm{~cm}$. 


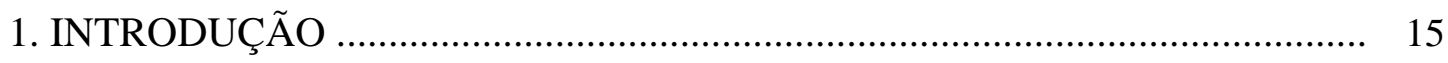

2. REVISÃO DE LITERATURA ……………………............................... 17

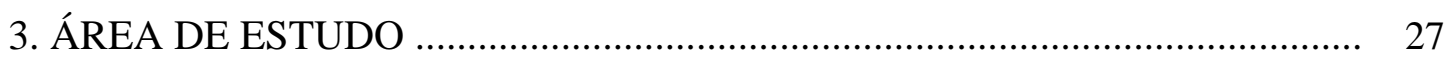

3.1. Caracterização da microbacia do córrego Entre Rios ....................................... 27

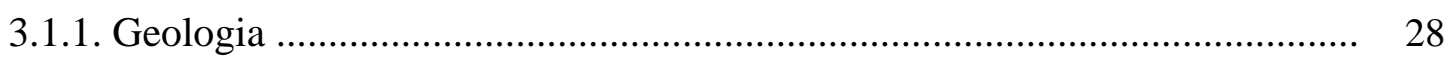

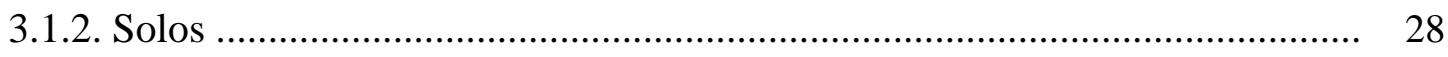

3.1.3. Vegetação ......................................................................................... 29

3.1.4. Aspectos climáticos ................................................................................. 29

3.2. Características dos pontos de amostragens .................................................. $\quad 30$

3.2.1. Águas fluviais e material particulado em suspensão (MPS) .......................... 30

3.2.2. Águas de chuva ...............................................................................

3.2.3. Pontos de amostragens dos solos da microbacia de drenagem ...................... 34

3.2.4. Sedimento de fundo …………………………….................................. 35

4. MATERIAL E MÉTODOS _......................................................................... 36

4.1. Materiais e equipamentos utilizados ............................................................ 36

4.2. Desenvolvimento metodológico .................................................................. 37

4.2.1. Protocolo de amostragem ........................................................................... 37

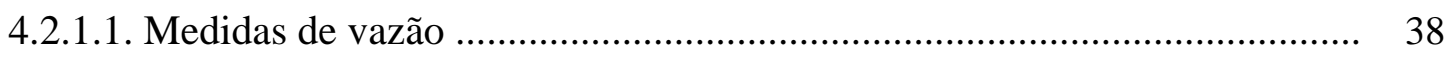

4.2.1.2. Amostragens de águas fluviais ................................................................. 39

4.2.1.3. Amostragens de águas de chuva ............................................................. 40

4.2.1.4. Amostragem de solos ........................................................................... 41

4.2.1.5. Amostragem de sedimentos de fundo ...................................................... 42

4.2.1.6. Amostragem de MPS .......................................................................... 42

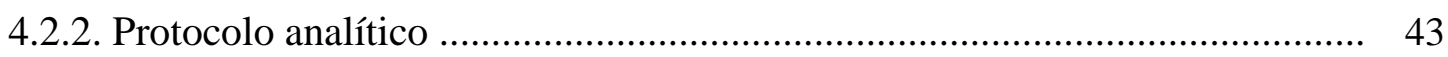

4.3. Aspectos hidrológicos da microbacia .............................................................. 44

4.4. Caracterização hidroquímica fluvial ............................................................ 46

4.4.1. Parâmetros físico-químicos ..................................................................... 46

4.4.2. Concentrações das espécies químicas fluviais e equilíbrio iônico ................. 46

4.4.3. Variabilidade temporal da concentração das principais espécies químicas .. 48

4.4.4. Relacionamento concentração-vazão ........................................................ 48

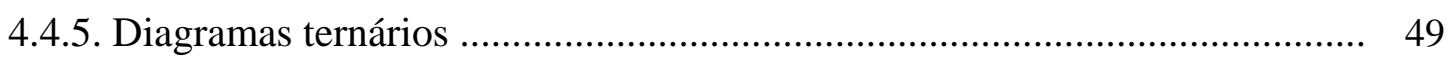

4.4.6. Matriz dos coeficientes de correlação ........................................................ 49

4.4.7. Metais dissolvidos de interesse ambiental ................................................. 49

4.4.8. Transporte fluvial de solutos ................................................................ 50

4.4.8.1. Método estocástico ................................................................................ 50 
4.4.8.2. Método de integração de áreas ............................................................. 51

4.5. Dinâmica do material particulado em suspensão (MPS) ................................ 52

4.5.1. Variabilidade temporal das concentrações de MPS ................................... 52

4.5.2. Relacionamento concentração-vazão do MPS ............................................ 52

4.5.3. Transporte fluvial de MPS ................................................................... 52

4.5.4. Degradação física da microbacia de drenagem ........................................... 53

4.6. Aportes atmosféricos totais ........................................................................... 53

4.7. Extração total e sequencial de metais nos solos e sedimentos de fundo .......... 55

4.8. Fundo geoquímico natural e fator de enriquecimento (EF) ........................... 57

5. RESULTADOS E DISCUSSÃO ............................................................. 59

5.1. Aspectos hidrológicos da microbacia ........................................................ 59

5.2. Caracterização da hidroquímica fluvial ...................................................... 65

5.2.1. Parâmetros físico-químicos ........................................................................ 65

5.2.2. Concentração das espécies químicas fluviais e equilíbrio iônico ................. 68

5.2.3. Variabilidade temporal das concentrações das principais espécies químicas 72

5.2.4. Relacionamento concentração-vazão ................................................... 80

5.2.5. Diagramas ternários ........................................................................... 95

5.2.6. Matriz dos coeficientes de correlação ....................................................... 97

5.2.7. Metais dissolvidos de interesse ambiental ............................................... 99

5.2.8. Transporte fluvial de solutos ............................................................ 101

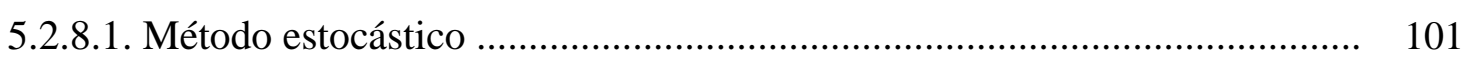

5.2.8.2. Método de integração de áreas .............................................................. 104

5.3. Dinâmica do material particulado em suspensão (MPS) ................................ 108

5.3.1. Variabilidade temporal das concentrações de MPS .................................... 108

5.3.2. Relacionamento concentração-vazão de MPS ........................................... 112

5.3.3. Transporte fluvial de MPS ................................................................... 114

5.3.4. Degradação física da microbacia de drenagem ........................................ 115

5.4. Aportes atmosféricos totais ..................................................................... 116

5.5. Extração total e sequencial de metais nos solos e sedimentos de fundo .......... 125

5.6. Fundo geoquímico natural e fator de enriquecimento (EF) ........................... 161

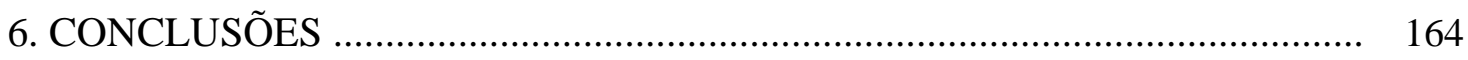

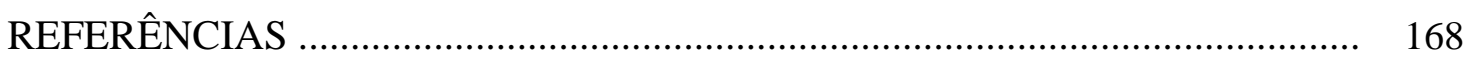

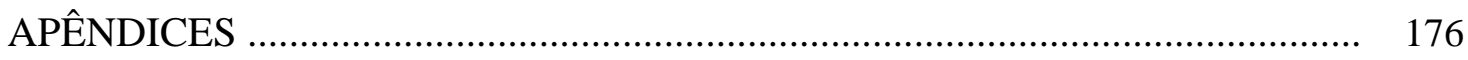




\section{INTRODUÇÃO}

O plantio de florestas homogêneas para exploração de madeira na indústria de papel e celulose vem aumentando substancialmente no país nas últimas décadas, sendo o Brasil, o maior produtor mundial de celulose com uma área plantada de eucaliptos superior a 3 milhões de hectares. Aliado ao crescente aumento de florestas homogêneas surgiu também a preocupação com os possíveis impactos ao meio ambiente devido a práticas silviculturais como preparo do solo, a exploração de madeira, a abertura, utilização e manutenção de estradas e carreadores que promovem alterações ambientais nas taxas de nutrientes transportados fluvialmente, erosões, decomposição de húmus, modificação nos processos biológicos e qualidade da água nas bacias de drenagem.

Independente do seu tamanho, as microbacias constituem ecossistemas adequados para avaliação de impactos causados pelas atividades antrópicas e o conhecimento das relações físicas, químicas e biológicas nestes ecossistemas, possibilitam o estabelecimento de um manejo adequado de uso da terra. Para Jenkins et al. (1994), qualquer bacia hidrográfica, independente de sua escala, pode ser considerada como unidade de estudo ideal, porque seus cursos d'água refletem toda a dinâmica daquele sistema.

A qualidade das águas em bacias ou microbacias de drenagem depende das interações dela com o ambiente (WALLING, 1980) e a avaliação de possíveis alterações a que estão sujeitos os ecossistemas naturais, sob ocupação intensiva agrícola, pode ser realizada com a utilização de diferentes metodologias, as quais se encontram associadas ao controle físico-químico das águas e ao transporte de material em suspensão em toda bacia de drenagem, constituindo-se desta maneira um monitoramento hidrogeoquímico (MORTATTI, 1995). 
O monitoramento hidrogeoquímico tem sido amplamente investigado em bacias de drenagem naturais, na Amazônia, na África e na Europa (MEYBECK, 1976; PROBST, 1983; BERNER et al., 1983; BOEGLIN et al., 1997; NKOUNKOU; PROBST, 1987; AMIOTTESUCHET, 1995; MESSAITFA, 1997; PERAY, 1998), e também em bacias agrícolas sob forte influência antrópica, como é o caso da bacia do rio Piracicaba, no Estado de São Paulo (BORTOLETTO JÚNIOR, 2004).

Em microbacias estes estudos não são muito frequentes, como o de Bibian (2007), que realizou a caracterização dos principais parâmetros hidrogeoquímicos na microbacia de drenagem do córrego Barra Bonita, no Estado de São Paulo, com área de 29,31 km², utilizando modelos de transporte de material nas fases dissolvida e particulada. No Brasil, outros trabalhos pioneiros foram desenvolvidos como os de Lima (1988), Vital et al. (1999) e Ranzini e Lima (2002), que utilizaram microbacias experimentais em regiões reflorestadas para avaliar seu comportamento hidrológico e as perdas de solos e nutrientes. Tais trabalhos tiveram um forte enfoque hidroquímico, embora não contemplando uma avaliação a componente geológica das microbacias, que é um importante parâmetro para estudos de transporte de material dissolvido.

Mediante ao exposto, o presente trabalho teve como objetivo realizar uma caracterização hidrogeoquímica na microbacia de drenagem Entre Rios, no município de Angatuba, São Paulo, reflorestada com eucaliptos utilizando-se modelos de transporte de material nas fases dissolvida e particulada, em distintos períodos e situações de amostragens, antes e depois da realização da colheita de madeira, procurando contribuir para um melhor entendimento dos processos de ocupação do solo bem com sua relação com a qualidade de água da referida microbacia, fornecendo subsídios para averiguações do seu grau de degradação. 


\section{REVISÃO DA LITERATURA}

Bacia hidrográfica ou bacia de drenagem pode ser definida como uma unidade de estudo que compreende os atributos físicos, químicos e biológicos do ecossistema terrestre de uma determinada região (BIBIAN, 2007). Sua delimitação está condicionada topograficamente pelas curvas de nível do terreno que convergem toda água oriunda das precipitações ou de corpos d’água superficiais localizados dentro deste limite para um canal de drenagem principal que podem ser rios, córregos e ribeirões (SWAMI; MATTOS, 1975). A microbacia de drenagem pode ser entendida como a menor unidade da paisagem para realização de estudos e processos hidrológicos (WALLING, 1980).

As bacias hidrográficas, independente da escala, são consideradas unidades de fundamental importância porque seus cursos d'água refletem toda a dinâmica daquele sistema (JENKINS et al., 1994). Seu estudo permite avaliar os principais impactos decorrentes da ocupação de sua área pelos interesses humanos (ODUM, 1988).

A escolha de uma bacia hidrográfica em estudos para mitigar a ocupação do solo por ações antrópicas reflete na preocupação em se utilizar os recursos como água, a madeira, os alimentos, as fibras, as pastagens, a vida silvestre, a recreação e outros componentes ambientais que podem ser produzidos e explorados para atender às necessidades da crescente população mundial (BROOKS et al., 1991).

Neste sentido, torna-se evidente que independente da escala espacial de uma bacia hidrográfica, o contínuo monitoramento dos sistemas fluviais pode evidenciar as principais alterações naturais e antrópicas que estão ocorrendo dentro de seus limites. Estes sistemas que na maioria das vezes estão sob forte influência dos diversos tipos de ocupação intensiva urbana, industrial ou agrícola, podem ser avaliados por diferentes metodologias que levam principalmente a busca da caracterização físico-química das águas fluviais e seu 
relacionamento com as características geológicas das bacias de drenagem em que se encontram (MORTATTI, 1995).

A origem da composição química da carga fluvial dissolvida pode estar relacionada a três fontes principais: uma relativa ao intemperismo de rochas que está ocorrendo no perfil rochoso da bacia; uma segunda relativa às atividades antrópicas nas bacias de drenagem que, em muitos casos possam ser de extrema importância, como nos casos de poluição crônica, e outra, relativa à entrada por meio de aportes atmosféricos, sob forma de precipitações (PROBST et al., 1994 e MORTATTI et al., 1997).

No estudo do balanço hidrogeoquímico de espécies químicas majoritárias, o estudo dos aportes atmosféricos totais é um importante parâmetro quando se faz necessárias correções nas cargas transportadas fluvialmente. A literatura contempla vários estudos sobre a carga dissolvida em águas pluviais, principalmente em grandes e médias bacias de drenagem (STALLARD; EDMOND, 1981; MORTATTI, 1995; NKOUNKOU; PROBST, 1987).

A caracterização físico-química das águas fluviais e seu relacionamento com as características geológicas têm sido amplamente investigado em diversas regiões do mundo com diferentes propósitos.

Tardy (1968 e 1971) baseado no estudo da composição química das águas de drenagem e na dinâmica do intemperismo em bacias na França, Noruega, Saara, Senegal, Chade, Costa do Marfim e Malásia, propôs um método de cálculo para se conhecer a razão $\mathrm{SiO}_{2} / \mathrm{Al}_{2} \mathrm{O}_{3}$ em rochas graníticas que mostra quais os tipos de materiais estão sendo formados em determinadas regiões.

Stallard e Edmond (1983) estudaram a relação entre as características geológicas e a carga dissolvida nas águas fluviais dos principais rios da bacia amazônica (seis milhões de quilômetros quadrados). As principais razões utilizadas para caracterização do material dissolvido no referido trabalho foram $\left(\mathrm{Ca}^{2+}+\mathrm{Mg}^{2+} / \mathrm{HCO}_{3}{ }^{-}+\mathrm{SO}_{4}{ }^{2-}\right)$ e $\left(\left(\mathrm{Na}^{+}+\mathrm{K}^{+}\right) / \mathrm{Cl}^{-}\right)$para 
rochas evaporíticas e, $\left(\mathrm{K}^{+} /\left(\mathrm{Na}^{+}-\mathrm{Cl}^{-}\right)+\mathrm{K}^{+}\right)$para rochas silicatadas. Em suas conclusões, foi verificado que as amostras podiam ser separadas em quatro principais grupos: rios que drenam regiões já bastante intemperizadas, regiões ricas em $\mathrm{SiO}_{2}$, regiões sedimentares e em regiões com presença bastante significativa de evaporitos, onde a carga fluvial é rica em $\mathrm{Na}^{+}$e $\mathrm{Cl}^{-}$

A variabilidade espacial e temporal das principais espécies químicas e mecanismos de alteração de rochas foram estudados por Probst e Bazerbachi (1986) nas águas do rio Garone (França) com uma área de $9980 \mathrm{~km}^{2}$. Foi observado pelos autores aumento das concentrações de $\mathrm{SiO}_{2}, \mathrm{~K}^{+}$e $\mathrm{NO}_{3}{ }^{-}$em função do aumento das vazões particularmente durante o período de cheia. De forma contrária, $\mathrm{Ca}^{2+}, \mathrm{Mg}^{2+}, \mathrm{Na}^{+}, \mathrm{HCO}_{3}{ }^{-}, \mathrm{SO}_{4}{ }^{2-}$ e $\mathrm{Cl}^{-}$foram diluídos pelo aumento do escoamento total. Com relação à carga dissolvida transportada, a bacia do rio Garonne liberou em solução 3,2 $\mathrm{t} \mathrm{km}^{-2} \mathrm{a}^{-1}$ de $\mathrm{SiO}_{2}$ e de $1,8 \mathrm{t} \mathrm{km}^{-2} \mathrm{a}^{-1}$ de $\mathrm{HCO}_{3}^{-}$de origem atmosférica/solo. Posteriormente a correção dos aportes atmosféricos, o transporte específico de material dissolvido foi de $119 \mathrm{t} \mathrm{km}^{-2} \mathrm{a}^{-1}$.

Probst et al. (1992) estudaram o comportamento das principais espécies químicas dissolvidas transportadas em função da vazão em dois importantes rios da África, o Congo e Ubangi durante os períodos de 1987 a 1989. Pelos resultados encontrados, os autores observaram que os sólidos dissolvidos totais (TDS) do rio Congo foi mais diluído do que o Ubangi. Para ambos os rios a carga inorgânica dissolvida foi composta principalmente por $\mathrm{HCO}_{3}{ }^{-}$e $\mathrm{SiO}_{2}$. O comportamento das concentrações de cátions e ânions em função das vazões observadas foi comparado com suas respectivas curvas de diluição teórica. No rio Congo evidenciou-se que as concentrações de solutos foram apenas diluídas pelo aumento das vazões, enquanto que para o rio Ubangi, o maior distanciamento da curva de concentração com relação à de diluição teórica indicou um maior aporte de solutos, durante o aumento de sua hidrógrafa. 
Probst (1986) em estudo da carga fluvial do rio Girou na França (520 km²), estimou a quantidade total de material dissolvido e particulado transportado utilizando o método de balanço parcial. $\mathrm{O}$ autor observou maiores concentrações de $\mathrm{NO}_{3}{ }^{-}$e $\mathrm{PO}_{4}{ }^{3-}$ em períodos de cheias devido ao acúmulo no solo pelo uso de fertilizantes e a queda nas concentrações de $\mathrm{Mg}^{2+}, \mathrm{Ca}^{2+}$ e $\mathrm{HCO}_{3}{ }^{-}$, os quais foram principalmente liberados pela dissolução de carbonatos. Os transportes específicos de material dissolvido e particulado foram respectivamente para o período de estudo de $95 \mathrm{t} \mathrm{km}^{-2} \mathrm{a}^{-1}$ e $27 \mathrm{t} \mathrm{km}^{-2} \mathrm{a}^{-1}$.

Martinelli et al. (1989) estimaram o transporte total de material dissolvido lançado no oceano Atlântico pela bacia Amazônica em $270 \times 10^{6} \mathrm{t} \mathrm{a}^{-1}$. Valor este que colocou o rio Amazonas como maior transportador de elementos dissolvidos do mundo. Os autores verificaram também que a origem dos transportes de $\mathrm{Ca}^{2+}$ e $\mathrm{SiO}_{2}$ foram devido à dissolução de silicatos. Os rios Amazônicos com alta taxa de exportação de alcalinidade apresentaram maior contribuição das formações carbonáticas das espécies químicas $\mathrm{Ca}^{2+}$ e $\mathrm{Mg}^{2+}$. Verificaram ainda que o rio Madeira contribuiu com maior fluxo de material dissolvido e foi atribuída a localização do mesmo que se encontra em regiões Andinas.

Moukolo et al. (1993) estudaram na bacia do Congo no Zaire $\left(3,7 \times 10^{6} \mathrm{~km}^{2}\right)$ e seus principais afluentes, os transportes de material dissolvido e particulado em suspensão que apresentaram respectivamente valores de $61,1 \times 10^{6} \mathrm{t} \mathrm{a}^{-1}$ e $30,6 \times 10^{6} \mathrm{t} \mathrm{a}^{-1}$. Os autores relacionaram esses resultados a uma fraca mineralização dessas águas.

Na bacia Amazônica, Mortatti (1995) efetuou estudos hidrogeoquímicos com objetivo de obter o balanço da erosão química e mecânica. As espécies químicas que apresentaram os maiores transportes fluviais anuais foram o $\mathrm{HCO}_{3}{ }^{-}\left(131,5 \times 10^{6} \mathrm{t} \mathrm{a}^{-1}\right)$, o $\mathrm{SiO}_{2}\left(31,8 \times 10^{6} \mathrm{t} \mathrm{a}^{-1}\right)$ e o $\mathrm{Ca}^{2+}\left(33,9 \times 10^{6} \mathrm{t} \mathrm{a}^{-1}\right)$. O TDS foi estimado em $254,3 \times 10^{6} \mathrm{ta}^{-1}$.

Mortatti et al. (1996) em estudo da caracterização química e particulada fluvial do canal principal do rio Piracicaba $\left(11430 \mathrm{~km}^{2}\right)$, determinaram as taxas de degradação física 
total e específica que foram respectivamente de $0,41 \times 10^{6} \mathrm{t} \mathrm{a}^{-1}$ e $48 \mathrm{t} \mathrm{km}^{-2} \mathrm{a}^{-1}$, o que indicou uma velocidade média de redução da espessura do solo de $24 \mathrm{~m} \mathrm{Ma}^{-1}$.

Peray (1998) estudou o transporte de material dissolvido na bacia hidrográfica do rio III em Strasburgo na França $\left(4760,5 \mathrm{~km}^{2}\right) \cdot \mathrm{O} \mathrm{HCO}_{3}^{-}$e o $\mathrm{Cl}^{-}$foram as espécies mais significativas, com valores de 268500 e $110170 \mathrm{t} \mathrm{a}^{-1}$, respectivamente. Os transportes relativos aos aportes atmosféricos também foram calculados sendo os mais significativos: $\mathrm{Na}^{+}$com $15054 \mathrm{t} \mathrm{a}^{-1} \mathrm{e} \mathrm{SO}_{4}{ }^{2-} \operatorname{com} 5251 \mathrm{t} \mathrm{a}^{-1}$.

Mortatti et al. (2003) estimaram os transportes da carga fluvial dissolvida e particulada visando à caracterização dos processos erosivos mecânicos predominantes na bacia de drenagem do rio Piracicaba $\left(11430 \mathrm{~km}^{2}\right)$. Os autores constataram uma degradação física da ordem de $90 \mathrm{t} \mathrm{km}^{-2} \mathrm{a}^{-1}$, o que representou uma taxa de redução da espessura do solo da ordem de $64 \mathrm{~m} \mathrm{Ma}^{-1}$, originada pelo transporte de sedimentos em suspensão com base nas suas concentrações e escoamento superficial rápido.

Bortoletto Júnior (2004) estudou a erosão mecânica na bacia do rio Corumbataí, com uma área de $1700 \mathrm{~km}^{2}$, por meio da dinâmica do material particulado transportado fluvialmente. O autor encontrou valores de 59,6 e 55,5 $\mathrm{t} \mathrm{km}^{-2} \mathrm{a}^{-1}$, respectivamente para os rios Tietê e Piracicaba.

Mortatti et al. (2004) investigaram a hidrologia dos rios Tietê e Piracicaba e verificaram a influência do escoamento superficial nos processos erosivos mecânicos nas suas respectivas bacias de drenagem. Os autores aplicaram a técnica de separação de hidrógrafas proposta por Hino e Hasebe (1984), para um período de vinte anos. Detectaram variações nos coeficientes de escoamento superficial rápido para os rios de estudo, sendo 0,304 para o Tietê e 0,274 para o Piracicaba, indicando que $30 \%$ do escoamento total apresentaram origem superficial e foram associados às entradas de chuvas da bacia. Para o escoamento subterrâneo 
foi estimado que sua contribuição em relação ao escoamento total foi de $70 \%$, sendo os coeficientes da ordem de 0,696 e 0,726, respectivamente.

Características hidrológicas e geoquímicas das bacias de drenagem dos rios Jamari (30430 km²) e Ji-paraná (60350 km²) no Estado de Rondônia foram investigadas por Mortatti, Probst e Ferreira (1992). Os autores utilizaram, para separação do hidrograma de cheia, a análise espectral de Fourier. O coeficiente anual médio do escoamento superficial calculado para a bacia de rio de Jiparana (36\%) foi mais elevado do que para o Jamari (32\%), e aumentos deste coeficiente foram observados durante o período de estudo, somente para o Jiparaná.

De uma maneira geral, os estudos hidrogeoquímicos fluviais em microbacias de drenagem são escassos no Brasil, conforme descrito anteriormente, mas importantes e pioneiros estudos na área de hidrologia florestal têm contribuído significativamente para o entendimento dos impactos hidrológicos no manejo de florestas plantadas pelo Laboratório de Hidrologia Florestal do Departamento de Ciências Florestais da ESALQ. Tais trabalhos referem-se aos processos hidrológicos que envolvem a precipitação, evapotranspiração, deflúvio, composição química das águas fluviais, produção e consumo de água, efeitos do corte raso da madeira, alteração no ciclo de nutrientes e perdas de solos (ARCOVA et al., 1985; SCÁRDUA, 1994; LIMA; ZAKIA, 1998; RANZINI et al., 2002 e 2004; VITAL et al., 1999).

Lima (1988) realizou um estudo sobre o relacionamento entre as chuvas, formação de escoamento superficial, perdas de solos e nutrientes em microbacias florestadas com eucalipto. Os resultados mostraram que as perdas dos nutrientes $\mathrm{NO}_{3}{ }^{-}$e $\mathrm{Ca}^{2+}$ estiveram altamente relacionadas com o escoamento superficial, observando menores correlações para outras espécies como $\mathrm{K}^{+}$e $\mathrm{Mg}^{2+}$. A maior incidência do escoamento superficial esteve restrita a solos altamente drenados onde a permeabilidade foi menor. Apesar de serem observados 
relacionamentos entre a chuva e escoamento foi evidenciado pelo autor um balanço positivo entre a entrada de nutrientes pela chuva e suas perdas por escoamento superficial.

Câmara e Lima (1999), em estudo para avaliar o efeito do corte raso de uma plantação de eucalipto de 50 anos, observaram que durante o primeiro ano após o corte raso do eucalipto houve um aumento no deflúvio anual de 94 mm em relação à média dos seis anos anteriores ao corte. Este aumento correspondeu a uma alteração de 1,0 \% na correlação precipitação/deflúvio.

Câmara et al., (2000), acompanharam a dinâmica dos nutrientes em uma microbacia coberta com plantação de eucalipto de 50 anos. Segundos os autores a alteração na cobertura vegetal não causou grande desequilíbrio no balanço geoquímico da microbacia no primeiro ano, que se mostrou positivo para $\mathrm{K}, \mathrm{Ca}, \mathrm{Fe}$ e $\mathrm{Na}$, permanecendo negativo para $\mathrm{Mg}$, associados a rebrota das árvores, a proteção do solo oferecida pela serapilheira e a preservação da mata ciliar. As maiores limitações ao cultivo da referida área, quando se considera o estoque de nutrientes no solo, estiveram relacionadas ao nitrogênio e ao fósforo.

O escoamento superficial, perdas de solo e perdas de nutrientes foram determinados durante quatro anos em parcelas experimentais no município de São Simão, Estado de São Paulo por Lima (1988). Uma das parcelas foi mantida sem vegetação enquanto as outras foram plantadas com Eucalyptus grandis com diferentes tratamentos silviculturais. O autor observou relacionamento do escoamento superficial e perda de solos em função da precipitação durante o primeiro ano. Verificou também variações entre os tratamentos de 1,0 a 10,4 t ha ${ }^{-1}$ e significativa redução deste parâmetro, após o crescimento das árvores. Em termos de nutrientes pelo escoamento superficial, foi observado redução na perda dos mesmos em função do crescimento vegetal na ordem $\mathrm{Ca}>\mathrm{K}>\mathrm{NO} 3>\mathrm{Mg}$.

Smolders et al. (2004) estudaram a variabilidade inter-anual da composição de íons e sua relação com a vazão do rio Pilcomayo (Bolívia). Os resultados mostraram que as 
concentrações das espécies químicas estudadas aumentaram enquanto a vazão do rio diminuía nos meses de seca que foram de maio a outubro e aumentavam substancialmente nos primeiros meses chuvosos. Segundo os referidos autores, as altas concentrações nos meses de seca estiveram relacionadas a processos evaporativos do clima, enquanto nos meses chuvosos as menores concentrações estiveram relacionadas a efeitos de diluição.

Ainda em termos de influência antrópica em bacias de drenagem, os metais pesados podem ser provenientes de resíduos industriais e esgotos domésticos, emissões de automóveis, atividades mineradoras, deposições atmosféricas e práticas agrícolas. No solo podem se apresentar distribuídos em diferentes compartimentos ou frações e a sua mobilidade e a biodisponibilidade vão depender de suas concentrações totais e a forma em que se encontram associados à fase sólida.

O conceito da distribuição de metais pesados em diferentes compartimentos do solo foi introduzido pelo trabalho pioneiro de Viets (1962), que classificou o solo como sendo composto por cinco principais fases ou compartimentos que afetavam a disponibilidade de metais e difundiu a idéia de extração sequencial. Posteriormente, muitos métodos de extração sequencial têm sido propostos, sendo um dos principais trabalhos o desenvolvido por Tessier et al. (1979), que serviu de base para a proposição de outros autores.

Os métodos de extração sequencial são considerados úteis em inferir sobre o potencial de remobilização dos elementos e principalmente para distinguir entre a origem natural ou antropogênica dos metais pesados e atualmente é a técnica disponível mais sofisticada e conveniente para avaliação de especiação em solos e sedimentos (NIREL; MOREL, 1990; HO; EVANS, 2000; FILGUEIRAS et al., 2002; GLEYZES et al., 2002; URE et al., 1993; HLAVAY et al., 2004.)

Diversas técnicas de fracionamento têm sido ultimamente usadas para extrações sequenciais de metais pesados principalmente em solos e sedimentos. Estas técnicas variam 
no número das frações extraídas, bem como na ordem e do tipo da solução extratora utilizada (COSTA, 2005). Normalmente esses fracionamentos começam com extrator mais fraco com $\mathrm{pH}$ próximo da neutralidade e terminam com o mais forte, diminuindo gradativamente o $\mathrm{pH}$ nas frações que podem ser entre cinco e sete (KABALA; SINGH, 2001). Para Harrison et al. (1981) a mobilidade dos metais diminui à medida que se segue a ordem de extração, sendo que fração solúvel/trocável é considerada a mais móvel e biodisponível (SASTRE et al., 2001).

As análises de extração sequencial na maioria das vezes requerem tempo e são bastante trabalhosas, mas permitem levantar informações importantes sobre a forma, o fluxo, a mobilidade e o transporte dos metais (SPOSITO et al., 1982). Podem auxiliar também na seleção de métodos simples dos metais, como por exemplo, na determinação dos teores solúveis e disponíveis. (GOMES, 1996).

O emprego dos métodos de extração sequencial para estudo da mobilidade dos metais pesados e monitoramento ambiental de bacias de drenagem vem crescendo nas últimas décadas.

Silva et al. (2002) realizaram um estudo das concentrações e possíveis associações químicas de alguns metais pesados em sedimentos do sistema de rios Tiête-Pinheiros em São Paulo. Os resultados obtidos para as espécies $\mathrm{Al}, \mathrm{Fe}, \mathrm{Mn}, \mathrm{Cu}, \mathrm{Cd}, \mathrm{Pb}, \mathrm{Zi}$ e Ni, Cr indicaram características de poluição desses metais pesados analisados nos três reservatórios: Billings, Pirapora e Rasgão.

Mortatti et al. (2002) estudaram os principais elementos traço e a distribuição das espécies químicas dos sedimentos em suspensão na bacia do rio Piracicaba. O procedimento envolveu a extração química sequencial nas seguintes frações: trocável, ácidos solúveis, óxidos de Fe e Mn, matéria orgânica e residual. Os resultados mostraram a não ocorrência de poluição e sim um acúmulo ou enriquecimento natural das espécies analisadas nas frações 
mais redutíveis e residuais. As terras raras estiveram, segundo os autores, associadas às frações ácidos solúveis, óxidos de ferro, matéria orgânica e residual, principalmente devido à presença de solos lateríticos. 


\section{3. ÁREA DE ESTUDO}

\subsection{Caracterização da microbacia do córrego Entre Rios}

O presente trabalho foi desenvolvido em uma microbacia localizada na fazenda Entre Rios, no município de Angatuba, São Paulo, pertence à Suzano Bahia Sul Papel e Celulose S.A., cuja área total é de 6.262,85 ha, a uma altitude média de 650 m (Figura 1). A microbacia de drenagem do córrego Entre Rios está localizada numa altitude média de 624 m em uma área de 160 ha ou $1,6 \mathrm{~km}^{2}$ entre os paralelos $23^{\circ} 16^{\prime} 30^{\prime \prime}$ e $23^{\circ} 17^{\prime} 30^{\prime \prime} \mathrm{S}$, e os meridianos 48²6’30” e $48^{\circ} 26^{\prime} 30^{\prime \prime} W$. Na área da microbacia existem seis glebas ou talhões plantados com Eucalyptus grandis Hill Ex Maiden (procedência Coff`s Harbour), com as seguintes numerações: 30, 31, 32, 33, 222 e 223.

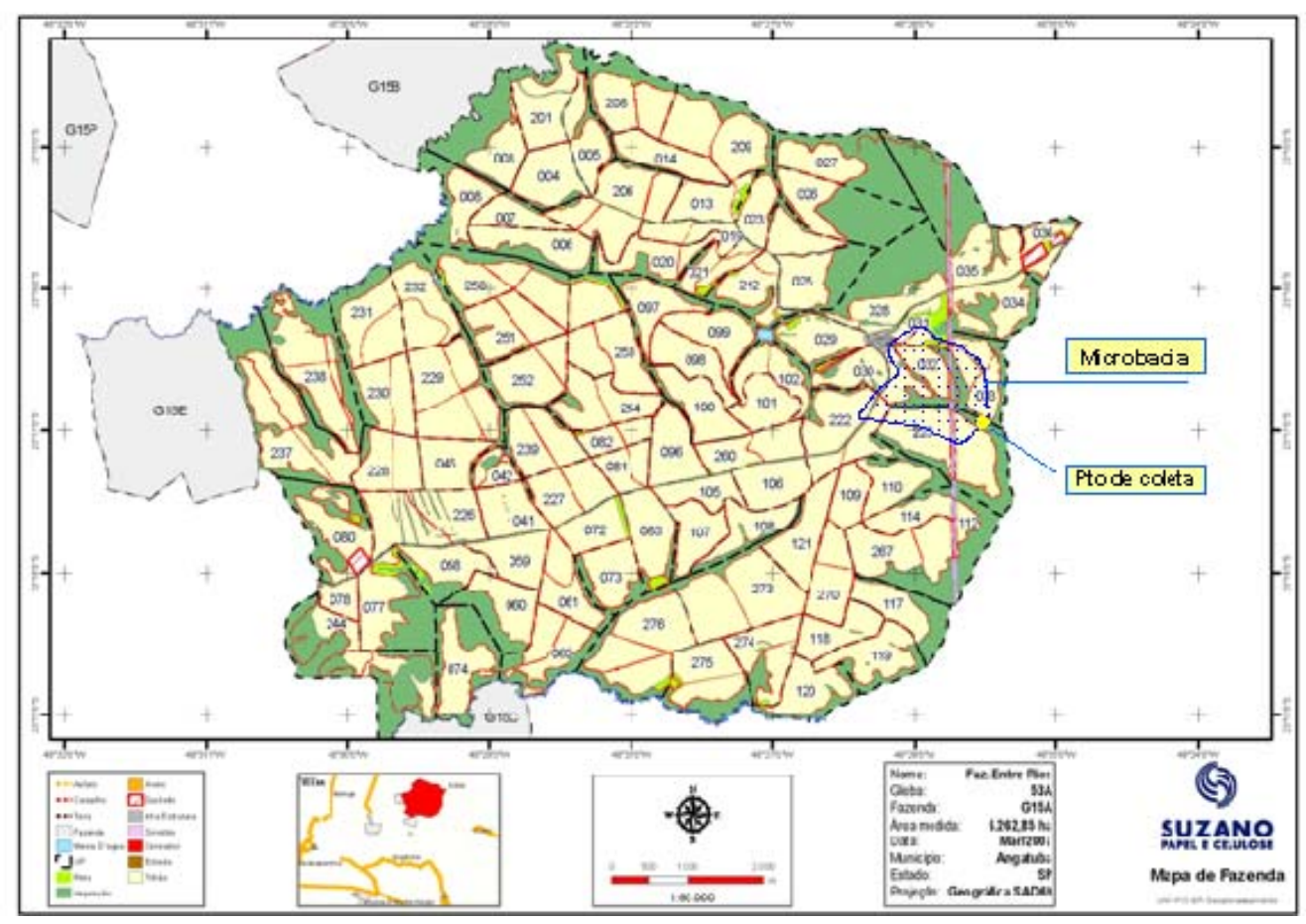

Figura 1. Localização geográfica da fazenda Entre Rios e microbacia de drenagem, distribuição dos talhões e ponto de coleta de águas fluviais em Angatuba, São Paulo. Fonte: Suzano Bahia Sul Papel e Celulose S.A. 
Dados obtidos junto à empresa mostrou que nos talhões 30, 31, 222 e 223, as declividades encontradas foram de 0 a 12\%, enquanto que no talhão 32 foi de 12,1 a $38 \%$. A área da microbacia, assim como toda a fazenda, está sobre intenso manejo agrícola decorrente de tratos culturais para obtenção de matéria-prima para produção de papel e celulose, desenvolvidos ao longo do ciclo de plantio de eucaliptos que pode chegar a oito anos (em média), dependendo da demanda requerida pela empresa e das espécies envolvidas em cada uma delas.

Técnicas agrícolas como correção do pH do solo por meio de calagem, onde são aplicadas gesso $\left(\mathrm{CaSO}_{4}\right)$, cinzas, subsolagem, além de adubação de plantio e de cobertura, são os principais manejos empregados nos referidos talhões que compõem a área da microbacia. Atividades essas que são mais intensificas nas épocas iniciais de plantio, entre o primeiro e terceiro ano, segundo informações obtidas junto à própria empresa (Tabela 1A, Apêndice 1).

\subsubsection{Geologia}

A região abrangente da área de estudo está associada preferencialmente ao Grupo São Bento, formação Pirambóia. A formação Pirambóia é composta por depósitos fluviais incluindo arenitos finos a médios, avermelhados, síltico-argilosos, com estratificação cruzada ou plano paralela, com níveis de folhelhos e arenitos argilosos de cores variegadas e raras intercalações de natureza areno-argilosa (IPT, 1981).

\subsubsection{Solos}

Os solos encontrados na microbacia e classificados pela empresa, segundo critérios preconizados no Sistema Brasileriro de Classificação de Solos (EMBRAPA, 2006) foram o LATOSSOLO VERMELHO-AMARELO Distrófico, textura arenosa (LVAd); LATOSSOLO VERMELHO, Distrófico, argiloso (LVd); CAMBISSOLO HÁPLICO Tb Distrófico (CXbd) 
e NEOSSOLO QUARTZARÊNICO Órtico típico (RQo) constituídos essencialmente por material quartzoso não apresentando horizonte B. As áreas correspondentes a cada tipo de solo foram estimadas em relação à área total da microbacia sendo em 26,6 (ha) ou 17,2\% (LVd); 33,6 (ha) ou 21,0\% (LVAd); 20,3 (ha) ou 12,7\% (CXbd); e 33,9 (ha) ou 21,2\% (RQo).

\subsubsection{Vegetação}

A cobertura vegetal característica bem como informações gerais sobre a área total da microbacia, contribuição de cada talhão na microbacia e sua representatividade em hectares, início e final do plantio das mudas, idades das árvores nos talhões, espaçamento e procedência do material genético do eucalipto plantado, podem ser observados na Tabela 1.

Tabela 1. Informações gerais da área da microbacia e povoamento de árvores existentes na microbacia do córrego Entre Rios, Angatuba, São Paulo. Fonte: Suzano Bahia Sul Papel e Celulose S.A.

\begin{tabular}{|c|c|c|c|c|c|c|c|c|}
\hline \multirow{2}{*}{ Gleba } & \multirow{2}{*}{$\begin{array}{c}\text { área } \\
\text { plantada } \\
\text { na Gleba } \\
\text { (ha) } \\
\end{array}$} & \multicolumn{2}{|c|}{ área na bacia } & \multicolumn{2}{|c|}{ Plantio } & \multirow{2}{*}{$\begin{array}{c}\text { idade (anos) } \\
\text { data } \\
23 / 3 / 2007\end{array}$} & \multirow{2}{*}{$\begin{array}{l}\text { espaçamento } \\
\text { (cm) }\end{array}$} & \multirow{2}{*}{$\begin{array}{c}\begin{array}{c}\text { material } \\
\text { genético }\end{array} \\
\text { procedência }\end{array}$} \\
\hline & & $(\%)$ & (ha) & inicio & fim & & & \\
\hline Talhão 30 & 27,82 & 2,4 & 3,9 & $27 / 7 / 2005$ & 29/7/2005 & 1,6 & $300 \times 200$ & $\begin{array}{c}\text { EUC SP0007 } \\
\text { (clones) }\end{array}$ \\
\hline Talhão 31 & 18,08 & 5,9 & 9,5 & 1/7/1998 & 2/7/1998 & 8,7 & $300 \times 200$ & $\begin{array}{c}\text { EUC SP0319 } \\
\text { (clones) }\end{array}$ \\
\hline Talhão 32 & 42,04 & 29,6 & 47,3 & 4/3/2004 & $10 / 3 / 2004$ & 3,0 & $300 \times 180$ & $\begin{array}{c}\text { EUC } \\
\text { EGR002043 } \\
\text { (sementes) } \\
\end{array}$ \\
\hline Talhão 33 & 41,25 & 4,3 & 6,9 & 1/8/1998 & 2/8/1998 & 8,6 & $300 \times 200$ & $\begin{array}{c}\begin{array}{c}\text { EUC SP0024 } \\
\text { (clones) }\end{array} \\
\end{array}$ \\
\hline Talhão 222 & 81,78 & 8,9 & 14,2 & $22 / 5 / 2002$ & $19 / 6 / 2002$ & 4,8 & $300 \times 220$ & $\begin{array}{c}\text { EUC SP0219 } \\
\text { (clones) }\end{array}$ \\
\hline Talhão 223 & 82,67 & 17,6 & 28,1 & $28 / 5 / 2002$ & $25 / 6 / 2002$ & 4,7 & $300 \times 220$ & $\begin{array}{c}\text { EUC BA9838 } \\
\text { (Híbrido } \\
\text { Grandis x } \\
\text { Urophylla) }\end{array}$ \\
\hline $\begin{array}{c}\text { Área } \\
\text { proteção }\end{array}$ & & 22,0 & 35,2 & & & & & \\
\hline $\begin{array}{c}\text { Área total } \\
\text { microbacia }\end{array}$ & & & 160 & & & & & \\
\hline
\end{tabular}

\subsubsection{Aspectos climáticos}

A região da área de estudo apresenta clima tipo Cfa, chuvoso com inverno frio, precipitações pluviométricas durante o ano todo e verões quentes, segundo a classificação de 
Köppen, correspondendo ao clima mesotérmico úmido, sem estiagem, e para o período de 1995 a 2007 apresentou precipitação anual média de 1499 mm, com temperatura mínima e máxima anual de $14,7{ }^{\circ} \mathrm{C}$ e $28,8^{\circ} \mathrm{C}$, respectivamente.

\subsection{Características dos pontos de amostragens}

\subsection{1. Águas fluviais e material particulado em suspensão (MPS)}

O ponto de amostragem para amostragem de águas fluviais e material particulado em suspensão da microbacia localizou-se cerca de 1400 metros da sede da Fazenda Entre Rios a uma altitude de 564 m em relação ao nível do mar (Figura 2).

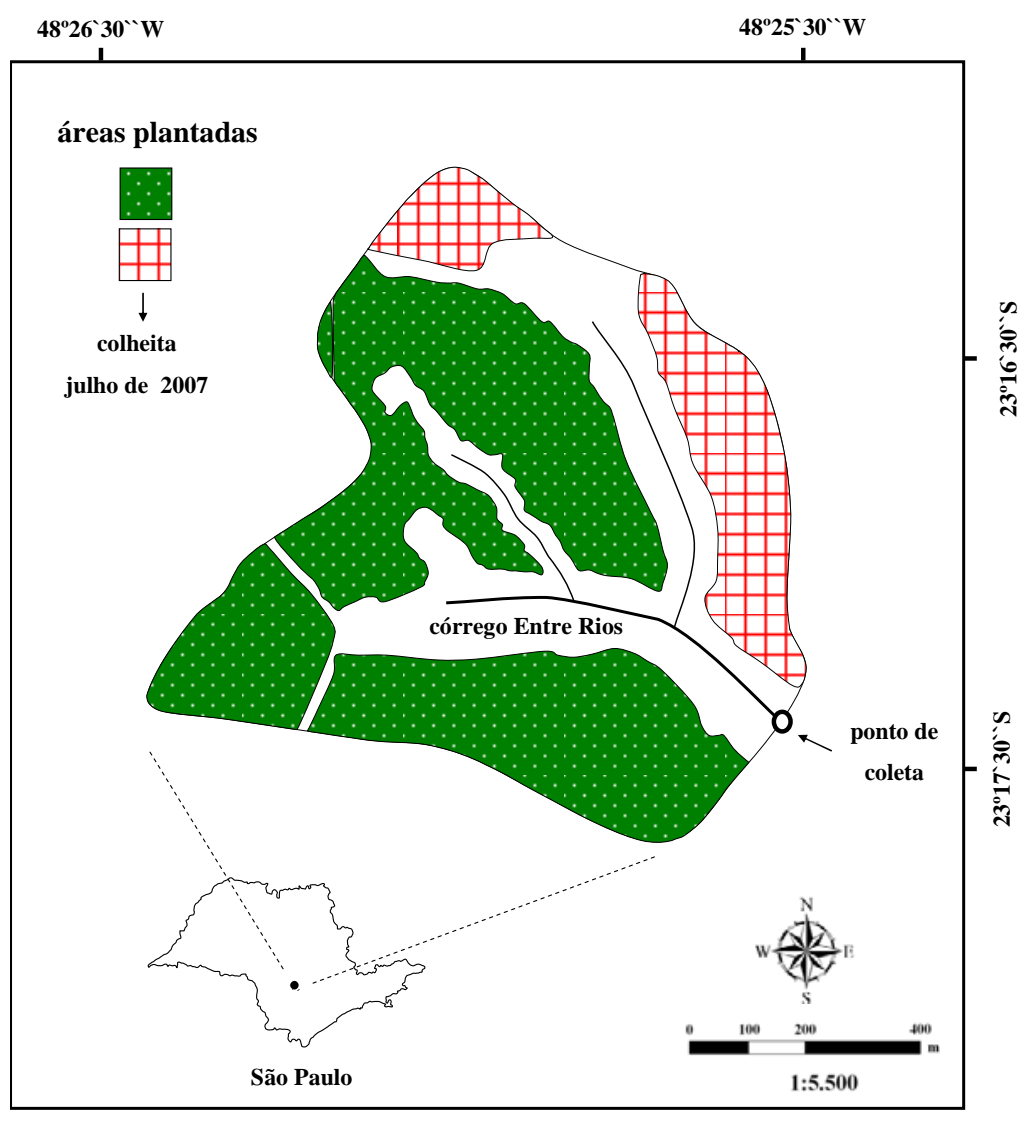

Figura 2. Localização do ponto de amostragem, áreas plantadas e de colheita da microbacia do córrego Entre Rios. Fonte: Suzano Bahia Sul Papel e Celulose S.A. 
Para a escolha do local em que foi realizada a instalação do vertedouro, levou-se em consideração uma simetria entre as margens, ou seja, que as mesmas não apresentassem desníveis tão acentuados, obtendo um escoamento homogêneo pelo vertedouro. É importante salientar que o ponto de amostragem de águas fluviais foi situado cerca de 3 metros a montante do vertedouro para se evitar possíveis contaminações das amostras pelo processo de remobilização de material particulado em suspensão.

No ponto de amostragem selecionado para coletas de águas e medidas de vazão foi efetuado a batimetria do local a qual pode ser observada na Figura 3. Basicamente, esta etapa consistiu em fincar duas estacas de madeira, uma em cada margem do córrego, e após esticar um barbante em cada extremidade das estacas, com auxílio de uma trena, efetuaram-se as medidas da profundidade do córrego aproximadamente a cada $20 \mathrm{~cm}$ de comprimento.

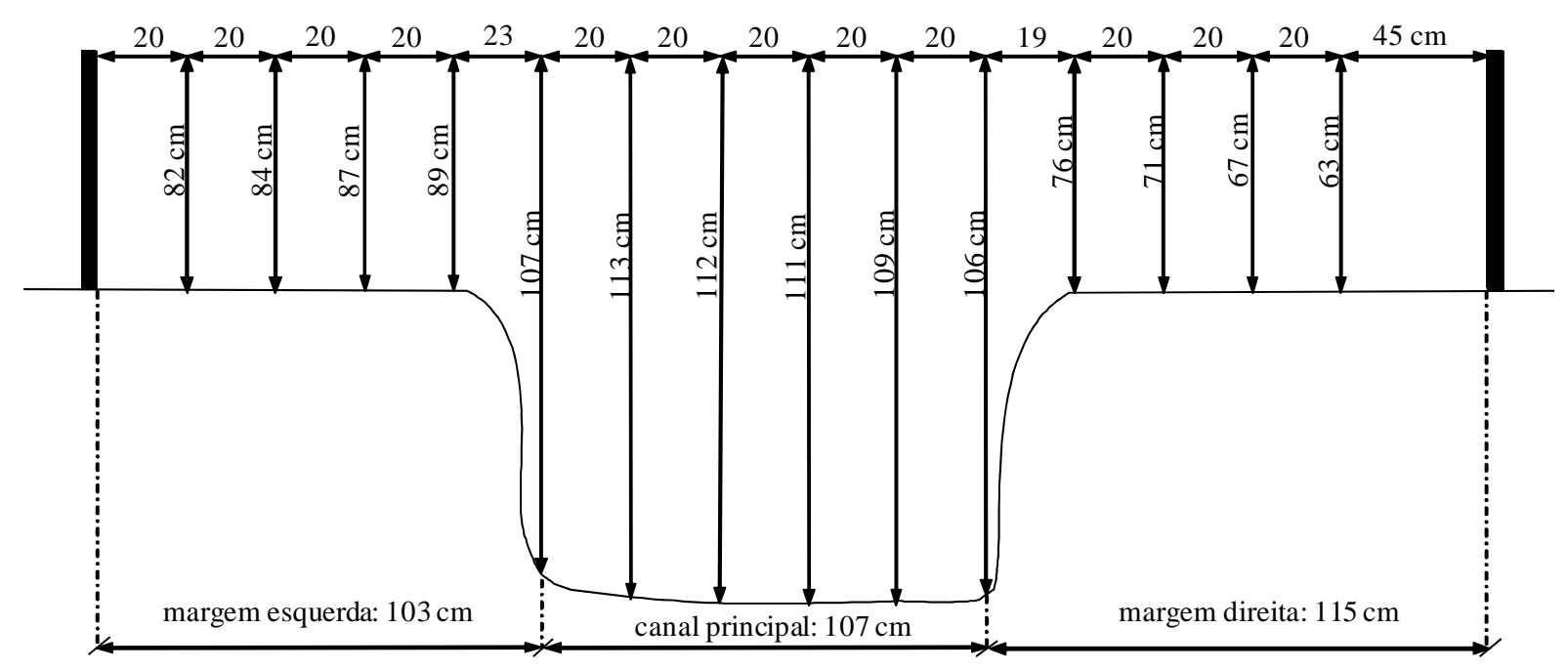

Figura 3. Esquema da batimetria realizada no ponto de coleta.

Após essa etapa, foi efetuada a instalação do vertedouro triangular de $90^{\circ}$ para a realização das medidas de vazão. A Figura 4 ilustra o esquema técnico de um vertedouro, segundo Cruciani (1993) e adotado no presente estudo. 


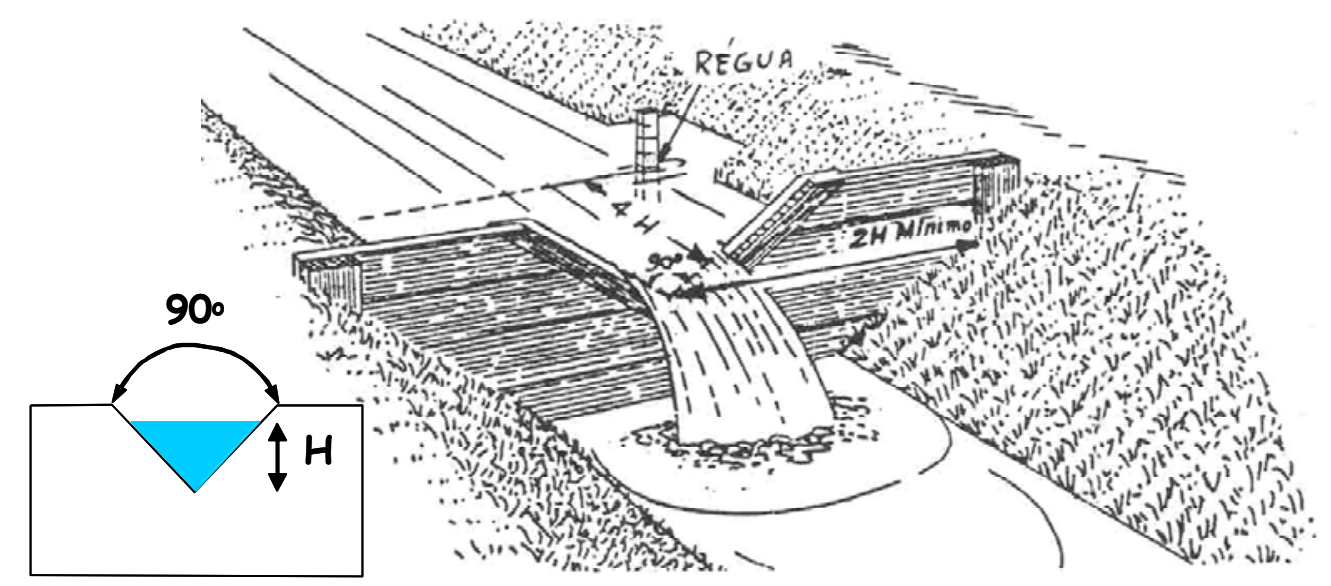

Figura 4. Esquema de um vertedouro triangular de $90^{\circ}$ e adotado no presente estudo. Fonte: extraído de Cruciani (1993).

O esquema da Figura 5 ilustra as medidas adotadas para confecção do vertedouro empregado no referido projeto. Foram utilizados para tal, chapas de aço de 0,5 cm de espessura, tendo $220 \mathrm{~cm}$ de comprimento e 76,3 cm de altura.

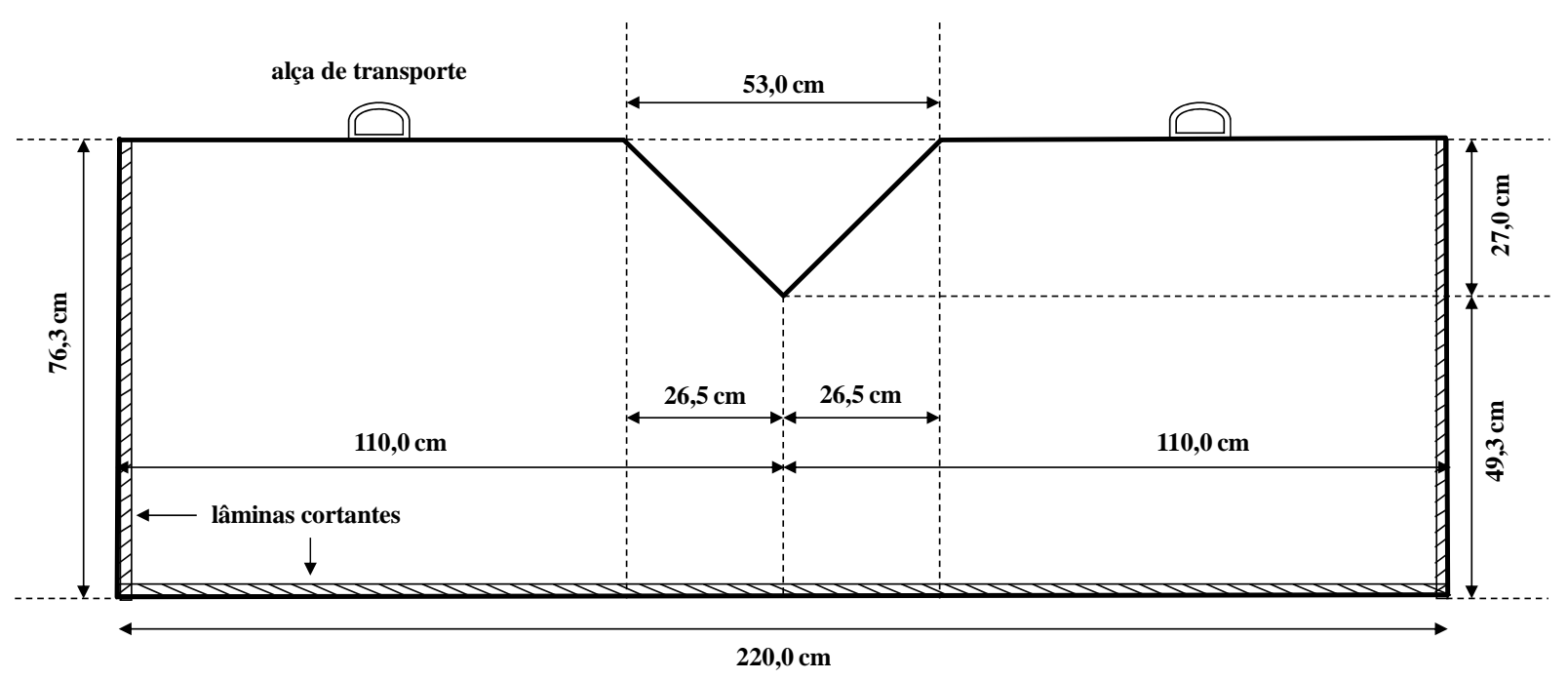

Figura 5. Esquema utilizado para construção do vertedouro empregado para as medidas de vazões do córrego Entre Rios, Angatuba, São Paulo. 


\subsection{2. Águas de chuva}

O ponto de amostragem para coleta de amostras de águas de chuva localizou-se na estação meteorológica da Fazenda Entre Rios (Lat. 23¹6’26,5” S e Long. 48²6’15” W), a uma altitude de 678 metros e distante cerca de 1450 metros do ponto de amostragem de águas fluviais da microbacia de drenagem. Foi instalado para tal, um modelo de pluviômetro desenvolvido por Mortatti (1995), composto de um funil de plástico com 20 centímetros de diâmetro interno, protegido por tela de plástico (Figura 6). Para sua fixação, utilizou-se uma haste de ferro de 1,27 centímetros, aproveitando um poste de concreto da estação meteorológica.

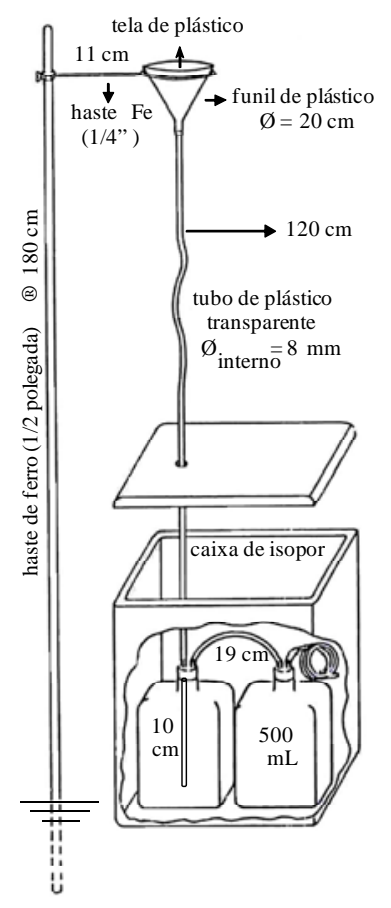

Figura 6. Esquema do coletor de águas de chuva instalado na estação meteorológica da empresa (desenvolvido por Mortatti, 1995).

É importante salientar que desde 1995, e durante todo o decorrer do projeto, a empresa possuiu um sistema de registro de informações sobre os aspectos climáticos precipitação, temperaturas máximas e mínimas e umidade relativa do ar. 


\subsubsection{Pontos de amostragem dos solos da microbacia de drenagem}

Os pontos de amostragens para coleta dos quatros distintos solos da microbacia foram escolhidos aleatoriamente, baseados no mapa de solos fornecido pela empresa (Figura 7). Este procedimento foi realizado na primeira excursão que ocorreu no dia 26 de setembro de 2006. Os pontos mostrados na Figura 7 abaixo representam respectivamente os solos LATOSSOLO VERMELHO AMARELO (LVAd), LATOSSOLO VERMELHO (LVd), CAMBISSOLO HÁPLICO (CXbd) e NEOSSOLO QUARTZARÊNICO (RQo), sendo que os três primeiros estiveram inseridos no talhão 32 enquanto que o (RQo) fez parte somente do talhão de número 223.

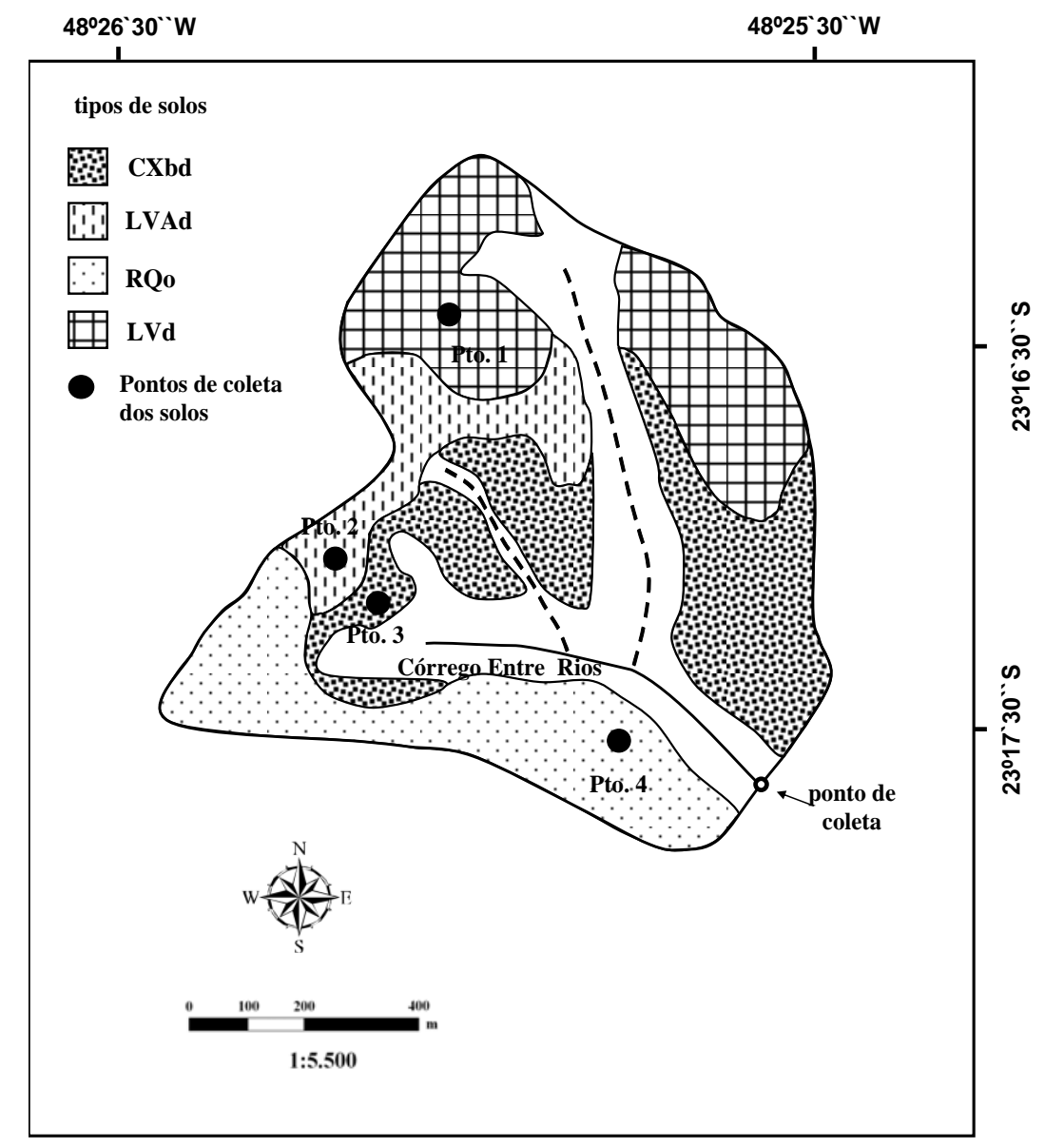

Figura 7. Pontos de amostragem dos solos CXbd, LVAd, LVd e RQo na microbacia Entre Rios, Angatuba, São Paulo. Fonte: Suzano Bahia Sul Papel e Celulose S.A. 


\subsubsection{Sedimentos de fundo}

Para amostragem de sedimentos de fundo do córrego e de material particulado em suspensão (MPS) utilizou-se o mesmo local de coleta para amostragem de águas fluviais descrito no item 3.2.1. Especificamente para sedimentos de fundo, as coletas foram efetuadas em dois períodos distintos referente aos dias 26/09/06 e 26/06/07. 


\section{MATERIAL E MÉTODOS}

\subsection{Materiais e equipamentos utilizados}

Vidraria convencional de laboratório;

Frascos de vidro (100, 500 e $1000 \mathrm{~mL})$;

Frascos de polietileno $(100,500$ e $1000 \mathrm{~mL})$;

Cromatógrafo iônico Dionex - ICS-90;

Bomba manual de vácuo Mityvac, $-100 \mathrm{kPa}$

Sistema de filtração manual à vácuo (47 mm);

Filtros de acetato celulose (Millipore - 0,45 $\mu \mathrm{m}$, com 47 mm de diâmetro);

Estufa de secagem com circulação de ar Marconi MA037;

Freezer horizontal Reubly CHDA 41;

Medidor digital de $\mathrm{pH}$ portátil Digimed DM2;

Medidor digital de condutividade portátil Digimed DM4;

Medidor digital de oxigênio dissolvido portátil Digimed DM4;

Microbureta de 2 mL Gilmont, para a microtitulação de Gran;

$\mathrm{N}_{2}$, gás inerte;

Sais para preparo de soluções e padrões para cromatografia iônica:

$\mathrm{NH}_{4} \mathrm{NO}_{3} ; \mathrm{CaCl}_{2} ; \mathrm{LiCl} ; \mathrm{NaF} ; \mathrm{NaNO}_{2} ; \mathrm{NaBr} ; \mathrm{NaH}_{2} \mathrm{PO}_{4} ; \mathrm{Na}_{2} \mathrm{SO}_{4}$; teor 99,0\%, Merck;

$\mathrm{NaCl}$; $\mathrm{KCl}$; teor 99,5\%, Merck;

$\mathrm{NaHCO}_{3}$; teor $99,7 \%$, Merck;

$\mathrm{Na}_{2} \mathrm{CO}_{3}$; teor $99,9 \%$, Merck;

$\mathrm{MgCl}_{2}$; teor 99,0\%, Labsynth;

$\mathrm{NaCH}_{3} \mathrm{COO}$; teor 99,0\%, J. T. Backer;

Ácidos para preparo de soluções e padrões para cromatografia iônica: 
$\mathrm{H}_{2} \mathrm{SO}_{4} ; \mathrm{HNO}_{3} ; \mathrm{HCl}$; p.a.;

Ácido Metanosulfônico $\left(\mathrm{CH}_{4} \mathrm{O}_{3} \mathrm{~S}\right), 98 \%$;

Hidróxido Tetrabutilamonio - TBAOH $\left(\mathrm{C}_{16} \mathrm{H}_{37} \mathrm{NO}\right)$, solução 40\%, Vetec;

Espectrômetro de emissão óptica com plasma indutivamente acoplado ICP-OES.

Sais utilizados para extração total pelo método da fusão alcalina:

Metaborato de Lítio Anidro $\left(\mathrm{LiBO}_{2}\right)$ p.a.;

Tetraborato de Lítio $\left(\mathrm{Li}_{2} \mathrm{~B}_{4} \mathrm{O}_{7}\right)$ p.a.;

Sais para preparo de padrões para extração sequencial seletiva de metais:

Nitrato de Magnésio $\left.\mathrm{Mg}\left(\mathrm{NO}_{3}\right)_{2} \cdot 6 \mathrm{H}_{2} \mathrm{O}\right), 100 \%$;

Acetato de Sódio $\left(\mathrm{CH}_{3} \mathrm{COONa}\right), 100.1 \%$

Ácido Acético (HOAc), 100\%

Ácido Ascórbico $\left(\mathrm{C}_{6} \mathrm{H}_{8} \mathrm{O}_{6}\right), 100 \%$

Cloreto Hidroxilamônio $\left(\mathrm{NH}_{2} \mathrm{OH} \mathrm{HCl}\right), 99 \%$

Oxalato de Amônio $\left(\mathrm{NH}_{4}\right)_{2} \mathrm{C}_{2} \mathrm{O}_{4} \mathrm{H}_{2} \mathrm{O}, 99 \%$

Ácido Oxálico $\left(\mathrm{H}_{2} \mathrm{C}_{2} \mathrm{O}_{4} \mathrm{H}_{2} \mathrm{O}\right)$ p.a.

Ácido Nítrico $\left(\mathrm{HNO}_{3}\right), 65 \%$

Acetato de Amônio $\left(\mathrm{NH}_{4} \mathrm{OAc}\right), 98.1 \%$

Peróxido de Hidrogênio $\left(\mathrm{H}_{2} \mathrm{O}_{2}\right), 35 \%$

\subsection{Desenvolvimento metodológico}

\subsubsection{Protocolo de amostragem}

No presente estudo foram realizadas amostragens de águas superficiais, de águas de chuva, do material particulado em suspensão (MPS), do sedimento de fundo do córrego Entre Rios e dos solos representativos que integraram a área da microbacia de drenagem. 
As medidas de vazões, coletas de águas fluviais e MPS foram realizadas no período entre 26/09/2006 a 05/12/2008 em um único ponto de amostragem descrito no item 3.2.1.

As amostragens de águas de chuva bem como a determinação de seu volume foram realizadas na estação meteorológica da Fazenda Entre Rios, descrita no item 3.2.2. e contemplou todos os eventos chuvosos do período de 13/10/2006 a 17/02/2008.

As amostragens dos solos foram efetuadas na primeira excursão realizada na microbacia Entre Rios, Angatuba, SP, no dia 26/09/2006 em quatro pontos representativos para cada tipo diferente de solo da microbacia escolhidos aleatoriamente (Figura 7 do item 3.2.3.).

As amostragens de sedimentos de fundo do córrego Entre Rios foram efetuadas em dois distintos períodos no dias 26/09/2006 e 26/06/2007 respectivamente, no mesmo local destinado as coletas das águas fluviais, porém posteriormente a coleta das mesmas nos referidos dias de amostragem.

Uma abordagem mais detalhada de todos os itens do protocolo de amostragem para cada tipo de coleta será descrito a seguir.

\subsubsection{Medidas de Vazão}

Para as medidas das vazões do córrego Entre Rios, utilizou-se um vertedouro triangular de $90^{\circ}$ (Figuras 4 e 5 do item 3.2.1.), instalado no dia 26/09/06, data da primeira excursão realizada à Fazenda Entre Rios. A instalação do aparato foi feita com a colaboração dos funcionários da empresa terceirizada TECPAR e dos membros do Laboratório de Hidrogeoquímica do CENA/USP. O vertedouro (Figura 8) foi instalado na foz da microbacia estudada e as vazões foram medidas durante o período de 26/09/06 a 05/12/07 que envolveram doze amostragens extensivas e duas amostragens intensivas. 


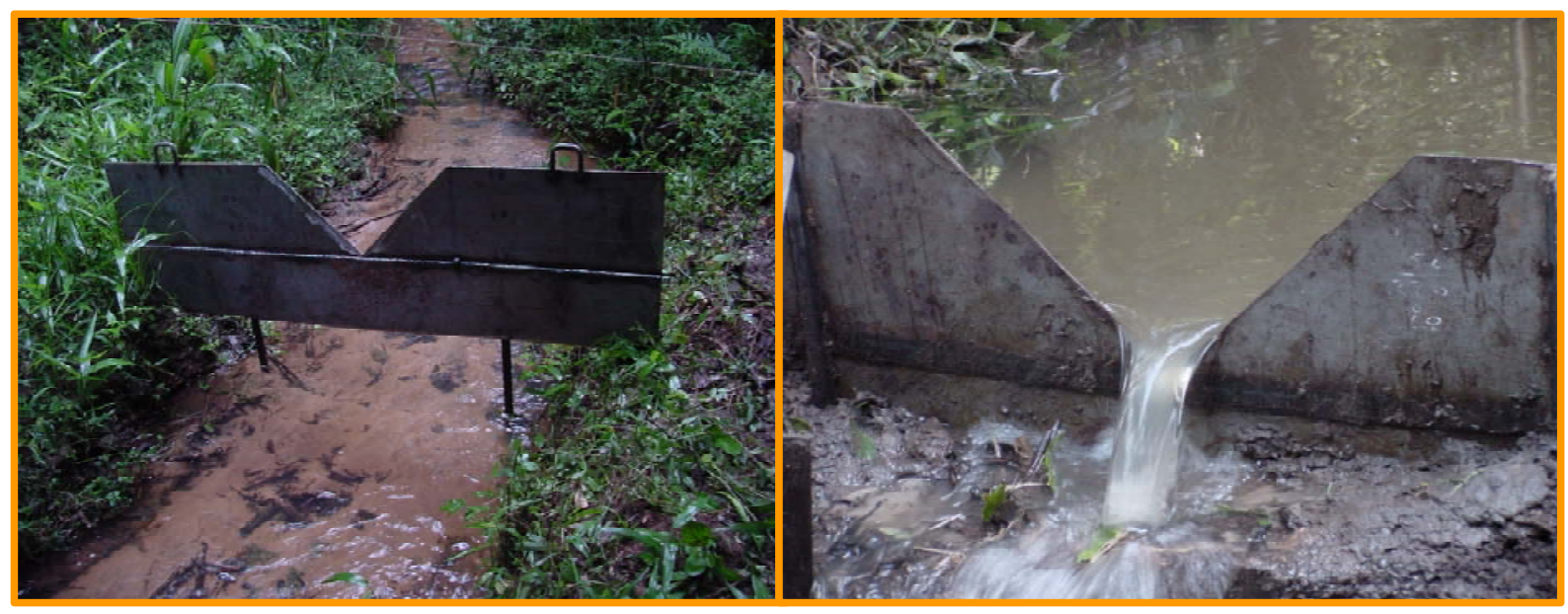

Figura 8. Instalação do vertedouro na microbacia do córrego Entre Rios, Angatuba, São Paulo.

Para estimativa dos valores das vazões relativo ao período do estudado, utilizou-se a fórmula de Thompson (BOS, 1976), sendo o valor adotado para o coeficiente da carga hidráulica de 0,014 .

$$
\mathrm{Q}=0,014 \mathrm{H}^{2,5}
$$

sendo Q a vazão $\left(\mathrm{L} \mathrm{s}^{-1}\right)$ e $\mathrm{H}$ a carga $(\mathrm{cm})$.

\subsubsection{Amostragem de águas fluviais}

As amostragens de águas fluviais foram feitas na estação de amostragem descrita anteriormente na área de estudo (Figura 2 do item 3.2.1.). Foram realizadas no total 14 excursões, sendo as 5 primeiras efetuadas com freqüência quinzenal e as restantes ao longo dos meses até o período completo do referido estudo de 26/09/2006 a 05/12/2007.

Foram realizadas ainda duas amostragens intensivas que ocorreram em duas situações distintas, uma anterior a colheita de madeira realizada entre os dias 17 e 18/03/2007 (intensiva1) e, a outra posterior a colheita de madeira efetuada em 05/12/2007 (intensiva 2). Basicamente o procedimento para coleta de águas fluviais consistiu em mergulhar o frasco de polietileno no eixo central do córrego, orientando sua boca no sentido contrário ao da 
correnteza até o volume se completar.

Foram amostrados em todo período estudado águas fluviais brutas e preservadas usando frascos de polietileno de $1000 \mathrm{~mL}$ e acondicionadas, logo após a coleta, em caixa de isopor com gelo para o transporte até o Laboratório de Isótopos Estáveis do CENA/USP, onde foram mantidas sob refrigeração a $4{ }^{\circ} \mathrm{C}$. A preservação das amostras foi efetuada com ácido sulfúrico $\mathrm{H}_{2} \mathrm{SO}_{4}$, na razão de $1 \mathrm{~mL}$ de ácido por litro de amostra, para análise de metais dissolvidos nas águas da microbacia do córrego Entre Rios.

Para as amostragens intensivas 1 e 2 foram coletados, tanto para amostras brutas quanto para preservadas, $1000 \mathrm{~mL}$ de águas fluviais usando frascos de polietileno e adotandose os mesmos procedimentos para refrigeração e preservação das amostras.

\subsubsection{Amostragem de águas de chuva}

As amostragens de águas de chuva, como mencionado anteriormente, foram realizadas no período de 13/10/2006 a 17/02/2008 em um pluviômetro do modelo descrito no item 3.2.2 instalado na estação meteorológica da Fazenda Entre Rios. Todas as amostras foram acondicionadas em frascos de polietileno de $100 \mathrm{~mL}$ devidamente identificadas com a data da coleta e o volume precipitado em mm de chuva, e mantidas sob refrigeração a $4{ }^{\circ} \mathrm{C}$ na sede da fazenda Entre Rios até o momento do transporte para o Laboratório Isótopos Estáveis do CENA/USP. Para uma melhor representatividade das amostras, foram consideradas somente as amostras cujas precipitações foram superiores a $5 \mathrm{~mm}$ de acordo com o protocolo estabelecido, pois estas proporcionaram volume adequado para a análise de todas as espécies químicas de interesse e evitam uma alta concentração destas espécies quando em precipitações baixas (BORTOLETTO JÚNIOR, 2004; FERNANDES, 2008).

A medida do volume de cada evento chuvoso foi realizada utilizando-se um pluviômetro da estação meteorológica, instalado no mesmo local do pluviômetro destinado as 
coletas de águas de chuva (Figura 9). O procedimento envolveu o esgotamento do reservatório do pluviômetro em uma proveta graduada e previamente calibrada, anotando-se o volume amostrado para cada um dos eventos chuvosos em fichas de controle na estação meteorológica e posteriormente repassada em planilhas eletrônicas, conforme procedimento adotado pelos funcionários da empresa.

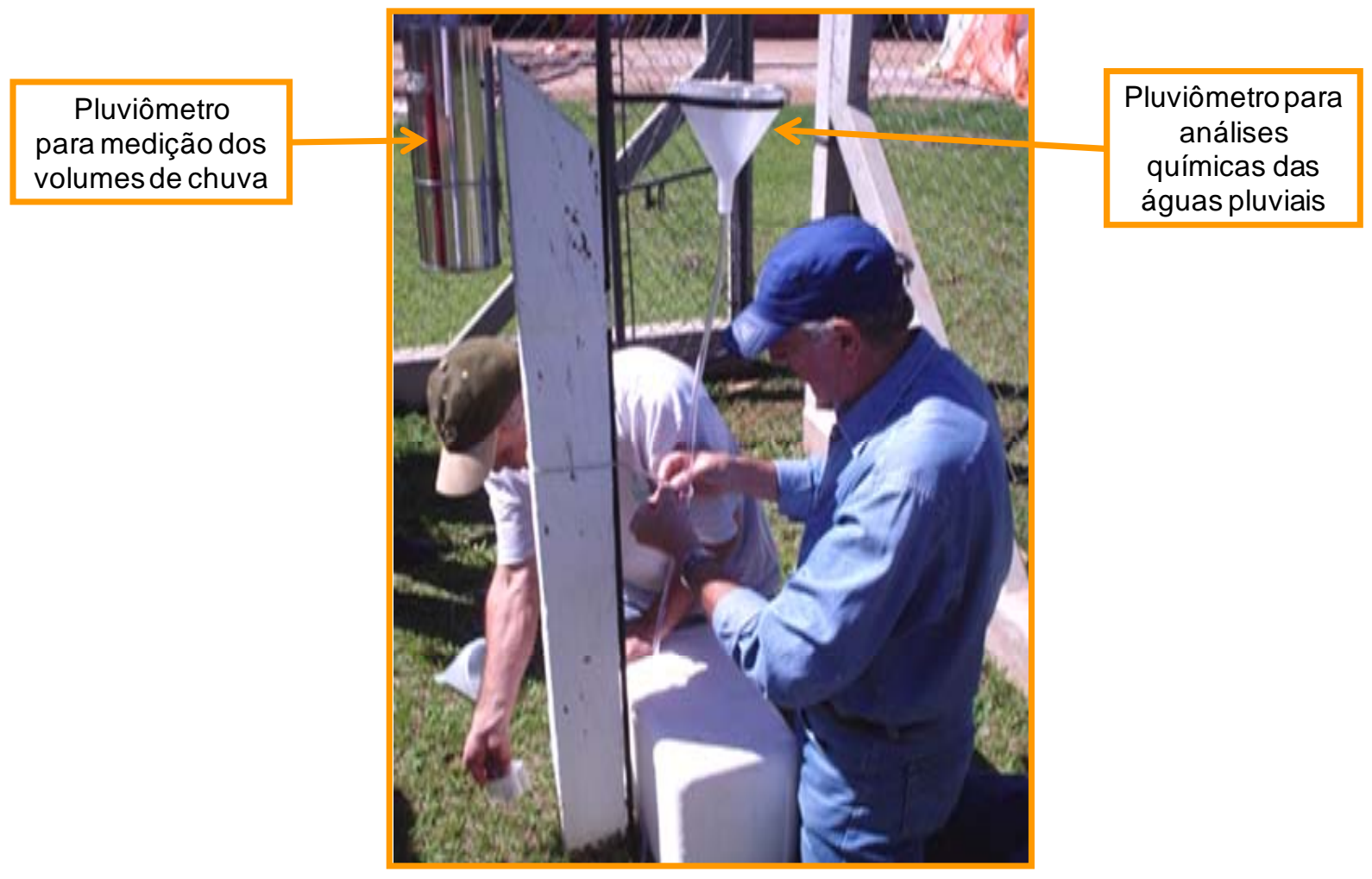

Figura 9. Detalhe da instalação do pluviômetro utilizado para amostragens de águas pluviais e medidas dos volumes de chuva na estação meteorológica da Fazenda Entre Rios.

\subsubsection{Amostragem de solos}

No presente estudo foram coletadas amostras dos quatros distintos solos localizados nos pontos mostrados anteriormente na Figura 7 do item 3.2.3. As profundidades foram de 0 10, 10-20 e 20-40 cm para cada solo. Utilizou-se para tal um trado tipo "Holandes" em aço inox, o qual possuía em sua haste de sustentação as marcações em centímetros utilizadas para 
as requeridas profundidades. Foram amostrados cerca de $1,0 \mathrm{~kg}$ de solo para as camadas de 0 10 e $10-20 \mathrm{~cm}$ e $1,9 \mathrm{~kg}$ para as camadas de $20-40 \mathrm{~cm}$, sendo os mesmos acondicionados em sacos plásticos devidamente identificados.

As amostras, após chegarem ao laboratório, foram dispostas em bandejas de plástico para secagem ao ar livre anotando-se seu peso inicial úmido. Para uma melhor homogeneização e secagem das amostras, adotou-se o procedimento de revolver as mesmas todos os dias ao longo de aproximadamente um mês e meio, até que as mesmas não apresentassem variações nos seus pesos, obtendo-se assim o peso seco em condições laboratoriais.

\subsubsection{Amostragem de sedimentos de fundo}

A amostragem dos sedimentos de fundo do córrego Entre Rios consistiu na retirada de uma alíquota de massa úmida de $1,062 \mathrm{~kg}$, em aproximadamente $15 \mathrm{~cm}$ de profundidade, e a uma distância de aproximadamente 3 metros a montante do vertedouro no mesmo ponto de coleta de águas fluviais em 26/09/06 e 26/06/07 (item 3.2.4).

Acondicionadas em recipientes de plástico, as amostras de sedimentos de fundo foram preservadas sob temperatura de $4{ }^{\circ} \mathrm{C}$ e posteriormente conduzidas para análise de AVS, extração total e extração sequencial seletiva dos principais metais pesados.

\subsubsection{Amostragem de MPS}

Para o presente estudo, o MPS foi definido como sendo partículas maiores que $63 \mu \mathrm{m}$ compostos de material orgânico constituintes do material vegetal das plantações de eucaliptos e espécies nativas das zonas ripárias existentes na microbacia de drenagem. As amostragens de MPS foram realizadas no mesmo local das amostragens de águas fluviais (item 4.2.1.2.), utilizando-se os mesmos procedimentos de conservação até a realização de sua filtração e 
quantificação, já em ambiente de laboratório. As amostras MPS foram coletadas durante 14 excursões com frequência mensal e o procedimento foi feito manualmente utilizando-se frascos de polietileno de $1000 \mathrm{~mL}$ para as amostragens extensivas e intensivas.

\subsubsection{Protocolo analítico}

Para as amostragens extensivas foram coletadas aproximadamente $1000 \mathrm{~mL}$ de águas fluviais em frascos de polietileno. Cerca de $500 \mathrm{~mL}$ das amostras foram filtradas em filtros milipore acetato $(0,45 \mu \mathrm{m})$ pré-pesadas, por processo de filtração a vácuo manual, para a quantificação do (MPS). Do filtrado, aproximadamente $100 \mathrm{~mL}$ foi utilizado para determinação da concentração de $\mathrm{HCO}_{3}{ }^{-}$, representado pela alcalinidade, determinado pelo método de micro titulação de Gran (EDMOND, 1970). Uma amostra do filtrado, $100 \mathrm{~mL}$, foi utilizada para determinação dos principais íons dissolvidos $\left(\mathrm{Na}^{+}, \mathrm{K}^{+}, \mathrm{Ca}^{2+}, \mathrm{NH}_{4}^{+}, \mathrm{Mg}^{2+}, \mathrm{Cl}^{-}\right.$, $\mathrm{NO}_{3}{ }^{-}, \mathrm{PO}_{4}{ }^{3-} \mathrm{e} \mathrm{SO}_{4}{ }^{2-}$ ) por cromatografia iônica com equipamento Dionex ICS-90.

Para as amostras preservadas, cerca de $500 \mathrm{~mL}$ de águas fluviais foram filtradas pelo mesmo processo de filtração já mencionado anteriormente, sendo parte deste filtrado (cerca de $100 \mathrm{~mL}$ ) destinado à análise de metais dissolvidos e teor de Si total por ICP-OES. O Si foi posteriormente convertido para $\mathrm{SiO}_{2}$.

Com relação às amostragens intensivas 1 e 2 , os volumes amostrados tanto para as coletas de águas brutas quanto para as preservadas foram de $1000 \mathrm{~mL}$, utilizando-se também frascos de polietileno e processo de filtração à vácuo manual descrito anteriormente.

Para as amostras de águas fluviais brutas das amostragens intensivas, todo o volume foi filtrado em filtros milipore acetato $(0,45 \mu \mathrm{m})$, pré-pesados, para quantificação do MPS. Do filtrado, um volume de $100 \mathrm{~mL}$ foi destinado para análise no cromatógrafo de íons e outros $100 \mathrm{~mL}$ para determinação da concentração de $\mathrm{HCO}_{3}{ }^{-}$.

Para as amostragens de águas preservadas das amostragens intensivas $100 \mathrm{~mL}$ foram 
filtrados em filtros milipore acetato $(0,45 \mu \mathrm{m})$ e submetidos à análise de metais dissolvidos por ICP-OES no Laboratório de Química Analítica do CENA/USP.

As 67 amostras de águas de chuva coletadas durante o experimento, conforme descrito no item 4.2.1.3., foram destinadas a análise dos íons majoritários pelos mesmos procedimentos adotados para as águas fluviais.

As análises mineralógicas foram realizadas por difração de raios $\mathrm{X}$, sendo as principais fases mineralógicas determinadas diretamente em amostras secas a $60{ }^{\circ} \mathrm{C}$ e nas frações $<63 \mu \mathrm{m}$, junto ao Núcleo de Pesquisa em Geoquímica e Geofísica da Litosfera (NUPEGEL) sediado no Campus Piracicaba, São Paulo.

Análises granulométricas dos solos foram efetuadas no Departamento de Solos da ESALQ/USP que utilizou para tal o método do densímetro simplificado (EMBRAPA, 1997).

Os principais metais pesados e algumas terras raras, extraídos dos solos e sedimentos de fundo de acordo com o método de extração seletiva utilizado, foram analisados por ICPOES, sendo as espécies principais: $\mathrm{Cr}, \mathrm{Cd}, \mathrm{Pb}, \mathrm{Ni}, \mathrm{Co}, \mathrm{Cu}, \mathrm{Zn}$ e Sc.

Alguns parâmetros associados à qualidade da água, como temperatura, $\mathrm{pH}$, oxigênio dissolvido e condutividade elétrica em amostras de águas fluviais foram avaliados por equipamentos portáteis, imediatamente após as coletas.

A extração de metais associados às fases lábeis dos solos e sedimentos foi realizada em sete etapas, a qual permitiu quantificar os elementos-traço contidos nas frações dissolvidas em água, trocáveis, ácido-solúveis, óxidos de $\mathrm{Mn}$, óxidos de $\mathrm{Fe}$ amorfo, óxidos de $\mathrm{Fe}$ cristalino e matéria orgânica.

\subsection{Aspectos hidrológicos da microbacia}

A caracterização hidrológica da microbacia do córrego Entre Rios foi avaliada mediante os dados meteorológicos de precipitação obtida junto ao posto meteorológico da 
fazenda Entre Rios, conforme descrito anteriormente no item 3.2.2., para o período de 01/01/1995 a 31/12/2007. Com isso, foi possível observar a variabilidade da precipitação total para este período e para os anos de 2006 e 2007, bem como para as amostragens intensivas.

No presente estudo, a separação dos dois hidrogramas de cheia foi realizada de acordo com o método de dois reservatórios (superficial e subterrâneo), usando filtros numéricos, descrito por Hino e Hasebe (1984) e utilizado por Mortatti et al. (1997).

A metodologia de separação dos hidrogramas de cheia proposta envolveu a utilização de um filtro numérico de separação de alta freqüência o qual permitiu somente a passagem dos sinais de baixa freqüência, associados à componente subterrânea do escoamento total. O filtro numérico de separação de alta freqüência, para uma série temporal dos dados do escoamento total $\left(\mathrm{Q}_{\mathrm{t}}\right)$ de um rio, calculados para uma equação de filtro de primeira ordem, é expresso da seguinte forma (equação 2):

$$
Q_{b}(t)=\alpha\left[B \cdot Q_{b} \cdot(t-1)\right]+A \cdot Q(t)
$$

onde $\mathrm{Q}_{\mathrm{b}}(\mathrm{t})$ corresponde à vazão do fluxo de base ou subterrâneo filtrado, $\alpha$ é o fator de ponderação escolhido de maneira a evitar os sinais filtrados negativos, A e B são constantes, expressas nas formas (equações 3 e 4):

$$
\begin{gathered}
\mathrm{B}=\frac{\Delta \mathrm{t}}{\mathrm{T}_{\mathrm{c}}} \\
\mathrm{A}=\frac{\mathrm{e}^{(-1 / \mathrm{Tc})}}{\mathrm{Tc}}
\end{gathered}
$$

onde, $\Delta \mathrm{t}$ corresponde ao intervalo de tempo e Tc foi calculado estatisticamente, através de séries temporais de Fourier, com determinação da frequência de corte (fc) da série de vazões após análise do periodograma, de acordo com a equação 5: 


$$
\mathrm{Tc}=(2 \pi \mathrm{fc})^{-1}
$$

As constantes de escoamento superficial $(\mathrm{Kr})$ e subterrâneo $(\mathrm{Kn})$ foram determinadas como sendo (equações 6 e 7):

$$
\begin{aligned}
& \mathrm{Kr}=\mathrm{Qr} / \mathrm{Qt} \\
& \mathrm{Kn}=\mathrm{Qn} / \mathrm{Qt}
\end{aligned}
$$

onde Qr e Qn são as componentes superficial rápido e subterrânea, respectivamente e Qt representa o escoamento total.

\subsection{Caracterização hidroquímica fluvial}

\subsubsection{Parâmetros físico-químicos}

Os principais parâmetros físico-químicos como $\mathrm{pH}$, condutividade elétrica, oxigênio dissolvido e temperatura da água foram avaliados nas águas fluviais do córrego Entre Rios no ponto de amostragem para as amostragens extensivas e intensivas.

\subsubsection{Concentrações das espécies químicas fluviais e equilíbrio iônico}

As concentrações de todas as espécies químicas foram normalizadas pelas vazões obtidas nos dias de amostragem de acordo com a equação 8 (KATTAN, 1989): 


$$
\mathrm{C}_{\mathrm{MNQ}}=\frac{\sum\left(\mathrm{Q}_{\mathrm{i}} \mathrm{C}_{\mathrm{i}}\right)}{\sum \mathrm{Q}_{\mathrm{i}}}
$$

onde $\mathrm{C}_{\mathrm{MNQ}}$ é a concentração média das espécies químicas normalizadas pela vazão (mg L $\mathrm{L}^{-1}$ ); $\mathrm{Q}_{\mathrm{i}}$ é a vazão medida no dia da amostragem $\left(\mathrm{L} \mathrm{s}^{-1}\right) ; \mathrm{C}_{\mathrm{i}}$ é a concentração medida para cada dia de amostragem $\left(\mathrm{mg} \mathrm{L}^{-1}\right)$ e $\sum \mathrm{Q}_{\mathrm{i}}$ é a somatória das vazões dos dias de amostragens $\left(\mathrm{L} \mathrm{s}^{-1}\right)$.

A partir dos resultados obtidos para os íons do córrego Entre Rios, a qualidade analítica das amostras foi determinada em função do equilíbrio iônico existente, utilizando-se a razão entre as somas de cátions $\left(\Sigma^{+}\right)$e a soma de ânions $\left(\Sigma^{-}\right)$, de acordo com descrito por Probst (1992), sendo erro analítico expresso de acordo com a equação 9:

$$
\Delta \%=\left(\frac{\left(\Sigma^{+}-\Sigma^{-}\right)}{\left(\Sigma^{+}+\Sigma^{-}\right)}\right) \cdot 200
$$

onde o $\Delta \%$ é o erro analítico; $\sum^{+}$e $\sum^{-}$a soma de cátions e ânions respectivamente.

Os valores médios de $\mathrm{C}_{\mathrm{MNQ}}$ obtidos pela equação 2 para cada uma das espécies químicas analisadas no córrego Entre Rios foram utilizados no cálculo da concentração dos sólidos dissolvidos totais (TDS), que é a soma aritmética das concentrações das principais espécies químicas fluviais em $\mathrm{mg} \mathrm{L}^{-1}$. Através das razões entre o $\mathrm{C}_{\mathrm{MNQ}}$ e TDS foi determinada a porcentagem de cada espécie química no córrego Entre Rios, de acordo com Peray (1998) e evidenciado na equação 10 :

$$
\mathrm{X} \%=\frac{\mathrm{C}_{\mathrm{MNQ}}}{\mathrm{TDS}} \cdot 100
$$

onde $\mathrm{X}(\%)$ é a abundância relativa da espécie química; $\mathrm{C}_{\mathrm{MNQ}}$ é a concentração média da espécie química normalizada pela vazão $\left(\mathrm{mg} \mathrm{L}^{-1}\right)$ e TDS representa a concentração dos sólidos dissolvidos totais $\left(\mathrm{mg} \mathrm{L}^{-1}\right)$. 


\subsubsection{Variabilidade temporal da concentração das principais espécies químicas}

O estudo da variação temporal da vazão e da concentração das espécies químicas foi uma das principais ferramentas na caracterização da hidroquímica fluvial da microbacia de drenagem, que permitiu verificar em qual fase da hidrógrafa a concentração foi mais pronunciada e se ela se encontrava em fase ou defasada com respeito à vazão. Para melhor interpretação e visualização dos resultados, as amostras foram separadas em períodos de amostragem extensivas, que corresponderam às excursões de $A_{1}$ a $A_{8}$ e $A_{10}$ a $A_{13}$, amostragem intensiva 1, excursão $\mathrm{A}_{9.1}$ a $\mathrm{A}_{9.9}$ e amostragem intensiva 2, excursão $\mathrm{A}_{14.1}$ a $\mathrm{A}_{14.9}$.

\subsubsection{Relacionamento concentração-vazão}

A partir das análises químicas das águas fluviais, foram verificados os relacionamentos existentes entre os valores de vazão e concentração das principais espécies químicas dissolvidas, em comparação com os valores dos modelos de diluição teórica sugerido por Probst et al. (1992) e utilizada por Mortatti (1995), de acordo com a equação 11:

$$
C_{i}=\frac{C_{\text {máx }} \cdot Q_{\text {mín }}}{Q_{i}}
$$

onde $C_{i}$ é a concentração de uma espécie química na curva de diluição $\left(\mathrm{mg} \mathrm{L}^{-1}\right) ; \mathrm{C}_{\text {máx }}$ é a concentração máxima observada da espécie química $\left(\mathrm{mg} \mathrm{L}^{-1}\right)$; $\mathrm{Q}_{\text {mín }}$ é a vazão mínima observada $\left(\mathrm{L} \mathrm{s}^{-1}\right)$ e $\mathrm{Q}_{\mathrm{i}}$ é a vazão do dia de amostragem $\left(\mathrm{L} \mathrm{s}^{-1}\right)$.

Para melhor visualização dos resultados, as amostras foram separadas em amostragem total (14 excursões juntas), amostragem intensiva 1, excursão A9.1 a A $_{9.9}$ e amostragem intensiva 2, excursão $A_{14.1}$ a $A_{14.9}$. 


\subsubsection{Diagramas ternários}

Numa análise complementar em relação à caracterização hidroquímica das principais espécies químicas dissolvidas fluviais do córrego Entre Rios, os valores das concentrações dos mesmos foram dispostos em diagramas ternários. Os diagramas ternários, no presente estudo, foram aplicados para os cátions $\mathrm{Ca}^{2+}, \mathrm{Mg}^{2+}, \mathrm{Na}^{+}+\mathrm{K}^{+}$e os ânions $\mathrm{HCO}_{3}^{-}, \mathrm{SO}_{4}^{2-} \mathrm{e} \mathrm{Cl}^{-}$, na base $\mu \mathrm{M}$ para amostragens extensivas, intensiva 1 e intensiva 2 , verificando a qualificação das águas da microbacia de drenagem face aos critérios de mineralização.

\subsubsection{Matriz dos coeficientes de correlação}

No presente estudo, as matrizes dos coeficientes de correlação linear simples foram estabelecidas entre as principais espécies químicas analisadas, relativos aos períodos de amostragens extensivas, intensiva 1 e intensiva 2, procurando identificar dentre as espécies químicas estudadas, comportamentos similares e interdependentes, visando futuras modelizações geoquímicas.

\subsubsection{Metais dissolvidos de interesse ambiental}

Algumas espécies químicas apresentam interesse ambiental devido a sua potencialidade de causar poluição ao meio ambiente. Neste contexto, alguns metais dissolvidos como $\mathrm{Ba}, \mathrm{V}, \mathrm{Cr}, \mathrm{Mo}, \mathrm{Mn}, \mathrm{Co}, \mathrm{Ni}, \mathrm{Cu}, \mathrm{Zn}, \mathrm{Cd}, \mathrm{B}, \mathrm{Pb}, \mathrm{Fe}$ e Al, bem como sua variabilidade ao longo de todo período de amostragem foram verificados para as águas fluviais do córrego Entre Rios. As análises dos metais foram realizadas por ICP-OES. 


\subsubsection{Transporte fluvial de solutos}

\subsubsection{Método estocástico}

O transporte da carga fluvial dissolvida nas águas da microbacia do córrego Entre Rios foi avaliado por meio da metodologia estocástica, de acordo com o descrito por Probst (1992) e Messaitfa (1997) referente às amostragens extensivas, intensiva 1 e intensiva 2. O método estocástico permitiu realizar a estimativa do transporte fluvial total envolvendo as concentrações normalizadas pelas vazões e as vazões dos dias de amostragem, conforme descrito na equação 12 :

$$
\mathrm{T}_{\mathrm{A}}=\left[\frac{\sum\left(\mathrm{Q}_{\mathrm{i}} \cdot \mathrm{C}_{\mathrm{i}}\right)}{\sum \mathrm{Q}_{\mathrm{i}}}\right] \cdot \mathrm{Q} \cdot 0,0864
$$

onde $\mathrm{T}_{\mathrm{A}}$ é o transporte fluvial total de uma determinada espécie química $\left(\mathrm{kg} \mathrm{d}^{-1}\right)$; $\mathrm{Q}_{\mathrm{i}}$ é a vazão medida no dia de amostragem $\left(\mathrm{L} \mathrm{s}^{-1}\right) ; \mathrm{C}_{\mathrm{i}}$ é a concentração das espécies químicas determinadas obtida para cada amostragem $\left(\mathrm{mg} \mathrm{L}^{-1}\right)$ e $\Sigma Q_{\mathrm{i}}$ é a somatória das vazões dos dias de amostragem $\left(\mathrm{L} \mathrm{s}^{-1}\right)$; Q é a vazão média diária para o período total de amostragem $\left(\mathrm{L} \mathrm{s}^{-1}\right)$; e o fator 0,0864 corresponde à correção da massa e do tempo no cálculo do transporte fluvial em $\mathrm{kg} \mathrm{d}^{-1}$.

Para as amostragens extensivas o cálculo do transporte fluvial total envolveu as amostras de $A_{1}$ a $A_{8}$ e $A_{10}$ a $A_{13}$, mais os picos das intensivas $A_{9.5}$ e $A_{14.4}$.

Os transportes fluviais específicos, para cada espécie química, calculados em termos de $\mathrm{t} \mathrm{km}^{-2} \mathrm{a}^{-1}$ para as extensivas e $\mathrm{kg} \mathrm{km}^{-2} \mathrm{~d}^{-1}$ para as intensivas, foram calculados associando a área da microbacia de drenagem conforme pode ser observado na equação 13:

$$
\mathrm{T}_{\mathrm{AE}}=\mathrm{T}_{\mathrm{A}} \cdot \mathrm{A}^{-1}
$$

onde A é a área da microbacia de drenagem $\left(\mathrm{km}^{2}\right)$. 


\subsubsection{Método de integração de áreas}

Um método alternativo para a estimativa do transporte fluvial das principais espécies químicas dissolvidas para as amostragens intensivas também foi utilizado no presente trabalho. O método de cálculo pela integração de áreas (MEYBECK, 1970) foi realizado determinando-se o volume de água transportado e as concentrações médias normalizadas pela vazão, para cada intervalo de tempo, observado entre vazões medidas nos períodos referentes às intensivas 1 e 2 , de acordo com as equações 14 e 15 , que expressam o transporte parcial para oito intervalos de tempo entre as vazões sucessivas:

$$
\begin{gathered}
T_{i, j}=C_{M N Q_{i, j}} \cdot V_{i, j} \\
T_{i, j}=\frac{\sum_{i=j-1}^{j=2}\left(C_{i} Q_{i}+C_{j} Q_{j}\right)}{\sum_{\substack{i=j-1 \\
j=2}}^{9}\left(Q_{i}+Q_{j}\right)} \cdot V_{i, j}
\end{gathered}
$$

sendo, $\mathrm{T}_{\mathrm{i}, \mathrm{j}}$ é o transporte parcial da espécie química dissolvida $(\mathrm{kg})$ nos intervalos de tempo considerados $\left(\mathrm{kg} \mathrm{d}^{-1}\right) ; \mathrm{C}_{\mathrm{MNQi}, \mathrm{j}}$ é a concentração média normalizada pela vazão no intervalo de tempo considerado $\left(\mathrm{mg} \mathrm{L}^{-1}\right)$ e $\mathrm{V}_{\mathrm{i}, \mathrm{j}}$ o volume de água transportado no intervalo de tempo considerado (L).

Após o cálculo dos respectivos transportes parciais dos hidrogramas de cheia referentes as intensivas 1 e 2 foi determinado o transporte fluvial total das principais espécies químicas dissolvidas no córrego Entre Rios, de acordo com a equação 16: 


$$
\mathrm{T}_{\mathrm{B}}=\sum_{\substack{i=j-1 \\ j=2}}^{9} \mathrm{~T}_{\mathrm{i}, \mathrm{j}}
$$

sendo: $\mathrm{T}_{\mathrm{B}}$ é o transporte fluvial total das principais espécies químicas dissolvidas $\left(\mathrm{kg} \mathrm{d}^{-1}\right)$.

$\mathrm{O}$ transporte fluvial específico em $\mathrm{kg} \mathrm{km}^{-2} \mathrm{~d}^{-1}$ para o referido método foi calculado da mesma forma que o método estocástico (equação 13), utilizando a área da microbacia de drenagem.

\subsection{Dinâmica do material particulado em suspensão (MPS)}

\subsubsection{Variabilidade temporal das concentrações de MPS}

A quantificação das concentrações do MPS foi realizada de acordo com o protocolo analítico estabelecido no item 4.2.2, sendo verificada a variabilidade das concentrações em função do tempo para os períodos de amostragem extensivas, intensiva 1 e intensiva 2.

\subsubsection{Relacionamento concentração-vazão de MPS}

O relacionamento concentração-vazão foi verificado entre as concentrações de MPS e vazões medidas para cada dia de amostragem, sendo utilizado o modelo logaritmo que melhor se ajustou ao comportamento dos dados obtidos. Para tal procedimento, utilizou-se o material particulado discutido no item 4.2.1.6., obtidas das coletas de amostras de águas fluviais na microbacia de drenagem durante todo o período de estudo (26/09/2006 a 05/12/2007).

\subsubsection{Transporte fluvial de MPS}

O transporte de MPS foi calculado pelo método estocástico proposto no item 4.4.8.1., de acordo com a equação 12, apenas substituindo os valores de concentração das espécies 
químicas dissolvidas pelas concentrações de MPS para as amostragens extensivas e intensivas. O transporte específico do MPS foi obtido de modo similar ao procedimento descrito em 4.4.8.1., para a carga dissolvida (equação 13).

\subsubsection{Degradação física da microbacia de drenagem}

No presente trabalho a erosão mecânica ou degradação física da microbacia de drenagem do córrego Entre Rios foi estimada de acordo com metodologia sugerida por Mortatti et al. (1997) e Boeglin e Probst (1998), expressa pela equação 17:

$$
\mathrm{EM}=\frac{\mathrm{T}_{\mathrm{MPS}}}{\mathrm{d}}
$$

onde, EM é a erosão mecânica (em $\left.\mathrm{m} \mathrm{Ma}^{-1}\right)$; $\mathrm{T}_{\mathrm{MPS}}$ é o transporte específico do material particulado em suspensão $\left(\mathrm{t} \mathrm{km}^{-2} \mathrm{a}^{-1}\right)$ e d é a densidade média dos solos $\left(\mathrm{t} \mathrm{m}^{-3}\right)$ da microbacia de drenagem.

\subsection{Aportes atmosféricos totais}

A influência dos aportes atmosféricos totais na carga dissolvida do canal principal da microbacia do córrego Entre Rios foi estimada através da análise das espécies químicas principais nas águas pluviais. As amostras de chuvas foram coletadas conforme descrito no item 4.2.1.3. No presente estudo, as concentrações médias das espécies químicas $\left(\mathrm{C}_{\mathrm{MNP}}\right)$ foram normalizadas em função da quantidade de precipitação no dia de amostragem por meio da equação 18 (BORTOLETTO JÚNIOR, 1999). 


$$
\mathrm{C}_{\mathrm{MNP}}=\frac{\sum \mathrm{P}_{\mathrm{i}} \cdot \mathrm{C}_{\mathrm{i}}}{\sum \mathrm{P}_{\mathrm{i}}}
$$

sendo $\mathrm{C}_{\mathrm{MNP}}$ é a concentração média das espécies químicas normalizadas pela vazão $\left(\mathrm{mg} \mathrm{L}^{-1}\right)$; $\mathrm{P}_{\mathrm{i}}$ é a precipitação medida no dia de amostragem $(\mathrm{mm}) ; \mathrm{C}_{\mathrm{i}}$ é a concentração medida para cada dia de amostragem $\left(\mathrm{mg} \mathrm{L}^{-1}\right)$ e $\sum \mathrm{P}_{\mathrm{i}}$ é a somatória das precipitações nos dias de amostragens.

Os cálculos do transporte total $\left(\mathrm{T}_{\mathrm{P}}\right)$ e específico $\left(\mathrm{T}_{\mathrm{PE}}\right)$ foram realizados de acordo com as equações 19 e 20 considerando-se a área de drenagem da microbacia

$$
\mathrm{T}_{\mathrm{P}}=\mathrm{C}_{\mathrm{P}} \cdot \mathrm{P} \cdot \mathrm{A}
$$

sendo $T_{P}$ é o transporte total de cada espécies química $\left(t a^{1}\right) ; C_{P}$ é a concentração média de cada espécie química normalizada pela precipitação $\left(\mathrm{mg} \mathrm{L}^{-1}\right)$; P é a precipitação média anual $\left(\mathrm{mm} \mathrm{a}^{-1}\right)$ e A é a área da microbacia $\left(\mathrm{km}^{2}\right)$.

$$
\mathrm{T}_{\mathrm{PE}}=\mathrm{C}_{\mathrm{P}} \cdot \mathrm{P}=\mathrm{T}_{\mathrm{P}} / \mathrm{A}
$$

sendo $\mathrm{T}_{\mathrm{PE}}$ é o transporte específico de cada espécie química $\left(\mathrm{t} \mathrm{km}^{-2} \mathrm{a}^{-1}\right)$.

As influências dos aportes atmosféricos totais nas cargas dissolvidas da microbacia de drenagem do córrego Entre Rios foram calculadas em função dos transportes fluviais (método estocástico), expressas em porcentagem, de acordo com a equação 21 (BORTOLETTO JÚNIOR, 2004):

$$
\text { Aporte Atmosférico Total }=\left(\mathrm{T}_{\text {pluvial }} / \mathrm{T}_{\text {fluvial }}\right) .100
$$

onde $\mathrm{T}_{\text {pluvial }}$ é o transporte pluvial total em $\mathrm{t} \mathrm{a}^{-1}$ para o ano de 2007; $\mathrm{T}_{\text {fluvial }}$ são os transportes totais em $\mathrm{t} \mathrm{a}^{-1}$ calculados para as amostragens extensivas e intensivas. 


\subsection{Extração total e sequencial de metais nos solos e sedimentos de fundo}

No presente estudo, o procedimento adotado para o cálculo de perda ao fogo dos resíduos dos solos e sedimentos foi realizado primeiramente pesando-se cerca de $5 \mathrm{~g}$ de solo moído $(63 \mu \mathrm{m})$ em cadinho de platina (pré-pesado) e conduzindo-os a estufa a $100{ }^{\circ} \mathrm{C}$ por 120 minutos. Após seu resfriamento, a mesma amostra foi levada a mufla a $1000{ }^{\circ} \mathrm{C}$ por 60 minutos para calcinação da amostra, pesando-se o cadinho ao final de cada etapa.

Para a realização da extração total pelo método da fusão alcalina (SAMUEL et al., 1985), sub amostras provenientes da calcinação de aproximadamente $100 \mathrm{mg}$ de solo e sedimentos de fundo foram homogeneizadas juntamente com $200 \mathrm{mg}$ de $\mathrm{LiBO}_{2}$ (metaborato de lítio) e $400 \mathrm{mg}$ de $\mathrm{LiB}_{4} \mathrm{O}_{7}$ (tetraborato de lítio). Dispostas em cadinhos de platina, as amostras foram pré-aquecidas em mufla a $500{ }^{\circ} \mathrm{C}$ elevando-se a temperatura a $1000{ }^{\circ} \mathrm{C}$ por 30 minutos. Após o resfriamento, o material fundido foi colocado em um béquer de plástico adicionando-se $50 \mathrm{~mL}$ de água deionizada fervente com agitação magnética e $5 \mathrm{~mL}$ de $\mathrm{HNO}_{3}$ (1:1) com agitação por 60 minutos. Após a dissolução do material fundido, completou-se o volume para $100 \mathrm{~mL}$ com água deionizada armazenando as amostras em frascos de polietileno para análises por ICP-OES.

O procedimento de extração sequencial seletiva adotado para determinação das diferentes espécies químicas realizadas no presente estudo foi descritos por Leleyter (1998) e Mortatti et al. (2002), e permitiu identificar cada uma das sete frações propostas, mudando as composições físico-químicas das fases aquosas com o emprego de soluções químicas distintas (Tabela 2). A soma de todas as frações lixiviáveis ( $\mathrm{S} 1$ a S6) representou nesse método a fração lábil do sedimento fluvial.

As etapas utilizadas no presente estudo foram: S1 $\rightarrow$ extração da fração solúvel em água; S2 $\rightarrow$ extração de cátions trocáveis; S3 $\rightarrow$ extração de cátions ligados aos ácidos solúveis; S4 $\rightarrow$ extração de cátions ligados aos óxidos de Mn; S5 $\rightarrow$ extração de cátions 
ligados aos óxidos de $\mathrm{Fe}$ amorfo; $\mathrm{S} 6 \rightarrow$ extração de cátions ligados aos óxidos de $\mathrm{Fe}$ cristalinos e S7 $\rightarrow$ extração de cátions ligados à matéria orgânica.

Tabela 2. Procedimento de extração sequencial em 7 etapas.

\begin{tabular}{|c|c|c|c|c|c|}
\hline & Fração & Extrator & tempo & $\mathrm{T}^{\circ} \mathrm{C}$ & $\mathrm{pH}$ \\
\hline S1 & Solúvel em água & $\mathrm{H}_{2} \mathrm{O}$ MiliQ & $30 \mathrm{~min}$ & 20 & 5,7 \\
\hline $\mathrm{S} 2$ & Trocável & $1 \mathrm{M} \mathrm{Mg}\left(\mathrm{NO}_{3}\right)_{2}$ & $2 \mathrm{~h}$ & 20 & 5,0 \\
\hline S3 & Ácido-solúvel & $1 \mathrm{M} \mathrm{NaOAc} / \mathrm{HOAc}$ & $5 \mathrm{~h}$ & 20 & 4,5 \\
\hline S4 & Óxido de Mn & $0,1 \mathrm{M} \mathrm{NH}_{2} \mathrm{OH} \mathrm{HCl}$ & $30 \mathrm{~min}$ & 20 & 3,5 \\
\hline S5 & Óxido de Fe amorfo & $0,2 \mathrm{M}\left(\mathrm{NH}_{4}\right)_{2} \mathrm{C}_{2} \mathrm{O}_{2}+0,2 \mathrm{M} \mathrm{H}_{2} \mathrm{C}_{2} \mathrm{O}_{4}$ & $4 \mathrm{~h}$ & 20 & 3,0 \\
\hline S6 & Óxido de Fe cristalizado & $0,2 \mathrm{M}\left(\mathrm{NH}_{4}\right)_{2} \mathrm{C}_{2} \mathrm{O}_{2}+0,2 \mathrm{M} \mathrm{H}_{2} \mathrm{C}_{2} \mathrm{O}_{4}+0,1 \mathrm{M} \mathrm{C}_{6} \mathrm{H}_{8} \mathrm{O}_{8}$ & $30 \mathrm{~min}$ & 85 & 2,3 \\
\hline S7 & Matéria orgânica & $35 \% \mathrm{H}_{2} \mathrm{O}_{2} \mathrm{HNO}_{3}$ seguido de $3,2 \mathrm{M} \mathrm{NH}_{4} \mathrm{OAc}$ & $5 \mathrm{~h}$ & 85 & 2,0 \\
\hline
\end{tabular}

Para cada fração, fase ou etapa da extração sequencial, os extratores e as amostras de solos e sedimentos $(63 \mu \mathrm{m})$, em torno de $1 \mathrm{~g}$, foram colocados em bombas de teflon e após a adição do extrator, as amostras foram agitadas continuamente nos tempos descritos na Tabela 2. Completado o tempo de reação de cada etapa, as soluções e as amostras foram separadas por filtragem em filtros de $0,45 \mu \mathrm{m}$ (filtro Millipore HVLP) em um sistema de filtração à vácuo manual. Todos os filtros utilizados foram secos em estufa a temperatura de $50{ }^{\circ} \mathrm{C}$ por 4 horas em média. O tempo médio de secagem dos filtros com as amostras ocorreu em função da quantidade de água Milli-Q utilizada para a remoção de resíduos de amostras contidas nas bordas do frasco. Após a secagem, os filtros e as amostras das etapas anteriores, retornavam a etapa seguinte com um novo extrator. O lixiviado de cada etapa, ou seja, a solução filtrada depois de pesada e medido o seu volume em proveta graduada foi acondicionada em tubos cilíndricos de $15 \mathrm{~mL}$ e mantidas a temperatura de $4{ }^{\circ} \mathrm{C}$ até a análise por ICP-OES. Para o aquecimento das amostras e extratores contidos na bomba de teflon, nas frações S6 e S7, utilizou-se de um aquecedor com agitador magnético. Todo o material utilizado foi previamente limpo e descontaminado mantendo-os em um recipiente com solução de ácido nítrico a 5\% antes da realização de cada etapa. 
O mesmo procedimento de extração foi utilizado nas determinações dos brancos relativos aos reagentes químicos empregados. Todas as extrações foram realizadas em duplicata considerando uma variabilidade de $5 \%$.

Por fim, a biodisponibilidade dos principais metais pesados $(\mathrm{Cr}, \mathrm{Cd}, \mathrm{Pb}, \mathrm{Ni}, \mathrm{Co}, \mathrm{Cu}$, $\mathrm{Zn}$ e Sc) nos solos e sedimentos de fundo do córrego Entre Rios foi avaliada pelo comportamento dos mesmos no processo de partição entre as fases lábil e residual no sentido de identificar os principais fatores de controle e fracionamento entre as fases aquosas e particuladas, proporcionando um melhor entendimento sobre a mobilidade dessas espécies químicas nestes ambientes. A porcentagem de cada espécie química nas frações foi calculada com base na concentração total dessa espécie, obtida pelo método de fusão alcalina.

\subsection{Fundo geoquímico natural e fator de enriquecimento (EF)}

O fundo geoquímico natural da microbacia de drenagem Entre Rios, considerando-se a concentração dos metais pesados $\mathrm{Cr}, \mathrm{Cd}, \mathrm{Pb}, \mathrm{Ni}, \mathrm{Co}, \mathrm{Cu}, \mathrm{Zn}$ e $\mathrm{Sc}$, foi determinado para as camadas mais profundas $(20-40 \mathrm{~cm})$ das amostras de terra dos solos CXbd, LVAd, LVd e RQo, por estes estarem mais próximos a nascente do córrego da microbacia.

Em termos comparativos, também foram utilizados os resultados médios das concentrações desses metais presentes na crosta terrestre, de acordo com Taylor e McLennan (1985).

Os fatores de enriquecimento para os metais pesados estudados foram calculados de acordo com Gresens (1967), usando Sc como agente normalizador e o fundo geoquímico dos principais solos a 20-40 cm de profundidade, através da equação 21. Para comparação dos resultados foram utilizados os valores dos metais da crosta terrestre (McLENNAN, 1995). O fator de enriquecimento $(\mathrm{EF})$ de um elemento $\mathrm{X}$ foi definido pela relação entre sua abundância na amostra e sua abundância natural equação 22: 


$$
\mathrm{EF}=\left(\mathrm{X}_{1} / \mathrm{Y}_{1}\right) /\left(\mathrm{X}_{2} / \mathrm{Y}_{2}\right)
$$

sendo, $\mathrm{X}_{1}$ o teor do elemento na amostra $\left(\mu \mathrm{g} \mathrm{g}^{-1}\right) ; \mathrm{Y}_{1}$ é o teor do Sc na amostra $\left(\mu \mathrm{g} \mathrm{g}^{-1}\right) ; \mathrm{X}_{2}$ é o teor do elemento de abundância natural na microbacia/crosta terrestre $\left(\mu \mathrm{g} \mathrm{g}^{-1}\right) ; \mathrm{Y}_{2}$ é o teor de Sc natural na microbacia/crosta continental terrestre em $\left(\mu \mathrm{g} \mathrm{g}^{-1}\right)$. 


\section{RESULTADOS E DISCUSSÃO}

Os resultados apresentados referem-se a 14 excursões de amostragens de águas fluviais realizadas durante o período de amostragem de 26/09/2006 a 05/12/2007, incluindo duas amostragens intensivas realizadas no período de 17 a 18/03 de 2007 e 05/12/2007, considerandose as 67 análises de águas pluviais durante o período de 13/10/2006 a 17/02/2008, bem como as amostragens de solos do período de 26/09/2007 e sedimentos de fundo dos dias 26/09/2007 de acordo com os protocolos estabelecidos no item 4.2.2.

\subsection{Aspectos hidrológicos da microbacia}

Os aspectos hidrológicos da microbacia do córrego Entre Rios foram avaliados de acordo com descrito no item 4.3., principalmente em função da precipitação na microbacia de drenagem. A análise da variabilidade mensal da precipitação durante o período de 1995 a 2007, de acordo com dados obtidos junto ao posto meteorológico da fazenda Entre Rios, mostrou que os meses mais chuvosos foram dezembro, janeiro, fevereiro e março com um máximo de $281 \mathrm{~mm}$, e os meses mais secos foram junho, julho e agosto com precipitações da ordem de $42 \mathrm{~mm}$ (Figura 10).

Para o ano de 2006 houve uma significativa seca nos meses de maio a agosto com precipitações inferiores a $10 \mathrm{~mm}$ (Figura 10). Em comparação ao ano de 2007, onde ocorreram a maioria das amostragens, inclusive as duas amostragens intensivas, o período chuvoso ocorreu nos meses de novembro, dezembro, janeiro e fevereiro e o períodos seco foi de abril a setembro com precipitações da ordem de $5 \mathrm{~mm}$ (Figura 11). Entretanto, pode ser verificada uma forte contribuição para o total anual de precipitação para o mês de julho (cerca de $134 \mathrm{~mm}$ ). Os meses chuvosos corroboraram com os meses escolhidos para a realização das duas intensivas, uma anterior e outra posterior à colheita da madeira, respectivamente em março e dezembro de 2007. 


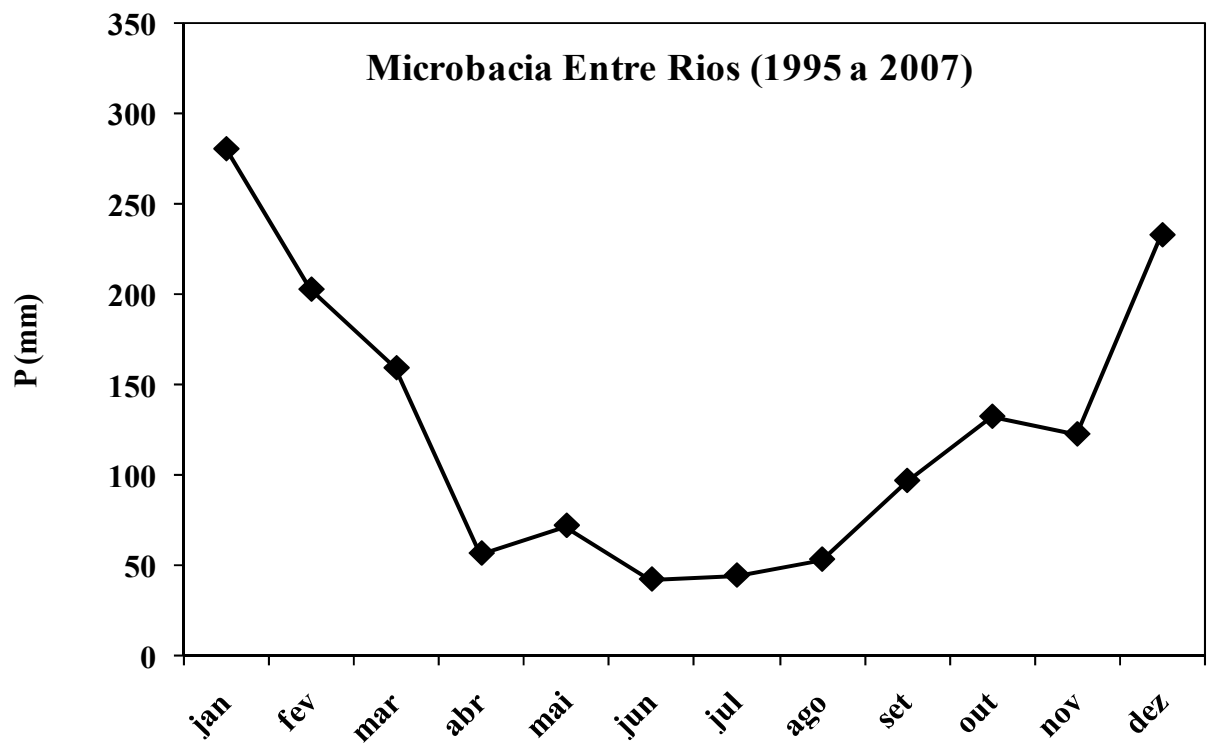

Figura 10. Variação da precipitação total mensal $(\mathrm{mm})$, durante os meses de janeiro a dezembro no período de 1995 a 2007, na microbacia Entre Rios.

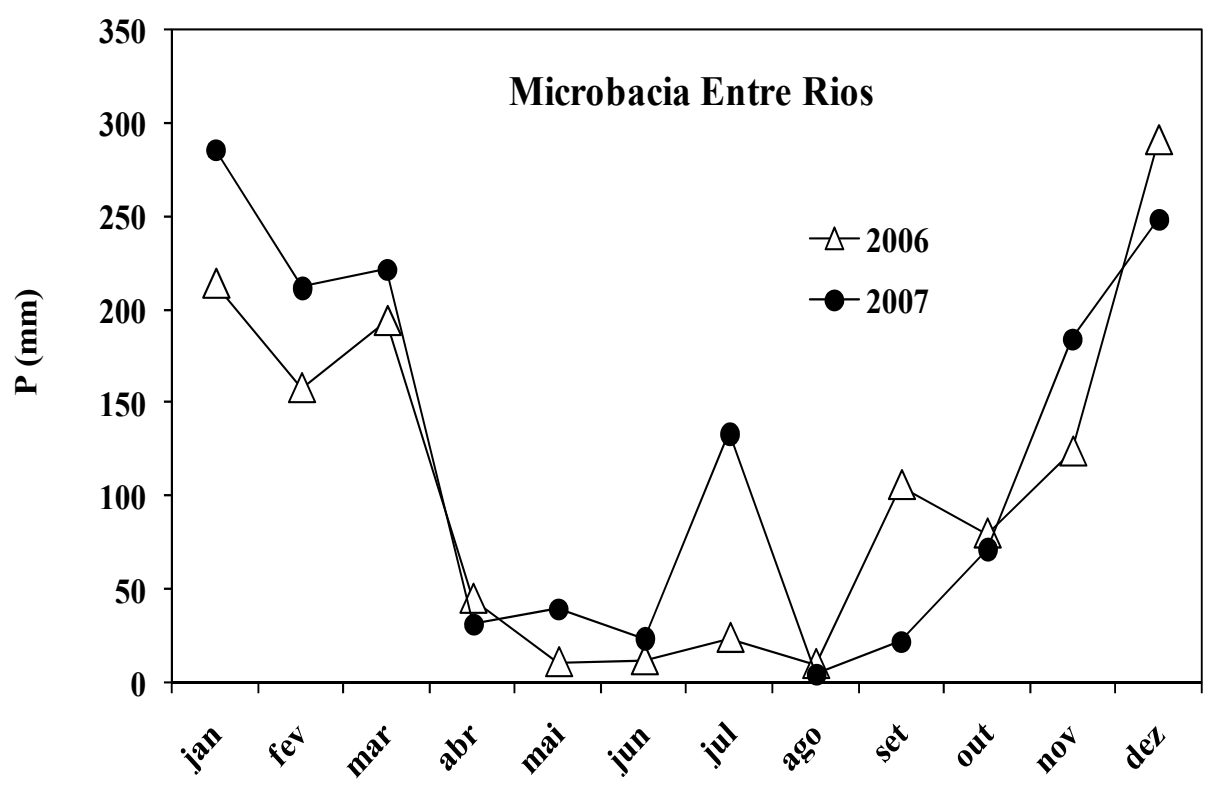

Figura 11. Variação da precipitação total mensal (mm), durante os meses de janeiro a dezembro de 2006 e 2007, na microbacia Entre Rios, Angatuba, São Paulo. 
Pode ser observada na Figura 12 a variabilidade da precipitação diária $(\mathrm{mm})$, bem como as medidas das vazões $\left(\mathrm{L} \mathrm{s}^{-1}\right)$ realizadas durante o período de amostragem de 26/09/2006 a 05/12/2007, sendo que os valores indicados nas intensivas 1 e 2 referem-se às maiores vazões obtidas nos períodos que foram respectivamente de 62 e $53 \mathrm{~L} \mathrm{~s}^{-1}$.

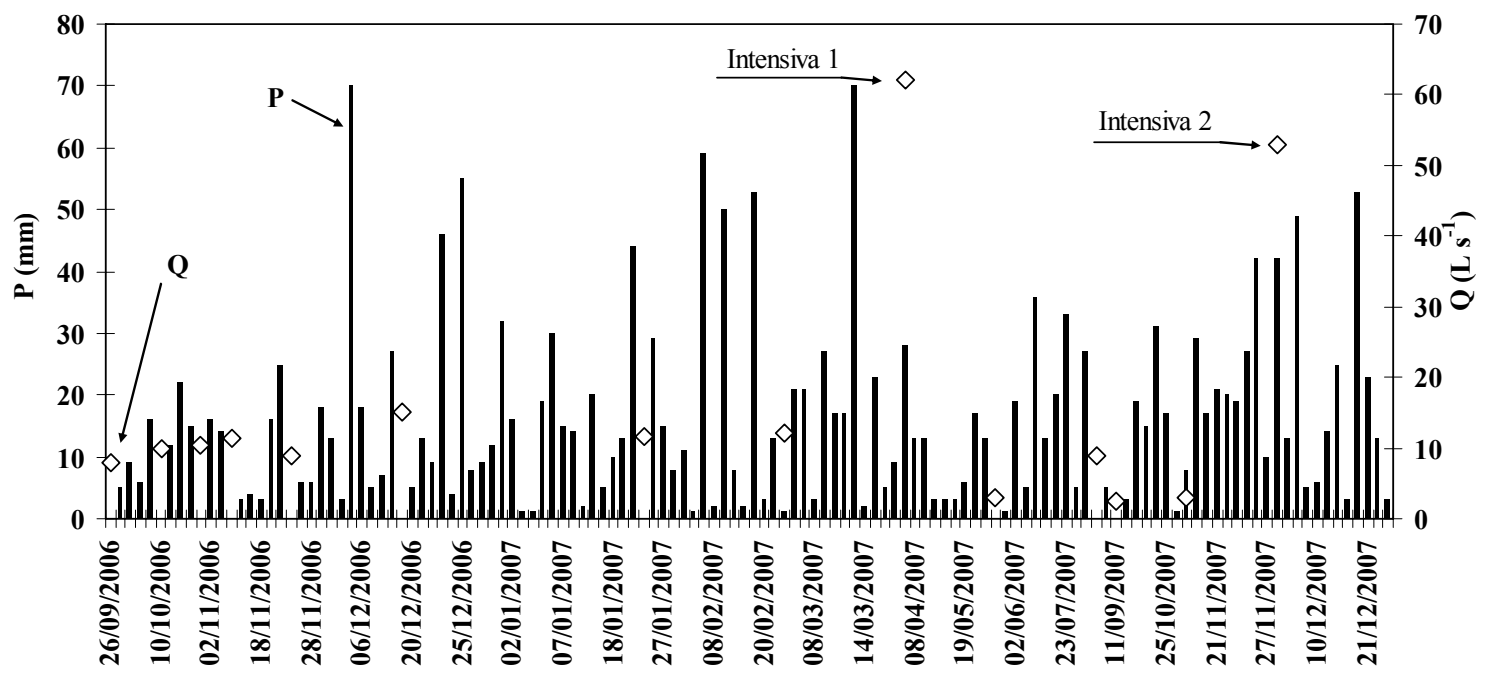

Figura 12. Precipitações diárias (mm) e vazões $\left(\mathrm{L} \mathrm{s}^{-1}\right)$ medidas no período de 26/09/2006 a 05/12/2007, na microbacia do córrego Entre Rios, Angatuba, São Paulo.

Foram observados baixos valores das vazões referentes às 12 amostragens extensivas foram baixos apesar de existirem altas precipitações ocorridas no período. Tais resultados podem ser justificados devido às coletas de águas fluviais serem efetuadas posteriores à ocorrência das chuvas. Como o tempo de residência da água de chuva na microbacia é rápido (aproximadamente 5 horas), algumas amostragens não foram suficientes para representar as altas vazões ocorridas no período.

Conforme descrito no item 4.3., foram observados os hidrogramas de cheia, referente às duas amostragens intensivas (Figuras 13 e 14). Pode ser observado que os picos de cheia relativos às intensivas 1 e 2 ocorreram em 2,5 e 2 horas, respectivamente. É importante salientar que a 
segunda amostragem intensiva ocorreu aproximadamente 5 meses após a colheita de madeira de eucaliptos que foi realizada no período de 01/07/2007 a 10/07/2007.

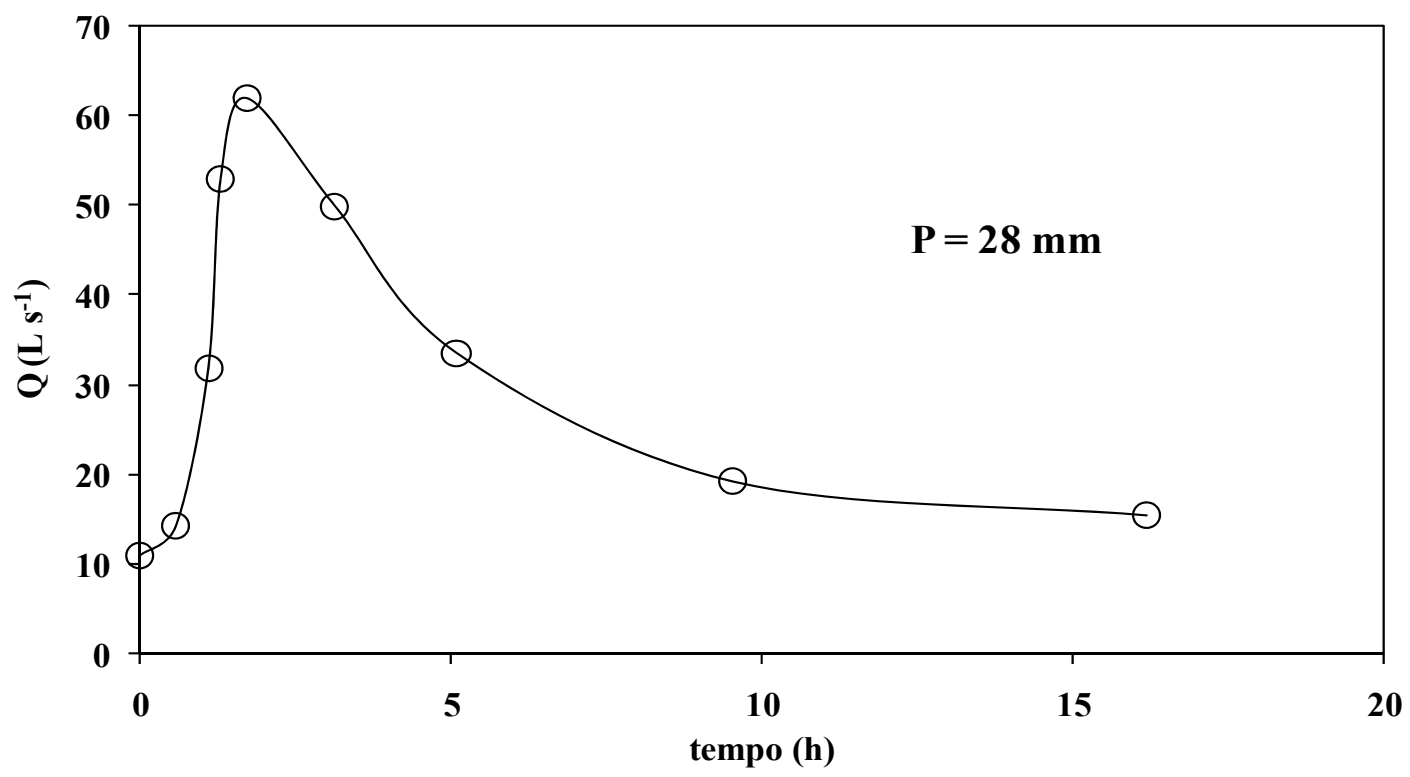

Figura 13. Hidrograma de cheia referente ao período de amostragem da primeira intensiva de águas fluviais, realizada no período de 17/03/2007 a 18/07/2007 na microbacia Entre Rios.

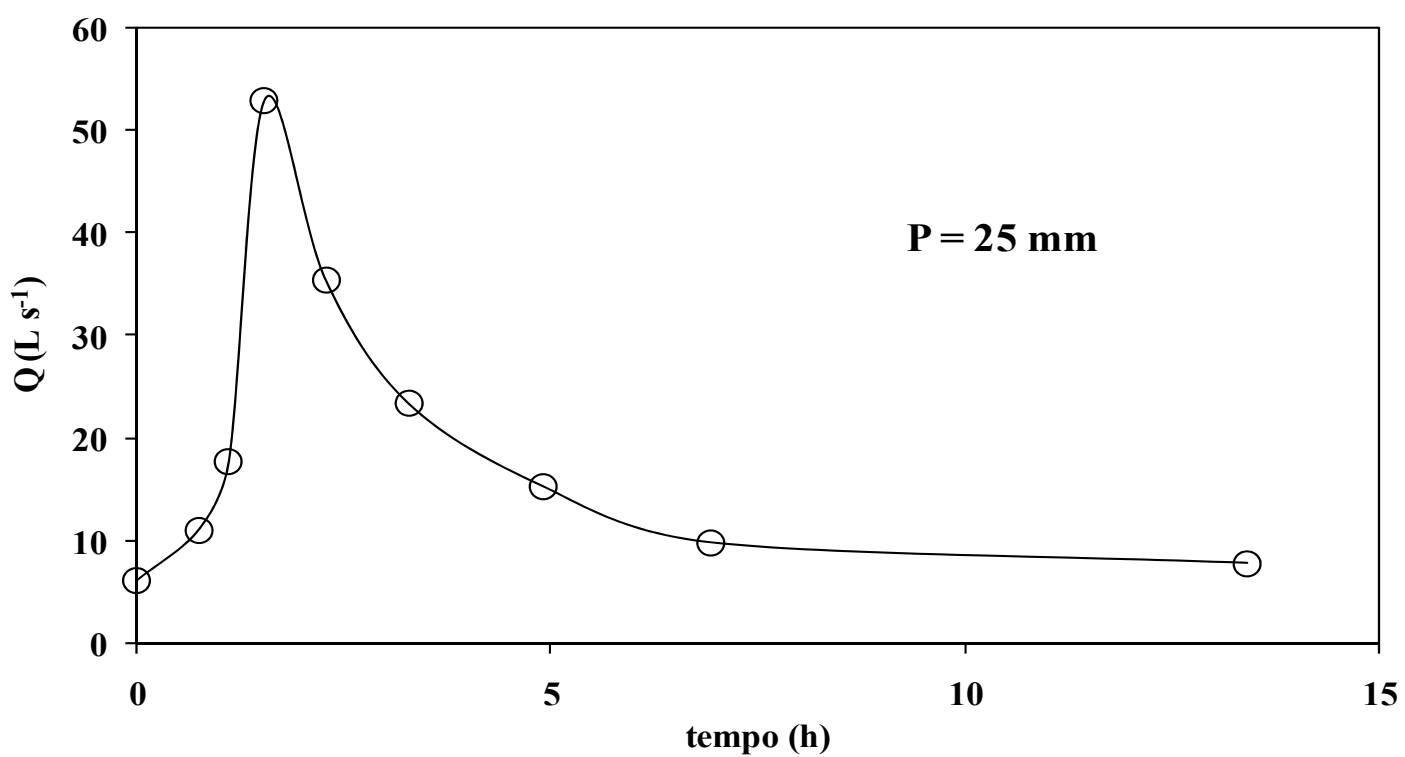

Figura 14. Hidrograma de cheia referente ao período de amostragem da segunda intensiva de águas fluviais, realizada em 05/12/2007 na microbacia Entre Rios, Angatuba, São Paulo. 
A primeira amostragem intensiva teve início às $17: 32 \mathrm{~h}$ do dia 17/03/2007 e término às 9:42 h no dia 18/03/2007 com uma duração total de 16,17 h. A segunda amostragem intensiva teve início às 9:30 $\mathrm{h}$ do dia 05/12/2007 e término às 22:55 h, correspondendo a um período de $13,42 \mathrm{~h}$.

Conforme proposto no presente trabalho (item 4.3.) efetuou-se a separação dos hidrogramas de cheia obtidos durante os dois eventos chuvosos (intensiva 1 e 2) ocorridos na microbacia do córrego Entre Rios.

Na Figura 15 encontram-se as separações dos hidrogramas de cheia para os períodos de 17 a 18/03/2007 (primeira intensiva) e de 05/12/2007 (segunda intensiva), com precipitações de 28 e $25 \mathrm{~mm}$, respectivamente. Os resultados obtidos para os eventos chuvosos apresentaram coeficientes médios de escoamento superficial $(\mathrm{Kr})$ e subterrâneo $(\mathrm{Kn})$ com valores de 0,3440 e 0,6560 respectivamente para a amostragem intensiva 1 e 0,3127 e 0,6873 para intensiva 2 . Tais valores representam a importância do escoamento subterrâneo na microbacia estudada, com cerca de $66 \%$ e $69 \%$ enquanto o escoamento superficial foi de $34 \%$ e $31 \%$, respectivamente nas intensivas 1 e 2. Pelos resultados obtidos não foi evidenciado a influência da colheita de madeira de eucaliptos ocorrida nos talhões 31 e 33 (Tabela 1) nos escoamentos superficiais e subterrâneos.

Foi possível verificar que durante os picos de cheia, as contribuições médias das águas subterrâneas foram de 52,5 e 41,2 \%, respectivamente para as amostragens intensivas 1 e 2 . Tais valores permitiram verificar uma maior contribuição da componente subterrânea na intensiva 1 possivelmente associadas ao período chuvoso em que foi realizada a amostragem. 

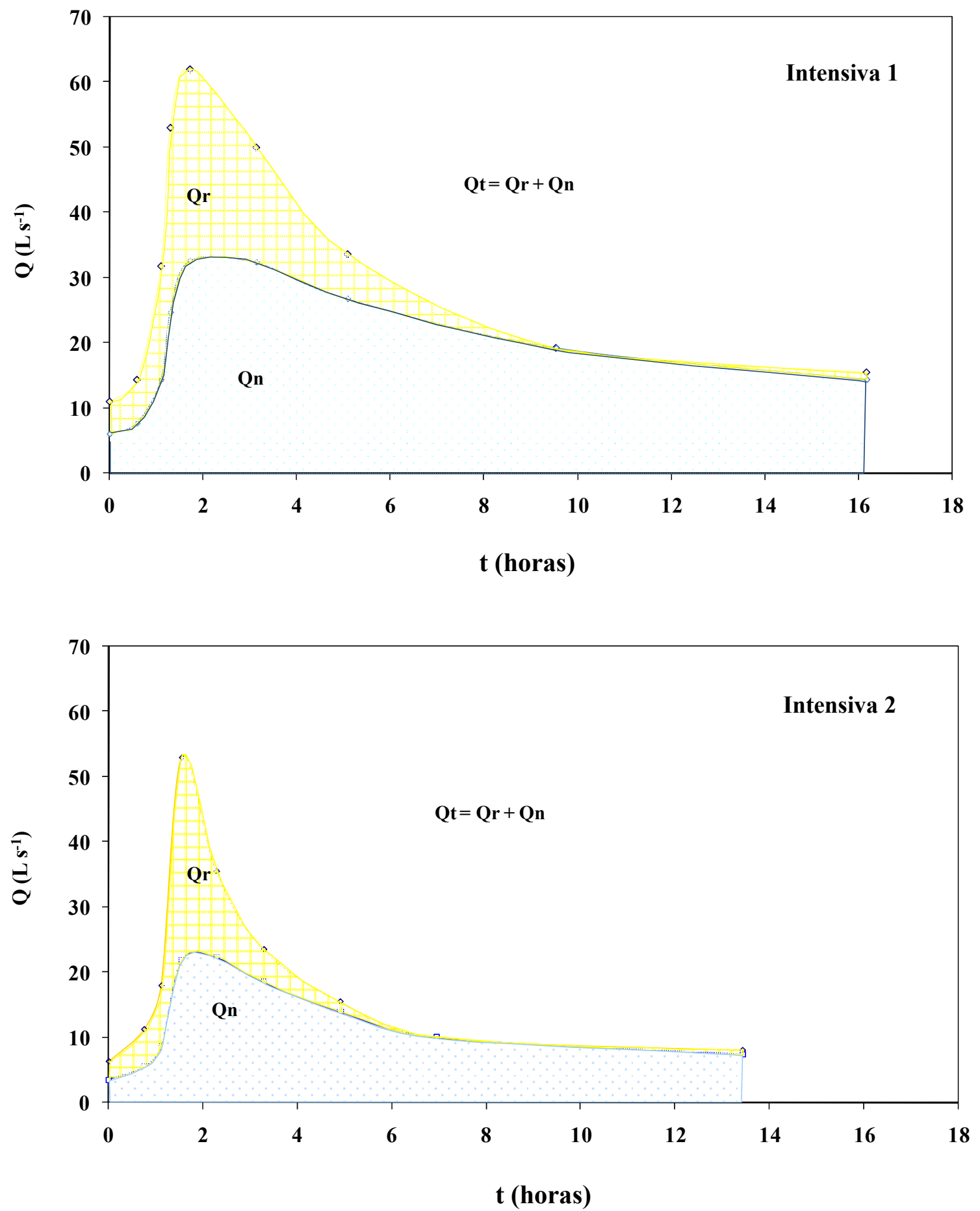

Figuras 15. Separação dos hidrogramas de cheia nos reservatórios superficial rápido (Qr) e (Qn) pelo método de filtros numéricos, correspondentes respectivamente a primeira e segunda amostragem intensiva no córrego Entre Rios. 


\subsection{Caracterização Hidroquímica Fluvial}

\subsubsection{Parâmetros físico-químicos}

$\mathrm{Na}$ Tabela 3 encontram-se os principais parâmetros físico-químicos determinados para as águas fluviais do córrego Entre Rios, Angatuba, São Paulo, no período de 26/09/2006 a 05/12/2007, de acordo com o protocolo estabelecido no item 4.4.1. 
Tabela 3. Resultados de vazão (Q), pH, condutividade elétrica (Cond.), oxigênio dissolvido (OD) e temperatura $(\mathrm{T})$ referentes às excursões realizadas na microbacia Entre Rios, Angatuba.

\begin{tabular}{|c|c|c|c|c|c|c|c|}
\hline Amostras & $\begin{array}{c}\text { Excursão } \\
\text { (data) }\end{array}$ & $\begin{array}{c}\text { tempo } \\
\text { (h) }\end{array}$ & $\begin{array}{c} \\
\left(\mathrm{L} \mathrm{s}^{-1}\right) \\
\end{array}$ & pH & $\begin{array}{c}\text { OD } \\
\left(\mathrm{mg} \mathrm{L}^{-1}\right) \\
\end{array}$ & $\begin{array}{c}\text { Cond. } \\
\left(\mu \mathrm{S} \mathrm{cm}^{-1}\right)\end{array}$ & $\begin{array}{c}\mathrm{T} \\
\left({ }^{\circ} \mathrm{C}\right) \\
\end{array}$ \\
\hline $\mathrm{A}_{1}$ & $26 / 09 / 06$ & $11: 00$ & 8,0 & 6,2 & 9,0 & 26,0 & 17,1 \\
\hline $\mathrm{A}_{2}$ & 10/10/06 & $10: 49$ & 10,0 & 6,4 & 4,0 & 25,5 & 23,2 \\
\hline $\mathrm{A}_{3}$ & $24 / 10 / 06$ & $11: 45$ & 10,5 & 5,8 & 4,1 & 24,2 & 22,5 \\
\hline $\mathrm{A}_{4}$ & 08/11/06 & $12: 42$ & 11,3 & 6,8 & 4,5 & 24,0 & 20,9 \\
\hline $\mathrm{A}_{5}$ & $22 / 11 / 06$ & $11: 30$ & 8,9 & 6,4 & 3,1 & 24,0 & 21,1 \\
\hline $\mathrm{A}_{6}$ & 19/12/06 & $11: 00$ & 15,0 & 6,3 & 3,2 & 21,1 & 23,8 \\
\hline $\mathrm{A}_{7}$ & $24 / 01 / 07$ & $11: 10$ & 11,5 & 6,0 & 2,4 & 23,9 & 21,8 \\
\hline $\mathrm{A}_{8}$ & $27 / 02 / 07$ & $11: 05$ & 12,0 & 6,6 & 3,1 & 25,9 & 23,4 \\
\hline $\mathrm{A}_{9.1}$ & $17 / 03 / 07$ & $17: 32$ & 11,0 & 6,3 & 7,4 & 24,8 & 22,8 \\
\hline $\mathrm{A}_{9.2}$ & $17 / 03 / 07$ & 18:07 & 14,3 & 6,4 & 6,9 & 26,4 & 22,7 \\
\hline $\mathrm{A}_{9.3}$ & $17 / 03 / 07$ & $18: 38$ & 31,8 & 6,3 & 6,2 & 21,3 & 22,7 \\
\hline $\mathrm{A}_{9.4}$ & $17 / 03 / 07$ & $18: 50$ & 53,0 & 6,2 & 6,4 & 20,5 & 22,6 \\
\hline $\mathrm{A}_{9.5}$ & $17 / 03 / 07$ & $19: 15$ & 62,0 & 6,2 & 6,1 & 20,0 & 22,7 \\
\hline $\mathrm{A}_{9.6}$ & $17 / 03 / 07$ & $20: 40$ & 50,0 & 6,1 & 6,3 & 20,0 & 22,6 \\
\hline $\mathrm{A}_{9.7}$ & $17 / 03 / 07$ & $22: 37$ & 33,6 & 6,1 & 5,6 & 19,1 & 22,6 \\
\hline $\mathrm{A}_{9.8}$ & $18 / 03 / 07$ & 03:04 & 19,2 & 6,2 & 5,9 & 19,0 & 22,8 \\
\hline $\mathrm{A}_{9.9}$ & $18 / 03 / 07$ & $09: 42$ & 15,5 & 6,1 & 5,2 & 19,9 & 25,5 \\
\hline $\mathrm{A}_{10}$ & $26 / 06 / 07$ & $12: 30$ & 2,9 & 5,8 & 3,2 & 19,4 & 18,7 \\
\hline $\mathrm{A}_{11}$ & $28 / 07 / 07$ & $11: 25$ & 9,0 & 6,4 & 7,6 & 18,7 & 14,5 \\
\hline $\mathrm{A}_{12}$ & $11 / 09 / 07$ & $11: 06$ & 2,5 & 5,7 & 4,1 & 18,7 & 19,0 \\
\hline $\mathrm{A}_{13}$ & $30 / 10 / 07$ & $11: 27$ & 3,0 & 6,3 & 3,2 & 43,9 & 20,0 \\
\hline $\mathrm{A}_{14.1}$ & 05/12/07 & 09:30 & 6,3 & 6,4 & 3,7 & 26,3 & 25,3 \\
\hline $\mathrm{A}_{14.2}$ & 05/12/07 & $10: 15$ & 11,2 & 6,4 & 3,6 & 23,0 & 24,9 \\
\hline $\mathrm{A}_{14.3}$ & $05 / 12 / 07$ & $10: 37$ & 17,9 & 6,3 & 3,4 & 26,1 & 25,1 \\
\hline $\mathrm{A}_{14.4}$ & 05/12/07 & $11: 03$ & 53,0 & 6,3 & 3,0 & 24,5 & 25,1 \\
\hline $\mathrm{A}_{14.5}$ & $05 / 12 / 07$ & $11: 47$ & 35,5 & 6,2 & 3,5 & 24,0 & 24,7 \\
\hline $\mathrm{A}_{14.6}$ & $05 / 12 / 07$ & $12: 47$ & 23,5 & 6,2 & 3,4 & 21,2 & 24,9 \\
\hline $\mathrm{A}_{14.7}$ & $05 / 12 / 07$ & $14: 24$ & 15,5 & 6,2 & 3,3 & 22,3 & 25,0 \\
\hline $\mathrm{A}_{14.8}$ & 05/12/07 & $16: 26$ & 10,0 & 6,4 & 3,8 & 20,6 & 24,2 \\
\hline $\mathrm{A}_{14.9}$ & $05 / 12 / 07$ & $22: 55$ & 8,0 & 6,5 & 3,8 & 20,9 & 25,0 \\
\hline
\end{tabular}

$\mathrm{A}_{9.1}$ a $\mathrm{A}_{9.9}$ representam o período de amostragem intensiva 1

$\mathrm{A}_{14.1}$ a $\mathrm{A}_{14.9}$ representam o período de amostragem intensiva 2 
Pode ser observado que as águas fluviais apresentaram valores de $\mathrm{pH}$ variando entre $5,7 \mathrm{e}$ 6,8. Valores similares de pH para águas fluviais foram encontrados por Ranzini e Lima (2002) para duas distintas microbacias, plantadas com Eucalyptus saligna Smith, situadas no município de Santa Branca (SP) e por Vital, et al. (1999) em duas microbacias no Vale do Paraíba (SP).

A temperatura da água do córrego Entre Rios, durante o período estudado variou de 14,5 a $25,5{ }^{\circ} \mathrm{C}$, Não foram observadas variações significativas nas temperaturas para as amostragens intensivas 1 e 2 , em que foram verificadas temperaturas médias de 23 e $25^{\circ} \mathrm{C}$, respectivamente. A baixa variação da temperatura ao longo dos períodos estudados podem estar relacionadas a cobertura vegetal existente na área de estudo. Na microbacia do córrego Entre Rios existe uma densa cobertura florestal formada por matas ciliares (nas margens do córrego) e fragmentos de eucaliptos (nas áreas de plantio próximas ao córrego) desde nascente até a sua foz e correspondem a $22 \%$ da área total da microbacia, ou seja, 35,2 ha (Tabela 1). Esta hipótese é compartilhada por outros autores que evidenciam a prevenção dos aumentos de temperatura da água em função da conservação da vegetação ou mata ciliar (SWIFT; MESSER, 1971; SUGIMOTO et al., 1997; ARCOVA; CICCO, 1999).

As concentrações de oxigênio dissolvido variaram nas amostragens extensivas de 3,2 a $9,0 \mathrm{mg} \mathrm{L}{ }^{-1}$. Na amostragem intensiva 1 o oxigênio dissolvido variou de 5,2 a 7,4 com um valor médio de $6,2 \pm 0,6$. Na amostragem intensiva 2 o valor médio de oxigênio dissolvido encontrado foi de $3,5 \pm 0,2$.

Os valores de condutividade elétrica verificados para as águas fluviais no presente estudo variaram entre 18,7 e 43,9 $\mu \mathrm{S} \mathrm{cm}^{-1}$, sendo encontrados valores mínimos e máximos antes da colheita de 19,0 e $26,4 \mu \mathrm{S} \mathrm{cm}^{-1}$ e posterior à colheita de 18,7 e $43,9 \mu \mathrm{S} \mathrm{cm}^{-1}$, respectivamente. Valores inferiores ao encontrado por Vital et al. (1999) que obtiveram 67 e $96 \mu \mathrm{S} \mathrm{cm}^{-1}$, antes da colheita de madeira e 94 e $130 \mu \mathrm{S} \mathrm{cm}^{-1}$, após a colheita. Ranzini e Lima (2002) obtiveram valores 
de condutividade elétrica mínimos e máximos de 34 e $38 \mu \mathrm{S} \mathrm{cm}^{-1}$ e de 38 e $52 \mu \mathrm{S} \mathrm{cm}^{-1}$, respectivamente para as águas fluviais de duas distintas microbacias reflorestadas com eucaliptos, no Vale do Paraíba, São Paulo. Os mesmos se mostraram superiores aos observados no presente estudo, sendo de 18,7 a $43,9 \mu \mathrm{S} \mathrm{cm}^{-1}$.

De acordo com Hen (1970), as condutividades baixas (em torno de $50 \mu \mathrm{S} \mathrm{cm}^{-1}$ ), podem indicar precipitação com baixa concentração de solutos e/ou rochas resistentes ao processo de intemperismo.

\subsubsection{Concentrações das espécies químicas fluviais e equilíbrio iônico}

As concentrações das principais espécies químicas dissolvidas obtidas nas amostras de águas fluviais da microbacia do córrego Entre Rios foram verificadas de acordo com estabelecido no item 4.4.2. A Tabela 4 apresenta os resultados dos cátions e ânions principais no período de 26/09/2006 a 05/12/2007, incluindo os sólidos dissolvidos totais (TDS). 
Tabela 4. Resultados analíticos das principais espécies químicas dissolvidas (cátions e ânions) nas águas do córrego Entre Rios, Angatuba, São Paulo.

\begin{tabular}{|c|c|c|c|c|c|c|c|c|c|c|c|c|c|c|}
\hline Amostras & $\begin{array}{c}\text { Excursão } \\
\text { (data) }\end{array}$ & $\begin{array}{c}Q \\
\left(\mathrm{~L} \mathrm{~s}^{-1}\right)\end{array}$ & $\mathrm{Ca}^{2+}$ & $\mathbf{M g}^{2+}$ & $\mathrm{Na}^{+}$ & $\mathbf{K}^{+}$ & $\mathbf{N H}_{4}{ }^{+}$ & $\begin{array}{c}\mathrm{SiO}_{2} \\
\left(\mathrm{mg} \mathrm{L}^{-1}\right)\end{array}$ & $\mathrm{HCO}_{3}^{-}$ & $\mathrm{Cl}^{-}$ & $\mathrm{SO}_{4}{ }^{2-}$ & $\mathrm{NO}_{3}^{-}$ & $\mathrm{PO}_{4}{ }^{3-}$ & TDS \\
\hline $\mathbf{A}_{1}$ & $26 / 09 / 06$ & 8,0 & 2,20 & 0,70 & 0,91 & 1,93 & 0,02 & 12,51 & 11,00 & 1,60 & 0,85 & 0,27 & 0,63 & 32,60 \\
\hline $\mathbf{A}_{2}$ & $10 / 10 / 06$ & 10,0 & 2,11 & 0,65 & 0,79 & 1,92 & 0,01 & 12,05 & 10,30 & 1,40 & 0,78 & 0,21 & nd & 30,22 \\
\hline $\mathbf{A}_{3}$ & $24 / 10 / 06$ & 10,5 & 2,10 & 0,63 & 0,87 & 1,87 & 0,02 & 12,95 & 11,00 & 1,00 & 0,76 & 0,22 & 0,05 & 31,46 \\
\hline $\mathbf{A}_{4}$ & 08/11/06 & 11,3 & 2,05 & 0,66 & 0,71 & 1,89 & 0,01 & 11,39 & 10,00 & 1,30 & 0,70 & 0,19 & 0,36 & 29,26 \\
\hline $\mathbf{A}_{5}$ & $22 / 11 / 06$ & 8,9 & 2,23 & 0,68 & 0,74 & 1,90 & 0,04 & 11,86 & 9,91 & 1,60 & 0,80 & 0,34 & 0,11 & 30,22 \\
\hline $\mathbf{A}_{6}$ & 19/12/06 & 15,0 & 1,90 & 0,45 & 0,60 & 1,76 & 0,07 & 12,31 & 9,50 & 0,90 & 0,55 & 0,19 & 0,04 & 28,26 \\
\hline $\mathbf{A}_{7}$ & $24 / 01 / 07$ & 11,5 & 2,07 & 0,64 & 0,65 & 1,90 & 0,02 & 10,91 & 10,10 & 1,13 & 0,60 & 0,13 & 0,03 & 28,18 \\
\hline $\mathbf{A}_{8}$ & $27 / 02 / 07$ & 12,0 & 2,04 & 0,62 & 0,67 & 1,80 & 0,05 & 11,19 & 10,20 & 1,54 & 0,55 & 0,57 & nd & 29,22 \\
\hline $\mathbf{A}_{9.1}$ & $17 / 03 / 07$ & 11,0 & 1,68 & 0,46 & 0,60 & 1,71 & 0,04 & 10,40 & 8,20 & 0,90 & 0,40 & 0,42 & 0,01 & 24,83 \\
\hline $\mathbf{A}_{9.2}$ & $17 / 03 / 07$ & 14,3 & 1,78 & 0,45 & 0,44 & 1,75 & 0,05 & 10,06 & 8,30 & 0,90 & 0,32 & 0,36 & 0,15 & 24,57 \\
\hline $\mathbf{A}_{9.3}$ & $17 / 03 / 07$ & 31,8 & 1,60 & 0,40 & 0,40 & 1,72 & 0,04 & 9,11 & 7,25 & 0,90 & 0,45 & 0,40 & 0,02 & 22,30 \\
\hline $\begin{array}{l}\text { A9.4 } \\
\text { (n) }\end{array}$ & $17 / 03 / 07$ & 53,0 & 1,20 & 0,30 & 0,30 & 1,50 & 0,03 & 8,97 & 6,20 & 0,51 & 0,22 & 0,35 & 0,06 & 19,64 \\
\hline $\mathbf{A}_{9.5}$ & $17 / 03 / 07$ & 62,0 & 1,00 & 0,30 & 0,35 & 1,50 & 0,02 & 7,74 & 5,30 & 0,64 & 0,36 & 0,38 & nd & 17,59 \\
\hline A9.6 & $17 / 03 / 07$ & 50,0 & 1,32 & 0,25 & 0,42 & 1,62 & 0,02 & 8,56 & 5,90 & 0,65 & 0,37 & 0,48 & 0,08 & 19,67 \\
\hline $\mathbf{A}_{9.7}$ & $17 / 03 / 07$ & 33,6 & 1,30 & 0,44 & 0,43 & 1,59 & 0,01 & 8,70 & 6,81 & 0,56 & 0,40 & 0,58 & 0,10 & 20,92 \\
\hline $\mathbf{A}_{9.8}$ & $18 / 03 / 07$ & 19,2 & 1,50 & 0,44 & 0,46 & 1,55 & 0,02 & 9,58 & 7,10 & 0,80 & 0,50 & 0,56 & nd & 22,51 \\
\hline $\mathbf{A}_{9.9}$ & $18 / 03 / 07$ & 15,5 & 1,67 & 0,47 & 0,49 & 2,00 & 0,02 & 9,83 & 7,60 & 1,30 & 0,80 & 0,50 & nd & 24,67 \\
\hline $\mathbf{A}_{10}$ & $26 / 06 / 07$ & 2,9 & 2,20 & 0,49 & 0,58 & 2,56 & 0,09 & 13,52 & 13,50 & 1,10 & 0,12 & 0,17 & nd & 34,35 \\
\hline $\mathbf{A}_{11}$ & $28 / 07 / 07$ & 9,0 & 1,59 & 0,43 & 0,55 & 2,10 & 0,11 & 11,54 & 10,00 & 0,74 & 0,46 & 0,23 & 0,11 & 27,87 \\
\hline $\mathbf{A}_{12}$ & $11 / 09 / 07$ & 2,5 & 2,09 & 0,43 & 0,49 & 2,30 & nd & 11,79 & 12,00 & 0,83 & 0,02 & 0,17 & 0,05 & 30,18 \\
\hline $\mathbf{A}_{13}$ & $30 / 10 / 07$ & 3,0 & 2,13 & 0,52 & 0,56 & 2,40 & 0,07 & 12,02 & 12,00 & 1,30 & 0,20 & 0,20 & nd & 31,41 \\
\hline $\mathbf{A}_{14.1}$ & 05/12/07 & 6,3 & 1,80 & 0,42 & 0,65 & 1,52 & nd & 8,82 & 8,20 & 0,76 & 0,60 & 0,34 & nd & 23,11 \\
\hline $\mathbf{A}_{14.2}$ & $05 / 12 / 07$ & 11,2 & 1,41 & 0,38 & 0,41 & 1,94 & nd & 7,97 & 6,72 & 1,51 & 0,43 & 0,34 & 0,09 & 21,20 \\
\hline $\mathbf{A}_{14.3}$ & 05/12/07 & 17,9 & 1,90 & 0,50 & 0,48 & 3,68 & nd & 9,83 & 7,80 & 2,17 & 1,02 & 1,49 & 0,11 & 28,97 \\
\hline $\mathbf{A}_{14.4}$ & 05/12/07 & 53,0 & 1,30 & 0,35 & 0,30 & 2,65 & nd & 6,96 & 4,97 & 1,70 & 0,91 & 0,62 & nd & 19,76 \\
\hline $\mathbf{A}_{14.5}$ & $05 / 12 / 07$ & 35,5 & 1,34 & 0,38 & 0,35 & 2,77 & nd & 5,88 & 5,21 & 2,46 & 0,73 & 0,49 & nd & 19,60 \\
\hline $\mathbf{A}_{14.6}$ & 05/12/07 & 23,5 & 1,51 & 0,43 & 0,30 & 2,57 & nd & 7,17 & 5,50 & 1,96 & 0,83 & 0,56 & nd & 20,83 \\
\hline $\mathbf{A}_{14.7}$ & 05/12/07 & 15,5 & 1,86 & 0,43 & 0,60 & 2,83 & nd & 8,31 & 6,75 & 1,96 & 0,99 & 0,96 & 0,17 & 24,84 \\
\hline $\mathbf{A}_{14.8}$ & 05/12/07 & 10,0 & 1,73 & 0,49 & 0,48 & 1,34 & nd & 7,45 & 7,26 & 0,89 & 1,08 & 0,37 & nd & 21,10 \\
\hline \multirow[t]{2}{*}{$\mathbf{A}_{14.9}$} & $05 / 12 / 07$ & 8,0 & 1,55 & 0,57 & 0,70 & 2,20 & nd & 8,27 & 7,80 & 1,20 & 1,10 & 0,44 & nd & 23,83 \\
\hline & & $\mathrm{C}_{\mathrm{MNQ}}$ & 1,51 & 0,41 & 0,45 & 1,98 & 0,02 & 8,92 & 7,02 & 1,15 & 0,57 & 0,47 & 0,06 & 22,57 \\
\hline
\end{tabular}

$\mathrm{C}_{\mathrm{MNQ}}=$ concentração média da espécie química normalizada pela vazão

$A_{1}$ a $A_{8}$ e $A_{10}$ a $A_{13}$ representam as amostragens normais

$\mathrm{A}_{9.1}$ a $\mathrm{A}_{9.9}$ representam a amostragem intensiva 1

$\mathrm{A}_{14.1}$ a $\mathrm{A}_{14.9}$ representam a amostragem intensiva 2

" nd " não determinado (< limite de detecção $=0,01 \mathrm{mg} \mathrm{L}^{-1)}$

O erro analítico envolvido neste estudo, expresso em porcentagem ( $\Delta$ em $\%)$, para um possível desequilíbrio iônico determinado de acordo com a metodologia descrita no item 4.4.2, foi menor que $10 \%$ (Figura 16). 


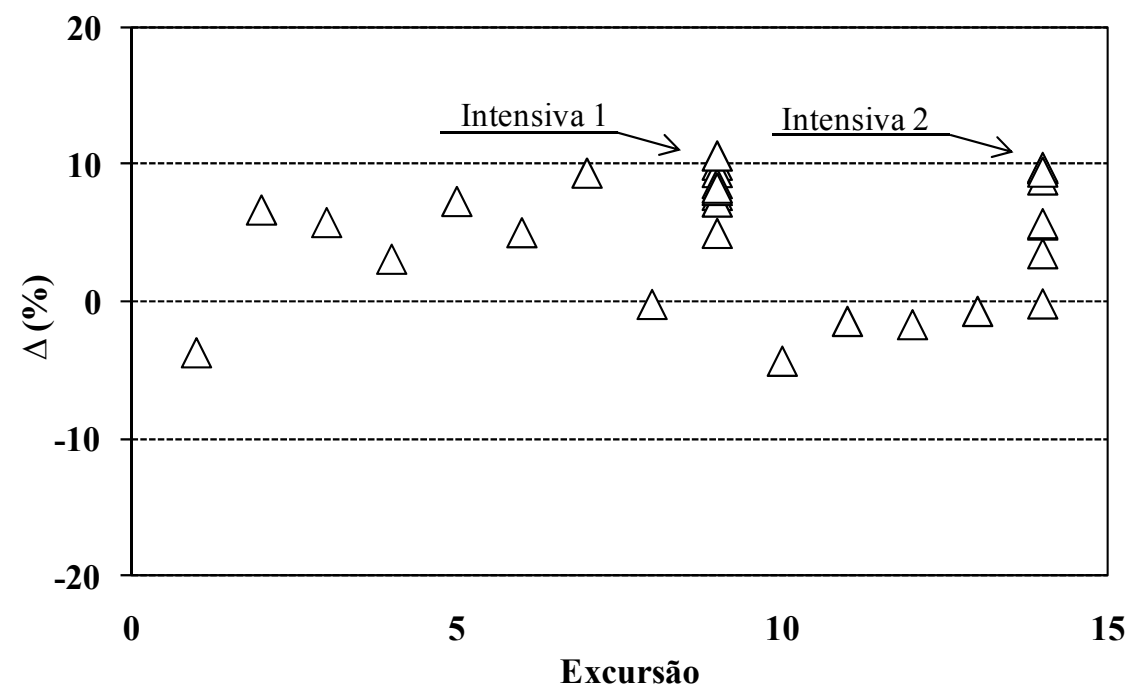

Figura 16. Erro analítico relativo (\%) ao equilíbrio iônico entre cátions e ânions referente a 14 excursões de amostras de águas fluviais da microbacia.

A razão entre a soma de cátions e ânions $\left(\right.$ meq $\left.\mathrm{L}^{-1}\right)$ para as amostras de água analisadas possibilitou também verificar a qualidade das análises químicas dos cátions e ânions principais, conforme observado na Figura 17.

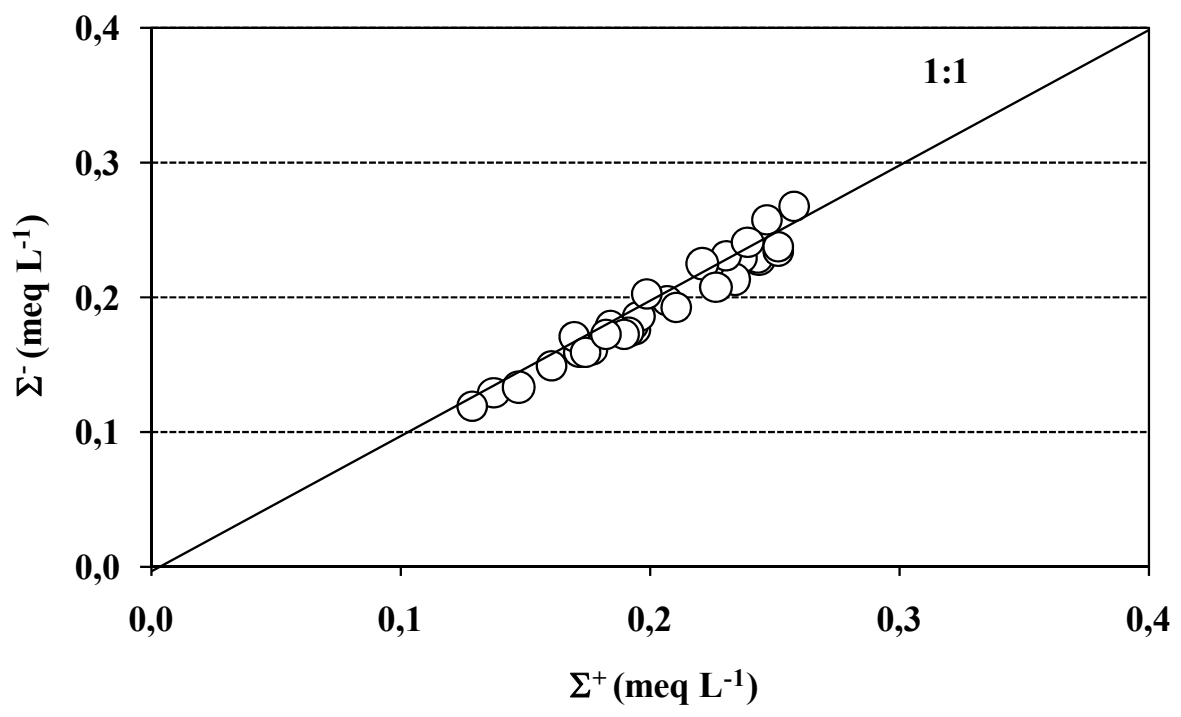

Figura 17. Razão entre a soma de cátions e de ânions nas amostras de águas do córrego Entre Rios, Angatuba, São Paulo, no período de 26/09/2006 a 05/12/2007. 
Através dos valores das concentrações médias normalizadas pelas vazões $\left(\mathrm{C}_{\mathrm{MNQ}}\right)$, foi possível, conforme citado no item 4.4.2., determinar as porcentagens das contribuições de cada espécie química nas águas do córrego Entre Rios, em termos dos sólidos dissolvidos totais (Figura 18). Pode ser observado para as amostragens extensivas, intensiva 1 e intensiva 2 que o $\mathrm{SiO}_{2}(40,1 ; 42,9$ e $34,1 \%)$ e o $\mathrm{HCO}_{3}^{-}(34,8 ; 31,4$ e $27,6 \%)$, apresentaram-se como as espécies mais representativas nas águas da microbacia. As origens destas espécies químicas estão intimamente ligadas a processos de intemperismo químico de rochas da região, participando de quase todas as reações de dissolução de minerais primários (GARRELS; MACKENZIE, 1971; PROBST et al., 1994; MORTATTI et al., 2006) e, especificamente na microbacia, dos minerais silicatados predominantes. Os cátions mais representativos para as águas da microbacia foram o $\mathrm{K}^{+}(6,5 ; 7,8$ e $12,0 \%)$ e o $\mathrm{Ca}^{2+}(6,8 ; 6,5$ e $6,9 \%)$, respectivamente. Com relação ao $\mathrm{Mg}^{2+}(2,0 ; 1,7$ e $1,9 \%)$ e $\mathrm{Na}^{+}(2,4 ; 1,9$ e $1,8 \%)$, os mesmos não apresentaram variações significativas no decorrer dos períodos estudados mantendo-se na mesma ordem de grandeza. $\mathrm{O} \mathrm{NO}_{3}{ }^{-}(0,9 ; 2,1$ e 3,0\%), o $\mathrm{SO}_{4}{ }^{2-}\left(2,1 ; 1,9\right.$ e 4,0\%) e o $\mathrm{PO}_{4}{ }^{3-}(0,4 ; 0,2$ e $0,1 \%)$ tiveram baixas porcentagens nas águas fluviais da microbacia para as amostragens extensivas, intensiva 1 e intensiva 2 , respectivamente.

Observou-se que o $\mathrm{Cl}^{-}$e o $\mathrm{K}^{+}$teve variações significativas entre os períodos estudados e um acréscimo na porcentagem dos mesmos foi mais evidente na intensiva 2. Na microbacia do córrego Entre Rios foram efetuados tratos culturais nos solos dos talhões 31 e 33 com a adição de $(\mathrm{KCl})$, nos dias 20/11/2007 e 01/12/2007 anterior a amostragem intensiva 2 (Tabela 1A, Apêndice 1). Este fato pode ter acentuado a concentração de $\mathrm{Cl}^{-}$e $\mathrm{K}^{+}$na carga dissolvida das águas do córrego Entre Rios, no referido período. Segundo a literatura, a presença do íon $\mathrm{Cl}^{-}$na carga dissolvida, na ausência de rochas evaporíticas na área de estudo e grandes distâncias com relação às zonas litorâneas, se deve possivelmente aos aportes antrópicos pontuais, como por exemplo, a utilização de insumos agrícolas (STALLARD; EDMOND,1981 e BIBIAN, 2007). 


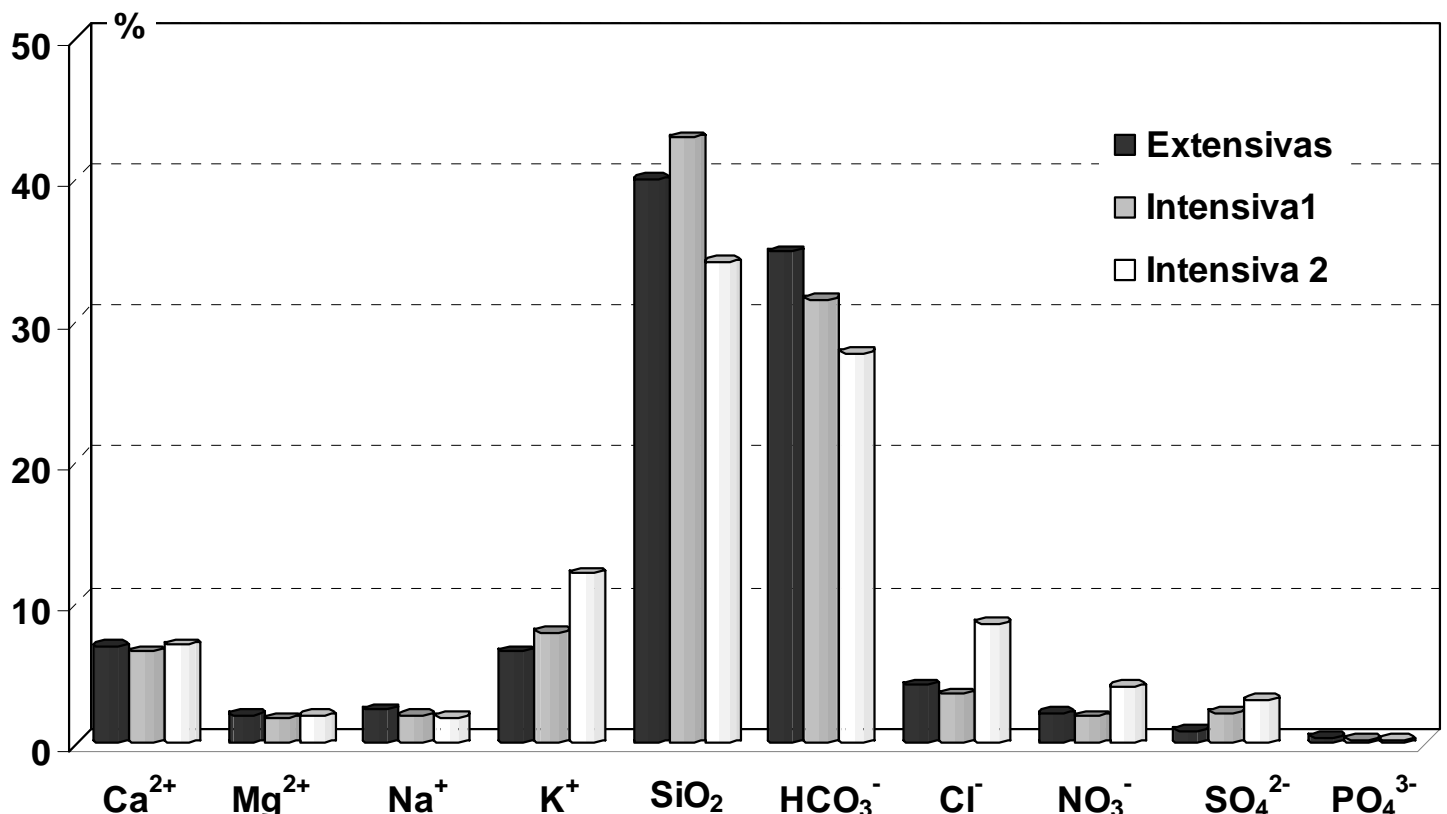

Figura 18. Porcentagem das principais espécies químicas dissolvidas no córrego Entre Rios, Angatuba, São Paulo em função do TDS no período de 26/09/2006 a 05/12/2007.

\subsubsection{Variabilidade temporal das concentrações das principais espécies químicas}

De acordo com estabelecido no item 4.4.3., o comportamento das concentrações das principais espécies químicas dissolvidas nas águas da microbacia do córrego Entre Rios (cátions ânions, $\mathrm{SiO}_{2}$ e TDS) foram averiguados em relação à sua variabilidade temporal.

Pode ser observado que o relacionamento temporal das concentrações das principais espécies químicas em função das vazões foi diferenciado nos três períodos de amostragem. Este comportamento foi melhor evidenciado quando observado o relacionamento das espécies químicas nos dois eventos chuvosos com amostragens intensivas (1 e 2).

De uma maneira geral, foi possível verificar que $\mathrm{Ca}^{2+}, \mathrm{Mg}^{2+}, \mathrm{Na}^{+}, \mathrm{HCO}_{3}^{-},{\mathrm{e} \mathrm{NO}_{3}}^{-}, \mathrm{SiO}_{2} \mathrm{e}$ TDS durante todos os períodos, apresentaram comportamento de diluição em função da vazão, ou 
seja, houve declínio dos valores de suas concentrações em função do aumento das respectivas vazões (Figuras de 19 a 24).

Nas amostragens extensivas, em função das baixas concentrações das espécies químicas e menor variabilidade das vazões, o comportamento de diluição foi menos evidente quando comparadas suas variabilidades nas amostragens intensivas, que apresentaram para a maioria dos íons ótimos relacionamentos com a vazão. 


\section{Amostragens}

Extensivas
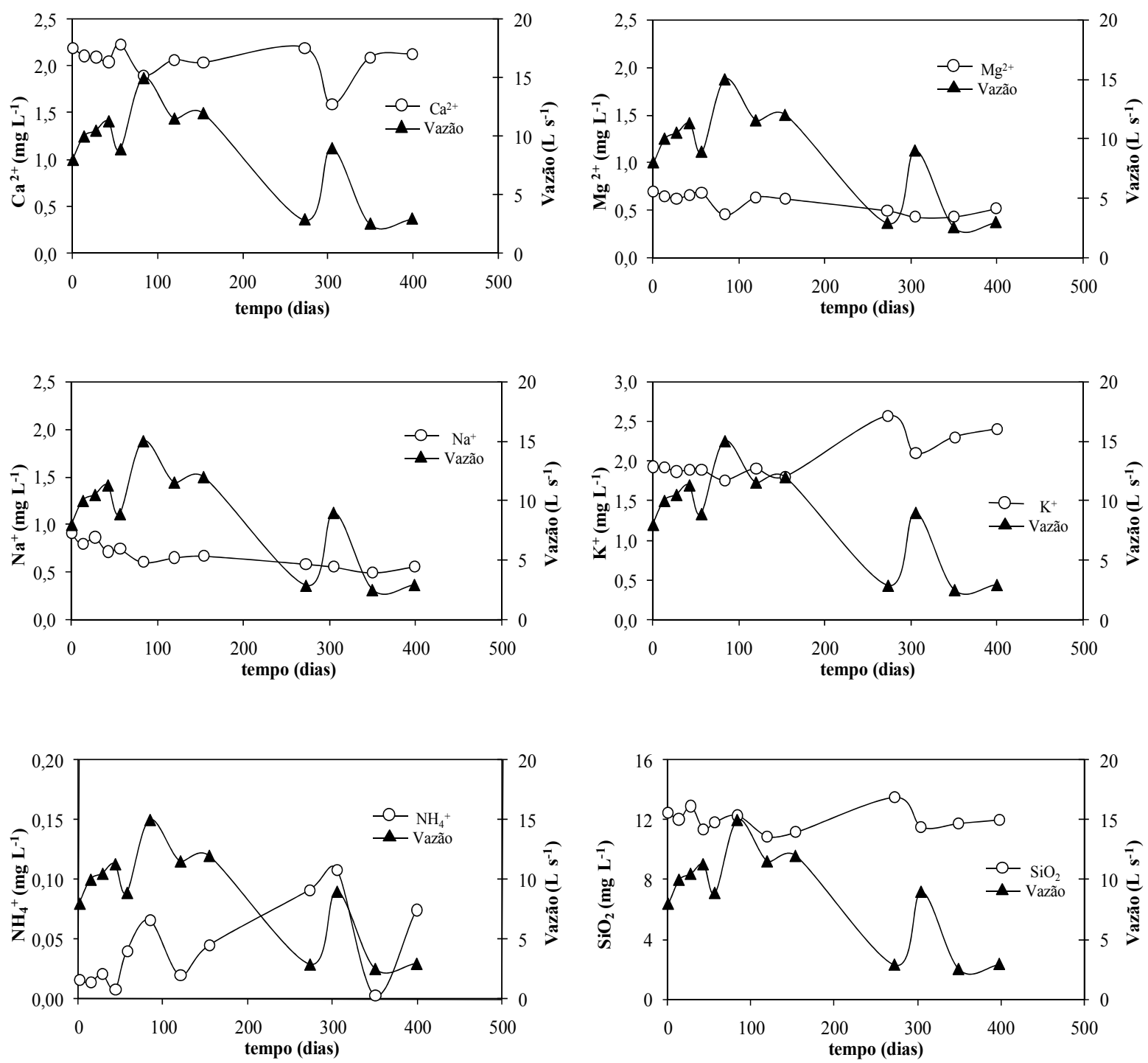

Figura 19. Variabilidade temporal da concentração $\left(\mathrm{mg} \mathrm{L}^{-1}\right)$ de cátions além de $\mathrm{SiO}_{2}$ em função das vazões $\left(\mathrm{L} \mathrm{s}^{-1}\right)$ para as amostras de águas do córrego Entre Rios, Angatuba, São Paulo, para as amostragens extensivas. 


\section{Amostragens}

Extensivas
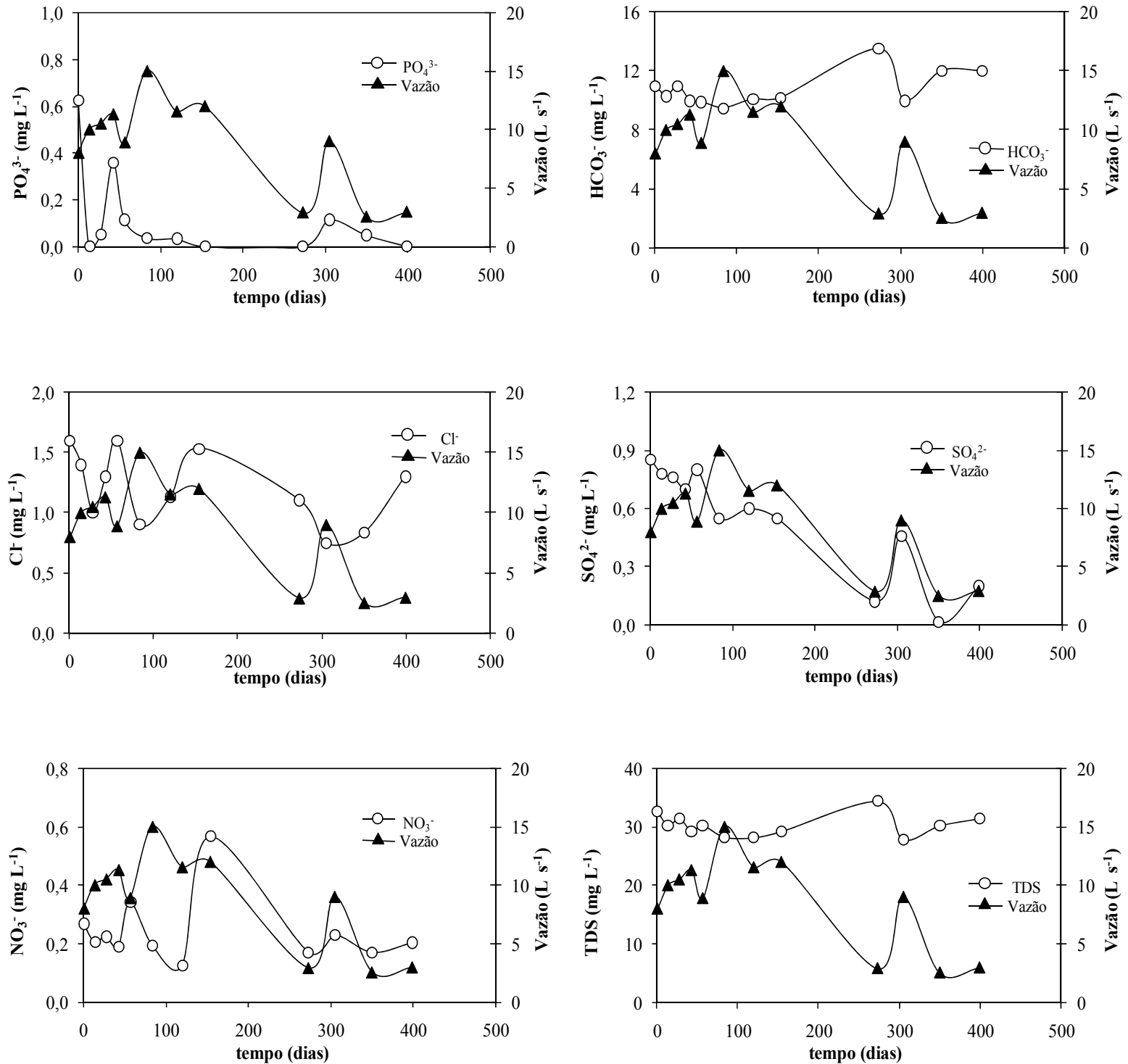

Figura 20. Variabilidade temporal da concentração $\left(\mathrm{mg} \mathrm{L}^{-1}\right)$ de ânions e TDS em função das vazões $\left(\mathrm{L} \mathrm{s}^{-1}\right)$ para as amostras de águas do córrego Entre Rios, Angatuba, São Paulo, para as amostragens extensivas. 
Amostragem

Intensiva 1
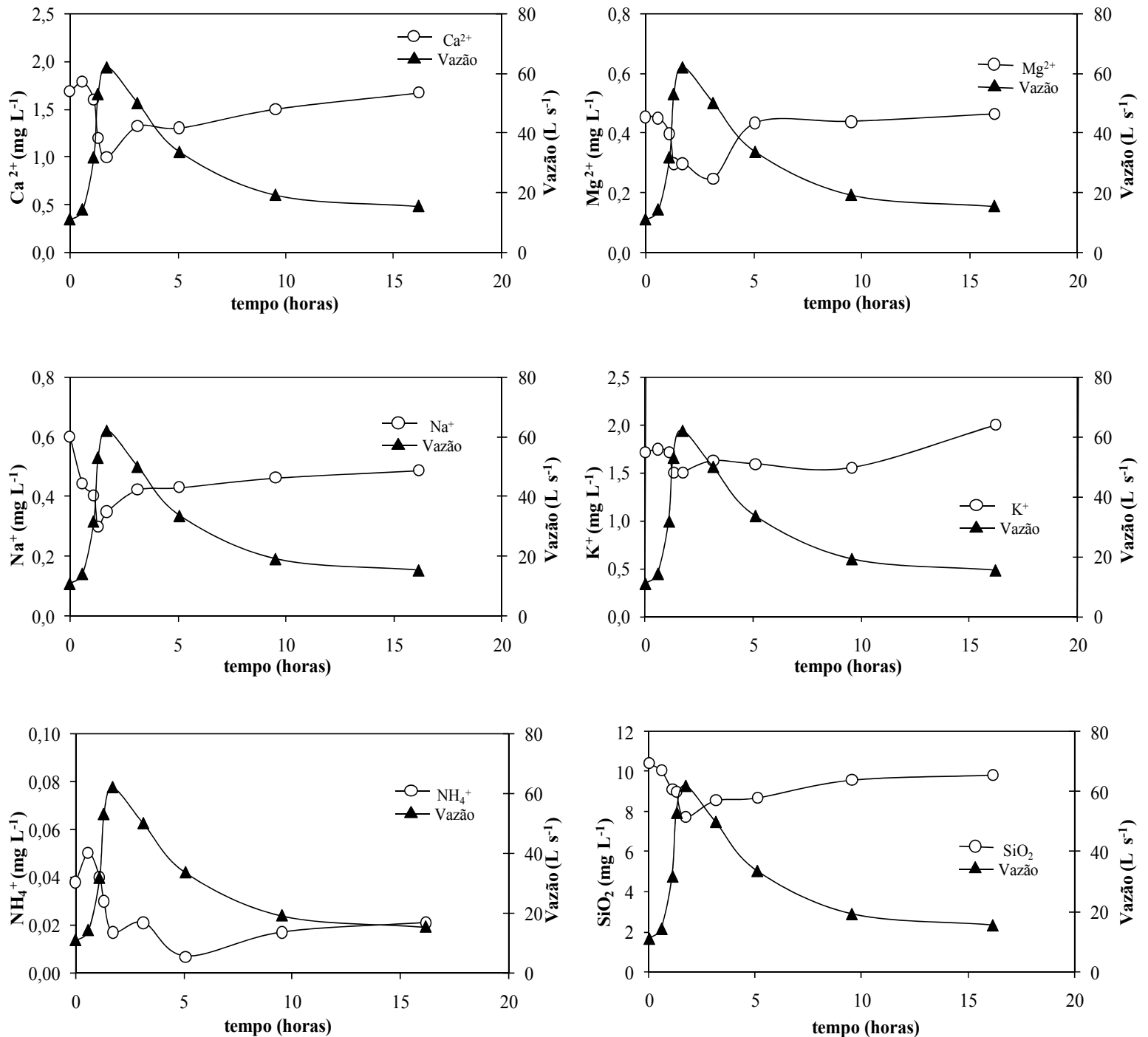

Figura 21. Variabilidade temporal da concentração $\left(\mathrm{mg} \mathrm{L}^{-1}\right)$ de ânions e TDS em função das vazões $\left(\mathrm{L} \mathrm{s}^{-1}\right)$ para as amostras de águas do córrego Entre Rios, Angatuba, São Paulo, para a amostragem intensiva 1. 


\section{Amostragem}

Intensiva 1
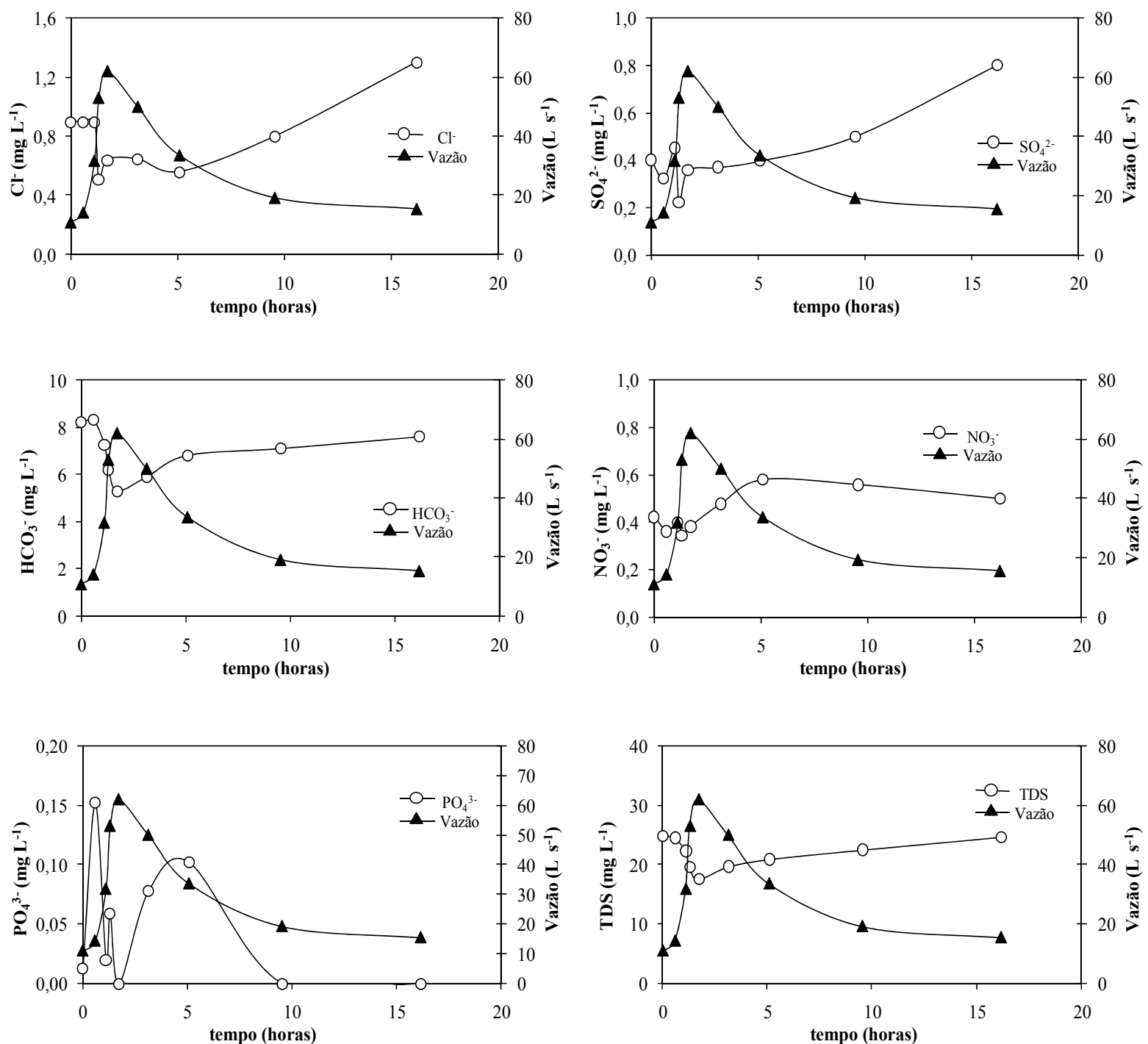

Figura 22. Variabilidade temporal da concentração $\left(\mathrm{mg} \mathrm{L}^{-1}\right)$ de ânions e TDS em função das vazões $\left(\mathrm{L} \mathrm{s}^{-1}\right)$ para as amostras de águas do córrego Entre Rios, Angatuba, São Paulo, para a amostragem intensiva 1. 


\section{Amostragem}

Intensiva 2
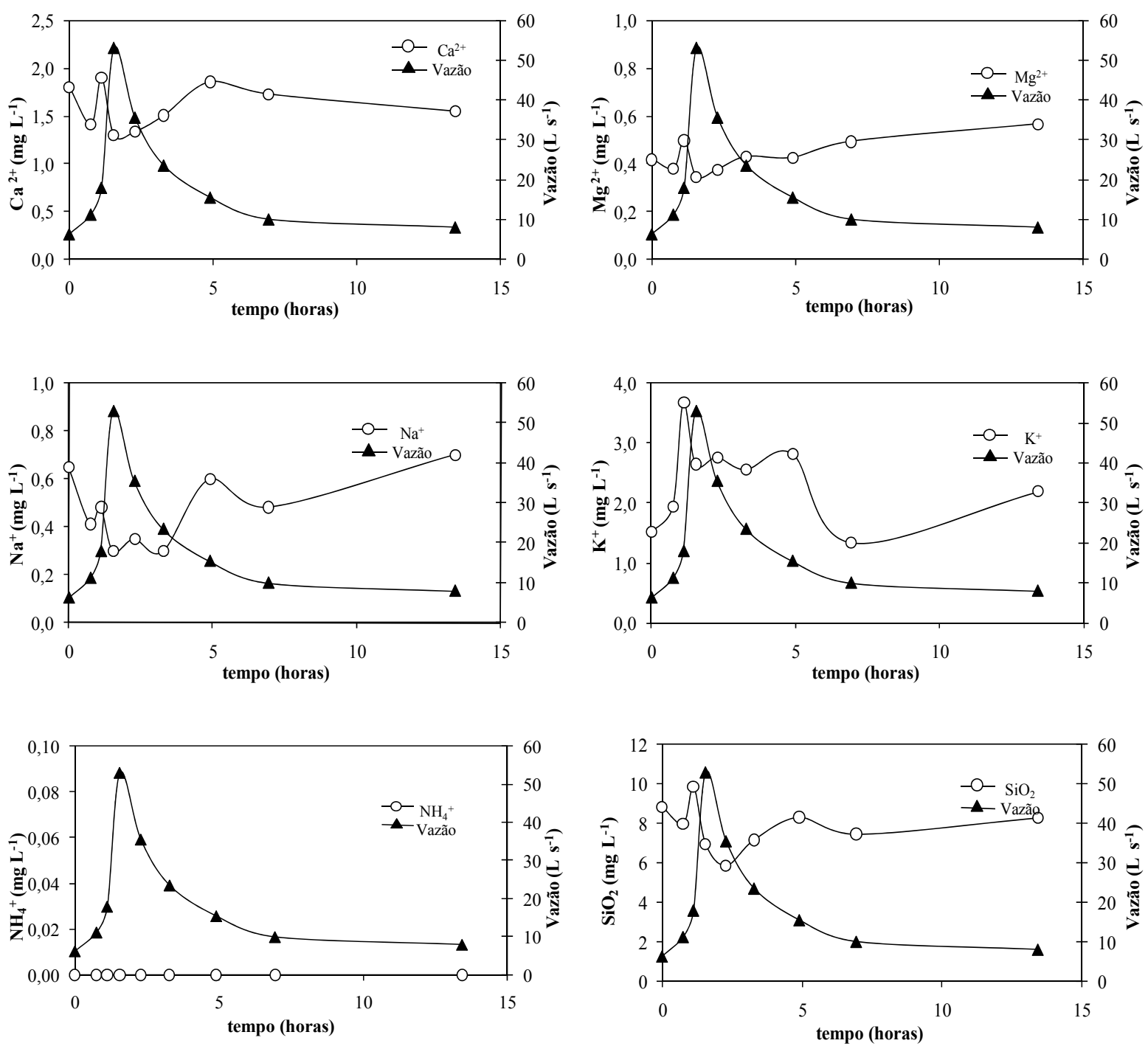

Figura 23. Variabilidade temporal da concentração $\left(\mathrm{mg} \mathrm{L}^{-1}\right)$ de ânions e TDS em função das vazões $\left(\mathrm{L} \mathrm{s}^{-1}\right)$ para as amostras de águas do córrego Entre Rios, Angatuba, São Paulo, para a amostragem intensiva 2. 


\section{Amostragem}

Intensiva 2
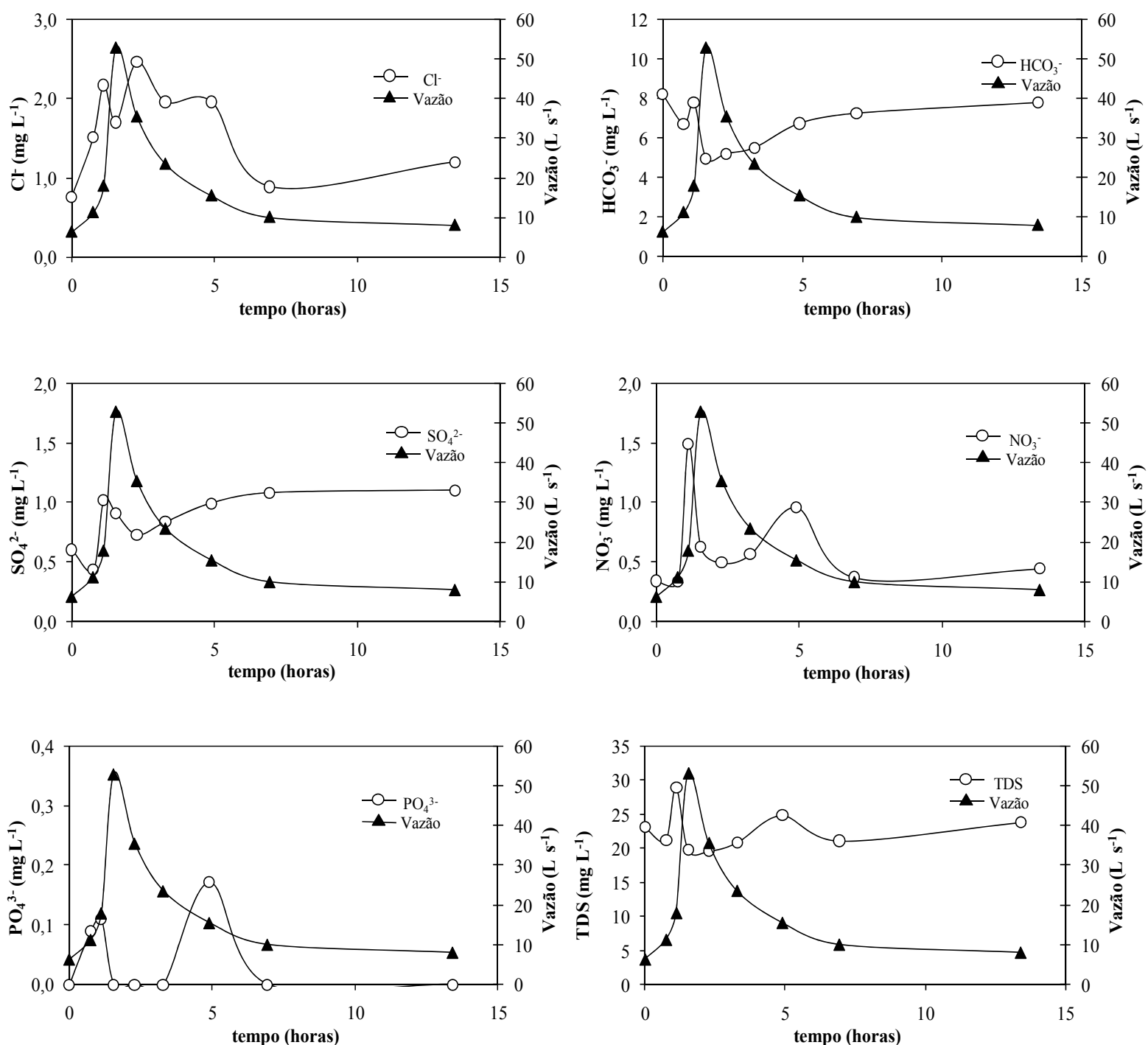

Figura 24. Variabilidade temporal da concentração $\left(\mathrm{mg} \mathrm{L}^{-1}\right)$ de ânions e TDS em função das vazões $\left(\mathrm{L} \mathrm{s}^{-1}\right)$ para as amostras de águas do córrego Entre Rios, Angatuba, São Paulo, para a amostragem intensiva 2. 
Foi observado que espécies como o $\mathrm{K}^{+}$e o $\mathrm{Cl}^{-}$tiveram comportamentos distintos ao longo dos períodos nas águas da microbacia do córrego Entre Rios. $\mathrm{O} \mathrm{K}^{+}$no período de amostragem extensiva não apresentou comportamento de diluição, evidenciando apenas um ligeiro aumento de suas concentrações ao final do mesmo período (Figura 19). Nos dois períodos de amostragens intensivas houve uma distinção ainda mais evidente em relação ao comportamento do $\mathrm{K}^{+}$. $\mathrm{Na}$ intensiva 1 conforme observado na Figura 21, as menores concentrações estiveram associadas às maiores vazões. Entretanto, na intensiva 2, as concentrações do elemento aumentaram juntamente com a vazão (Figura 23). Tal comportamento corroborou com o observado para o íon $\mathrm{Cl}^{-}$no mesmo período de coleta evidenciando sua influência associada aos tratos culturais proferidos na área experimental.

Os elementos $\mathrm{NH}_{4}{ }^{+}, \mathrm{SO}_{4}{ }^{2-}, \mathrm{PO}_{4}{ }^{3-}$ e $\mathrm{NO}_{3}{ }^{-}$em função das baixas concentrações, apresentaram comportamentos mais complexos, não sendo possível verificar um comportamento definido nos três períodos de amostragem. A baixa concentração das espécies químicas, aliada a ocorrências como degradação da matéria orgânica, nitrificação, aplicação de insumos agrícolas na área da microbacia podem ter interferido nos resultados.

\subsubsection{Relacionamento concentração-vazão}

A partir dos resultados analíticos foram verificados os relacionamentos existentes entre os valores de vazão e concentração das principais espécies químicas dissolvidas, em comparação com suas respectivas curvas de diluição teórica calculada de acordo com descrito no item 4.4.4.

As Figuras 25 e 26 representam o relacionamento concentração-vazão para o $\mathrm{Ca}^{2+} \mathrm{e} \mathrm{Mg}^{2+}$ dissolvido nas águas do córrego Entre Rios observados nos períodos de estudo. Pode ser observado que as concentrações de $\mathrm{Ca}^{2+}$ e $\mathrm{Mg}^{2+}$ não seguiram a curva de diluição teórica expressas para o período de amostragem total, intensiva 1 e intensiva 2 . Tal comportamento pode 
estar associado aos aportes difusos destas espécies químicas nas águas do córrego Entre Rios, como os relacionados principalmente aos aportes atmosféricos totais, tratos culturais efetuados em toda microbacia e ainda processos ligados às alterações de rochas.

O relacionamento concentração-vazão para o $\mathrm{Na}^{+}$presente nas águas da microbacia Entre Rios pode ser observado na Figura 27 para amostragem total, intensiva 1 e intensiva 2. As concentrações de $\mathrm{Na}^{+}$não se aproximaram das respectivas curvas de diluição teórica, verificando uma relação desta espécie química com aportes difusos ligados a aportes pluviais totais e processos de intemperismo de rochas silicatadas. 

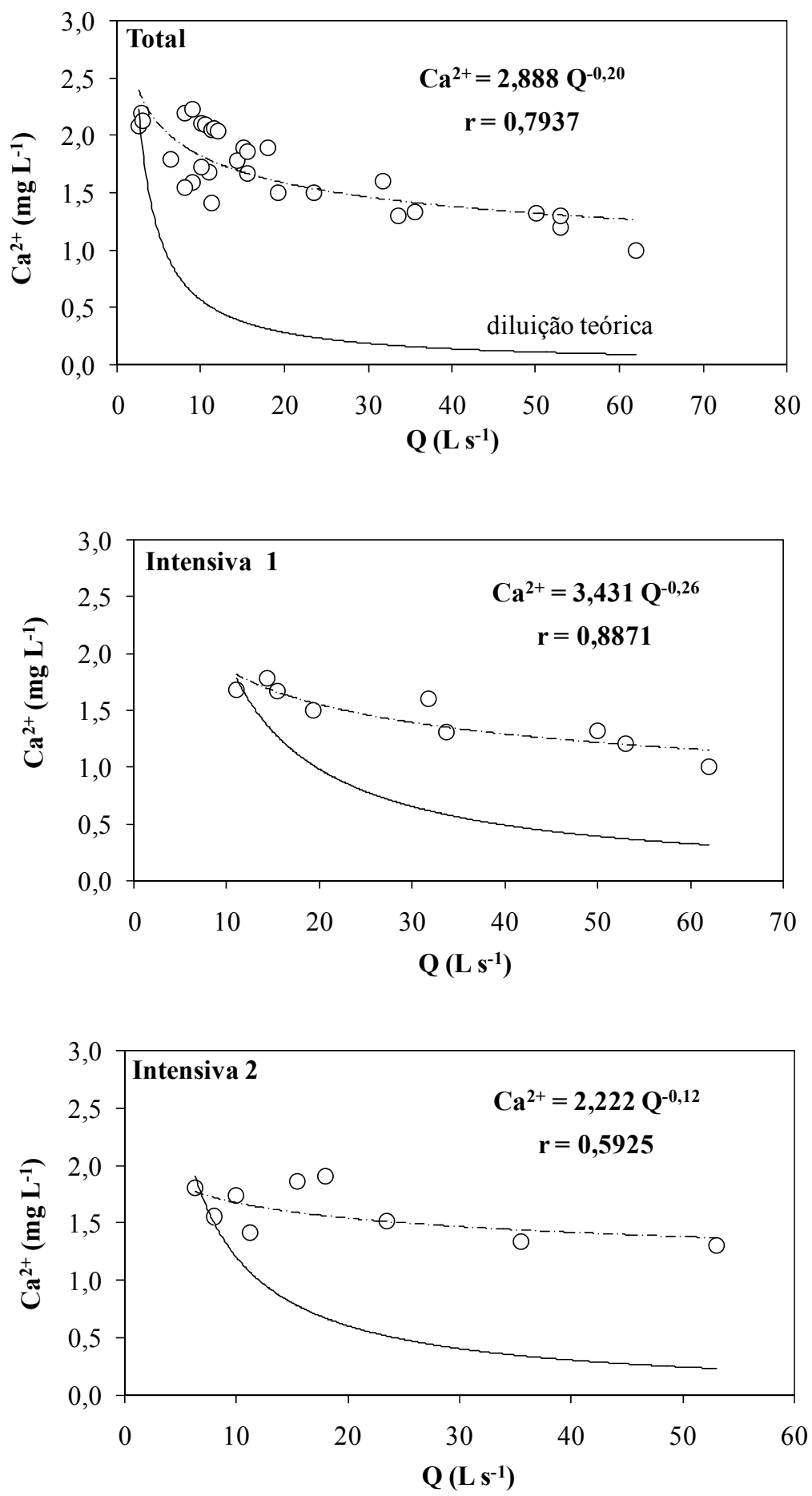

Figura 25. Relacionamento entre a concentração de $\mathrm{Ca}^{2+}\left(\mathrm{mg} \mathrm{L}^{-1}\right)$ e a vazão $\left(\mathrm{L} \mathrm{s}^{-1}\right)$, dissolvidos no córrego Entre Rios, Angatuba, São Paulo, para as amostragens total, intensiva 1 e 2. 

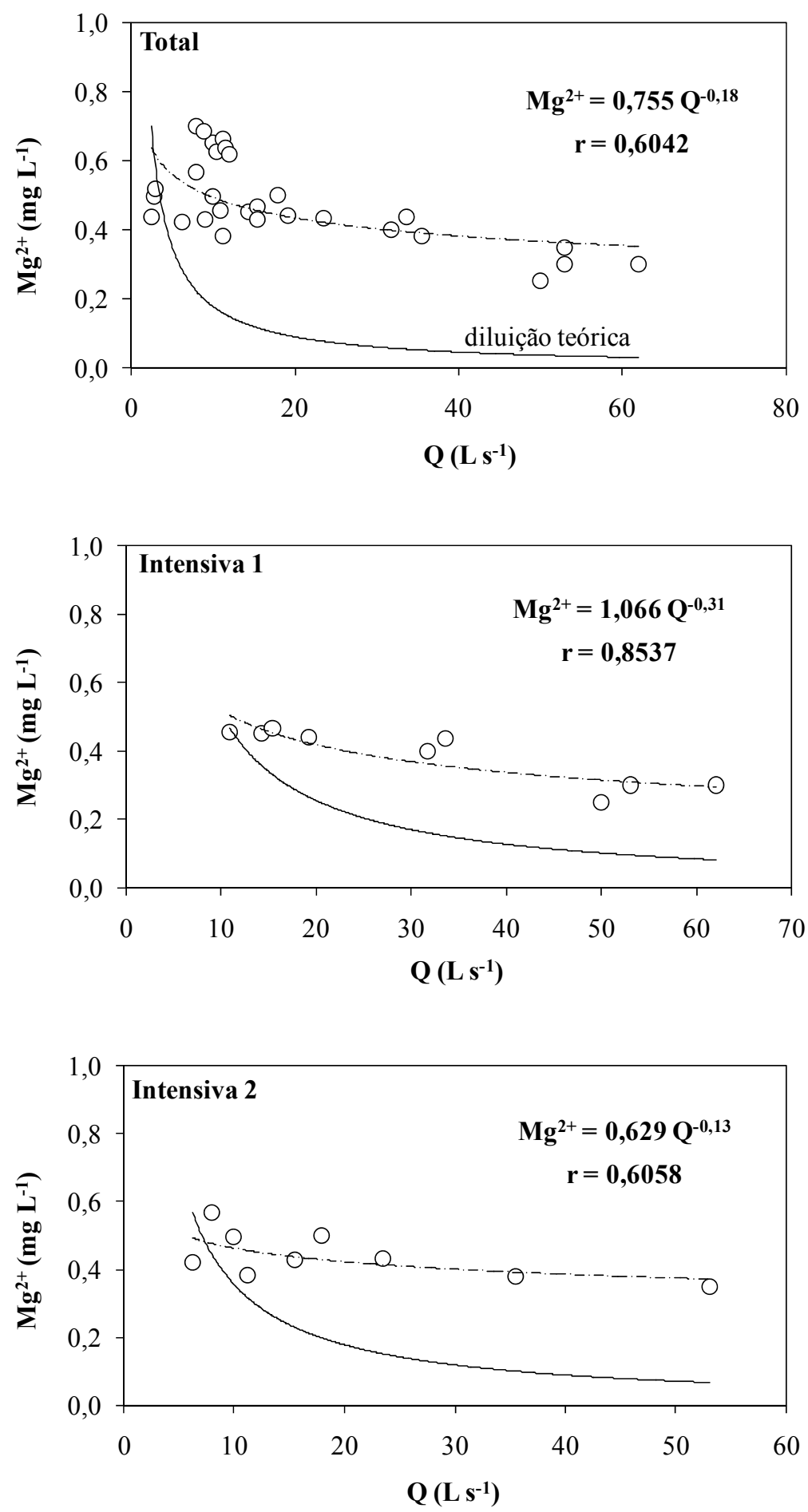

Figura 26. Relacionamento entre a concentração de $\mathrm{Mg}^{2+}\left(\mathrm{mg} \mathrm{L}^{-1}\right)$ e a vazão $\left(\mathrm{L} \mathrm{s}^{-1}\right)$, dissolvidos no córrego Entre Rios, Angatuba, São Paulo, para as amostragens total, intensiva 1 e 2. 

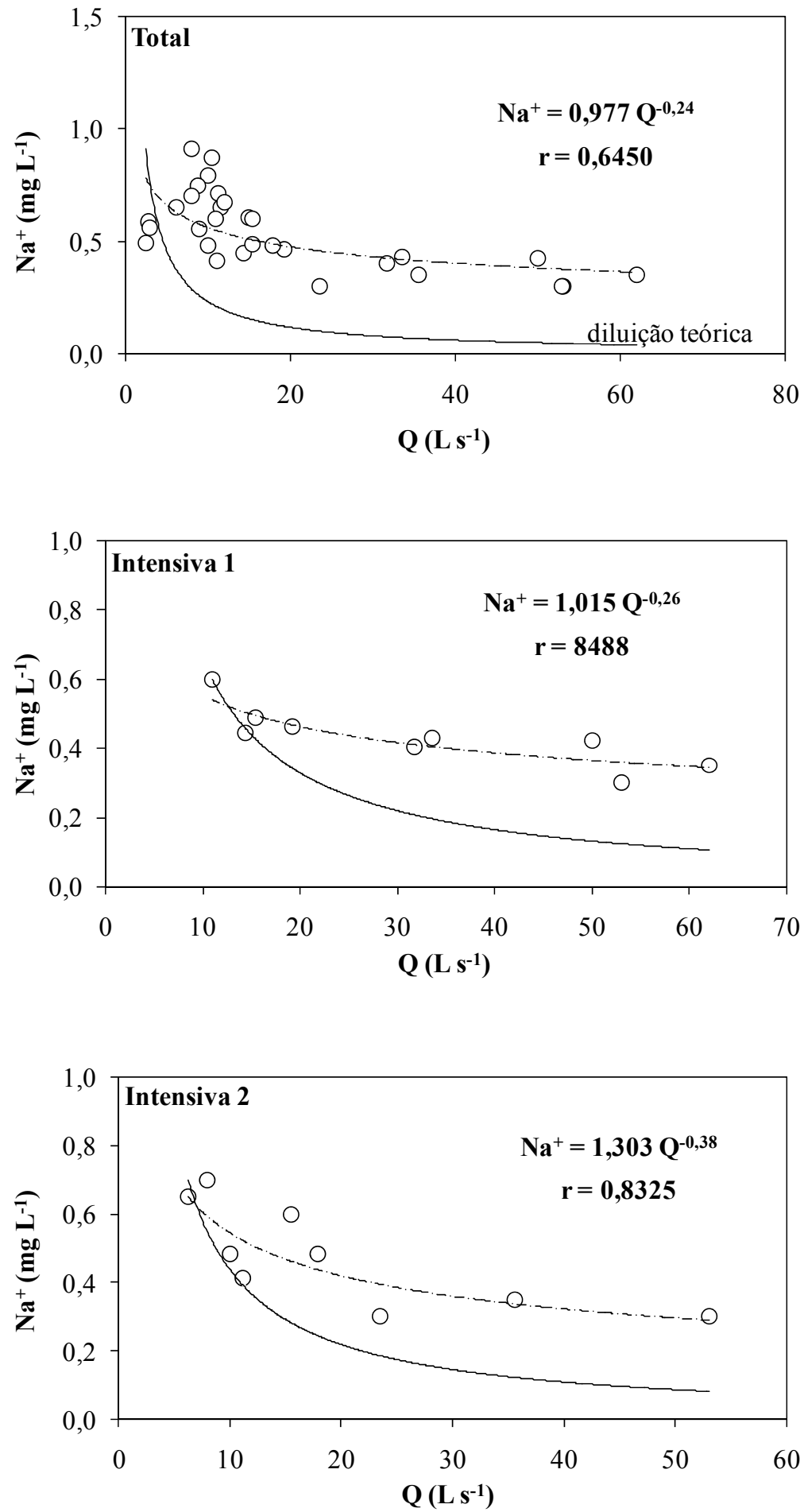

Figura 27. Relacionamento entre a concentração de $\mathrm{Mg}^{2+}\left(\mathrm{mg} \mathrm{L}^{-1}\right)$ e a vazão $\left(\mathrm{L} \mathrm{s}^{-1}\right)$, dissolvidos no córrego Entre Rios, Angatuba, São Paulo, para as amostragens total, intensiva 1 e 2. 
Comportamentos aleatórios foram observados entre as concentrações de $\mathrm{K}^{+} \mathrm{e}$ as respectivas curvas de diluição teórica calculadas para as duas amostragens intensivas (Figura 28). $\mathrm{Na}$ amostragem intensiva 1 , foi verificado que as concentrações de $\mathrm{K}^{+}$não seguiram a curva de diluição teórica evidenciando aportes difusos ocorridos na microbacia que podem estar associados aos aportes atmosféricos. Entretanto, na intensiva 2 observou-se que a curva referente às concentrações de $\mathrm{K}^{+}$se apresentou contrária à diluição teórica, ou seja, houve aumento da concentração desta espécie química em função do aumento da vazão. Esta anomalia, como dito anteriormente, pode estar associada principalmente ao aporte antrópico de ocorrência difusa ocorrida na microbacia decorrente de tratos culturais efetuados nos talhões 31 e 033 , que em conjunto com processos de lixiviação e escoamento superficial rápido, transportaram quantidades significativas de $\mathrm{K}^{+}$para o curso d'água principal da microbacia de drenagem. O período total, que contemplou aos períodos de amostragens extensivas mais intensiva 1 e 2 , em função da dispersão dos dados ocorrida, apresentou um comportamento aleatório de $\mathrm{K}^{+}$entre as vazões e concentrações, com baixo coeficiente de correlação.

Com relação ao $\mathrm{Cl}^{-}$(Figura 29), as concentrações obtidas na amostragem total não se aproximaram de sua respectiva curva de diluição teórica e o comportamento entre as vazões e concentrações também foi aleatória, obtendo-se baixo coeficiente de correlação $(r=0,1349)$. Na amostragem intensiva 1 , as concentrações obtidas apresentaram tendência à diluição conforme o aumento das vazões. Porém, na amostragem intensiva 2 (após a colheita de madeira), as concentrações de $\mathrm{Cl}^{-}$apresentaram semelhança ao comportamento do $\mathrm{K}^{+}$, ou seja, houve relacionamento positivo com a vazão, caracterizando também aporte antrópico de origem difusa. Segundo Garcia-Esteves et al. (2007) e Bibian (2007) inexistindo rochas evaporíticas na área da microbacia é possível haver outras fontes de $\mathrm{Cl}^{-}$tais como aportes atmosféricos e filmes salinos nos solos agricultáveis. 

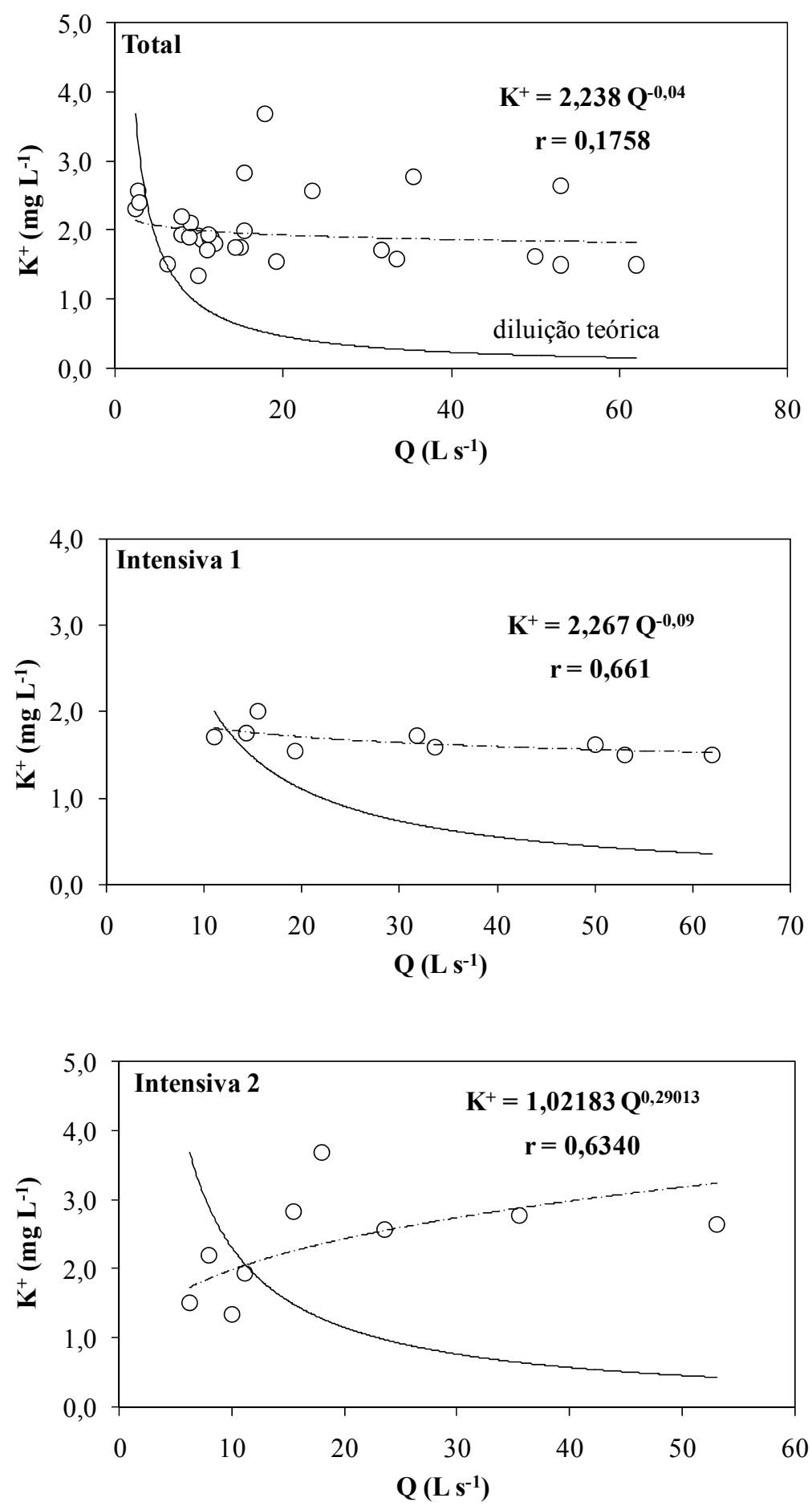

Figura 28. Relacionamento entre a concentração de $\mathrm{K}^{+}\left(\mathrm{mg} \mathrm{L}^{-1}\right)$ e a vazão $\left(\mathrm{L} \mathrm{s}^{-1}\right)$, dissolvidos no córrego Entre Rios, Angatuba, São Paulo, para as amostragens total, intensiva 1 e 2. 

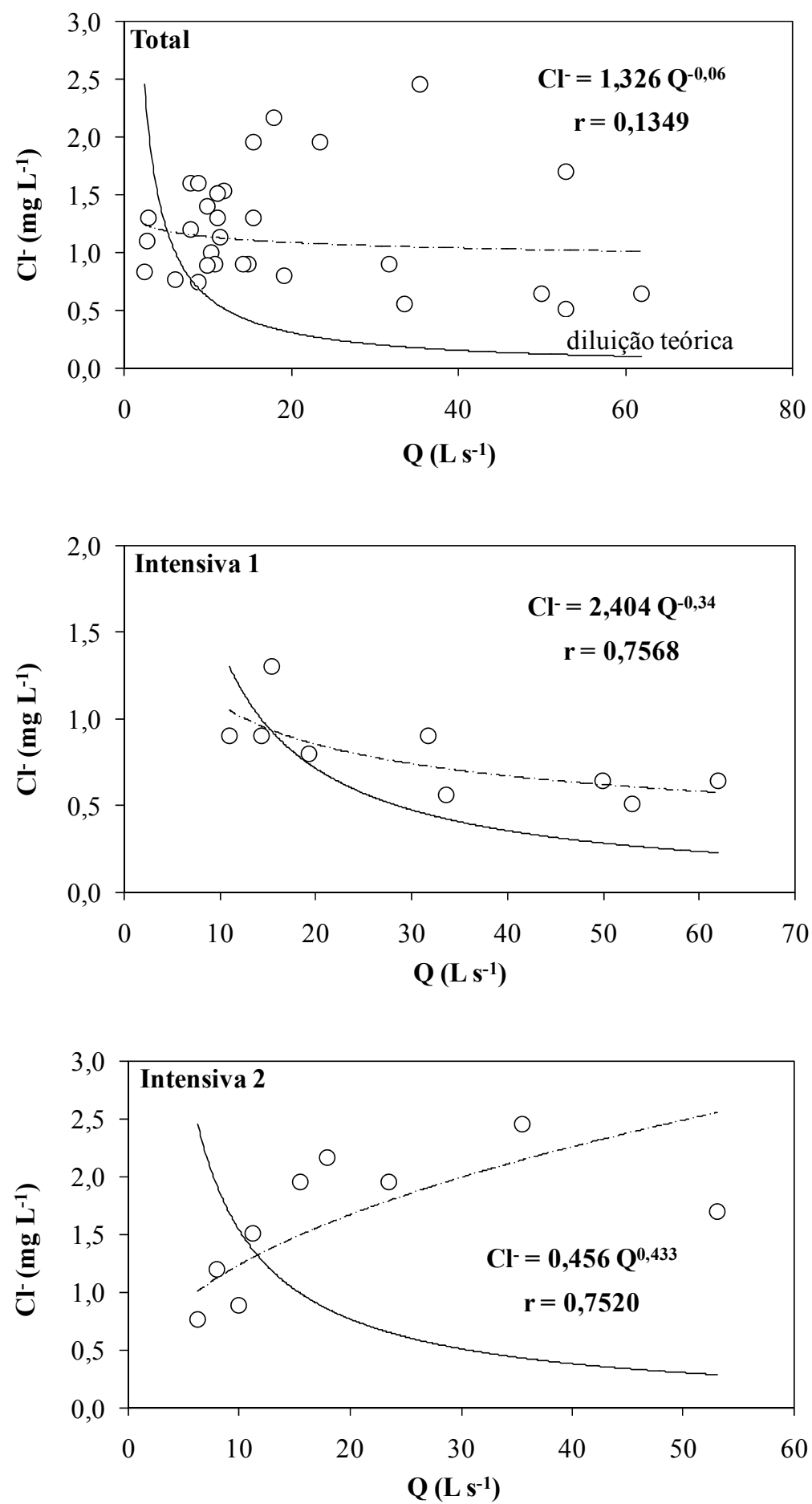

Figura 29. Relacionamento entre a concentração de $\mathrm{Cl}^{-}\left(\mathrm{mg} \mathrm{L}^{-1}\right)$ e a vazão $\left(\mathrm{L} \mathrm{s}^{-1}\right)$, dissolvidos no córrego Entre Rios, Angatuba, São Paulo, para as amostragens total, intensiva 1 e 2. 
$\mathrm{O}$ relacionamento concentração-vazão observado para $\mathrm{o} \mathrm{NO}_{3}^{-}$foi aleatório nas amostragens total, intensiva 1 e intensiva 2, conforme pode ser verificado na Figura 30. Nas amostragens extensivas e intensiva 2 (após a colheita), as curvas referentes às concentrações se apresentaram contrárias às respectivas curvas de diluição, evidenciando aportes antrópicos de origem difusa associadas possivelmente à solubilização de fertilizantes e da matéria orgânica mineralizada presentes na área de estudo, uma vez que houve um aporte de insumos agrícolas na área da microbacia no referido período, como dito anteriormente.

As concentrações de $\mathrm{SO}_{4}{ }^{2-}$ observadas para os três períodos amostrados apesar de baixos coeficientes de correlação, apresentaram comportamento similares ao do $\mathrm{K}^{+}$e $\mathrm{Cl}^{-}$. $\mathrm{Na}$ amostragem total e intensiva 2 , diferentemente da intensiva 1 em que as concentrações estiveram próximas à curva de diluição teórica, observou-se aumento da concentração de $\mathrm{SO}_{4}{ }^{2-}$ com a vazão que podem estar relacionados com os aportes atmosféricos e tratos culturais efetuados na área da microbacia (Figura 31).

$\mathrm{O}$ comportamento das concentrações de $\mathrm{PO}_{4}{ }^{3-}$ não permitiu nenhum ajuste de curva bilogarítmo ou de potência satisfatório. As concentrações de $\mathrm{PO}_{4}{ }^{3-}$ em todo período de estudo foram inferiores à $0,63 \mathrm{mg} \mathrm{L}^{-1}$, apresentando pouca relação com os valores de obtidos de vazão (Tabela 4). Sua presença esteve associada aos tratos culturais recorrentes na microbacia de drenagem, que atingem os corpos d'água devido sua rápida mobilização no solo. 

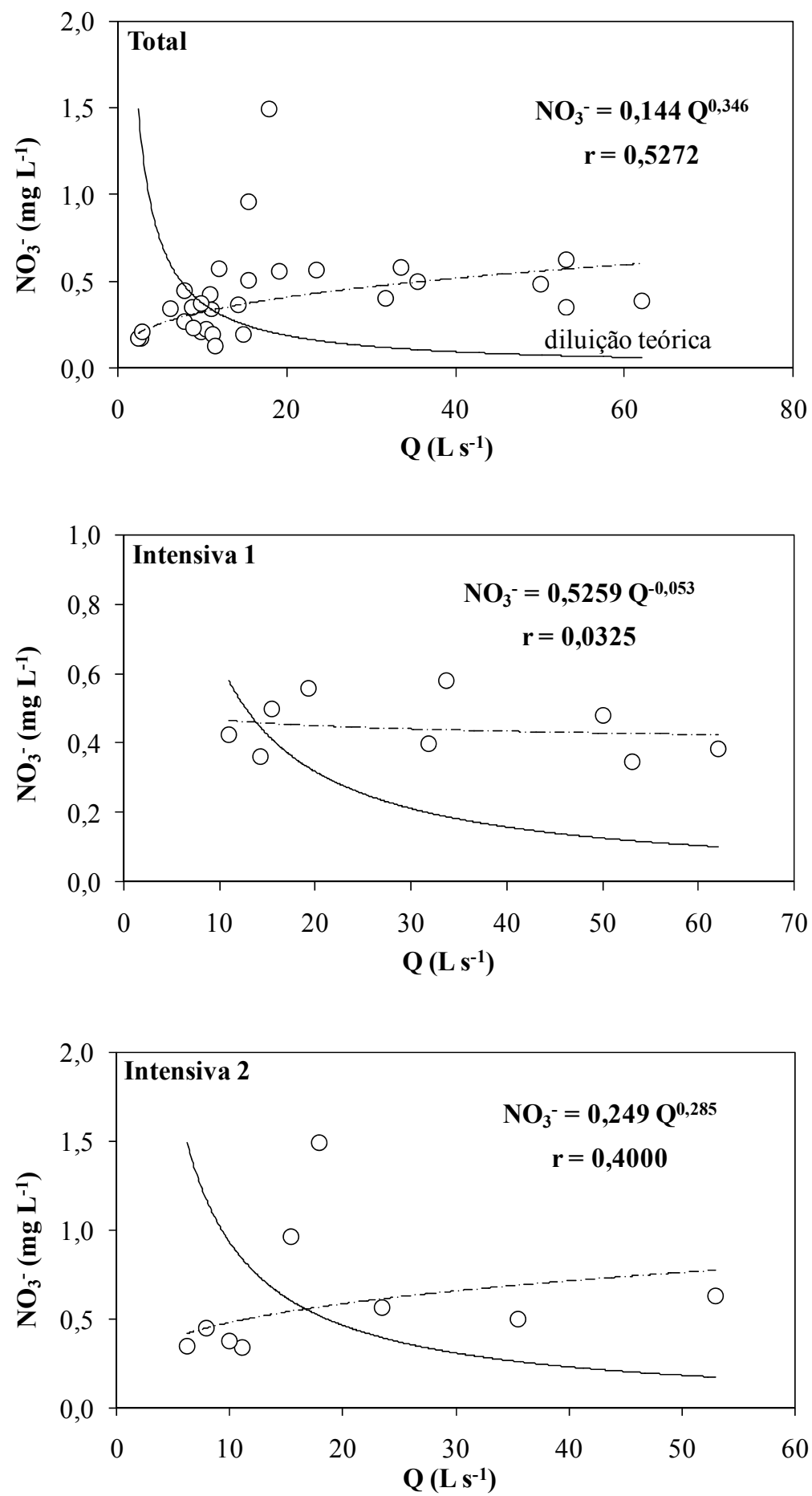

Figura 30. Relacionamento entre a concentração de $\mathrm{NO}_{3}^{-}\left(\mathrm{mg} \mathrm{L}^{-1}\right)$ e a vazão $\left(\mathrm{L} \mathrm{s}^{-1}\right)$, dissolvidos no córrego Entre Rios, Angatuba, São Paulo, para as amostragens total, intensiva 1 e 2. 

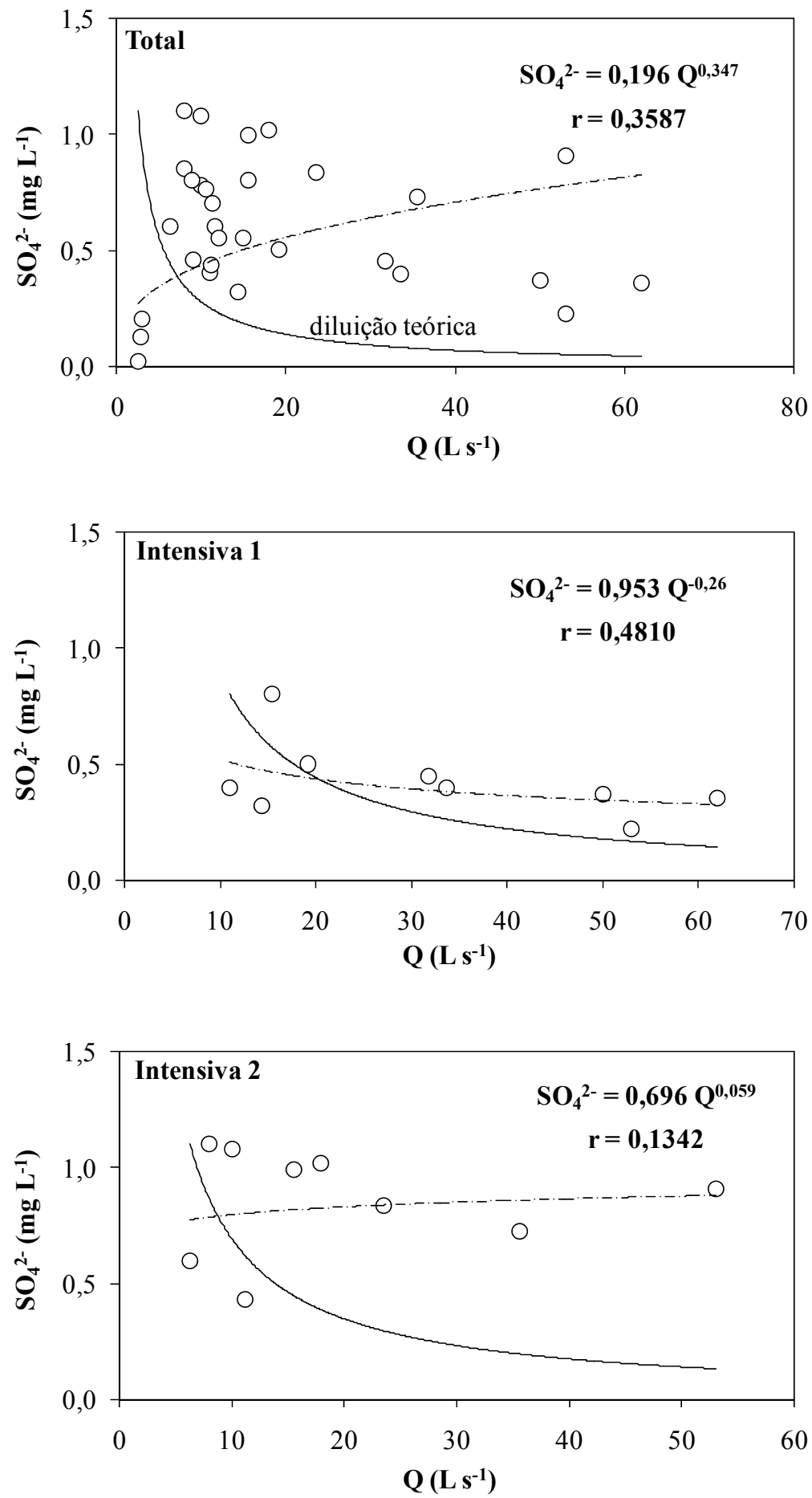

Figura 31. Relacionamento entre a concentração de $\mathrm{SO}_{4}{ }^{2-}\left(\mathrm{mg} \mathrm{L}^{-1}\right)$ e a vazão $\left(\mathrm{L} \mathrm{s}^{-1}\right)$, dissolvidos no córrego Entre Rios, Angatuba, São Paulo, para as amostragens total, intensiva 1 e 2. 
A Figura 32 apresenta o relacionamento concentração-vazão para o íon $\mathrm{HCO}_{3}^{-}$e seu respectivo comportamento em relação à curva de diluição teórica para os três períodos de amostragens. Pode ser observado pelo deslocamento entre a curva de diluição teórica e as concentrações de $\mathrm{HCO}_{3}{ }^{-}$influências de aportes difusos associados às alterações de rochas e também aos aportes atmosféricos totais.

As concentrações de $\mathrm{SiO}_{2}$ na microbacia de drenagem do córrego Entre Rios não seguiram a curva de diluição teórica em todo período estudado, evidenciando a ocorrência de aportes difusos, associado à dissolução de minerais silicatados existentes na área da microbacia (Figura 33). As baixas concentrações observadas em vazões elevadas corroboram com a baixa solubilidade da sílica e seu lento processo de dissolução, sendo rapidamente lavada do solo durante eventos de chuvas intensas (SEMHI et al. 2000).

A Figura 34 contém o ajuste de curva de diluição teórica com os valores de concentração de TDS para a amostragem total, intensiva 1 e intensiva 2. O TDS seguiu o padrão de comportamento do íon maior, ${\mathrm{o} \mathrm{HCO}_{3}}^{-}$na amostragem total e intensiva1. Na intensiva 2, no entanto, os valores de TDS não seguiram padrão semelhante, apresentando um coeficiente de correlação não significativo, o que pode ter ocorrido em função dos altos valores associados aos íons $\mathrm{K}^{+}$e $\mathrm{Cl}^{-}$nas águas fluviais da microbacia Entre Rios neste mesmo período. 

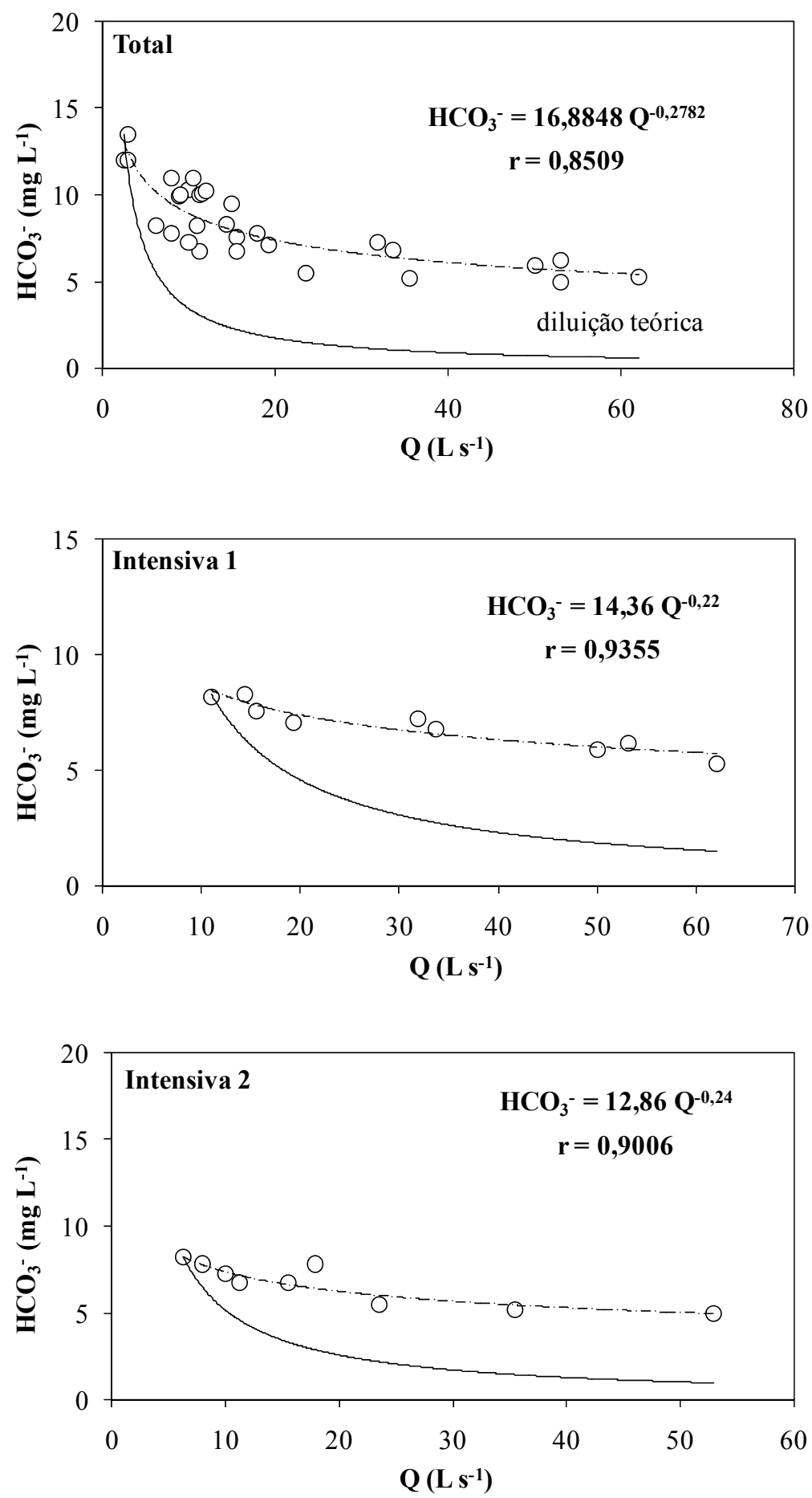

Figura 32. Relacionamento entre a concentração de $\mathrm{HCO}_{3}^{-}\left(\mathrm{mg} \mathrm{L}^{-1}\right)$ e a vazão $\left(\mathrm{L} \mathrm{s}^{-1}\right)$, dissolvidos no córrego Entre Rios, Angatuba, São Paulo, para as amostragens total, intensiva 1 e 2. 

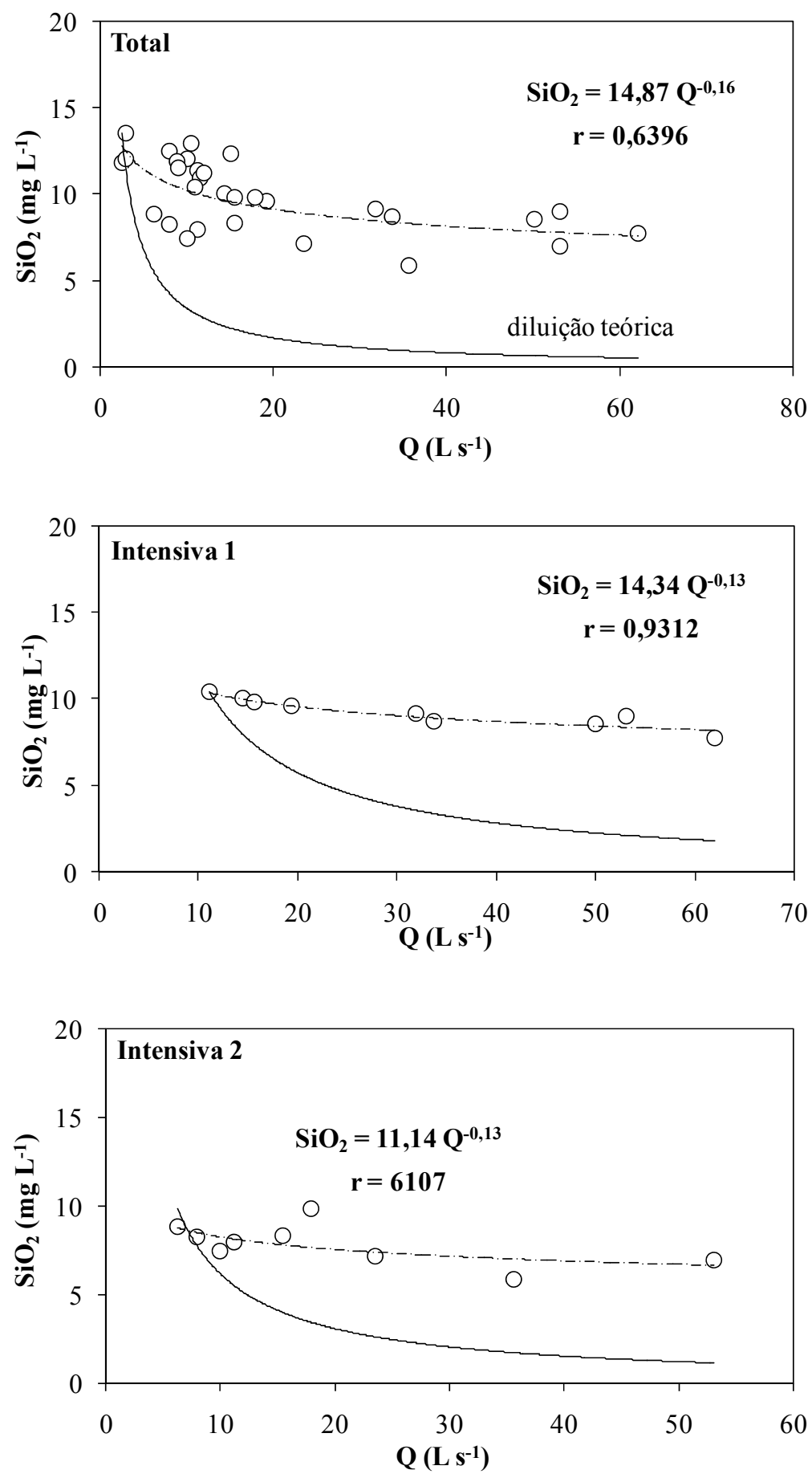

Figura 33. Relacionamento entre a concentração de $\mathrm{SiO}_{2}\left(\mathrm{mg} \mathrm{L}^{-1}\right)$ e a vazão $\left(\mathrm{L} \mathrm{s}^{-1}\right)$, dissolvidos no córrego Entre Rios, Angatuba, São Paulo, para as amostragens total, intensiva 1 e 2. 

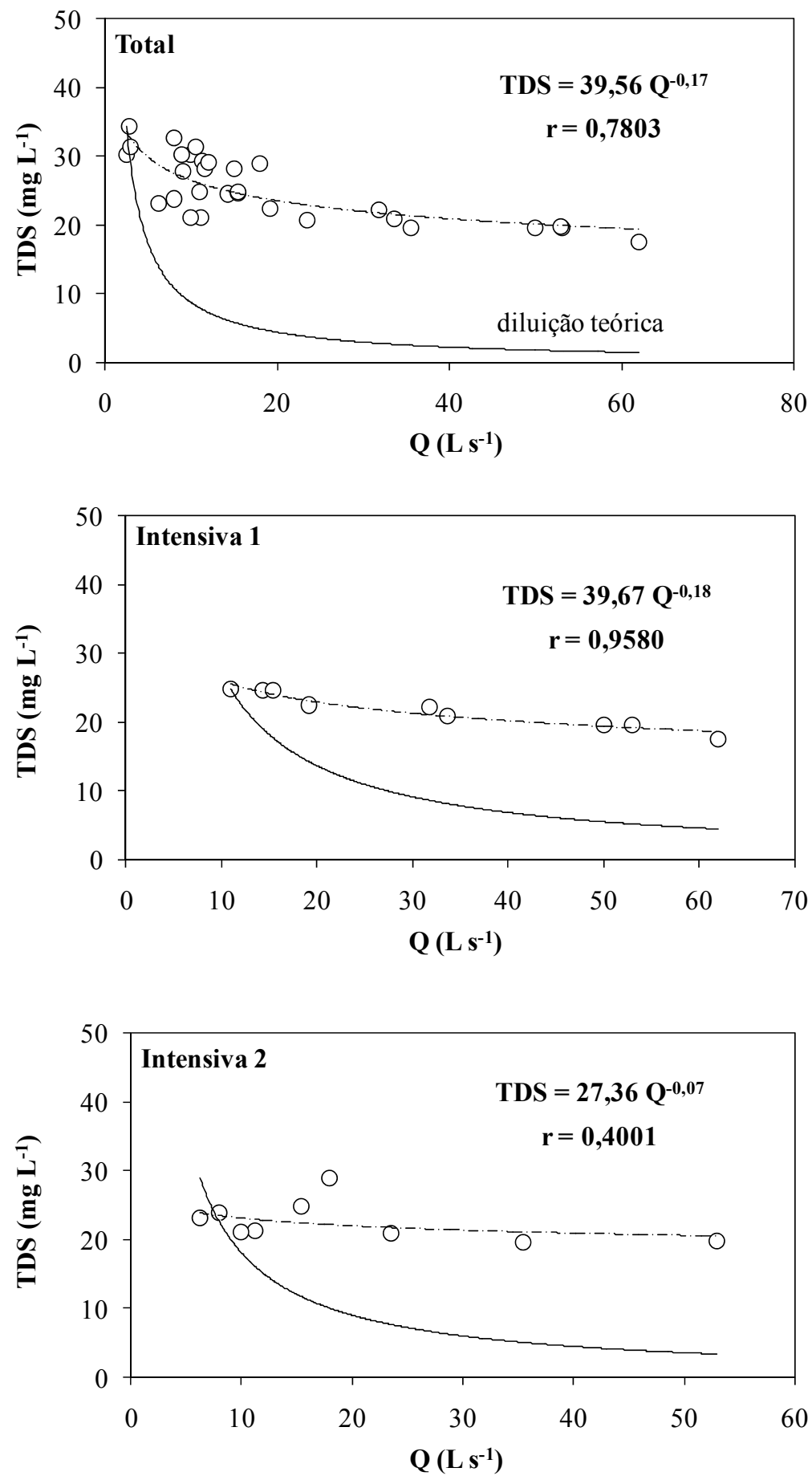

Figura 34. Relacionamento entre a concentração de TDS $\left(\mathrm{mg} \mathrm{L}^{-1}\right)$ e a vazão $\left(\mathrm{L} \mathrm{s}^{-1}\right)$, dissolvidos no córrego Entre Rios, Angatuba, São Paulo, para as amostragens total, intensiva 1 e 2. 
As concentrações de $\mathrm{NH}_{4}{ }^{+}$durante todo período de estudo foram bastantes baixas não podendo, em alguns casos como nas amostragens total e intensiva 2, verificar o seu relacionamento em função das vazões obtidas. Tais evidencias indicaram um comportamento aleatório dessa espécie química durante todo experimento, uma vez que as formas nitrogenadas não são conservativas estando a todo momento em processo de transformação.

\subsubsection{Diagramas Ternários}

Como foi descrito no item 4.4.5., foram construídos diagramas ternários para cátions e ânions com objetivo de caracterizar as águas do córrego Entre Rios, os quais podem ser verificados na Figura 35 para as amostragens extensivas, intensiva 1 e intensiva 2.

Para os cátions das águas do córrego Entre Rios foi verificada uma tendência para o vértice $\mathrm{Na}^{+}+\mathrm{K}^{+}(40$ a $70 \%)$, seguidas de $\mathrm{Ca}^{2+}(20$ a $40 \%)$ e $\mathrm{Mg}^{2+}(10$ e $20 \%)$ para os três

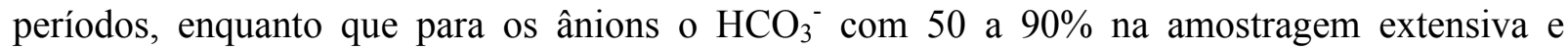
intensiva 1 e 70 a 90\% na intensiva 2 foi a espécie química dominante nessas águas. Dessa forma, as águas do córrego Entre Rios apresentam-se como uma característica sódico-potássica e bicarbonatada. Tais evidências podem ser atribuídas à constituição geológica da microbacia com predominância de silicatos. 

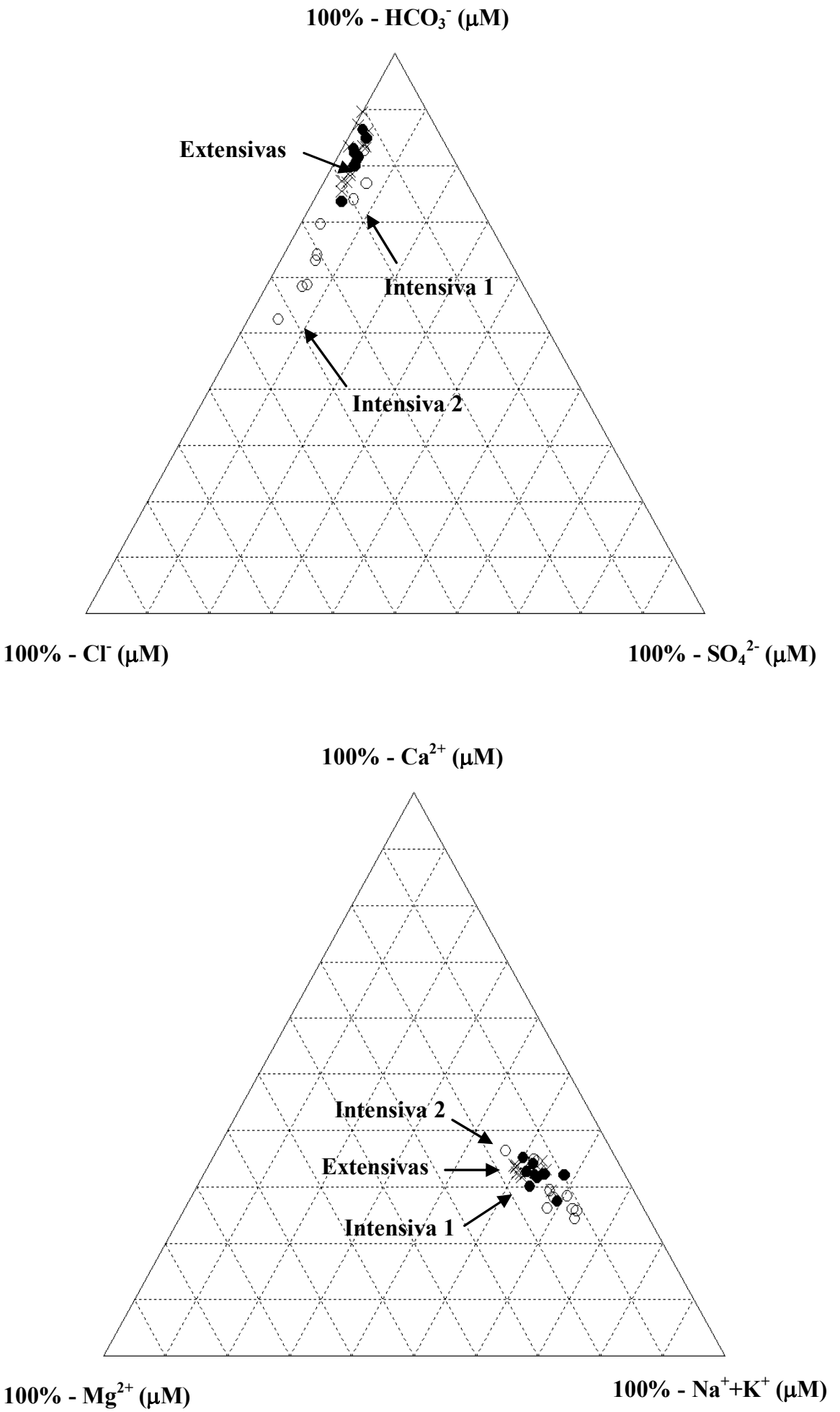

Figura 35. Diagramas ternários de cátions e ânions dissolvidos nas águas fluviais do córrego Entre Rios, Angatuba, São Paulo, nos períodos estudados. 


\subsubsection{Matriz dos coeficientes de correlação}

As matrizes dos coeficientes de correlação linear simples foram estabelecidas ente as principais espécies químicas analisadas para o córrego Entre Rios e os parâmetros condutividade elétrica, $\mathrm{pH}$, TDS e vazão, relativo ao período de amostragens extensivas, intensiva 1 e intensiva 2, conforme citado no item 4.4.6. Nas Tabelas 5, 6 e 7 podem ser verificados os coeficientes de correlação obtidos para os três períodos. Observou-se que muitas espécies químicas apresentaram coeficientes negativos em relação à vazão, sugerindo a influência do processo de diluição nas concentrações das mesmas, principalmente para $\mathrm{Mg}^{2+}, \mathrm{Na}^{+}$e $\mathrm{Ca}^{2+}$ na intensiva $1{\mathrm{e} \mathrm{HCO}_{3}}^{-}$nas duas intensivas.

De uma maneira geral puderam ser observados na microbacia de drenagem do córrego Entre Rios correlações geoquímicas entre as espécies estudadas, como por exemplo, o $\mathrm{HCO}_{3}{ }^{-}$ com $\mathrm{SiO}_{2}, \mathrm{~K}^{+}, \mathrm{Na}^{+}, \mathrm{Ca}^{2+}$ e $\mathrm{Mg}^{2+} ; \mathrm{SO}_{4}{ }^{2-}$ com $\mathrm{Mg}^{2+}, \mathrm{Na}^{+}$e $\mathrm{K}^{+} ; \mathrm{Cl}^{-}$com K $\mathrm{K}^{+}$.

Tabela 5. Matriz dos coeficientes de correlação entre as principais espécies químicas dissolvidas no córrego Entre Rios, Angatuba, São Paulo, no período de amostragem extensiva.

\begin{tabular}{|c|c|c|c|c|c|c|c|c|c|c|c|c|c|c|}
\hline & Cond. & pH & TDS & $\mathrm{PO}_{4}{ }^{3-}$ & $\mathrm{NO}_{3}^{-}$ & $\mathrm{SO}_{4}{ }^{2-}$ & $\mathrm{Cl}^{-}$ & $\mathrm{HCO}_{3}^{-}$ & $\mathrm{SiO}_{2}$ & $\mathrm{NH}_{4}{ }^{+}$ & $\mathbf{K}^{+}$ & $\mathrm{Na}^{+}$ & $\mathrm{Mg}^{2+}$ & $\mathrm{Ca}^{2+}$ \\
\hline $\mathbf{Q}$ & $-0,233$ & 0,487 & $\underline{-0,643}$ & 0,077 & 0,254 & $\underline{0,712}$ & 0,085 & $\underline{-0,874}$ & $-0,362$ & $-0,171$ & $\underline{-0,925}$ & 0,380 & 0,334 & $-0,340$ \\
\hline $\mathrm{Ca}^{2+}$ & 0,310 & $-0,232$ & $\underline{0,676}$ & 0,140 & 0,046 & 0,087 & $\underline{0,642}$ & 0,430 & 0,338 & $-0,501$ & 0,159 & 0,405 & 0,565 & $\mathbf{x}$ \\
\hline $\mathbf{M g}^{2+}$ & 0,208 & 0,360 & 0,137 & 0,457 & 0,296 & $\underline{0,795}$ & $\underline{0,820}$ & $-0,314$ & $-0,146$ & $\underline{-0,605}$ & $-0,524$ & $\underline{0,837}$ & $\mathbf{x}$ & $\mathbf{x}$ \\
\hline $\mathrm{Na}^{+}$ & 0,061 & 0,157 & 0,266 & 0,544 & 0,200 & $\underline{0,862}$ & $\underline{0,586}$ & $-0,270$ & 0,223 & $-0,505$ & $-0,560$ & $\mathbf{x}$ & $\mathbf{x}$ & $\mathbf{x}$ \\
\hline $\mathbf{K}^{+}$ & 0,166 & $-0,478$ & $\underline{0,584}$ & $-0,236$ & $-0,366$ & $\underline{-0,829}$ & $-0,271$ & $\underline{0,896}$ & 0,414 & 0,427 & $\mathbf{x}$ & $\mathbf{x}$ & $\mathbf{x}$ & $\mathbf{x}$ \\
\hline $\mathrm{NH}_{4}^{+}$ & 0,045 & 0,032 & 0,038 & $-0,334$ & 0,041 & $-0,401$ & $-0,331$ & 0,198 & 0,242 & $\mathbf{x}$ & $\mathbf{x}$ & $\mathbf{x}$ & $\mathbf{x}$ & $\mathbf{x}$ \\
\hline $\mathrm{SiO}_{2}$ & $-0,073$ & $-0,520$ & $\underline{0,811}$ & 0,027 & $-0,239$ & $-0,140$ & $-0,097$ & $\underline{0,625}$ & $\mathbf{x}$ & $\mathbf{x}$ & $\mathbf{x}$ & $\mathbf{x}$ & $\mathbf{x}$ & $\mathbf{x}$ \\
\hline $\mathrm{HCO}_{3}{ }^{-}$ & 0,138 & $\underline{-0,633}$ & $\underline{0,821}$ & $-0,141$ & $-0,263$ & $\underline{-0,699}$ & $-0,124$ & $\mathbf{x}$ & $\mathbf{x}$ & $\mathbf{x}$ & $\mathbf{x}$ & $\mathbf{x}$ & $\mathbf{x}$ & $\mathbf{x}$ \\
\hline $\mathrm{Cl}^{-}$ & 0,428 & 0,484 & 0,285 & 0,376 & 0,547 & 0,522 & $\mathbf{x}$ & $\mathbf{x}$ & $\mathbf{x}$ & $\mathbf{x}$ & $\mathbf{x}$ & $\mathbf{x}$ & $\mathbf{x}$ & $\mathbf{x}$ \\
\hline $\mathrm{SO}_{4}{ }^{2-}$ & $-0,027$ & 0,469 & $-0,201$ & 0,463 & 0,251 & $\mathbf{x}$ & $\mathbf{x}$ & $\mathbf{x}$ & $\mathbf{x}$ & $\mathbf{x}$ & $\mathbf{x}$ & $\mathbf{x}$ & $\mathbf{x}$ & $\mathbf{x}$ \\
\hline $\mathrm{NO}_{3}^{-}$ & 0,093 & 0,454 & $-0,085$ & $-0,004$ & $\mathbf{x}$ & $\mathbf{x}$ & $\mathbf{x}$ & $\mathbf{x}$ & $\mathbf{x}$ & $\mathbf{x}$ & $\mathbf{x}$ & $\mathbf{x}$ & $\mathbf{x}$ & $\mathbf{x}$ \\
\hline $\mathrm{PO}_{4}{ }^{3-}$ & $-0,039$ & 0,288 & 0,183 & $\mathbf{x}$ & $\mathbf{x}$ & $\mathbf{x}$ & $\mathbf{x}$ & $\mathbf{x}$ & $\mathbf{x}$ & $\mathbf{x}$ & $\mathbf{x}$ & $\mathbf{x}$ & $\mathbf{x}$ & $\mathbf{x}$ \\
\hline TDS & 0,185 & $-0,438$ & $\mathbf{x}$ & $\mathbf{x}$ & $\mathbf{x}$ & $\mathbf{x}$ & $\mathbf{x}$ & $\mathbf{x}$ & $\mathbf{x}$ & $\mathbf{x}$ & $\mathbf{x}$ & $\mathbf{x}$ & $\mathbf{x}$ & $\mathbf{x}$ \\
\hline pH & 0,238 & $\mathbf{x}$ & $\mathbf{x}$ & $\mathbf{x}$ & $\mathbf{x}$ & $\mathbf{x}$ & $\mathbf{x}$ & $\mathbf{x}$ & $\mathbf{x}$ & $\mathbf{x}$ & $\mathbf{x}$ & $\mathbf{x}$ & $\mathbf{x}$ & $\mathbf{x}$ \\
\hline
\end{tabular}


Tabela 6. Matriz dos coeficientes de correlação entre as principais espécies químicas dissolvidas no córrego Entre Rios, Angatuba, São Paulo, no período de amostragem intensiva 1.

\begin{tabular}{|c|c|c|c|c|c|c|c|c|c|c|c|c|c|c|}
\hline & Cond. & pH & TDS & $\mathrm{PO}_{4}{ }^{3-}$ & $\mathrm{NO}_{3}^{-}$ & $\mathrm{SO}_{4}{ }^{2-}$ & $\mathrm{Cl}^{-}$ & $\mathrm{HCO}_{3}^{-}$ & $\mathrm{SiO}_{2}$ & $\mathrm{NH}_{4}^{+}$ & $\mathbf{K}^{+}$ & $\mathrm{Na}^{+}$ & $\mathrm{Mg}^{2+}$ & $\mathrm{Ca}^{2+}$ \\
\hline $\mathbf{Q}$ & $-0,489$ & $-0,376$ & $-0,974$ & $-0,033$ & $-0,273$ & $-0,499$ & $\underline{-0,713}$ & $\underline{-0,955}$ & $-0,925$ & $-0,382$ & $\begin{array}{l}-0,661 \\
\end{array}$ & $-0,816$ & $\underline{-0,915}$ & $-0,926$ \\
\hline $\mathrm{Ca}^{2+}$ & 0,619 & 0,503 & $\underline{0,968}$ & 0,143 & 0,036 & 0,426 & $\underline{0,754}$ & $\underline{0.953}$ & $\underline{0.911}$ & 0,624 & $\underline{0,747}$ & $\underline{0,702}$ & $\underline{0,765}$ & $\mathbf{x}$ \\
\hline $\mathbf{M g}^{2+}$ & 0,345 & 0,318 & $\underline{0,856}$ & $-0,016$ & 0,331 & 0,518 & 0,641 & $\underline{0,866}$ & $\underline{0,758}$ & 0,210 & 0,579 & $\underline{0,674}$ & $\mathbf{x}$ & $\mathbf{x}$ \\
\hline $\mathrm{Na}^{+}$ & 0,409 & 0,161 & $\underline{0,775}$ & $-0,158$ & 0,359 & 0,458 & 0,583 & $\underline{0,726}$ & $\underline{0,739}$ & 0,173 & 0,546 & $\mathbf{x}$ & $\mathbf{x}$ & $\mathbf{x}$ \\
\hline $\mathbf{K}^{+}$ & 0,284 & 0,032 & $\underline{0,760}$ & $-0,064$ & 0,097 & $\underline{0,778}$ & $\underline{0,928}$ & 0,648 & 0,601 & 0,291 & $\mathbf{x}$ & $\mathbf{x}$ & $\mathbf{x}$ & $\mathbf{x}$ \\
\hline $\mathrm{NH}_{4}^{+}$ & $\underline{0,874}$ & $\underline{0,885}$ & 0,513 & 0,279 & $\underline{-0,726}$ & $-0,248$ & 0,305 & 0,597 & 0,571 & $\mathbf{x}$ & $\mathbf{x}$ & $\mathbf{x}$ & $\mathbf{x}$ & $\mathbf{x}$ \\
\hline $\mathrm{SiO}_{2}$ & 0,623 & 0,474 & $\underline{0,955}$ & 0,063 & 0,011 & 0,316 & 0,637 & $\underline{0,943}$ & $\mathbf{x}$ & $\mathbf{x}$ & $\mathbf{x}$ & $\mathbf{x}$ & $\mathbf{x}$ & $\mathbf{x}$ \\
\hline $\mathrm{HCO}_{3}^{-}$ & $\underline{0,677}$ & 0,556 & $\underline{0,974}$ & 0,184 & 0,029 & 0,318 & 0,652 & $\mathbf{x}$ & $\mathbf{x}$ & $\mathbf{x}$ & $\mathbf{x}$ & $\mathbf{x}$ & $\mathbf{x}$ & $\mathbf{x}$ \\
\hline $\mathrm{Cl}^{-}$ & 0,260 & 0,145 & $\underline{0,778}$ & $-0,314$ & 0,079 & $\underline{0,838}$ & $\mathbf{x}$ & $\mathbf{x}$ & $\mathbf{x}$ & $\mathbf{x}$ & $\mathbf{x}$ & $\mathbf{x}$ & $\mathbf{x}$ & $\mathbf{x}$ \\
\hline $\mathrm{SO}_{4}{ }^{2-}$ & $-0,277$ & $-0,367$ & 0,495 & $-0,489$ & 0,507 & $\mathbf{x}$ & $\mathbf{x}$ & $\mathbf{x}$ & $\mathbf{x}$ & $\mathbf{x}$ & $\mathbf{x}$ & $\mathbf{x}$ & $\mathbf{x}$ & $\mathbf{x}$ \\
\hline $\mathrm{NO}_{3}^{-}$ & $-0,575$ & $-0,639$ & 0,112 & $-0,120$ & $\mathbf{x}$ & $\mathbf{x}$ & $\mathbf{x}$ & $\mathbf{x}$ & $\mathbf{x}$ & $\mathbf{x}$ & $\mathbf{x}$ & $\mathbf{x}$ & $\mathbf{x}$ & $\mathbf{x}$ \\
\hline $\mathrm{PO}_{4}{ }^{3-}$ & 0,425 & 0,240 & 0,056 & $\mathbf{x}$ & $\mathbf{x}$ & $\mathbf{x}$ & $\mathbf{x}$ & $\mathbf{x}$ & $\mathbf{x}$ & $\mathbf{x}$ & $\mathbf{x}$ & $\mathbf{x}$ & $\mathbf{x}$ & $\mathbf{x}$ \\
\hline TDS & 0,574 & 0,420 & $\mathbf{x}$ & $\mathbf{x}$ & $\mathbf{x}$ & $\mathbf{x}$ & $\mathbf{x}$ & $\mathbf{x}$ & $\mathbf{x}$ & $\mathbf{x}$ & $\mathbf{x}$ & $\mathbf{x}$ & $\mathbf{x}$ & $\mathbf{x}$ \\
\hline pH & $\underline{0,849}$ & $\mathbf{x}$ & $\mathbf{x}$ & $\mathbf{x}$ & $\mathbf{x}$ & $\mathbf{x}$ & $\mathbf{x}$ & $\mathbf{x}$ & $\mathbf{x}$ & $\mathbf{x}$ & $\mathbf{x}$ & $\mathbf{x}$ & $\mathbf{x}$ & $\mathbf{x}$ \\
\hline Cond & $\mathbf{x}$ & $\mathbf{x}$ & $\mathbf{x}$ & $\mathbf{x}$ & $\mathbf{x}$ & $\mathbf{x}$ & $\mathbf{x}$ & $\mathbf{x}$ & $\mathbf{x}$ & $\mathbf{x}$ & $\mathbf{x}$ & $\mathbf{x}$ & $\mathbf{x}$ & $\mathbf{x}$ \\
\hline
\end{tabular}

Tabela 7. Matriz dos coeficientes de correlação entre as principais espécies químicas dissolvidas no córrego Entre Rios, Angatuba, São Paulo, no período de amostragem intensiva 2.

\begin{tabular}{|c|c|c|c|c|c|c|c|c|c|c|c|c|c|}
\hline & Cond. & pH & TDS & $\mathrm{PO}_{4}{ }^{3-}$ & $\mathrm{NO}_{3}^{-}$ & $\mathrm{SO}_{4}{ }^{2-}$ & $\mathrm{Cl}^{-}$ & $\mathrm{HCO}_{3}^{-}$ & $\mathrm{SiO}_{2}$ & $\mathbf{K}^{+}$ & $\mathrm{Na}^{+}$ & $\mathrm{Mg}^{2+}$ & $\mathrm{Ca}^{2+}$ \\
\hline $\mathbf{Q}$ & 0,224 & $-0,532$ & $-0,447$ & $-0,228$ & 0,120 & 0,025 & 0,553 & $\underline{-0,855}$ & $-0,597$ & 0,441 & $-0,742$ & $-0,628$ & $-0,637$ \\
\hline $\mathrm{Ca}^{2+}$ & 0,167 & 0,070 & $\underline{0,803}$ & 0,505 & 0,520 & 0,358 & $-0,233$ & $\underline{0,760}$ & $\underline{0,788}$ & 0,068 & 0,632 & 0,525 & $\mathbf{x}$ \\
\hline $\mathrm{Mg}^{2+}$ & $-0,373$ & 0,517 & 0,575 & $-0,009$ & 0,201 & 0,662 & $-0,317$ & $\underline{0,692}$ & 0,510 & $-0,037$ & 0,641 & $\mathbf{x}$ & $\mathbf{x}$ \\
\hline $\mathrm{Na}^{+}$ & $-0,020$ & 0,573 & 0,545 & 0,209 & 0,001 & 0,248 & $-0,544$ & $\underline{0,853}$ & 0,617 & $-0,275$ & $\mathbf{x}$ & $\mathbf{x}$ & $\mathbf{x}$ \\
\hline $\mathbf{K}^{+}$ & 0,335 & $-0,591$ & 0,492 & 0,468 & $\underline{0,859}$ & 0,273 & $\underline{0,862}$ & $-0,272$ & 0,163 & $\mathbf{x}$ & $\mathbf{x}$ & $\mathbf{x}$ & $\mathbf{x}$ \\
\hline $\mathrm{SiO}_{2}$ & 0,353 & 0,371 & $\underline{0,898}$ & 0,510 & 0,542 & 0,152 & $-0,271$ & $\underline{0,829}$ & $\mathbf{x}$ & $\mathbf{x}$ & $\mathbf{x}$ & $\mathbf{x}$ & $\mathbf{x}$ \\
\hline $\mathrm{HCO}_{3}^{-}$ & 0,134 & 0,658 & $\underline{0,688}$ & 0,213 & 0,128 & 0,144 & $-0,595$ & $\mathbf{x}$ & $\mathbf{x}$ & $\mathbf{x}$ & $\mathbf{x}$ & $\mathbf{x}$ & $\mathbf{x}$ \\
\hline $\mathrm{Cl}^{-}$ & 0,161 & $\underline{-0,800}$ & 0,087 & 0,352 & 0,566 & 0,023 & $\mathbf{x}$ & $\mathbf{x}$ & $\mathbf{x}$ & $\mathbf{x}$ & $\mathbf{x}$ & $\mathbf{x}$ & $\mathbf{x}$ \\
\hline $\mathrm{SO}_{4}{ }^{2-}$ & $-0,380$ & 0,025 & 0,373 & 0,031 & 0,430 & $\mathbf{x}$ & $\mathbf{x}$ & $\mathbf{x}$ & $\mathbf{x}$ & $\mathbf{x}$ & $\mathbf{x}$ & $\mathbf{x}$ & $\mathbf{x}$ \\
\hline $\mathrm{NO}_{3}^{-}$ & 0,380 & $-0,402$ & $\underline{0,794}$ & 0,639 & $\mathbf{x}$ & $\mathbf{x}$ & $\mathbf{x}$ & $\mathbf{x}$ & $\mathbf{x}$ & $\mathbf{x}$ & $\mathbf{x}$ & $\mathbf{x}$ & $\mathbf{x}$ \\
\hline $\mathrm{PO}_{4}{ }^{3-}$ & 0,126 & $-0,286$ & 0,616 & $\mathbf{x}$ & $\mathbf{x}$ & $\mathbf{x}$ & $\mathbf{x}$ & $\mathbf{x}$ & $\mathbf{x}$ & $\mathbf{x}$ & $\mathbf{x}$ & $\mathbf{x}$ & $\mathbf{x}$ \\
\hline TDS & 0,326 & 0,100 & $\mathbf{x}$ & $\mathbf{x}$ & $\mathbf{x}$ & $\mathbf{x}$ & $\mathbf{x}$ & $\mathbf{x}$ & $\mathbf{x}$ & $\mathbf{x}$ & $\mathbf{x}$ & $\mathbf{x}$ & $\mathbf{x}$ \\
\hline pH & $-0,118$ & $\mathbf{x}$ & $\mathbf{x}$ & $\mathbf{x}$ & $\mathbf{x}$ & $\mathbf{x}$ & $\mathbf{x}$ & $\mathbf{x}$ & $\mathbf{x}$ & $\mathbf{x}$ & $\mathbf{x}$ & $\mathbf{x}$ & $\mathbf{x}$ \\
\hline
\end{tabular}

Significativas correlações obtidas nas intensivas 1 e 2 entre o $\mathrm{HCO}_{3}{ }^{-}$e $\mathrm{SiO}_{2}$ indicaram a ocorrência de intemperismo de rochas na microbacia de drenagem, bem como as altas correlações de $\mathrm{Mg}^{2+} \mathrm{e} \mathrm{Ca}^{2+}$ nas três situações, indicaram existência de aportes possivelmente associados à aplicação de insumos carbonatados, como os originados dos processos de calagem. 


\subsubsection{Metais dissolvidos de interesse ambiental}

No presente estudo foram determinadas as espécies químicas $\mathrm{Ba}, \mathrm{V}, \mathrm{Cr}, \mathrm{Mo}, \mathrm{Mn}, \mathrm{Co}, \mathrm{Ni}$, $\mathrm{Cu}, \mathrm{Zn}, \mathrm{Cd}, \mathrm{B}, \mathrm{Pb}, \mathrm{Fe}$ e $\mathrm{Al}$ dissolvidas nas águas do córrego Entre Rios, conforme descrito no item 4.4.7. Na Tabela 8 encontram-se os resultados das vazões e concentrações de $\mathrm{Ba}, \mathrm{Fe}, \mathrm{B}, \mathrm{Mn}$ e Al e limites de detecção. Os elementos V $(0,01), \mathrm{Cr}(0,02)$, Mo $(0,01), \mathrm{Co}(0,01), \mathrm{Ni}(0,015)$, $\mathrm{Cd}(0,005), \mathrm{Pb}(0,1), \mathrm{Zn}(0,03)$ e $\mathrm{Cu}(0,005)$ que não foram reportados na tabela porque estavam abaixo do limite de detecção. Os valores dos elementos entre parênteses são dados em $\mathrm{mg} \mathrm{L}^{-1}$.

Foi observado que entre os metais analisados, o Fe foi o de maior predominância estando sua origem possivelmente relacionada aos processos de laterização e fertilidade dos solos. Com exceção do $\mathrm{Fe}$, todos os demais elementos apresentaram valores menores do que $1 \mathrm{mg} \mathrm{L^{-1 }}$ (Tabela 8). De uma maneira geral as concentrações observadas dos referidos metais foram baixas conforme o esperado. 
Tabela 8. Vazões e concentrações dos metais dissolvidos nas amostras de águas fluviais do córrego Entre Rios durante o período de estudo.

\begin{tabular}{|c|c|c|c|c|c|c|c|}
\hline tras & Excursão & $\begin{array}{c}Q \\
\left(L s^{-1}\right)\end{array}$ & $\mathbf{B a}$ & $\mathrm{Fe}$ & $\begin{array}{c}\text { B } \\
\left(m g L^{-1}\right)\end{array}$ & Mn & Al \\
\hline $\mathrm{A}_{1}$ & $26 / 09 / 2006$ & 8,0 & 0,007 & 0,534 & 0,006 & 0,021 & 0,076 \\
\hline $\mathrm{A}_{2}$ & $10 / 10 / 2006$ & 10,0 & 0,006 & 0,691 & 0,006 & 0,018 & 0,092 \\
\hline $\mathrm{A}_{3}$ & $24 / 10 / 2006$ & 10,5 & 0,004 & 0,724 & 0,010 & 0,018 & 0,084 \\
\hline $\mathrm{A}_{4}$ & 08/11/2006 & 11,3 & L.D. & 1,092 & 0,008 & 0,029 & 0,088 \\
\hline $\mathrm{A}_{5}$ & $22 / 11 / 2006$ & 8,9 & 0,004 & 1,074 & 0,007 & 0,031 & 0,082 \\
\hline $\mathrm{A}_{6}$ & $19 / 12 / 2006$ & 15,0 & 0,041 & 1,427 & 0,008 & 0,037 & 0,072 \\
\hline $\mathrm{A}_{7}$ & $24 / 01 / 2007$ & 11,5 & 0,041 & 1,283 & 0,008 & 0,071 & 0,087 \\
\hline $\mathrm{A}_{8}$ & $27 / 02 / 2007$ & 12,0 & 0,041 & 1,219 & 0,007 & 0,058 & 0,076 \\
\hline $\mathrm{A}_{9.1}$ & $17 / 03 / 2007$ & 11,0 & 0,046 & 1,212 & 0,010 & 0,062 & 0,144 \\
\hline $\mathrm{A}_{9.2}$ & $17 / 03 / 2007$ & 14,3 & 0,043 & 1,619 & 0,012 & 0,072 & 0,164 \\
\hline $\mathrm{A}_{9.3}$ & $17 / 03 / 2007$ & 31,8 & 0,050 & 2,920 & 0,015 & 0,116 & 0,218 \\
\hline $\mathrm{A}_{9.4}$ & $17 / 03 / 2007$ & 53,0 & 0,053 & 4,883 & 0,024 & 0,152 & 0,287 \\
\hline $\mathrm{A}_{9.5}$ & $17 / 03 / 2007$ & 70,0 & 0,046 & 3,904 & 0,020 & 0,100 & 0,308 \\
\hline $\mathrm{A}_{9.6}$ & $17 / 03 / 2007$ & 50,0 & 0,043 & 2,602 & 0,017 & 0,073 & 0,318 \\
\hline $\mathrm{A}_{9.7}$ & $17 / 03 / 2007$ & 33,6 & 0,043 & 1,421 & 0,020 & 0,050 & 0,286 \\
\hline $\mathrm{A}_{9.8}$ & $18 / 03 / 2007$ & 19,2 & 0,040 & 1,159 & 0,019 & 0,049 & 0,178 \\
\hline $\mathrm{A}_{9.9}$ & $18 / 03 / 2007$ & 15,5 & 0,040 & 1,136 & 0,011 & 0,054 & 0,145 \\
\hline $\mathrm{A}_{10}$ & $26 / 06 / 2007$ & 2,9 & 0,031 & 3,131 & nd & 0,175 & 0,158 \\
\hline $\mathrm{A}_{11}$ & $28 / 07 / 2007$ & 9,0 & 0,030 & 0,684 & nd & 0,045 & 0,044 \\
\hline $\mathrm{A}_{12}$ & $11 / 09 / 2007$ & 2,5 & 0,041 & 0,829 & nd & 0,028 & L.D. \\
\hline $\mathrm{A}_{13}$ & $30 / 10 / 2007$ & 3,0 & 0,049 & 1,745 & nd & 0,047 & 0,043 \\
\hline $\mathrm{A}_{14.1}$ & $05 / 12 / 2007$ & 3,4 & L.D. & 0,863 & nd & 0,030 & 0,065 \\
\hline $\mathrm{A}_{14.2}$ & $05 / 12 / 2007$ & 6,3 & 0,005 & 0,734 & nd & 0,025 & 0,052 \\
\hline $\mathrm{A}_{14.3}$ & $05 / 12 / 2007$ & 11,2 & 0,005 & 2,396 & nd & 0,070 & 0,216 \\
\hline $\mathrm{A}_{14.4}$ & $05 / 12 / 2007$ & 17,9 & L.D. & 3,935 & nd & 0,140 & 0,290 \\
\hline $\mathrm{A}_{14.5}$ & $05 / 12 / 2007$ & 53,0 & 0,016 & 6,426 & 0,017 & 0,207 & 0,260 \\
\hline $\mathrm{A}_{14.6}$ & $05 / 12 / 2007$ & 35,5 & 0,009 & 1,527 & 0,006 & 0,038 & 0,136 \\
\hline $\mathrm{A}_{14.7}$ & $05 / 12 / 2007$ & 23,5 & 0,009 & 0,635 & nd & 0,018 & 0,114 \\
\hline $\mathrm{A}_{14.8}$ & $05 / 12 / 2007$ & 15,5 & 0,010 & 0,848 & nd & 0,022 & 0,129 \\
\hline $\mathrm{A}_{14.9}$ & $05 / 12 / 2007$ & 8,5 & 0,009 & 0,391 & nd & 0,011 & 0,071 \\
\hline $\mathrm{A}_{14.10}$ & $05 / 12 / 2007$ & 6,3 & 0,012 & 0,555 & nd & 0,018 & 0,079 \\
\hline \multicolumn{3}{|c|}{ Limite de detecção (L.D.) } & 0,003 & 0,030 & 0,005 & 0,002 & 0,020 \\
\hline
\end{tabular}




\subsubsection{Transporte fluvial de solutos}

\subsubsection{Método estocástico}

O transporte das principais espécies químicas dissolvidas nas águas da microbacia Entre Rios foi avaliado pelo método estocástico conforme descrito no item 4.4.8.1., para as amostragens extensivas e intensivas.

$\mathrm{Na}$ Tabela 9 podem ser observados os resultados do transporte total e específico das principais espécies químicas obtidos pelo método estocástico para o período de amostragens extensivas que incluíram os picos de cheia das duas amostragens intensivas na microbacia do córrego Entre Rios.

Pode ser observado que o $\mathrm{SiO}_{2}$ foi a espécie química com maior carga transportada fluvialmente para o período estudado correspondendo, em termos de transporte total a $4,71 \mathrm{t} \mathrm{a}^{-1}$, o que representou em termos de transporte específico em $2,95 \mathrm{t} \mathrm{km}^{-2} \mathrm{a}^{-1}$. Tais resultados podem ser justificados devido à formação geológica da microbacia de drenagem, com presença de silicatos. Para os cátions, os maiores valores de transporte foram observados para $\mathrm{K}^{+} \mathrm{e} \mathrm{Ca}^{2+}$ correspondendo respectivamente, em termos de transporte específico, a $0,61 \mathrm{e} 0,48 \mathrm{t} \mathrm{km}^{-2} \mathrm{a}^{-1}$. Em relação aos ânions, maiores valores de transporte total e específico foram observados para espécie química $\mathrm{HCO}_{3}{ }^{-}$. O transporte de TDS para este período foi de $11,83 \mathrm{t} \mathrm{a}^{-1}$, o que representou em termos de transporte específico a $7,39 \mathrm{t} \mathrm{km}^{-2} \mathrm{a}^{-1}$. 
Tabela 9. Transporte total $\left(\mathrm{T}_{\mathrm{A}} \mathrm{em} \mathrm{t} \mathrm{a}^{-1} \mathrm{e} \mathrm{kg} \mathrm{d}^{-1}\right)$ e transporte específico $\left(\mathrm{T}_{\mathrm{AE}} \mathrm{em} \mathrm{t} \mathrm{km} \mathrm{km}^{-2} \mathrm{e} \mathrm{kg} \mathrm{km}^{-2} \mathrm{~d}^{-1}\right)$ das principais espécies químicas dissolvidas ocorridas no córrego Entre Rios, Angatuba, no período das amostragens extensivas.

\begin{tabular}{|c|c|c|c|c|c|}
\hline Espécie & $T_{A}\left(t^{-1}\right)$ & $T_{A E}\left(t_{k m}^{-2} a^{-1}\right)$ & Espécie & $T_{A}\left(k g ~ d^{-1}\right)$ & $T_{A E}\left(\mathrm{~kg} \mathrm{~km}^{-2} \mathrm{~d}^{-1}\right)$ \\
\hline $\mathrm{Ca}^{2+}$ & 0,77 & 0,48 & $\mathrm{Ca}^{2+}$ & 2,12 & 1,33 \\
\hline $\mathrm{Mg}^{2+}$ & 0,22 & 0,14 & $\mathrm{Mg}^{2+}$ & 0,61 & 0,38 \\
\hline $\mathrm{Na}^{+}$ & 0,25 & 0,16 & $\mathrm{Na}^{+}$ & 0,68 & 0,43 \\
\hline $\mathrm{K}^{+}$ & 0,98 & 0,61 & $\mathrm{~K}^{+}$ & 2,68 & 1,68 \\
\hline $\mathrm{NH}_{4}^{+}$ & 0,01 & 0,01 & $\mathrm{NH}_{4}^{+}$ & 0,03 & 0,02 \\
\hline $\mathrm{SiO}_{2}$ & 4,71 & 2,95 & $\mathrm{SiO}_{2}$ & 12,92 & 8,07 \\
\hline $\mathrm{HCO}_{3}^{-}$ & 3,78 & 2,36 & $\mathrm{HCO}_{3}^{-}$ & 10,34 & 6,47 \\
\hline $\mathrm{Cl}^{-}$ & 0,58 & 0,36 & $\mathrm{Cl}^{-}$ & 1,59 & 0,99 \\
\hline $\mathrm{SO}_{4}{ }^{2-}$ & 0,30 & 0,19 & $\mathrm{SO}_{4}^{2-}$ & 0,83 & 0,52 \\
\hline $\mathrm{NO}_{3}^{-}$ & 0,19 & 0,12 & $\mathrm{NO}_{3}^{-}$ & 0,51 & 0,32 \\
\hline $\mathrm{PO}_{4}{ }^{3-}$ & 0,03 & 0,02 & $\mathrm{PO}_{4}{ }^{3-}$ & 0,08 & 0,05 \\
\hline TDS & 11,83 & 7,39 & TDS & 32,40 & 20,25 \\
\hline
\end{tabular}

Os transportes totais e específicos foram também calculados para os dois períodos de amostragens intensivas, uma anterior e outra posterior a colheita de madeira com precipitações de 28 e $25 \mathrm{~mm}$, respectivamente, de acordo com a metodologia proposta. Nas Tabelas 10 e 11 são apresentados respectivamente os valores dos transportes totais e específicos das principais espécies químicas para estes períodos. Os transportes totais e específicos de TDS para as amostragens intensivas foram, respectivamente, 57,29 $\mathrm{kg} \mathrm{d}^{-1}$ e $35,81 \mathrm{~kg} \mathrm{~km}^{-2} \mathrm{~d}^{-1}$ (intensiva 1) e $37,65 \mathrm{~kg} \mathrm{~d}^{-1}$ e $23,53 \mathrm{~kg} \mathrm{~km}^{-2} \mathrm{~d}^{-1}$ (intensiva 2). Foram observados maiores valores de $\mathrm{SiO}_{2}$ e o $\mathrm{HCO}_{3}{ }^{-}$, em termos de transporte total e específico associados principalmente à formação geológica da área de estudo e aos aportes atmosféricos.

Das espécies químicas analisadas, $\mathrm{o}^{-}$foi o elemento que apresentou os maiores valores em termos de transporte total e específico no segundo período de amostragem da intensiva 2 sob um evento chuvoso de $25 \mathrm{~mm}$. 
Tabela 10. Transporte total $\left(\mathrm{T}_{\mathrm{A}}\right.$ em kg d $\left.\mathrm{d}^{-1}\right)$ e transporte específico $\left(\mathrm{T}_{\mathrm{AE}}\right.$ em $\left.\mathrm{kg} \mathrm{km}^{-2} \mathrm{~d}^{-1}\right)$ das principais espécies químicas dissolvidas ocorridas no córrego Entre Rios, Angatuba, no período de amostragem intensiva 1.

\begin{tabular}{|c|c|c|}
\hline Espécie & $T_{A}\left(k g ~ d^{-1}\right)$ & $T_{A E}\left(k g ~ k m^{-2} d^{-1}\right)$ \\
\hline $\mathrm{Ca}^{2+}$ & 3,70 & 2,31 \\
\hline $\mathrm{Mg}^{2+}$ & 0,97 & 0,61 \\
\hline $\mathrm{Na}^{+}$ & 1,11 & 0,69 \\
\hline $\mathrm{K}^{+}$ & 4,48 & 2,80 \\
\hline $\mathrm{NH}_{4}^{+}$ & 0,07 & 0,04 \\
\hline $\mathrm{SiO}_{2}$ & 24,58 & 15,36 \\
\hline $\mathrm{HCO}_{3}^{-}$ & 18,00 & 11,25 \\
\hline $\mathrm{Cl}^{-}$ & 1,97 & 1,23 \\
\hline $\mathrm{SO}_{4}^{2-}$ & 1,07 & 0,67 \\
\hline $\mathrm{NO}_{3}^{-}$ & 1,22 & 0,76 \\
\hline $\mathrm{PO}_{4}^{3-}$ & 0,13 & 0,08 \\
\hline TDS & 57,29 & 35,81 \\
\hline
\end{tabular}

Tabela 11. Transporte total $\left(\mathrm{T}_{\mathrm{A}}\right.$ em $\left.\mathrm{kg} \mathrm{d} \mathrm{d}^{-1}\right)$ e transporte específico $\left(\mathrm{T}_{\mathrm{AE}}\right.$ em $\left.\mathrm{kg} \mathrm{km}^{-2} \mathrm{~d}^{-1}\right)$ das principais espécies químicas dissolvidas ocorridas no córrego Entre Rios, Angatuba, no período de amostragem intensiva 2 .

\begin{tabular}{|c|c|c|}
\hline Espécie & $T_{A}\left(k_{g ~ d}{ }^{-1}\right)$ & $T_{A E}\left(\mathrm{~kg} \mathrm{~km}^{-2} \mathrm{~d}^{-1}\right)$ \\
\hline $\mathrm{Ca}^{2+}$ & 2,61 & 1,63 \\
\hline $\mathrm{Mg}^{2+}$ & 0,71 & 0,44 \\
\hline $\mathrm{Na}^{+}$ & 0,70 & 0,43 \\
\hline $\mathrm{K}^{+}$ & 4,52 & 2,83 \\
\hline $\mathrm{NH}_{4}^{+}$ & 0,00 & 0,00 \\
\hline $\mathrm{SiO}_{2}$ & 12,83 & 8,02 \\
\hline $\mathrm{HCO}_{3}^{-}$ & 10,41 & 6,50 \\
\hline $\mathrm{Cl}^{-}$ & 3,20 & 2,00 \\
\hline $\mathrm{SO}_{4}^{2-}$ & 1,49 & 0,93 \\
\hline $\mathrm{NO}_{3}{ }^{-}$ & 1,14 & 0,71 \\
\hline $\mathrm{PO}_{4}^{3-}$ & 0,05 & 0,03 \\
\hline TDS & 37,65 & 23,53 \\
\hline
\end{tabular}


Tais valores de transporte corroboraram com altos valores de $\mathrm{K}^{+}$para o mesmo período. Possivelmente este fato se deveu, como dito anteriormente, a uma maior lixiviação destes elementos aos corpos d'água por conseqüência da supressão da cobertura florestal densa e ao protocolo de adubações na área florestada com eucaliptos em parte da microbacia, realizado duas semanas antes da referida amostragem. Segundo Vital et al. (1999), a remoção da floresta conduz a um aumento no deflúvio e na quantidade de nutrientes que deixam a bacia após o corte raso da floresta, principalmente os elementos $\mathrm{N}, \mathrm{P}$ e K. Outros autores afirmam que os primeiros anos após supressão da floresta são fundamentais para o monitoramento de águas de deflúvio em função do aumento da concentração dos referidos nutrientes nos cursos d'água em microbacias (HORNBECK; KROPELIN, 1982; HOPMANS et al., 1987; STEVENS et al., 1995).

Este tipo de mobilidade observada para o $\mathrm{K}^{+}$também foi verificada por Ranzini e Lima (2002), estudando a ciclagem geoquímica de nutrientes em uma microbacia $\left(0,072 \mathrm{~km}^{2}\right)$ reflorestada com Eucalyptus saligna, São Paulo, onde o balanço positivo de $\mathrm{K}^{+}$indicou uma saída desse nutriente pelo deflúvio decorrente da facilidade com que este íon foi lixiviado das copas das árvores e da serapilheira pelas águas das chuvas até os cursos d'água.

As demais espécies químicas se mostraram pouco representativas nos períodos estudados, com baixas concentrações, exceto para $\mathrm{Ca}^{2+}$, nas duas intensivas.

\subsubsection{Método de integração de áreas}

Conforme descrito no item 4.4.8.2., no presente trabalho foi utilizado um método alternativo para estimativa da carga dissolvida fluvial transportada nas duas amostragens intensivas. A Tabela 12 apresenta os resultados dos transportes fluviais totais e específicos, obtidos pelo método de integração de áreas. 
Tabela 12. Transporte total $\left(\mathrm{T}_{\mathrm{B}}\right.$ em $\left.\mathrm{kg} \mathrm{d}^{-1}\right)$ e transporte específico $\left(\mathrm{T}_{\mathrm{BE}}\right.$ em $\left.\mathrm{kg} \mathrm{km}^{-2} \mathrm{~d}^{-1}\right)$ das principais espécies químicas dissolvidas ocorridas no córrego Entre Rios, Angatuba, no período de amostragem intensiva 1 e 2, pelo método de integração de áreas.

\begin{tabular}{|c|c|c|c|c|c|}
\hline \multicolumn{3}{|c|}{ Intensiva 1} & \multicolumn{3}{|c|}{ Intensiva 2} \\
\hline Espécie & $T_{B}\left(\mathrm{~kg} \mathrm{~d}^{-1}\right)$ & $T_{B E}\left(\mathrm{~kg} \mathrm{~km}^{-2} \mathrm{~d}^{-1}\right)$ & Espécie & $T_{B}\left(\mathrm{~kg} \mathrm{~d}^{-1}\right)$ & $T_{B E}\left(\mathrm{~kg} \mathrm{~km}^{-2} \mathrm{~d}^{-1}\right)$ \\
\hline $\mathrm{Ca}^{2+}$ & 3,27 & 2,04 & $\mathrm{Ca}^{2+}$ & 2,07 & 1,29 \\
\hline $\mathrm{Mg}^{2+}$ & 0,91 & 0,57 & $\mathrm{Mg}^{2+}$ & 0,58 & 0,36 \\
\hline $\mathrm{Na}^{+}$ & 1,02 & 0,64 & $\mathrm{Na}^{+}$ & 0,60 & 0,37 \\
\hline $\mathrm{K}^{+}$ & 3,87 & 2,42 & $\mathrm{~K}^{+}$ & 3,10 & 1,94 \\
\hline $\mathrm{NH}_{4}^{+}$ & 0,04 & 0,03 & $\mathrm{NH}_{4}^{+}$ & 0,00 & 0,00 \\
\hline $\mathrm{SiO}_{2}$ & 21,30 & 13,31 & $\mathrm{SiO}_{2}$ & 9,82 & 6,13 \\
\hline $\mathrm{HCO}_{3}^{-}$ & 15,79 & 9,87 & $\mathrm{HCO}_{3}^{-}$ & 8,39 & 5,24 \\
\hline $\mathrm{Cl}^{-}$ & 1,77 & 1,11 & $\mathrm{Cl}^{-}$ & 2,19 & 1,37 \\
\hline $\mathrm{SO}_{4}{ }^{2-}$ & 1,07 & 0,67 & $\mathrm{SO}_{4}^{2-}$ & 1,22 & 0,76 \\
\hline $\mathrm{NO}_{3}^{-}$ & 1,20 & 0,75 & $\mathrm{NO}_{3}^{-}$ & 0,77 & 0,48 \\
\hline $\mathrm{PO}_{4}^{3-}$ & 0,11 & 0,07 & $\mathrm{PO}_{4}{ }^{3-}$ & 0,04 & 0,02 \\
\hline TDS & 50,35 & 31,47 & TDS & 28,77 & 17,98 \\
\hline
\end{tabular}

A Figura 36 ilustra o relacionamento entre as vazões medidas em cada intervalo de tempo (identificadas pelas diferentes áreas) e as respectivas taxas de transportes parciais para o TDS obtidos nos períodos de coletas intensivas 1 e 2 .

Os resultados dos transportes parciais, relativos ao método de integração de áreas para as principais espécies químicas incluindo $\mathrm{SiO}_{2}$ e TDS transportados pelo córrego Entre Rios, bem como as concentrações médias normalizadas e os respectivos volumes de água escoados em cada de intervalo de tempo relativo às amostragens intensivas 1 e 2 , podem ser observadas nas Tabelas 1B a 4B (Apêndice 2). 

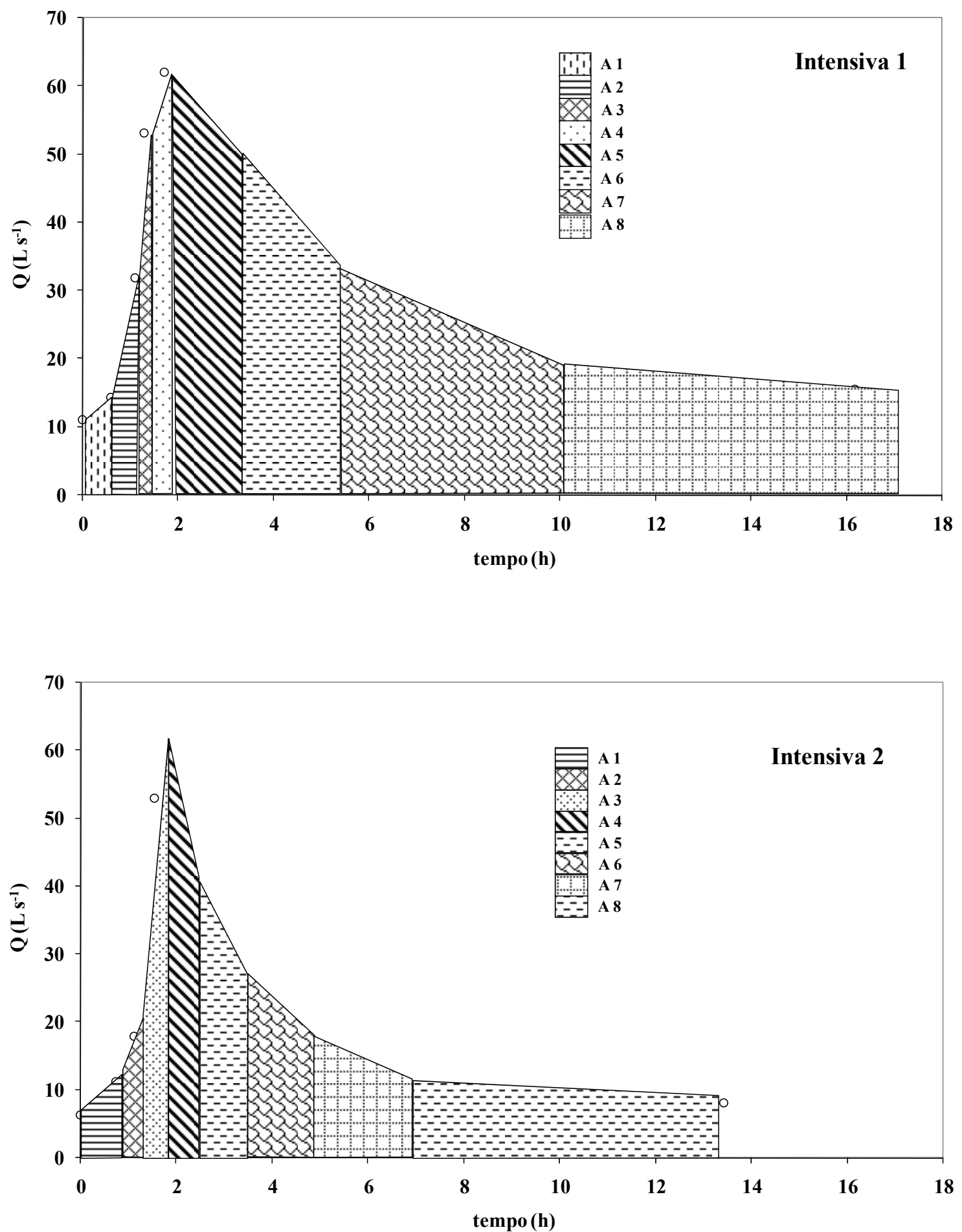

Figura 36. Relacionamento entre as vazões nos respectivos intervalos de tempo e as taxas de transportes parciais para o TDS nos períodos de coletas intensiva 1 e 2, na microbacia do córrego Entre Rios. 


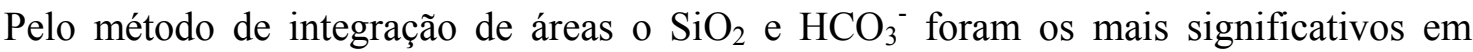
ambos os períodos de amostragem, com 21,30 e 15,79 $\mathrm{kg} \mathrm{d}^{-1}$ e 9,82 e 8,39 $\mathrm{kg} \mathrm{d}^{-1}$, em termos de transporte total para as intensivas 1 e 2 , respectivamente, que em transporte específico correspondeu a 13,31 e $9,87 \mathrm{~kg} \mathrm{~km}^{-2} \mathrm{~d}^{-1}$ (intensiva1) e 6,13 e $5,24 \mathrm{~kg} \mathrm{~km}^{-2} \mathrm{~d}^{-1}$ (intensiva 2).

Pode ser ainda verificado que os valores de TDS transportados fluvialmente, para os hidrogramas analisados foram significativamente baixos se comparados com a carga específica de TDS obtida em uma microbacia de $29,30 \mathrm{~km}^{2}$ com influência agrícola e antrópica de 119,58 $\mathrm{kg} \mathrm{km}^{-2} \mathrm{~d}^{-1}$ (BIBIAN, 2007). Considerando-se a especificidade e variabilidade de cada área de estudo, o transporte específico obtido no presente trabalho também pode ser considerado baixo em relação à bacia hidrográfica do rio Corumbataí $\left(1700 \mathrm{~km}^{2}\right)$, da ordem de $124,38 \mathrm{~kg} \mathrm{~km}^{-2} \mathrm{~d}^{-1}$ (BORTOLETTO JÚNIOR et al., 2002). Resultados similares aos obtidos no presente trabalho em termos de TDS foram observados por Meybeck (1986) em duas microbacias graníticas na França com cobertura de floresta de Pinus SP $\left(5,65\right.$ e $\left.3,91 \mathrm{~km}^{2}\right)$, com transportes específicos de 24 e 57 $\mathrm{kg} \mathrm{km}^{-2} \mathrm{~d}^{-1}$, respectivamente.

De uma maneira geral, os dois métodos empregados para o cálculo do transporte de material dissolvido nas duas amostragens intensivas apresentaram resultados similares. Os transportes calculados pelo método estocástico se mostraram ligeiramente superiores devido ao fato de se utilizar nesses cálculos os valores médios das concentrações normalizadas pela vazão que dependem do número de amostras representativas do hidrograma de cheia, podendo superestimar os resultados, como no presente trabalho, ou mesmo subestimar. Já para o método de integração de áreas isso não ocorreu devido o cálculo ser efetuado em diferentes fases da hidrógrafa, entre os tempos de amostragem e as respectivas vazões medidas, configurando áreas parciais correspondentes aos volumes parciais escoados nos respectivos intervalos de tempo. Não 
foram encontradas diferenças significativas $(\alpha=0,05)$ ao compararem-se os métodos estocásticos e de integração de áreas, de acordo com a aplicação do teste $t$ de Student.

Como vantagem de utilização do método de integração de áreas, foi possível calcular as taxas de transportes para cada intervalo de tempo e identificar os períodos de maior taxa de transporte relativo aos hidrogramas de cheia (intensiva 1 e 2) (Tabelas de 1B a 4B, Apêndice 2). Os transportes fluviais que apresentaram taxas mais elevadas de TDS $\left(3,83\right.$ e $3,14 \mathrm{~kg} \mathrm{~h}^{-1}$, respectivamente para as intensivas 1 e 2) se mostraram junto ao ponto máximo da cheia, no final da subida dos hidrogramas. No entanto, os períodos de recessão foram distintos, com definição após 10 e 7 horas respectivamente para intensivas 1 e 2 . Eventos chuvosos anteriores à amostragem de águas fluviais do córrego Entre Rios da intensiva 1 contribuíram para a saturação do solo e alteraram a relação entre o escoamento superficial e subterrâneo.

\subsection{Dinâmica do material particulado em suspensão (MPS)}

\subsubsection{Variabilidade temporal das concentrações de MPS}

A quantificação das concentrações do MPS para os três períodos estudados foi realizada de acordo com descrito no item 4.5.1., sendo verificada a variabilidade das concentrações em função do tempo. A Tabela 13 apresenta valores de MPS, em função da vazão para o córrego Entre Rios para as amostragens extensivas e intensivas.

Foi observado pelos resultados obtidos, aumento da concentração de MPS em função das respectivas vazões. Tal variabilidade permitiu verificar que os períodos que ocorreram os maiores arrastes de material foram justamente nos das maiores vazões. Os maiores valores, em termos de concentrações, foram obtidos no segundo período de amostragem (intensiva 2). Este fato pode ter ocorrido em função da colheita de madeira em 10,2\% da área da microbacia de drenagem, 
deixando o solo por alguns meses sem uma cobertura florestal mais densa, aliado ao fato da ocorrência de um período relativamente seco (ausência de chuvas) anterior ao evento estudado.

Tabela 13. Valores de vazão e MPS para o córrego Entre Rios, obtidos durante o período de estudo.

\begin{tabular}{|c|c|c|}
\hline Excursão & $\begin{array}{c}Q \\
\left(L \mathbf{s}^{-1}\right)\end{array}$ & $\begin{array}{c}\text { MPS } \\
\left(\mathrm{mg} \mathrm{L}^{-1}\right)\end{array}$ \\
\hline 26/09/2006 & 8,0 & 7,3 \\
\hline $10 / 10 / 2006$ & 10,0 & 7,7 \\
\hline $24 / 10 / 2006$ & 10,5 & 16,3 \\
\hline $08 / 11 / 2006$ & 11,3 & 16,3 \\
\hline $22 / 11 / 2006$ & 8,9 & 6,0 \\
\hline $19 / 12 / 2006$ & 15,0 & 3,3 \\
\hline $24 / 01 / 2007$ & 11,5 & 21,7 \\
\hline $27 / 02 / 2007$ & 12,0 & 15,0 \\
\hline $17 / 03 / 2007$ & 11,0 & 8,0 \\
\hline $17 / 03 / 2007$ & 14,3 & 10,3 \\
\hline $17 / 03 / 2007$ & 31,8 & 17,7 \\
\hline $17 / 03 / 2007$ & 53,0 & 21,3 \\
\hline $17 / 03 / 2007$ & 62,0 & 50,2 \\
\hline $17 / 03 / 2007$ & 50,0 & 50,0 \\
\hline $17 / 03 / 2007$ & 33,6 & 36,1 \\
\hline $18 / 03 / 2007$ & 19,2 & 19,2 \\
\hline $18 / 03 / 2007$ & 15,5 & 12,6 \\
\hline $26 / 06 / 2007$ & 2,9 & 5,9 \\
\hline $28 / 07 / 2007$ & 9,0 & 16,8 \\
\hline $11 / 09 / 2007$ & 2,5 & 3,6 \\
\hline $30 / 10 / 2007$ & 3,0 & 6,2 \\
\hline 05/12/2007 & 6,3 & 23,9 \\
\hline $05 / 12 / 2007$ & 11,2 & 48,2 \\
\hline $05 / 12 / 2007$ & 17,9 & 57,4 \\
\hline $05 / 12 / 2007$ & 53,0 & 80,6 \\
\hline $05 / 12 / 2007$ & 35,5 & 39,0 \\
\hline $05 / 12 / 2007$ & 23,5 & 26,1 \\
\hline $05 / 12 / 2007$ & 15,5 & 17,3 \\
\hline $05 / 12 / 2007$ & 10,0 & 12,9 \\
\hline $05 / 12 / 2007$ & 8,0 & 11,6 \\
\hline
\end{tabular}


A Figura 37 ilustra os resultados dos valores de vazão e concentração de MPS em função do tempo para as amostragens extensivas e os dois picos das amostragens intensivas realizadas na microbacia do córrego Entre Rios.

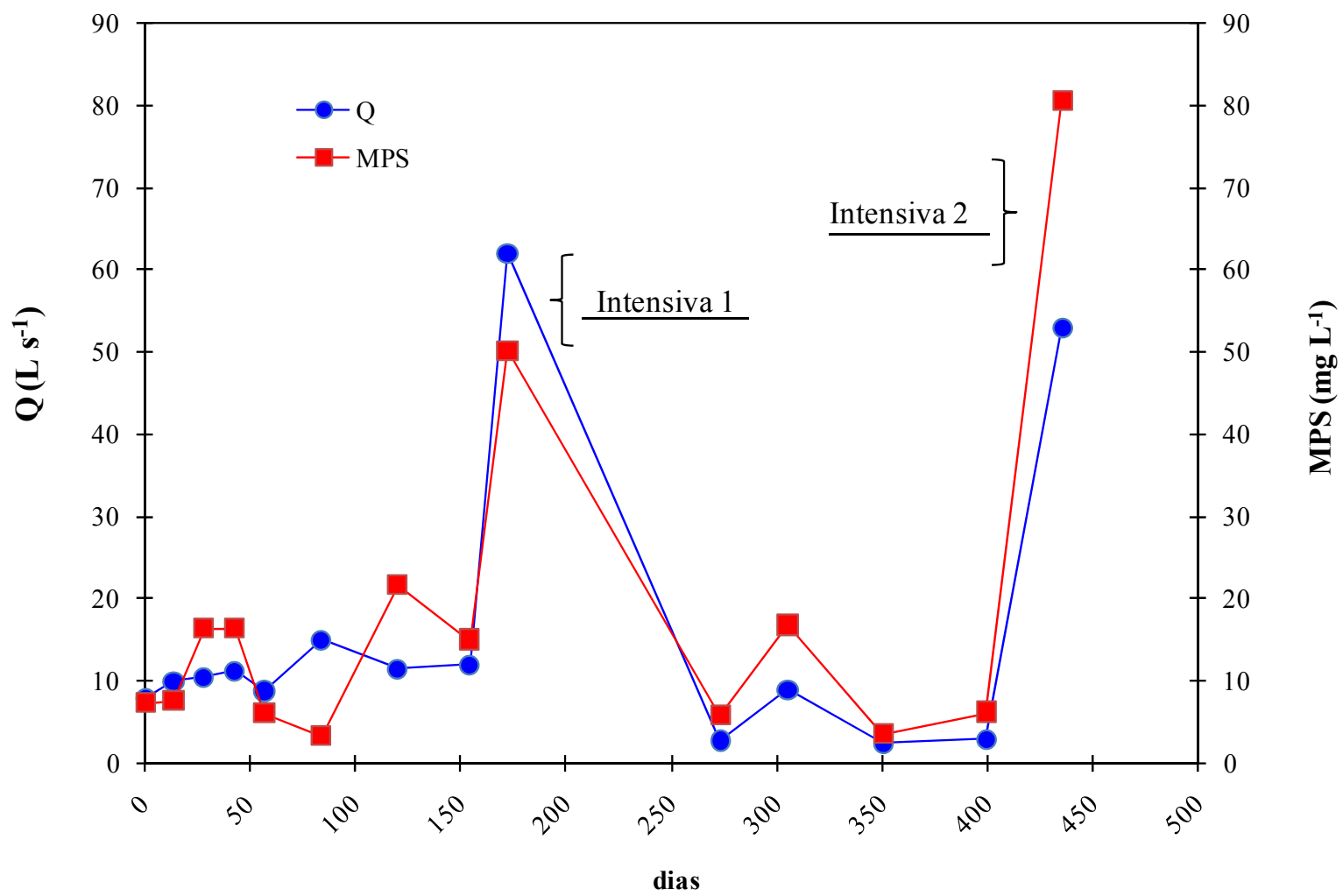

Figura 37. Variabilidade temporal das concentrações de material particulado em suspensão (MPS) e vazões (Q) na microbacia Entre Rios, durante o período de 26/09/2006 a 05/12/2007.

Pode ser observado nas amostragens extensivas que as maiores concentrações de MPS estiveram associadas aos períodos de maiores vazões, refletindo dessa forma o rápido período de recarga desse sistema uma vez que pela análise da precipitação, esse tempo de residência é bastante curto. 
As Figuras 38 e 39 ilustram a variabilidade das concentrações de MPS e valores de vazão em função do tempo para as amostragens intensivas 1 e 2 realizadas na microbacia do córrego Entre Rios.

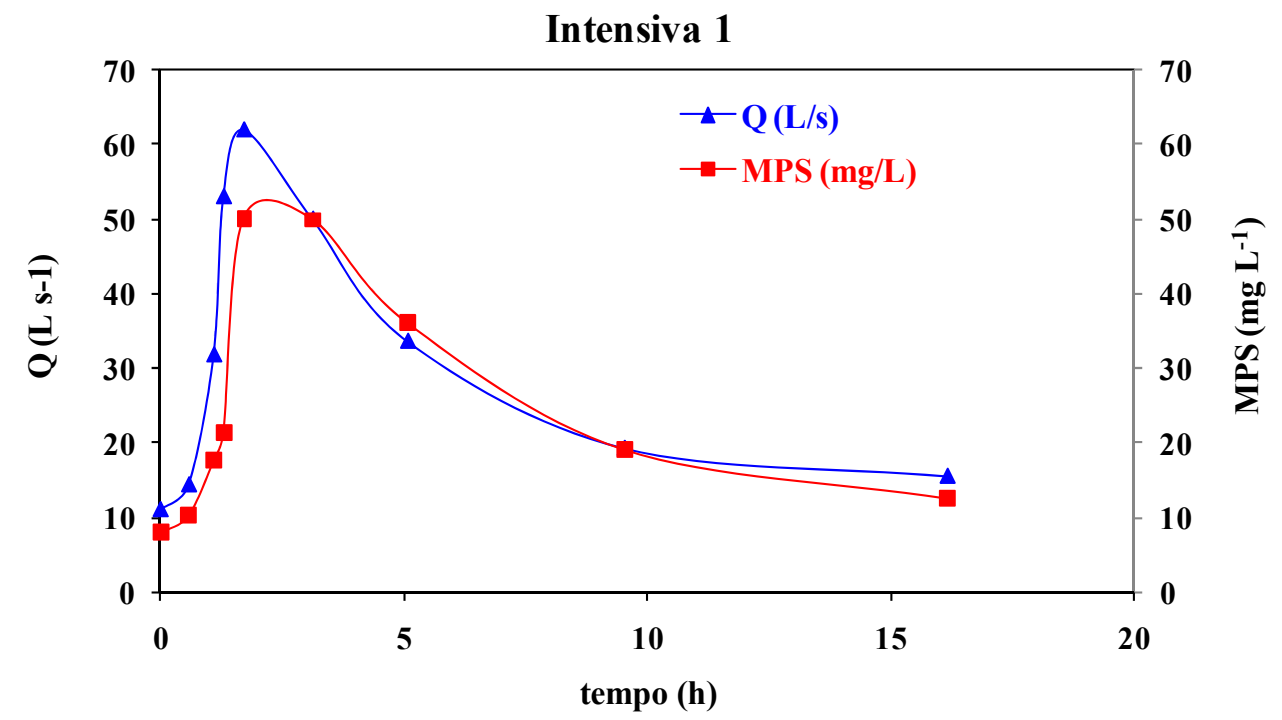

Figura 38. Valores de vazão e concentração de MPS em função do tempo da primeira amostragem intensiva, realizada no período de 17 e 18/03/2007 no córrego Entre Rios.

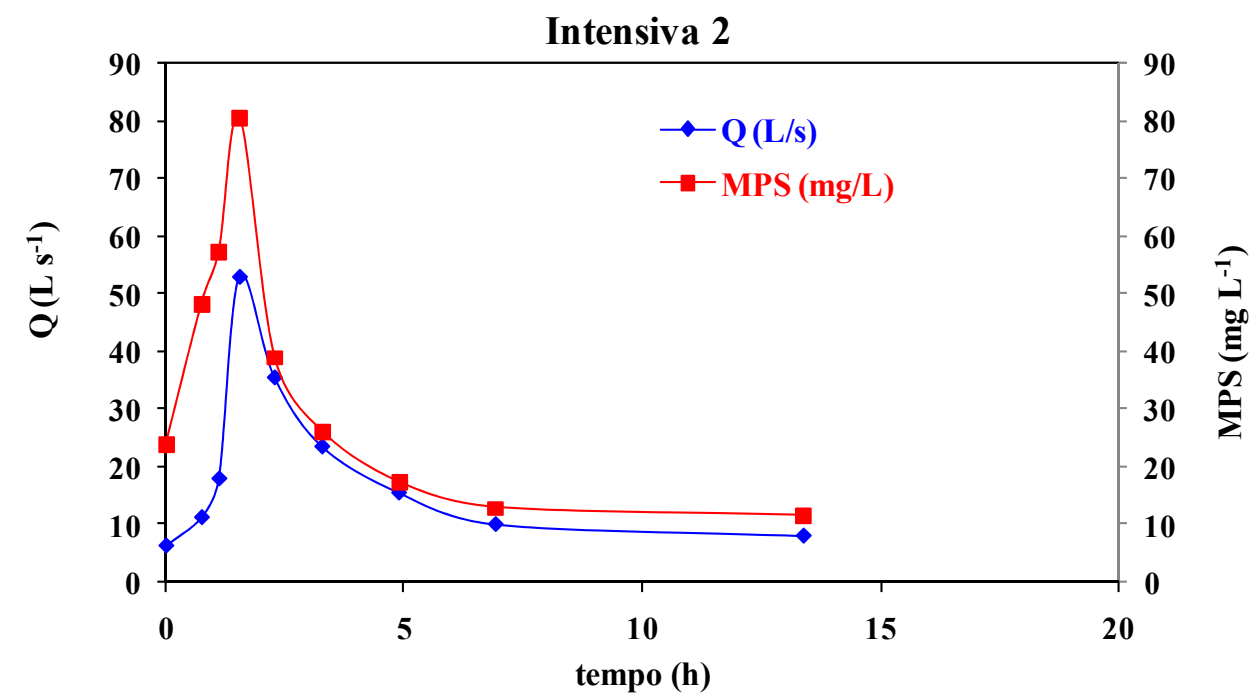

Figura 39. Valores de vazão e concentração de MPS em função do tempo da segunda amostragem intensiva, realizada no período de 17 e 18/03/2007 no córrego Entre Rios. 
$\mathrm{Na}$ amostragem intensiva 1 foi observada uma concentração máxima de $50,2 \mathrm{mg} \mathrm{L}^{-1}$ de MPS, enquanto que na amostragem intensiva 2 a concentração máxima obtida foi de $80,6 \mathrm{mg} \mathrm{L}^{-1}$. Para o período após a realização da colheita de madeira, todas as concentrações de MPS observadas se encontraram maiores que os valores obtidos na amostragem intensiva 1. Tal situação também foi reportada por alguns autores que evidenciaram aumentos na produção de sedimentos após o primeiro ano da realização do corte raso em duas distintas microbacias nos municípios de Itantinga (SP) e Santa Branca (SP), respectivamente (CÂMARA, 1999 e VITAL, 1999).

\subsubsection{Relacionamento concentração-vazão de MPS}

As concentrações de MPS conforme descrito no item 4.5.2., foram normalizadas pelas respectivas vazões (equação 2) e apresentou valores médios para o período de amostragens extensivas de $39,18 \mathrm{mg} \mathrm{L}^{-1}, 32,08 \mathrm{mg} \mathrm{L}^{-1}$ para intensiva 1 e $46,89 \mathrm{mg} \mathrm{L}^{-1}$ para intensiva 2.

No presente estudo foram verificados nas Figuras 40 e 41 os comportamentos dos MPS em função das respectivas vazões nos períodos anteriores e posteriores a colheita de madeira.

O modelo que melhor se ajustou ao comportamento das concentrações do MPS em função das vazões foi o linear, característicos para pequenos rios e de acordo com observado por Probst e Bazerbachi (1986), com coeficientes de correlação significativos ( $p>0,01)$. Pode ser observado pela equação de regressão linear uma maior taxa de transporte de MPS $\left(1,124 \mathrm{mg} \mathrm{s}^{-1}\right)$ durante o período de amostragem intensiva 2 , em comparação com a intensiva $1\left(0,72 \mathrm{mg} \mathrm{s}^{-1}\right)$. Tal fato pode ser atribuído ao período seco anterior às amostragens e ao corte da madeira na área reflorestada, como mencionado anteriormente, que contribuiu para um aumento no escoamento superficial rápido na área de drenagem. 


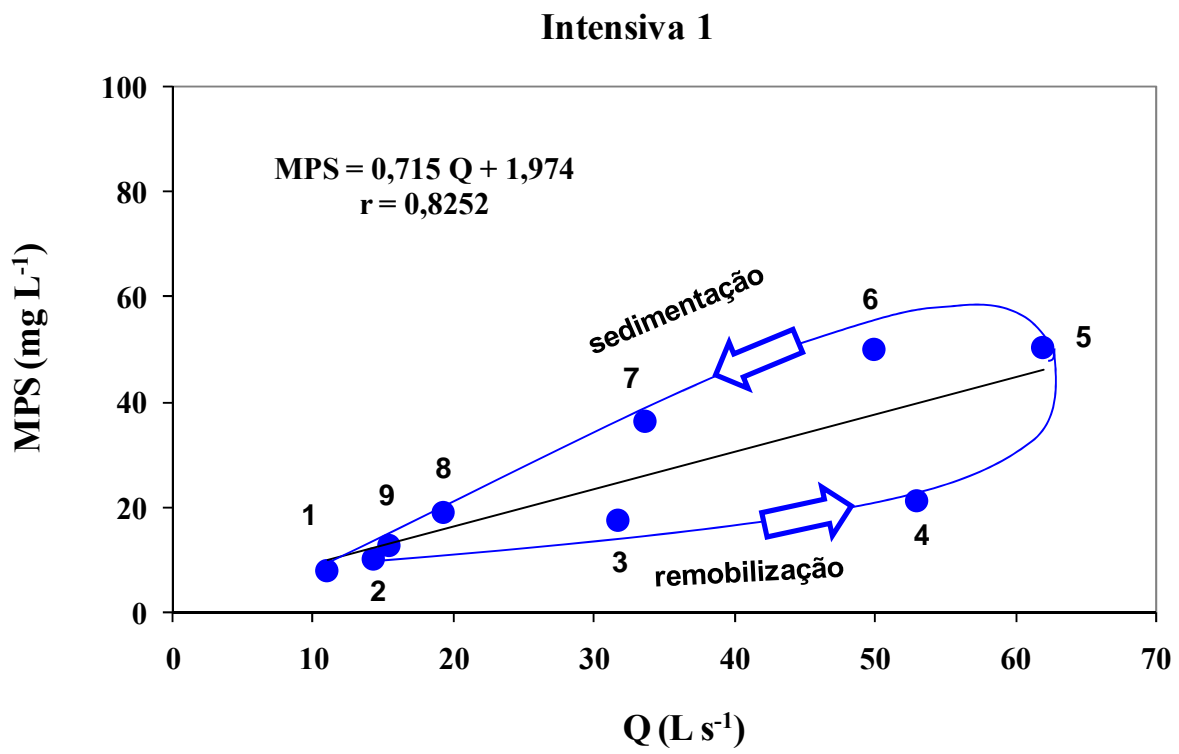

Figuras 40. Variabilidade das concentrações do material particulado em suspensão (MPS) em função da vazão $(\mathrm{Q})$ para o córrego Entre Rios na amostragem intensiva 1.

\section{Intensiva 2}

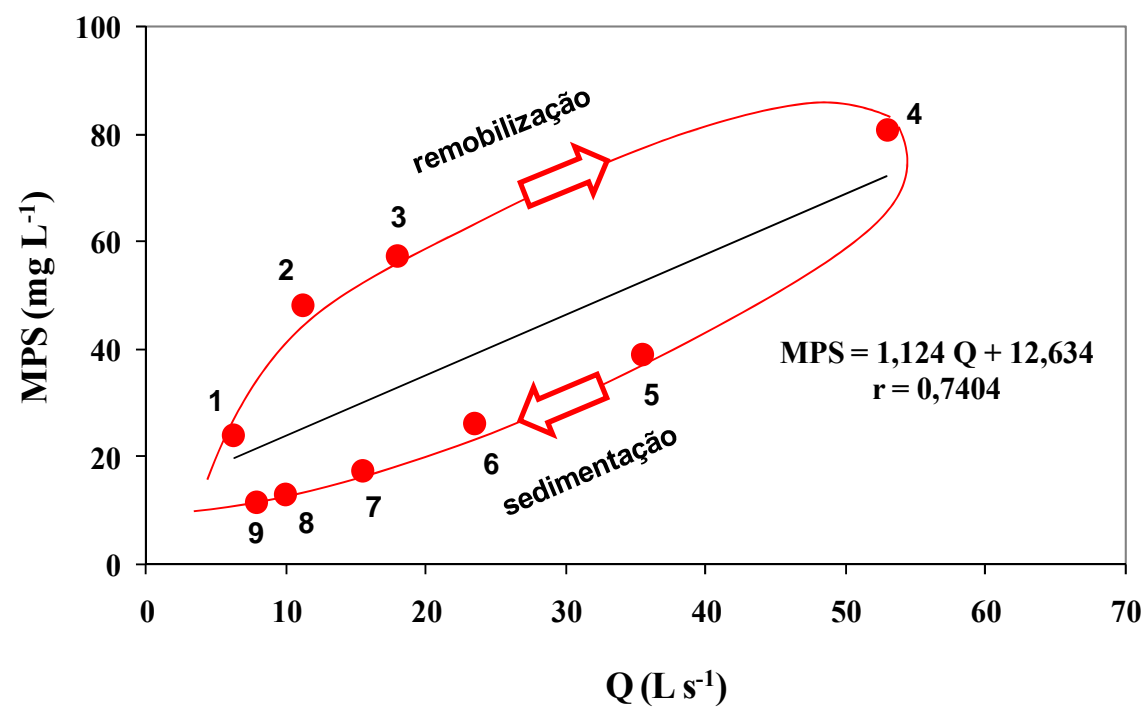

Figuras 41. Variabilidade das concentrações do material particulado em suspensão (MPS) em função da vazão $(\mathrm{Q})$ para o córrego Entre Rios na amostragem intensiva 2. 
Foi possível ainda observar em ambas às amostragens a ocorrência dos processos de remobilização e sedimentação da carga particulada. Durante o processo de remobilização da intensiva 2 (pontos de 1 a 4) as concentrações de MPS se mostraram superiores em relação ao processo de sedimentação (pontos de 4 a 9), com uma variação no sentido horário, característicos desses ambientes fluviais, com subida e descida de água no canal bastante rápida. Por outro lado, durante o período de amostragem intensiva 1, esse processo se inverte, com maiores concentrações de MPS durante a sedimentação, sentido anti-horário. Tal situação pode ter sido influenciada por um período bastante úmido (chuvas intensas) anterior a referida amostragem, apresentando uma subida rápida das águas, mas com um lento processo de recessão, que pode ser melhor verificado em função dos períodos totais dos dois hidrogramas de cheia que na intensiva 1 foi 16,17 horas e a intensiva 2 foi de 13,42 horas.

\subsubsection{Transporte fluvial de MPS}

O transporte fluvial de MPS foi calculado de acordo com a metodologia estocástica descrita no item 4.4.8.1. Na Tabela 14 podem ser observados os resultados dos transportes totais e específicos nos três períodos de observação.

Tabela 14. Resultados do transporte total $\left(\mathrm{T} \mathrm{em} \mathrm{ta}^{-1} \mathrm{e} \mathrm{kg} \mathrm{d}^{-1}\right)$ e específico $\left(\mathrm{T}_{\mathrm{E}} \mathrm{em} \mathrm{t} \mathrm{km} \mathrm{km}^{-2} \mathrm{a}^{-1} \mathrm{e} \mathrm{kg} \mathrm{km}^{-2} \mathrm{~d}^{-1}\right)$ para o MPS nas amostragens extensivas, intensiva 1 e 2, calculados para a microbacia do córrego Entre Rios.

\begin{tabular}{ccccc}
\hline Amostragens & $\mathbf{T}\left(\mathbf{t ~ a}^{\mathbf{- 1}}\right)$ & $\mathbf{T}_{\mathbf{E}}\left(\mathbf{t} \mathbf{~ k m}^{-\mathbf{2}} \mathbf{a}^{-\mathbf{1}}\right)$ & $\mathbf{T} \mathbf{( \mathbf { k g ~ d } ^ { \mathbf { 1 } } )}$ & $\mathbf{T}_{\mathbf{E}}\left(\mathbf{k g ~ k m}^{-\mathbf{2}} \mathbf{d}^{\mathbf{- 1}}\right)$ \\
\hline Extensivas & 19,39 & 12,12 & 53,11 & 33,20 \\
Intensiva 1 & - & - & 89,48 & 55,92 \\
Intensiva 2 & - & - & 81,45 & 50,91 \\
\hline
\end{tabular}


De uma forma geral pode ser observado valores similares em termos de transportes totais e específicos nas duas amostragens intensivas. Foi possível verificar ainda que os valores de transportes na amostragem intensiva 1 foram maiores que os observados na amostragem intensiva 2. Em termos de transporte específico, foram obtidos $55,92 \mathrm{~kg} \mathrm{~km}^{-2} \mathrm{~d}^{-1}$ para intensiva 1 e 50,91 $\mathrm{kg} \mathrm{km}^{-2} \mathrm{~d}^{-1}$ para intensiva 2. Os valores mais elevados obtidos na primeira amostragem intensiva podem ser justificados devido à maior precipitação ocorrida no dia da coleta de $28 \mathrm{~mm}$, enquanto na intensiva 2 foi de $25 \mathrm{~mm}$. Além disso, no referido período o solo encontrou-se em maiores condições de saturação devido à ocorrência de fortes chuvas em dias que antecederam a amostragem. Conforme comentários anteriores, este fato colaborou para que o escoamento superficial rápido exercesse um maior poder erosivo mecânico na carga sólida transportada fluvialmente para o córrego Entre Rios. Tais resultados evidenciaram a importância do estudo de hidrogramas de cheia em microbacias de drenagem.

Nas amostragens extensivas em que foram considerados os picos das duas intensivas, os valores calculados para os transportes totais e específicos, foram respectivamente de $19,39 \mathrm{t} \mathrm{a}^{-1} \mathrm{e}$ $12,12 \mathrm{t} \mathrm{km}^{-2} \mathrm{a}^{-1}$.

\subsubsection{Degradação física da microbacia de drenagem}

De acordo com o transporte específico do MPS na microbacia de drenagem calculado no item 5.3.3., como sendo $12,12 \mathrm{t} \mathrm{km}^{-2} \mathrm{a}^{-1}$ e os valores da densidade média dos solos da região da microbacia, estimados a partir da literatura (Gava, 2005) como sendo 1,43 $\mathrm{t} \mathrm{m}^{-3}$, foi possível calcular a taxa de erosão mecânica para a referida microbacia.

Conforme cálculo realizado com auxílio da equação 17, a erosão mecânica (EM) mostrouse com uma taxa de degradação física dos solos de $8,7 \mathrm{~m} \mathrm{Ma}^{-1}$. A taxa de redução dos solos obtida para a microbacia do córrego Entre Rios se mostrou superior a outras bacias de drenagem 
como a do Congo com 7,4 $\mathrm{m} \mathrm{Ma}^{-1}$ (NKOUNKOU; PROBST, 1987) e Jamari e Ji-paraná com 6,5 $\mathrm{m} \mathrm{Ma}^{-1}$ (MORTATTI et al., 1992). Tal superioridade está associado intenso manejo realizado na microbacia, onde o processo de erosão mecânica é mais intenso do que em áreas naturais como as das bacias citadas acima. Por outro lado, se mostrou inferior quando comparadas as bacias dos rios Tietê e Piracicaba, sob intensa influência antrópica, com 42,6 e 37,0 m Ma ${ }^{-1}$ (BORTOLETTO JÚNIOR, 2004).

\subsection{Aportes atmosféricos totais}

A caracterização dos aportes atmosféricos e a verificação de sua influência na carga dissolvida fluvial foram realizadas de acordo com os procedimentos descritos no item 4.6. do presente estudo. Os resultados das análises químicas para os íons maiores e o total precipitado na microbacia do córrego Entre Rios, são apresentados na Tabelas 15. 
Tabela 15. Resultados de precipitação, pH, TDS e concentrações de cátions e ânions das amostras de água de chuva ocorridas na microbacia de drenagem no período de 13/10/06 a 17/02/08.

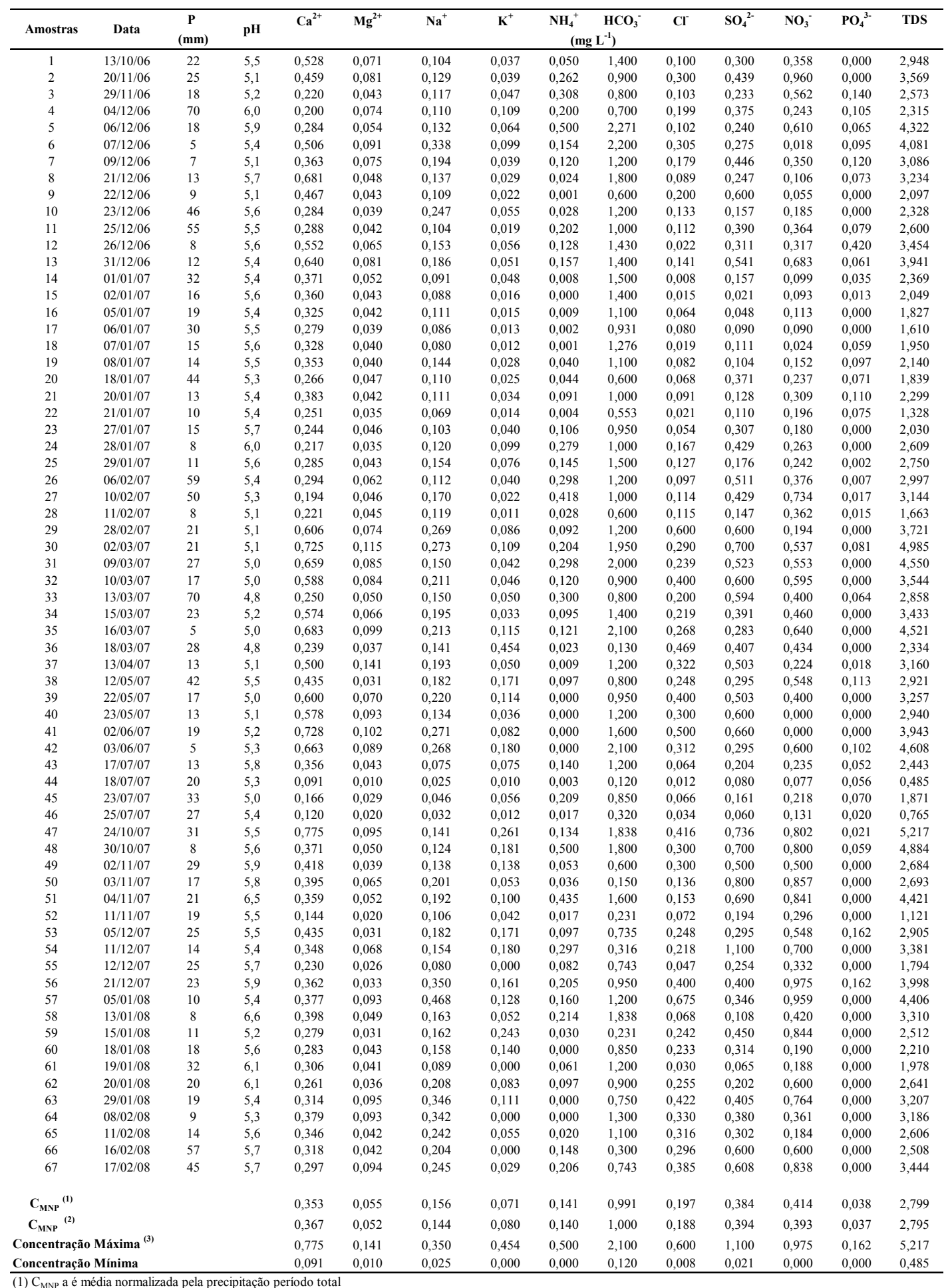

(1) $C_{M N e}$ a é média normalizada pela precipitação para ano de 2007

(3) concentração máxima obtida acima do limite de qualificação

$<0,01$ valor abaixo do limite de qualificação 
O balanço iônico entre as principais espécies químicas nas águas de chuva da microbacia de drenagem Entre Rios calculado em meq L $\mathrm{L}^{-1}$ (Tabela 1C do Apêndice 3) pode ser observado na Figura 42, que representou o relacionamento entre a soma de cátions $\left(\Sigma^{+}\right)$e a soma de ânions $\left(\Sigma^{-}\right)$. O alinhamento 1:1 do equilíbrio iônico foi respeitado com erro máximo de 11,5\%.

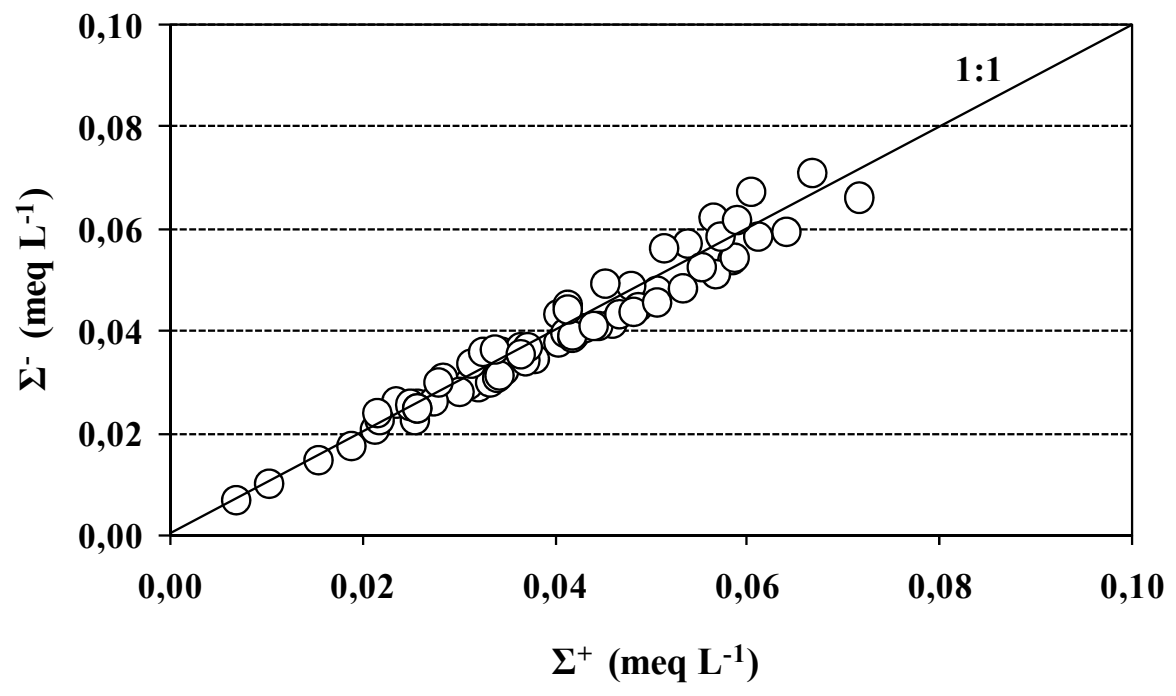

Figura 42. Relacionamento entre a soma de cátions $\left(\Sigma^{+}\right)$e a soma de ânions $\left(\Sigma^{-}\right)$nas amostras de água de chuva na microbacia de drenagem Entre Rios no período de 13/10/2006 a 17/02/2008.

Considerando-se os valores de TDS da Tabela 15 calculados pelas concentrações cátions e ânions, de acordo com Mortatti (1995) e já descrito anteriormente no item 4.3.3. para águas fluviais, foi calculada a abundância relativa (Figura 43) para as espécies químicas de interesse nas águas pluviais da microbacia de drenagem Entre Rios seguindo-se o modelo descrito por Peray (1998). 


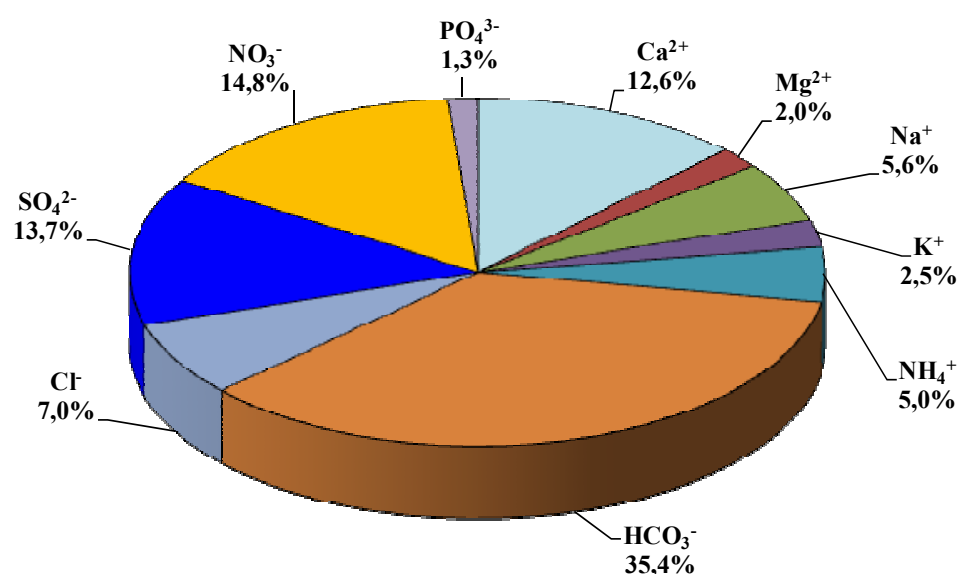

Figura 43. Abundância relativa em porcentagem das principais espécies químicas nas águas pluviais da microbacia de drenagem Entre Rios referente ao período de 13/10/2006 a 17/02/2008.

Como pode ser observado, o $\mathrm{Ca}^{2+}(12,6 \%)$ e $\mathrm{Na}^{+}(5,6 \%)$ foram os cátions que apresentaram valores mais significativos nas amostras de água de chuva, enquanto que para os ânions, os maiores valores para as abundâncias relativas foram o $\mathrm{HCO}_{3}^{-}(35,4 \%), \mathrm{NO}_{3}^{-}(14,8 \%) \mathrm{e}$ $\mathrm{SO}_{4}{ }^{2-}(13,7 \%)$ de acordo com as médias normalizadas pela precipitação relativa ao período de estudo.

As entradas atmosféricas, caracterizadas pelos transportes pluviais (totais e específicos) das principais espécies químicas nas águas da chuva para a microbacia de drenagem Entre Rios foram calculados considerando os totais precipitados de $1466 \mathrm{~mm}$ referente ao período de 01/01/2007 a 21/12/2007. Os cálculos do transporte total $\left(\mathrm{T}_{\mathrm{P}}\right)$ e específico $\left(\mathrm{T}_{\mathrm{PE}}\right)$ foram realizados de acordo com as equações 12 e 13, descritas no item 4.5 considerando-se a área de drenagem da microbacia (Tabela 16). 
Tabela 16. Transporte pluvial total $\left(\mathrm{t} \mathrm{a}^{-1}\right)$ e específico $\left(\mathrm{t} \mathrm{km}^{2} \mathrm{a}^{-1}\right)$ das principais espécies químicas nas águas de chuva da microbacia Entre Rios relativas ao período de 01/01/2007 a 21/12/2007.

\begin{tabular}{cccc}
\hline Espécies & $\mathbf{C}_{\mathbf{M N P}}$ & $\mathbf{T}_{\mathbf{P}}\left(\mathbf{t} \mathbf{a}^{-\mathbf{1}}\right)$ & $\mathbf{T}_{\mathbf{P E}}\left(\mathbf{t ~ k m}^{-\mathbf{2}} \mathbf{a}^{-\mathbf{1}}\right)$ \\
\hline $\mathrm{Ca}^{2+}$ & 0,367 & 0,86 & 0,54 \\
$\mathrm{Mg}^{2+}$ & 0,052 & 0,12 & 0,08 \\
$\mathrm{Na}^{+}$ & 0,144 & 0,34 & 0,21 \\
$\mathrm{~K}^{+}$ & 0,080 & 0,19 & 0,12 \\
$\mathrm{NH}_{4}{ }^{+}$ & 0,140 & 0,33 & 0,20 \\
$\mathrm{HCO}_{3}{ }^{-}$ & 1,000 & 2,35 & 1,47 \\
$\mathrm{Cl}^{-}$ & 0,188 & 0,44 & 0,28 \\
$\mathrm{SO}_{4}{ }^{2-}$ & 0,394 & 0,92 & 0,58 \\
$\mathrm{NO}_{3}{ }^{-}$ & 0,393 & 0,92 & 0,58 \\
$\mathrm{PO}_{4}{ }^{3-}$ & 0,037 & 0,09 & 0,05 \\
$\mathrm{TDS}^{-}$ & 2,795 & 6,56 & 4,10 \\
\hline
\end{tabular}

As espécies químicas mais significativas nos aportes atmosféricos foram $\mathrm{HCO}_{3}{ }^{-}, \mathrm{SO}_{4}{ }^{2-}$, $\mathrm{NO}_{3}{ }^{-}$e $\mathrm{Ca}^{2+}$. O total das principais espécies químicas precipitadas nas águas da chuva (TDS) foi de $6,56 \mathrm{t} \mathrm{a}^{-1}$ que correspondeu em termos de transporte específico a 4,10 $\mathrm{t} \mathrm{km}^{-2} \mathrm{a}^{-1}$.

Foram verificadas nas amostras das águas de chuva as influências dos sais cíclicos marinhos em função da razão com o íon $\mathrm{Cl}^{-}$. De acordo com Stallard e Edmond (1981) e Meybeck (1987) a presença dos íons $\mathrm{Cl}^{-}$nas águas de chuva são geralmente derivadas da reciclagem de sais marinhos na atmosfera.

A Figura 44 ilustra o relacionamento da razão $\mathrm{Ca}^{2+} / \mathrm{Cl}^{-}$das amostras de chuva coletadas no período estudado em comparação com a reta desses sais cíclicos na chuva marinha, de valor igual a 0,019, de acordo com Stallard e Edmond (1981). 


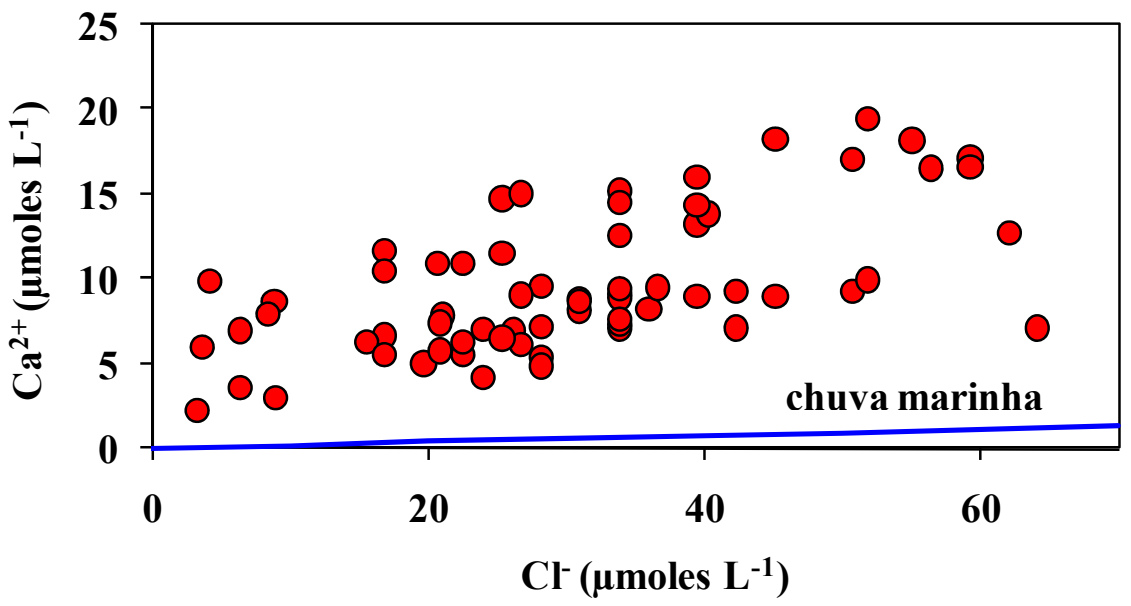

Figura 44. Relacionamento de $\mathrm{Ca}^{2+}$ e $\mathrm{Cl}^{-}$nas amostras analisadas de água de chuva da microbacia de drenagem Entre Rios com a razão $\mathrm{Ca}^{2+} / \mathrm{Cl}^{-}$dos sais cíclicos na chuva marinha, durante o período estudado.

Pode ser observado que o $\mathrm{Ca}^{2+}$ obtido nas chuvas da microbacia de drenagem Entre Rios não foram provenientes de sais marinhos, apesar da pouca distância ao oceano, cerca de $317 \mathrm{~km}$, estando os pontos muito acima da razão 0,019. Desta forma, a origem está associada a emissões terrestres, ligadas a emissões gasosas, via tratos culturais ocorridos na região.

A razão $\mathrm{Mg}^{2+} / \mathrm{Cl}^{-}$dos sais cíclicos na chuva marinha de valor igual a 0,016 Stallard e Edmond (1981), observada na Figura 45, mostrou-se estar associada à emissões terrestres, porém com possível influência dos aportes relacionados à chuva marinha. 


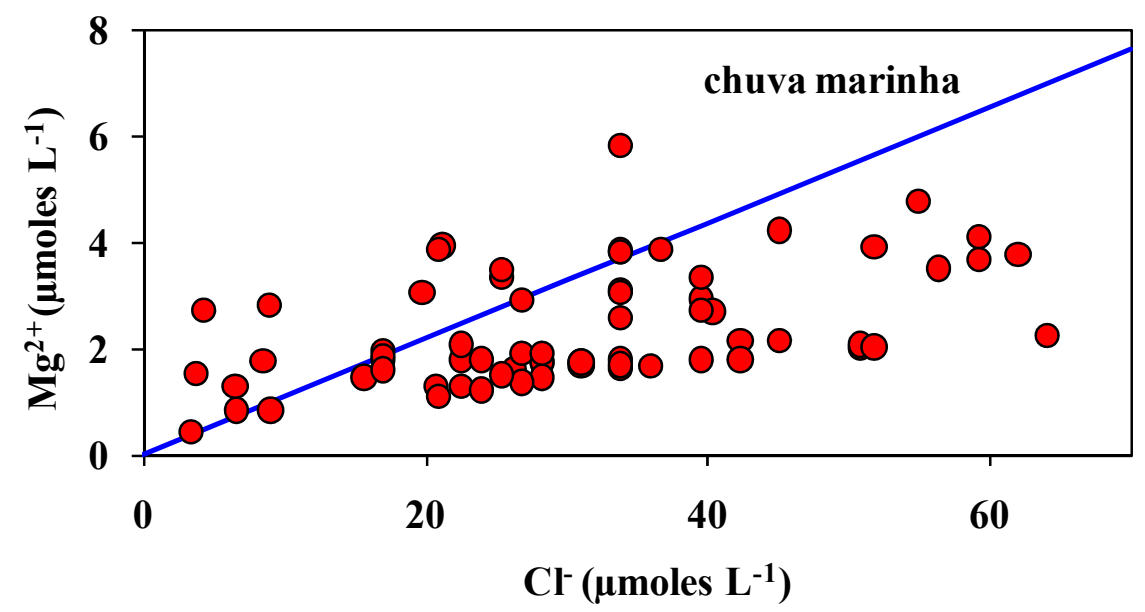

Figura 45. Relacionamento de $\mathrm{Mg}^{2+}$ e $\mathrm{Cl}^{-}$nas amostras analisadas de água de chuva da microbacia de drenagem Entre Rios com a razão $\mathrm{Mg}^{2+} / \mathrm{Cl}^{-}$dos sais cíclicos na chuva marinha, durante o período estudado.

A espécie química $\mathrm{Na}^{+}$mostrou-se ser originado de emissões terrestres com um pouco de sais cíclicos (Figura 46). A razão $\mathrm{Na}^{+} / \mathrm{Cl}^{-}$dos sais cíclicos na chuva marinha foi igual a 0,841 (STALLARD; EDMOND, 1981).

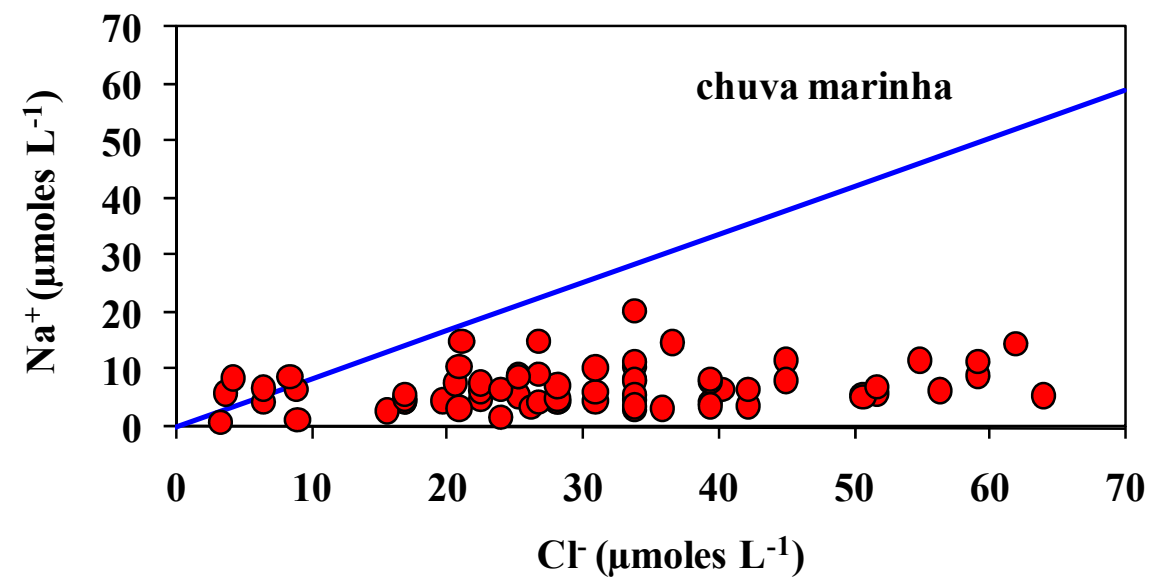

Figura 46. Relacionamento de $\mathrm{Na}^{+}$e $\mathrm{Cl}^{-}$nas amostras analisadas de água de chuva da microbacia de drenagem Entre Rios com a razão $\mathrm{Na}^{+} / \mathrm{Cl}^{-}$dos sais cíclicos na chuva marinha, durante o período estudado. 
A exemplo das espécies anteriores, o comportamento do $\mathrm{K}^{+}$em função do $\mathrm{Cl}^{-}$nas águas de chuva analisadas mostrou-se estar ligada também às emissões terrestres, porém com pouco de sais cíclicos (Figura 47). A razão $\mathrm{K}^{+} / \mathrm{Cl}^{-}$dos sais cíclicos na chuva marinha foi utilizada igual 0,017 (STALLARD; EDMOND, 1981).

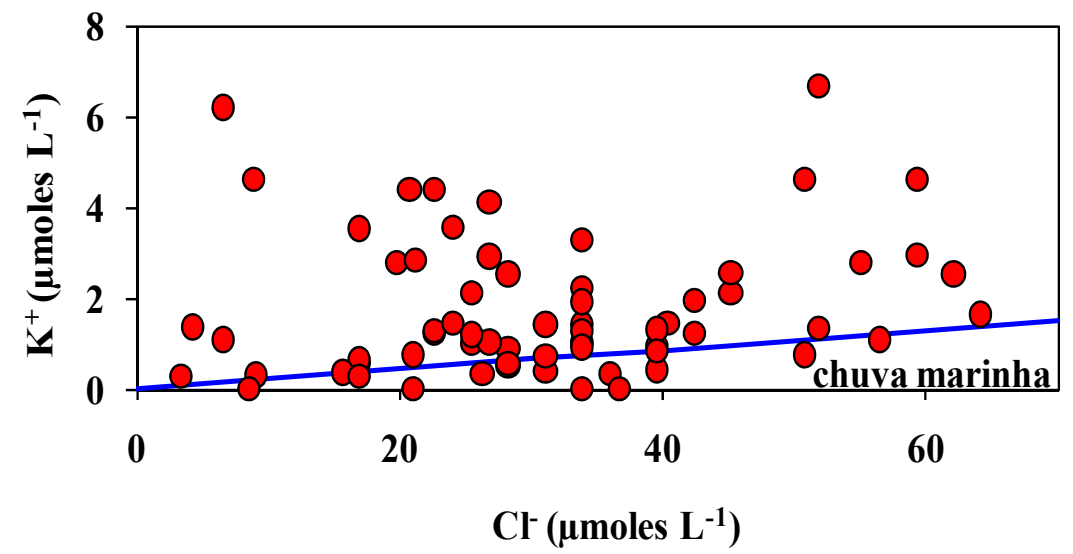

Figura 47. Relacionamento de $\mathrm{K}^{+}$e $\mathrm{Cl}^{-}$nas amostras analisadas de água de chuva da microbacia de drenagem Entre Rios com a razão $\mathrm{K}^{+} / \mathrm{Cl}^{-}$dos sais cíclicos na chuva marinha, durante o período estudado.

A Figura 48 ilustra o comportamento do $\mathrm{SO}_{4}{ }^{2-}$ em função do $\mathrm{Cl}^{-}$nas águas de chuva da microbacia de drenagem Entre Rios e o seu relacionamento com a razão $\mathrm{SO}_{4}{ }^{2-} / \mathrm{Cl}^{-}$utilizando-se valor de 0,127 de acordo com (STALLARD; EDMOND, 1981). Sua origem está relacionada às emissões gasosas via combustão de queima de vegetação, liberação pelas plantas e possivelmente de sais marinhos cíclicos.

As concentrações de $\mathrm{HCO}_{3}{ }^{-}, \mathrm{NO}_{3}{ }^{-}$e $\mathrm{PO}_{4}{ }^{3-}$ não foram comparadas com a chuva marinha. Porém os resultados da razão $\mathrm{NO}_{3}{ }^{-} / \mathrm{Cl}^{-}$e $\mathrm{PO}_{4}{ }^{3-} / \mathrm{Cl}^{-}$das amostras de chuva apresentaram alta dispersão em seus valores e nos induziu a concluir que sua origem poderia estar relacionada às emissões terrestres. Possivelmente a contribuição do $\mathrm{HCO}_{3}{ }^{-}$nas águas pluviais analisadas na 
microbacia se deve à significativa presença de $\mathrm{CO}_{2}$ natural da atmosfera terrestre, que se dissolve em meio à umidade formando $\mathrm{H}_{2} \mathrm{CO}_{3}$, que é um ácido fraco e ioniza-se em $\mathrm{H}^{+}$e $\mathrm{HCO}_{3}{ }^{-}$. (NKOUNKOU; PROBST, 1987; MORTATTI, 1995).

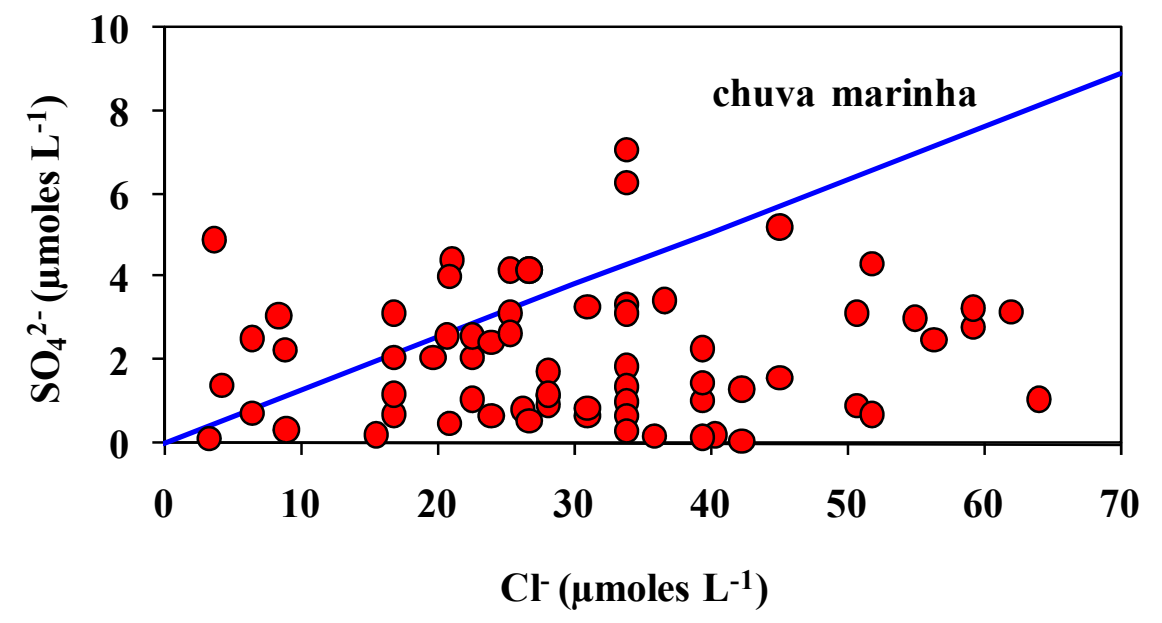

Figura 48. Relacionamento de $\mathrm{SO}_{4}{ }^{2-} \mathrm{e}^{-}$nas amostras analisadas de água de chuva da microbacia de drenagem Entre Rios com a razão $\mathrm{SO}_{4}{ }^{2-} / \mathrm{Cl}^{-}$dos sais cíclicos na chuva marinha, durante o período estudado.

A influência dos aportes atmosféricos e a sua verificação na carga dissolvida fluvial foram realizadas de acordo com os procedimentos descritos no item 4.6. do presente trabalho. Para o cálculo das razões entre o transporte dos principais íons dissolvidos nas águas pluviais e fluviais $\left(\mathrm{t}^{-1}\right)$ foram utilizados os resultados da Tabela 9, item 5.1.8. e da Tabela 16, item 5.3.

Foram obtidas altas razões $(100 \%)$ para os cátions $\mathrm{Ca}^{2+}$ e $\mathrm{Na}^{+}$e para os ânions $\mathrm{SO}_{4}{ }^{2-} \mathrm{e}$ $\mathrm{PO}_{4}{ }^{3-}$ consideradas as amostragens das coletas extensivas e picos das intensivas. Esse resultado permitiu evidenciar o controle dos aportes atmosféricos totais sobre as águas do córrego Entre Rios durante os períodos de recarga do sistema mesmo com a contribuição difusa do intemperismo de rochas da microbacia de drenagem. Menores influências, mais importantes contribuições na química da água do rio pela chuva ocorreram para os cátions $\mathrm{Mg}^{2+}$ e aos ânions 
$\mathrm{HCO}_{3}{ }^{-}$e $\mathrm{Cl}^{-}$com valores de 55,$2 ; 62,1$ e $76,1 \%$ respectivamente. A baixa razão verificada para o $\mathrm{K}^{+}(19,2 \%)$ mostrou pouca contribuição dos aportes pluviais totais na microbacia de drenagem. Isso pode estar associado à influência de insumos agrícolas utilizados na área de estudo uma vez que não foi constatada a presença de minerais contendo $\mathrm{K}^{+}$nos solos pela análise dos difratogramas de raios $\mathrm{X}$. As razões obtidas para íons nitrogenados $\mathrm{NH}_{4}^{+}$e $\mathrm{NO}_{3}^{-}$foram altas (100\%), porém não se pode afirmar sobre o seu controle pela água da chuva na microbacia devido suas formas nitrogenadas não serem conservativas estando a todo momento em processo de transformação, conforme discutido anteriormente.

\subsection{Extração total e sequencial de metais nos solos e sedimentos de fundo}

Os resultados da constituição mineralógica dos solos CXbd, LVAd, LVd, RQo nas profundidades de 0-10, 10-20 e 20-40 cm e sedimentos de fundo (ITA1 e ITA10) utilizando-se da análise de difração de raios $\mathrm{X}$, mostrou pelos espectrogramas em todas as amostras de terra dos quatro distintos solos e para as duas amostras de sedimentos significativa quantidade de quartzo $\left(\mathrm{SiO}_{2}\right)$, bem como a presença de hematita $\left(\mathrm{Fe}_{2} \mathrm{O}_{3}\right)$ e caulinita $\left(\mathrm{Al}_{2} \mathrm{Si}_{2} \mathrm{O}_{5}(\mathrm{OH})_{4}\right)$.

$\mathrm{Na}$ Tabela 17 encontram-se os resultados das análises granulométricas referente às amostras de terra dos quatro principais tipos de solos coletados nas profundidades de $0-10,10-20$ e 20-40 cm. Os valores de areia, silte e argila total estão expressos em porcentagem, apresentando na tabela a classe de textura dos solos e sua densidade em $\mathrm{g} \mathrm{cm}^{-3}$. Exceto para o LATOSSOLO VERMELHO (LVd) de textura argilosa, o CAMBIOSSOLO HÁPLICO (CXbd), LATOSSOLO VERMELHO AMARELO (LVAd) e o NEOSSOLO QUARTZARÊNICO (RQo) foram classificados como textura arenosa. 
Tabela 17. Análises granulométricas dos solos CXbd, LVAd, LVd, e RQo da microbacia Entre Rios, Angatuba, São Paulo.

\begin{tabular}{|c|c|c|c|c|c|c|c|c|}
\hline \multirow{3}{*}{ Tipo } & \multirow{3}{*}{$\begin{array}{l}\text { Prof. } \\
\text { (cm) }\end{array}$} & \multicolumn{4}{|c|}{ Areia } & \multirow{2}{*}{ Silte } & \multirow{2}{*}{$\begin{array}{c}\text { Argila } \\
\text { total } \\
\end{array}$} & \multirow{3}{*}{$\begin{array}{c}\text { Classe } \\
\text { de } \\
\text { textura }\end{array}$} \\
\hline & & grossa & média & fina & muito fina & & & \\
\hline & & \multicolumn{6}{|c|}{$\%$} & \\
\hline \multirow{3}{*}{ Cxbd } & $0-10$ & 3 & 33 & 47 & 9 & 2 & 6 & arenosa \\
\hline & $10-20$ & 3 & 29 & 50 & 10 & 2 & 6 & arenosa \\
\hline & $20-40$ & 4 & 34 & 47 & 7 & 2 & 6 & arenosa \\
\hline \multirow{3}{*}{ LVAd } & $0-10$ & 2 & 20 & 53 & 13 & 4 & 8 & arenosa \\
\hline & $10-20$ & 2 & 20 & 55 & 13 & 2 & 8 & arenosa \\
\hline & $20-40$ & 2 & 25 & 51 & 12 & 2 & 8 & arenosa \\
\hline \multirow{3}{*}{ LVd } & $0-10$ & 1 & 11 & 31 & 7 & 12 & 38 & argilosa \\
\hline & $10-20$ & 0 & 7 & 30 & 10 & 11 & 42 & argilosa \\
\hline & $20-40$ & 1 & 7 & 32 & 7 & 13 & 40 & argilosa \\
\hline \multirow{3}{*}{ RQo } & $0-10$ & 5 & 31 & 42 & 12 & 4 & 6 & arenosa \\
\hline & $10-20$ & 4 & 28 & 44 & 14 & 2 & 8 & arenosa \\
\hline & $20-40$ & 4 & 28 & 42 & 14 & 2 & 10 & arenosa \\
\hline
\end{tabular}

Pode ser observado para o solo CXbd (solo mais influente) que o mesmo é composto de areias médias e finas principalmente, cerca de $80 \%$ do total, evidenciando um baixo poder de retenção de espécies químicas.

Os resultados das análises químicas dos óxidos principais nas amostras das três profundidades dos solos CXbd, LVAd, LVd e RQo representativos da microbacia Entre Rios e duas amostras de sedimentos de fundo ITA1 e ITA10, encontram-se na Tabela 18. Para obtenção da composição química total utilizou-se o método da fusão alcalina de acordo com os protocolos analíticos descritos no item 4.7.

As concentrações dos cátions maiores $\mathrm{CaO}, \mathrm{MgO}, \mathrm{Na}_{2} \mathrm{O}, \mathrm{K}_{2} \mathrm{O}$ e $\mathrm{Mn}_{3} \mathrm{O}_{4}$ observadas no presente estudo foram baixas $(<0,8 \%)$ para todas as amostras de solos e sedimentos. Nas amostras de terra do solo CXbd, não foram observadas variabilidades maiores do que quatro vezes entre as concentrações dos óxidos principais nas amostras de terra em profundidade, exceto 
para o $\mathrm{CaO}$ entre as profundidades de 0-10 e 20-40 cm. As maiores contribuições do solo CXbd que representou $12,7 \%$ da área total foram os elementos $\mathrm{SiO}_{2}(>71 \%), \mathrm{Al}_{2} \mathrm{O}_{3}(>8 \%)$ e também o $\mathrm{Fe}_{2} \mathrm{O}_{3}(>2,5 \%)$. Observou-se ainda que na profundidade de $0-10 \mathrm{~cm}$ houve maior perda ao fogo (P.F.) que certamente foi devido à concentração mais elevada de matéria orgânica.

Tabela 18. Composição química (\%) dos óxidos principais para as amostras de terra nas profundidades de 0-10, 10-20 e 20-40 cm dos solos CXbd, LVAd, LVd e RQo e sedimentos ITA1 e ITA10 na microbacia Entre Rios, Angatuba, São Paulo.

\begin{tabular}{|c|c|c|c|c|c|c|c|c|c|c|c|}
\hline Tipo & $\begin{array}{l}\text { Prof. } \\
\text { (cm) }\end{array}$ & P.F. (\%) & $\mathrm{CaO}$ & $\mathrm{MgO}$ & $\mathrm{Na}_{2} \mathrm{O}$ & $\mathrm{K}_{2} \mathrm{O}$ & $\mathrm{Fe}_{2} \mathrm{O}_{3}$ & $\mathrm{Al}_{2} \mathrm{O}_{3}$ & $\mathrm{Mn}_{3} \mathrm{O}_{4}$ & $\mathrm{SiO}_{2}$ & $\mathrm{P}_{2} \mathrm{O}_{5}$ \\
\hline CXbd & $0-10$ & 14,29 & 0,25 & 0,17 & 0,70 & 0,32 & 3,46 & 9,64 & 0,05 & 71,14 & 0,07 \\
\hline \multirow{3}{*}{ LVAd } & $20-40$ & 6,14 & 0,06 & 0,10 & 0,74 & 0,20 & 2,57 & 8,58 & 0,03 & 78,38 & 0,03 \\
\hline & $0-10$ & 8,64 & 0,07 & 0,09 & 0,57 & 0,15 & 3,03 & 5,69 & 0,04 & 80,31 & 0,02 \\
\hline & $20-40$ & 5,73 & 0,06 & 0,11 & 0,52 & 0,15 & 4,00 & 9,04 & 0,05 & 90,61 & 0,02 \\
\hline \multirow[t]{3}{*}{ LVd } & $0-10$ & 10,11 & 0,06 & 0,44 & 0,45 & 0,18 & 25,03 & 18,48 & 0,30 & 29,49 & 0,02 \\
\hline & $10-20$ & 13,77 & 0,06 & 0,44 & 0,48 & 0,13 & 24,76 & 19,42 & 0,29 & 29,86 & 0,02 \\
\hline & $20-40$ & 11,33 & 0,12 & 0,42 & 0,37 & 0,09 & 24,19 & 18,55 & 0,27 & 27,73 & 0,03 \\
\hline RQo & $0-10$ & 10,86 & 0,20 & 0,17 & 0,15 & 0,16 & 2,31 & 8,42 & 0,03 & 77,68 & 0,04 \\
\hline Sed ITA10 & & 7,94 & 0,13 & 0,20 & 0,32 & 0,74 & 3,18 & 2,39 & 0,06 & 79,25 & 0,01 \\
\hline
\end{tabular}

Nas amostras de terra do solo LVAd, não foram observadas variações significativas (quatro vezes) entre as concentrações dos óxidos em relação às três profundidades. Os óxidos que mais contribuíram para este solo que representou $21,0 \%$ da área total da microbacia do córrego Entre Rios foram o $\mathrm{SiO}_{2}(>80 \%), \mathrm{Al}_{2} \mathrm{O}_{3}(>5 \%)$ e $\mathrm{Fe}_{2} \mathrm{O}_{3}(>3,0 \%)$.

Para as amostras de terra do solo LVd, não foram observadas variações significativas (quatro vezes) entre as concentrações dos óxidos em profundidade. As contribuições dos óxidos para este solo que representou cerca de $17,2 \%$ da área da microbacia foram o $\mathrm{SiO}_{2}(>27 \%)$, $\mathrm{Fe}_{2} \mathrm{O}_{3}(>24 \%)$ e $\mathrm{Al}_{2} \mathrm{O}_{3}(>18 \%)$. 
Com relação às amostras de terra do solo RQo, foi observada pequena variabilidade (três vezes) entre as concentrações de $\mathrm{CaO}$ nas profundidades de 0-10 e 10-20 cm. Este solo representou $21,2 \%$ da área da microbacia e as maiores contribuições foram dos $\mathrm{SiO}_{2}(>77 \%)$, $\mathrm{Al}_{2} \mathrm{O}_{3}(>7 \%)$ e $\mathrm{Fe}_{2} \mathrm{O}_{3}(>2,2 \%)$.

Para as amostras de sedimentos ITA1 e ITA10, não foram observadas diferenças significativas (quatro vezes) entre as concentrações dos óxidos nas amostras. As maiores contribuições foram do $\mathrm{SiO}_{2}(>79 \%), \mathrm{Al}_{2} \mathrm{O}_{3}$ e $\mathrm{Fe}_{2} \mathrm{O}_{3}(>2,6 \%)$.

Em termos gerais, o $\mathrm{SiO}_{2}$ foi o óxido que apresentou maior contribuição para a microbacia ( $>70 \%$ ) para os solos CXbd, LVAd e RQo. O alto teor de $\mathrm{SiO}_{2}$ encontrado pode ser justificado pela presença de solos arenosos que possuem predominância de quartzo. O solo LVd classificado como argiloso (Tabela 18) teve concentrações de óxidos de alumínio (> 18\%) e ferro ( $>24 \%)$ que podem ter sido originadas de minerais primários como a gibsita $\left(\mathrm{Al}_{2} \mathrm{O}_{3}\right)$ e hematita $\left(\mathrm{Fe}_{2} \mathrm{O}_{3}\right)$ constituintes principais da fração argila em latossolos (KER, 1997).

Foi possível verificar pelos resultados obtidos uma maior concentração de $\mathrm{Fe}_{2} \mathrm{O}_{3}$ e $\mathrm{Al}_{2} \mathrm{O}_{3}$ em relação ao $\mathrm{SiO}_{2}$ no solo LVd.

De acordo com o procedimento descrito no item 4.7., promoveu-se a extração total dos metais $\mathrm{Cr}, \mathrm{Cd}, \mathrm{Pb}, \mathrm{Ni}, \mathrm{Co}, \mathrm{Cu}, \mathrm{Zn}$ e $\mathrm{Sc}$ nos solos e sedimentos de fundo da microbacia do córrego Entre Rios. Os resultados obtidos dos principais metais pesados para as amostras de solos nas profundidades de 0-10, 10-20 e 20-40 cm da microbacia Entre Rios encontram-se na Tabela 19. 
Tabela 19. Composição química $\left(\mu \mathrm{g} \mathrm{g}^{-1}\right)$ dos metais pesados principais nas amostras de solos da microbacia de drenagem Entre Rios.

\begin{tabular}{|c|c|c|c|c|c|c|c|c|c|}
\hline \multirow{2}{*}{ Tipo } & \multirow{2}{*}{ Prof. (cm) } & $\mathrm{Cr}$ & $\mathrm{Cd}$ & $\mathrm{Pb}$ & $\mathrm{Ni}$ & $\mathrm{Co}$ & $\mathrm{Cu}$ & $\mathrm{Zn}$ & $\mathrm{Sc}$ \\
\hline & & \multicolumn{8}{|c|}{$\left(\mu \mathrm{g} \mathrm{g}^{-1}\right)$} \\
\hline CXbd & $0-10$ & 27,64 & 2,66 & n.d. & n.d. & 10,54 & 25,94 & 36,90 & 5,29 \\
\hline CXbd & $10-20$ & 28,78 & 2,31 & n.d. & n.d. & 10,23 & 16,25 & 23,86 & 5,09 \\
\hline CXbd & $20-40$ & 26,30 & 2,29 & n.d. & n.d. & 6,72 & 11,93 & 22,50 & 5,38 \\
\hline LVAd & $0-10$ & 24,33 & 2,07 & n.d. & n.d. & 15,39 & 39,09 & 36,63 & 3,15 \\
\hline LVAd & $10-20$ & 24,27 & 2,47 & n.d. & n.d. & 13,45 & 12,17 & 35,73 & 4,30 \\
\hline LVAd & $20-40$ & 23,48 & 2,25 & n.d. & n.d. & 13,04 & 10,06 & 34,18 & 6,84 \\
\hline $\mathrm{LVd}$ & $0-10$ & 90,68 & 4,31 & 23,18 & 47,63 & 186,46 & 207,84 & 170,35 & 41,39 \\
\hline LVd & $10-20$ & 87,90 & 3,60 & 19,84 & 49,32 & 187,21 & 207,22 & 153,44 & 49,75 \\
\hline $\mathrm{LVd}$ & $20-40$ & 89,50 & 3,80 & 24,23 & 48,62 & 178,54 & 205,73 & 145,10 & 40,70 \\
\hline RQo & $0-10$ & 37,99 & 2,39 & n.d. & n.d. & 4,98 & 13,65 & n.d. & 4,76 \\
\hline RQo & $10-20$ & 24,82 & 2,02 & n.d. & n.d. & 3,93 & 12,68 & n.d. & 5,43 \\
\hline RQo & $20-40$ & 26,25 & 2,11 & n.d. & n.d. & 4,34 & 6,87 & n.d. & 5,03 \\
\hline ITA1 & & 32,97 & 2,99 & n.d. & n.d. & 17,62 & 17,92 & 34,81 & 3,10 \\
\hline ITA10 & & 31,57 & 2,80 & n.d. & n.d. & 17,32 & 17,45 & 43,21 & 3,09 \\
\hline
\end{tabular}

n.d. - não determinado

Pode ser observado que os teores de $\mathrm{Cr}, \mathrm{Co}, \mathrm{Cu}, \mathrm{Zn}$ e $\mathrm{Sc}$ foram os mais elevados e correspondem às amostras do solo LVd nas três profundidades estudadas em relação às demais amostras de solos. Já para o Cd as concentrações foram semelhantes entre as amostras de solos em todas as profundidades. Foi observado que as concentrações de $\mathrm{Pb}$ e Ni nas amostras do solo LVd não variaram significativamente entre as profundidades. Características do LVd como textura argilosa e elevado grau de alteração de rochas podem justificar esses elevados teores. De maneira geral pode ser observado que as concentrações dos metais pesados não variaram entre as amostras dos solos e sedimentos de fundo, exceto para o Co e Zn nas amostras dos solos RQo para as profundidades estudadas que apresentaram baixas concentrações.

A análise de metais pesados em solos e sedimentos de fundo tem sido utilizada para um melhor entendimento das cargas críticas e grau de toxicidade desses metais em função das influências antrópicas em bacias e de drenagem. No presente estudo, verificou-se a distribuição dos principais metais pesados nos solos e sedimentos de fundo do córrego Entre Rios, conforme 
descrito no item 4.7. Os resultados das concentrações $\left(\mu \mathrm{g} \mathrm{g}{ }^{-1}\right)$ dos principais metais pesados nas frações biodisponível (S1 a S7) e residual para as amostras de solos e sedimentos de fundo ITA1 e ITA10 da microbacia Entre Rios encontram-se na Tabela 1D a 9D (Apêndice 4). As Figuras de 49 a 79 mostram a distribuição dos metais (\%) estudados extraídos seletivamente nos solos e sedimentos de fundo na microbacia do córrego Entre Rios

O elemento $\mathrm{Cr}$ no solo $\mathrm{CXbd}$, variou em aproximadamente $49 \%$ na profundidade de $0-10$ $\mathrm{cm}$ e $57 \%$ da fração residual nas profundidades de $10-20$ e $20-40 \mathrm{~cm}$, respectivamente (Figura 49). Na profundidade de $0-10 \mathrm{~cm}$, os $51 \%$ referentes à fração lábil foram distribuídos em $26 \%$ associados aos óxidos de ferro cristalino (S6), 13\% aos trocáveis $(\mathrm{S} 2), 8 \%$ à matéria orgânica (S7) e $4 \%$ aos óxidos de ferro amorfo (S5). Na profundidade de $10-20 \mathrm{~cm}$, os $43 \%$ referentes à fração lábil foram distribuídos em $22 \%$ associados aos óxidos de ferro cristalino (S6), $12 \%$ aos trocáveis (S2), 7\% à matéria orgânica (S7) e $2 \%$ aos óxidos de ferro amorfo (S5). Na profundidade de $20-40 \mathrm{~cm}$, os $43 \%$ referentes à fração lábil foram distribuídos em $20 \%$ associados aos óxidos de ferro cristalino (S6), 10\% aos trocáveis (S2), 9\% à matéria orgânica (S7), 3\% aos óxidos de ferro amorfo (S5) e 1\% aos ácidos solúveis (S3). 


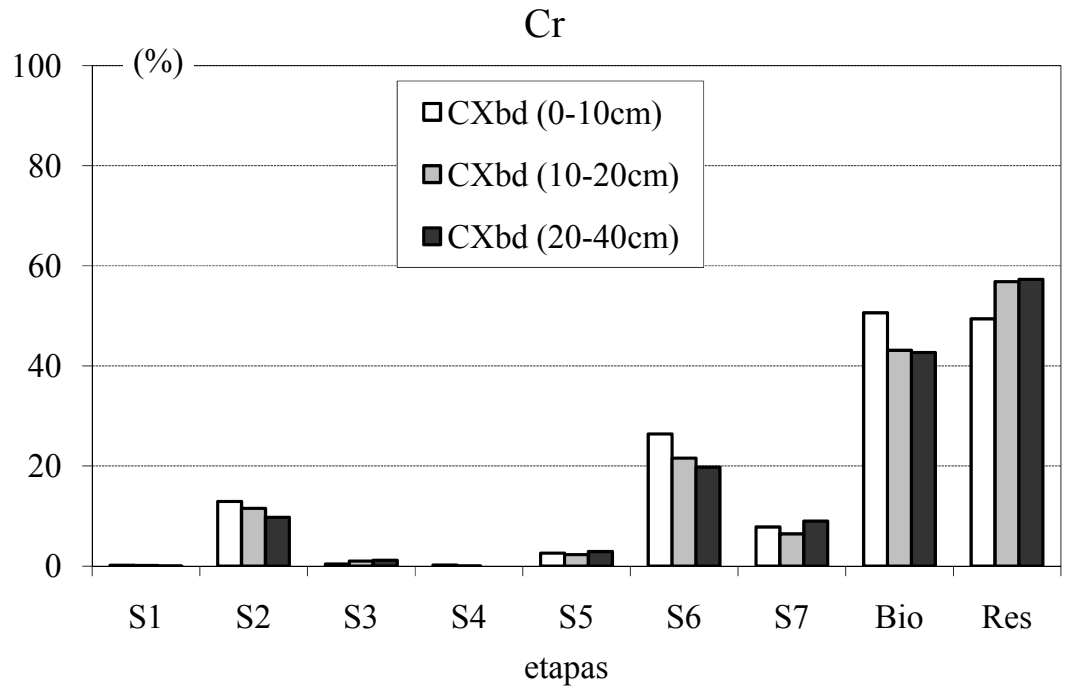

Figura 49. Porcentagem de Cr lixiviado nas etapas de S1 a S7, frações biodisponível (Bio) e residual (Res) para o solo CXbd, na microbacia Entre Rios, Angatuba, São Paulo.

No LVAd, houve contribuição da fração residual de aproximadamente $50 \%$ nas profundidades de $0-10$ e $10-20 \mathrm{~cm}$ e $61 \%$ para a profundidade de $20-40 \mathrm{~cm}$, respectivamente (Figura 50). A fração biodisponível, cerca de 50\% da profundidade de 0-10 cm, esteve associada em $23 \%$ associados aos óxidos de ferro cristalinos (S6), 13\% aos trocáveis (S2), 11\% à matéria orgânica (S7) e 3\% aos óxidos de ferro amorfo (S5). Na profundidade de $10-20 \mathrm{~cm}$, os $50 \%$ referentes à fração lábil foram distribuídos em $26 \%$ associados aos óxidos de ferro cristalinos (S6), 11\% aos trocáveis (S2), 6\% à matéria orgânica (S7), 6\% aos óxidos de ferro amorfo (S5) e $1 \%$ aos ácidos solúveis (S3). Na profundidade de $20-40 \mathrm{~cm}$, os $39 \%$ referentes à fração biodisponível estavam distribuídos cerca de 14\% associados aos óxidos de ferro cristalinos (S6), $12 \%$ aos trocáveis $(\mathrm{S} 2), 10 \%$ à matéria orgânica $(\mathrm{S} 7)$ e $2 \%$ aos óxidos de ferro amorfo $(\mathrm{S} 5)$ e $1 \%$ aos ácidos solúveis (S3). 


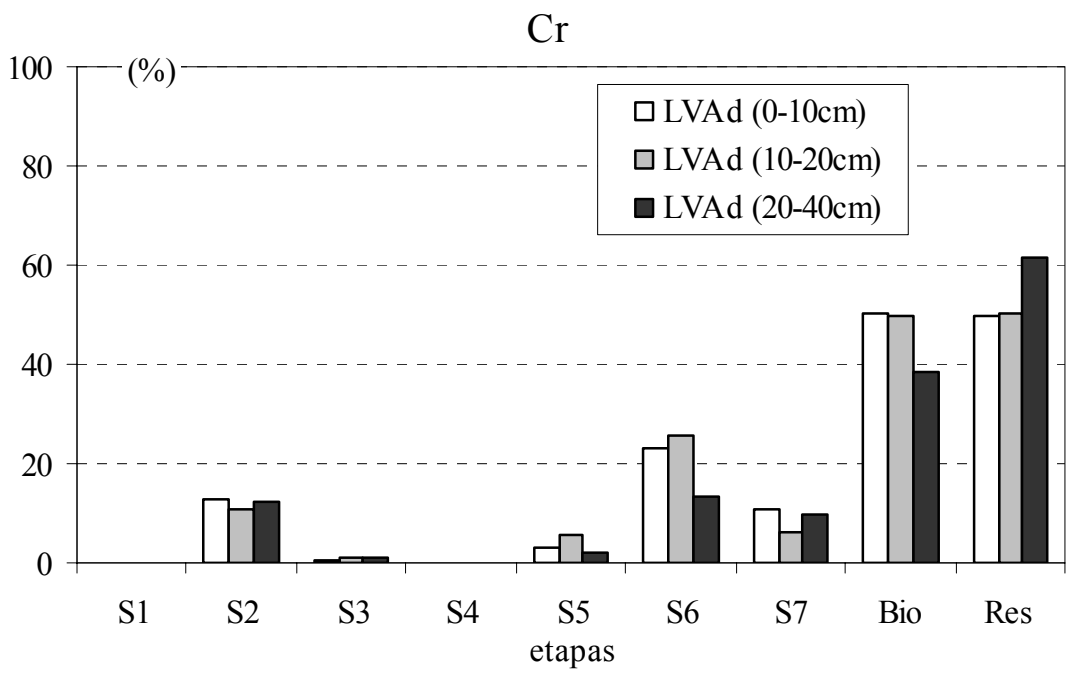

Figura 50. Porcentagem de Cr lixiviado nas etapas de S1 a S7, frações biodisponível (Bio) e residual (Res) para o solo LVAd, na microbacia Entre Rios, Angatuba, São Paulo.

Para o solo LVd houve distribuição em $72 \%$ da fração residual para a profundidade de 0 $10 \mathrm{~cm}$ e $73 \%$ para a profundidade de $10-20$ e $20-40 \mathrm{~cm}$ (Figura 51). Na profundidade de $0-10 \mathrm{~cm}$, os $28 \%$ referentes à fração lábil foram distribuídos em $17 \%$ associados aos óxidos de ferro cristalinos (S6), 4\% aos óxidos de ferro amorfo (S5) e à matéria orgânica (S7) e 3\% trocáveis (S2). Na profundidade de $10-20 \mathrm{~cm}$, os $27 \%$ referentes à fração lábil foram distribuídos em cerca de $20 \%$ associados aos óxidos de ferro cristalinos (S6), 3\% aos óxidos de ferro amorfo (S5) e 1\% à matéria orgânica (S7) e $3 \%$ aos trocáveis (S2). Na profundidade de 20-40 cm, os 27\% referentes à fração biodisponível estavam em aproximadamente $21 \%$ associados aos óxidos de ferro cristalinos $(\mathrm{S} 6), 3 \%$ aos trocáveis $(\mathrm{S} 2), 2 \%$ à matéria orgânica $(\mathrm{S} 7)$ e 1\% aos óxidos de ferro amorfo (S5). 


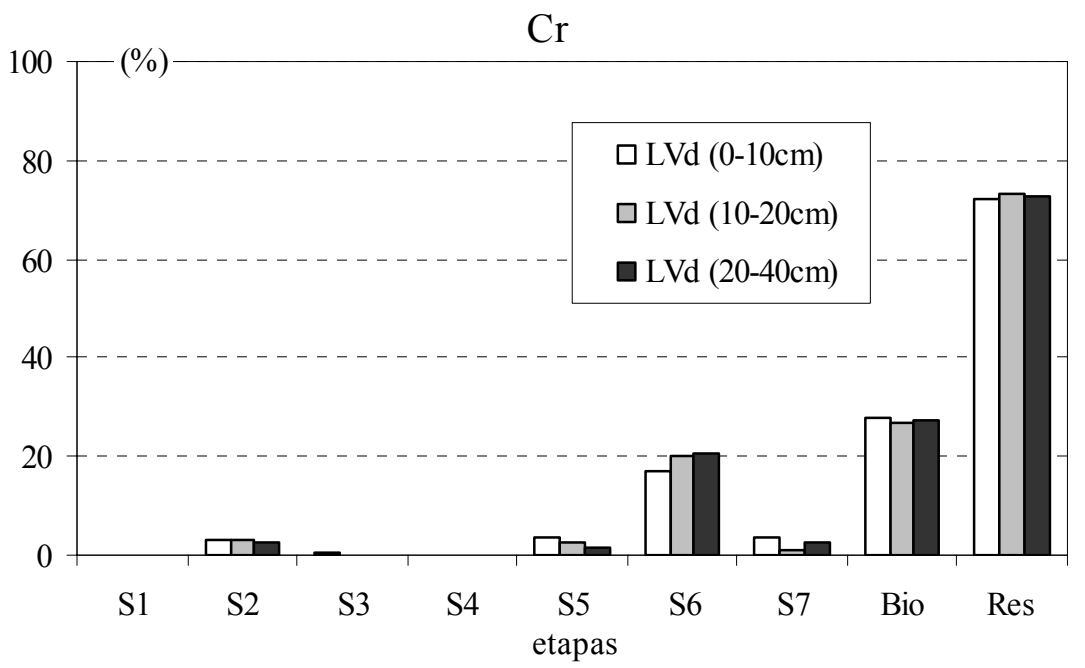

Figura 51. Porcentagem de Cr lixiviado nas etapas de S1 a S7, frações biodisponível (Bio) e residual (Res) para o solo LVd, na microbacia Entre Rios, Angatuba, São Paulo.

Para o solo RQo houve a contribuição aproximadamente de 54\% para a profundidade de 0-10 cm e 64 e $65 \%$ para as profundidades $10-20$ e 20-40 cm na fração residual, respectivamente (Figura 52). Os 29\% referentes à fração biodisponível $(0-10 \mathrm{~cm})$, foram associadas em 13\% aos óxidos de ferro cristalinos (S6), 7\% trocáveis (S2) e à matéria orgânica $(\mathrm{S} 7)$ e 1\% aos óxidos de ferro amorfo (S5) e aos ácidos solúveis (S3). Na profundidade de 10-20 cm, os 36\% referentes à fração lábil foram distribuídos em $20 \%$ associados aos óxidos de ferro cristalinos (S6), $8 \%$ trocáveis (S2), 5\% à matéria orgânica (S7), 2\% aos ácidos solúveis (S3) e 1\% aos óxidos de ferro amorfo (S5). Na profundidade de $20-40 \mathrm{~cm}$, os $35 \%$ referentes à fração biodisponível estavam aproximadamente 14\% associados aos óxidos de ferro cristalinos (S6), 9\% à matéria orgânica (S7), $8 \%$ aos trocáveis (S2), $2 \%$ aos óxidos de ferro amorfo (S5) e 2\% aos ácidos solúveis (S3). 
$\mathrm{Cr}$

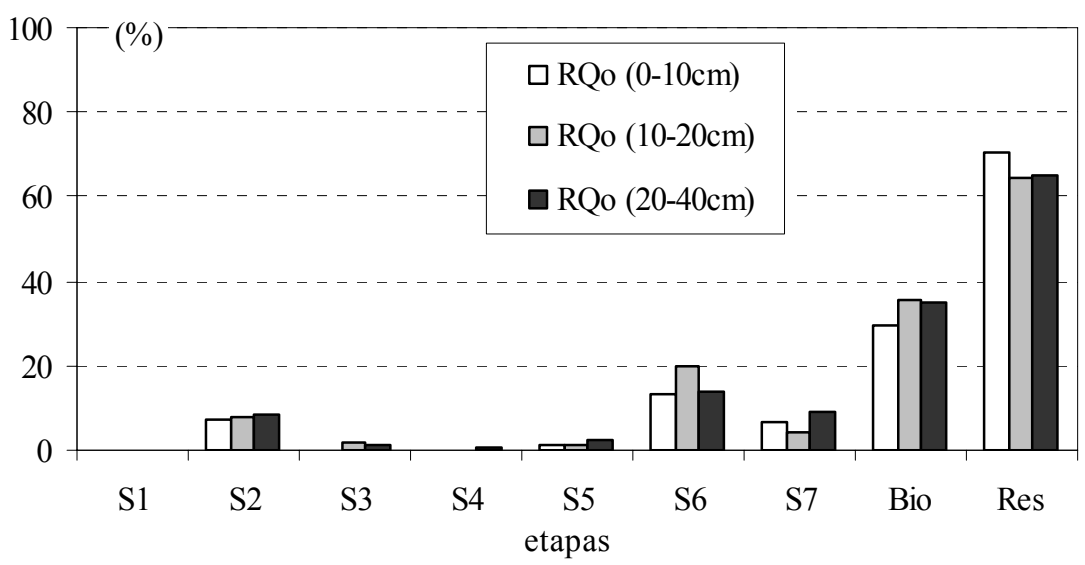

Figura 52. Porcentagem de Cr lixiviado nas etapas de S1 a S7, frações biodisponível (Bio) e residual (Res) para o solo RQo, na microbacia Entre Rios, Angatuba, São Paulo.

Para as amostras de sedimentos de fundo ITA1 e ITA10, houve diferenças significativas na fração residual, de 58 e 70\%, respectivamente. Para a amostra ITA1 (Figura 53), cerca de 42\% da fração lábil distribuíram-se em cerca de $17 \%$ associados aos óxidos de ferro cristalinos (S6), $9 \%$ à matéria orgânica $(\mathrm{S} 7), 8 \%$ trocáveis $(\mathrm{S} 2), 7 \%$ aos óxidos de ferro amorfo $(\mathrm{S} 5)$ e 1\% aos ácidos solúveis (S3). Para a amostra ITA10, os 30\% referentes à fração biodisponível, foram distribuídos em $11 \%$ aos óxidos de ferro cristalinos (S6), 7\% aos trocáveis (S2) e à matéria orgânica (S7), 4\% aos óxidos de ferro amorfo (S5) e 1\% aos ácidos solúveis (S3). 


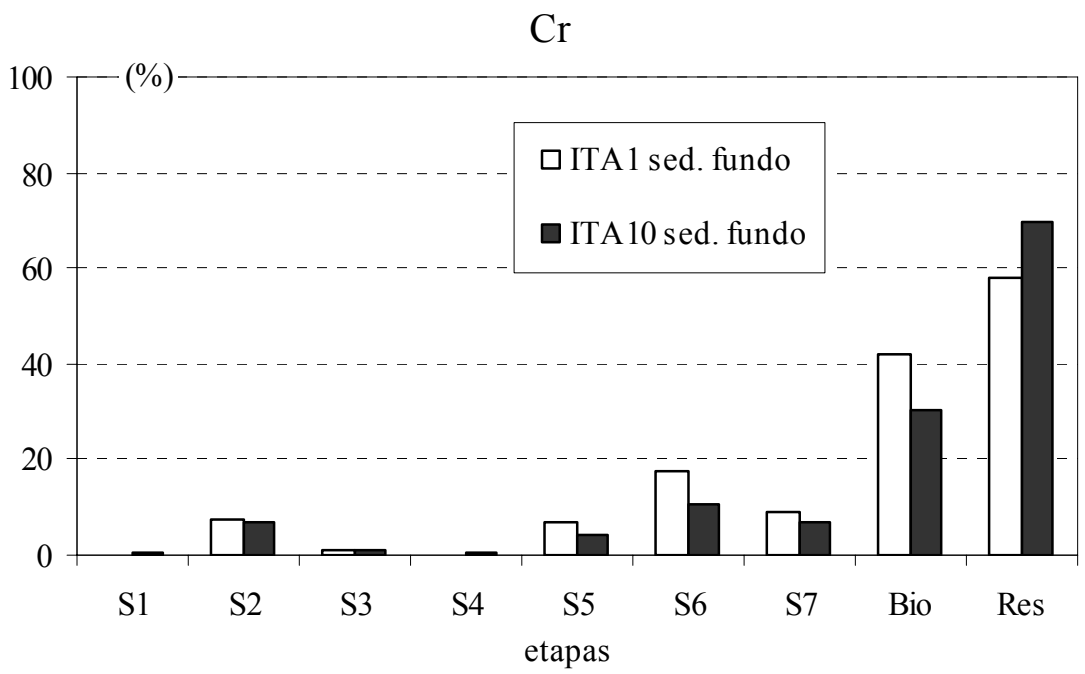

Figura 53. Porcentagem de Cr lixiviado nas etapas de S1 a S7, frações biodisponível (Bio) e residual (Res) para as amostras de sedimentos de fundo ITA1 e ITA10 coletadas no período chuvoso e seco, respectivamente, na microbacia Entre Rios, Angatuba, São Paulo.

De maneira geral, foi observado que o $\mathrm{Cr}$ teve maiores porcentagens das frações biodisponíveis nas amostras dos solos e sedimentos da microbacia de drenagem principalmente ligados aos óxidos de ferro cristalino (S6).

Na Figura 54 pode ser observado para as amostras de solo CXbd nas profundidades de 0$10,10-20$ e $20-40 \mathrm{~cm}, 66,70$ e $74 \%$, respectivamente na fração residual. Na fração lábil ou biodisponível da profundidade de $0-10 \mathrm{~cm}$ os $34 \%$ da fração biodisponível, distribui-se em $21 \%$ associados aos óxidos de ferro cristalinos (S6), 7\% aos trocáveis (S2), 3\% aos óxidos de ferro amorfo (S5) e 1\% à matéria orgânica (S7), aos óxidos de manganês (S4) e dissolvida em água (S1). Na profundidade de $10-20 \mathrm{~cm}$, os $30 \%$ da fração biodisponível foram distribuídos em $16 \%$ associados aos óxidos de ferro cristalinos (S6), 7\% à matéria orgânica (S7), 3\% aos ácidos solúveis (S3) e trocáveis (S2) e 1\% aos óxidos de manganês (S4) e óxidos de ferro amorfo (S5). Na profundidade de $20-40 \mathrm{~cm}$, os $26 \%$ da fração biodisponível foram associados em $12 \%$ aos óxidos de ferro cristalinos (S6), 6\% aos ácidos solúveis (S3), 4\% à matéria orgânica (S7), 3\% aos 
óxidos de manganês (S4) e 1\% aos óxidos de ferro amorfo (S5).

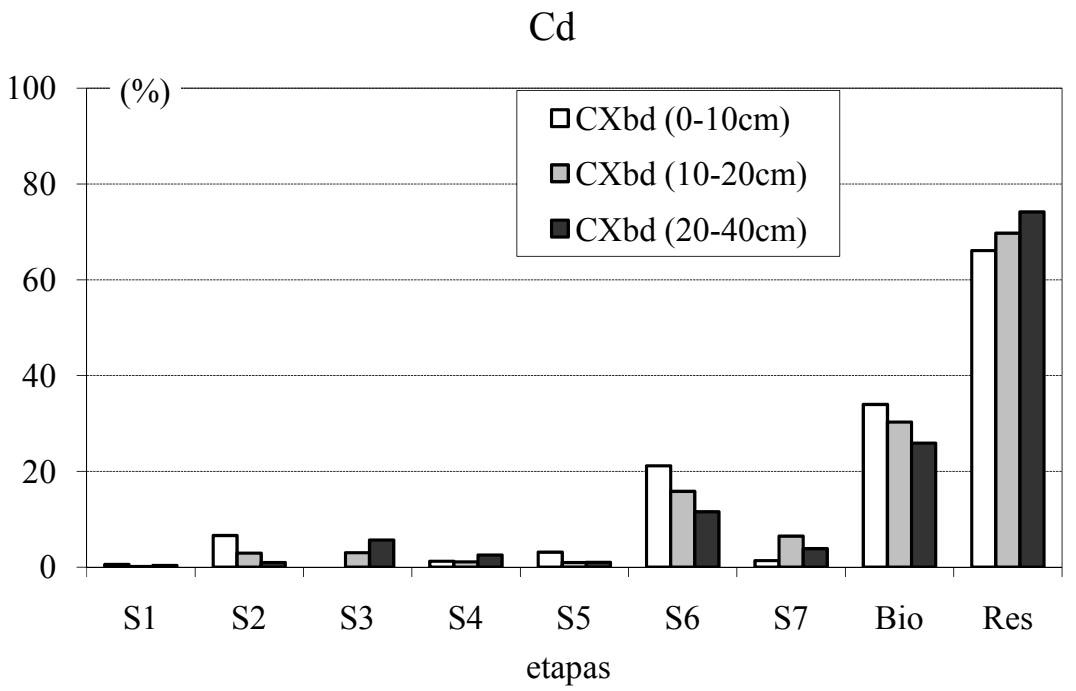

Figura 54. Porcentagem de Cd lixiviado nas etapas de S1 a S7, frações biodisponível (Bio) e residual (Res) para o solo CXbd, na microbacia Entre Rios, Angatuba, São Paulo.

No LVAd, a fração residual representou 57, 62 e 93\%, para as profundidades de 0-10, 10 20 e 20-40 cm, respectivamente (Figura 55). Na profundidade de 0-10 cm, a fração lábil contribuiu em $43 \%$ e distribuiu-se em $16 \%$ associados aos óxidos de ferro cristalinos (S6), 12\% aos trocáveis $(\mathrm{S} 2), 6 \%$ à matéria orgânica $(\mathrm{S} 7), 4 \%$ aos ácidos solúveis $(\mathrm{S} 3), 3 \%$ aos óxidos de ferro amorfo (S5) e 2\% aos óxidos de manganês (S4). Na profundidade de $10-20 \mathrm{~cm}$, os $38 \%$ da fração biodisponível foram distribuídos em 17\% associados aos óxidos de ferro cristalinos (S6), $6 \%$ aos trocáveis (S2), aos ácidos solúveis e óxidos de ferro amorfo (S5), 3\% aos óxidos de manganês (S4). Na profundidade de 20-40 cm, os $10 \%$ da fração biodisponível foram distribuídos em 5\% associados aos óxidos de ferro cristalinos (S6) e aos trocáveis (S2). 


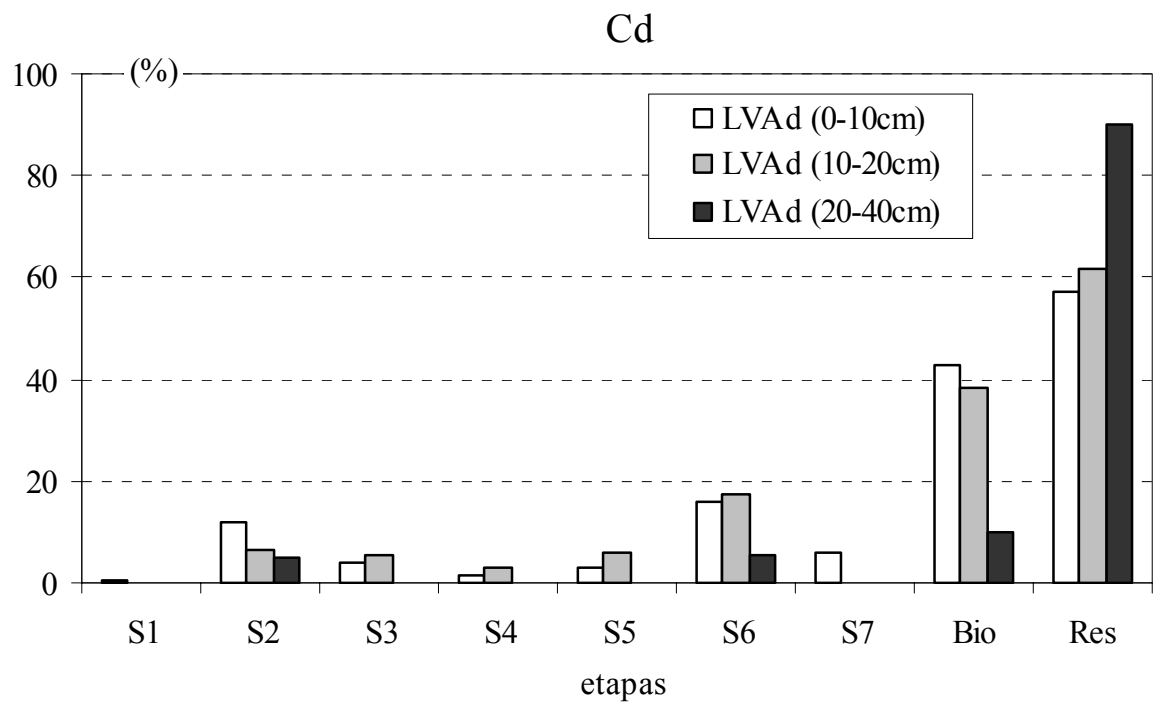

Figura 55. Porcentagem de Cd lixiviado nas etapas de S1 a S7, frações biodisponível (Bio) e residual (Res) para o solo LVAd, na microbacia Entre Rios, Angatuba, São Paulo.

Para o LVd houve apenas $0,2 \%$ de contribuição da fração residual para as profundidades de $0-10,11 \%$ para a profundidade $10-20 \mathrm{~cm}$ e cerca de $1 \%$ da fração residual na profundidade 20-40 cm (Figura 56). Na profundidade de 0-10 cm, os 99,8 \% referentes à fração lábil esteve associada em 73\% aos óxidos de ferro cristalinos (S6), 12\% aos óxidos de ferro amorfo (S5), 5\% aos ácidos solúveis $(\mathrm{S} 3)$ e trocáveis $(\mathrm{S} 2)$ e 4,8\% à matéria orgânica $(\mathrm{S} 7)$. Na profundidade de 10$20 \mathrm{~cm}$, os $89 \%$ da fração biodisponível foram distribuídos em 53\% aos óxidos de ferro cristalinos (S6), 12\% à matéria orgânica (S7), 11\% aos óxidos de ferro amorfo (S5), 10\% associados aos ácidos solúveis (S3) e 3\% aos trocáveis (S2). Na profundidade de 20-40 cm, os 99\% da fração biodisponível foram distribuídos cerca de $75 \%$ associados aos óxidos de ferro cristalinos (S6), $16 \%$ à matéria orgânica (S7) e 4\% aos trocáveis (S2) e aos óxidos de ferro amorfo (S5). 


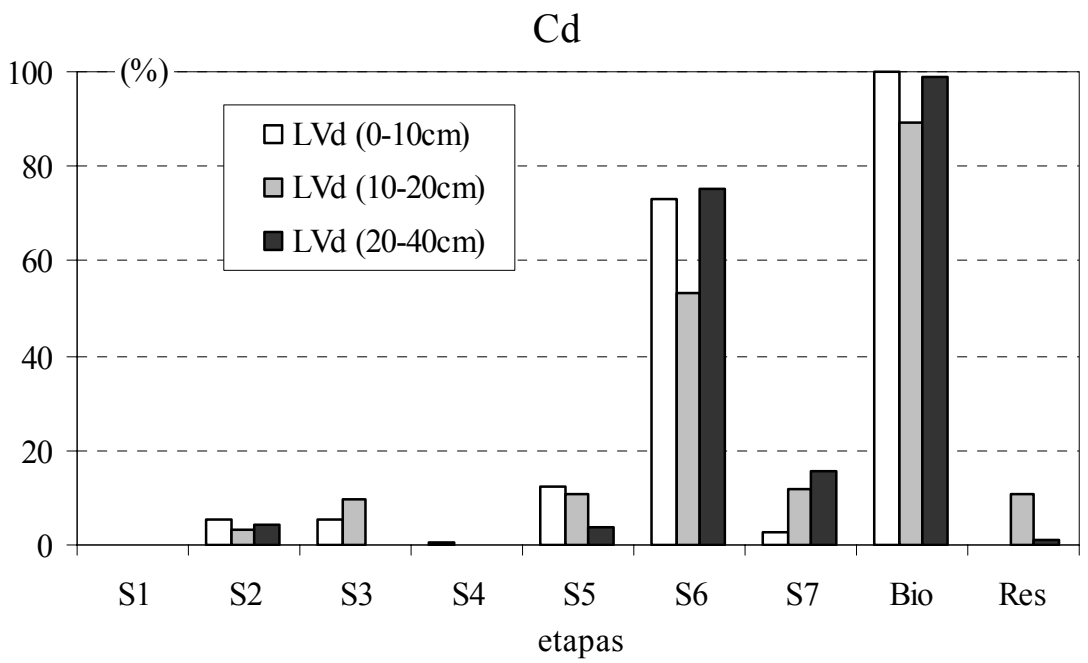

Figura 56. Porcentagem de Cd lixiviado nas etapas de S1 a S7, frações biodisponível (Bio) e residual (Res) para o solo LVd, na microbacia Entre Rios, Angatuba, São Paulo.

Para o RQo houve contribuição cerca de 84,75 e $37 \%$ da fração residual para as profundidades de $0-10,10-20$ e $20-40 \mathrm{~cm}$ respectivamente (Figura 57). Na profundidade de $0-10$ $\mathrm{cm}$, os $16 \%$ referentes à fração lábil se distribuiu em cerca $7 \%$ associados aos óxidos de ferro cristalinos (S6) e trocáveis (S2) e 2\% aos ácidos solúveis (S3). Na profundidade de 10-20 cm, os $25 \%$ da fração biodisponível foram distribuídos em 10\% aos trocáveis (S2), 8\% aos óxidos de ferro cristalinos (S6) e 7\% aos ácidos solúveis (S3). Na profundidade de $20-40 \mathrm{~cm}$, os $63 \%$ da fração biodisponível foram distribuídos em $22 \%$ aos óxidos de ferro cristalinos (S6), $12 \%$ à matéria orgânica (S7), 10\% aos trocáveis (S2), 9\% aos ácidos solúveis (S3) e 5\% aos óxidos de ferro amorfo (S5) e aos óxidos de manganês (S4). 
$\mathrm{Cd}$

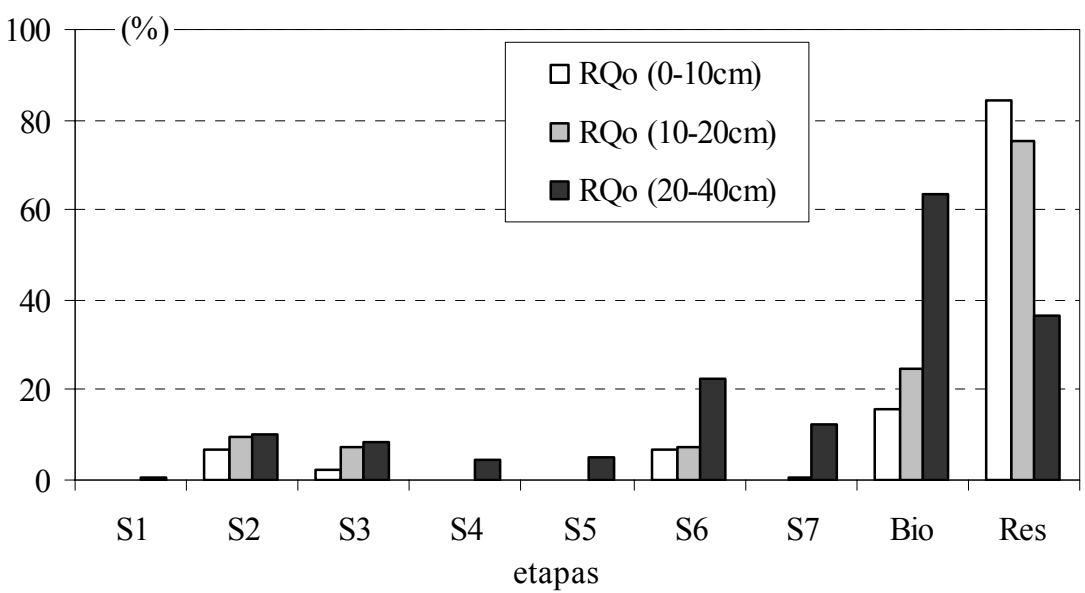

Figura 57. Porcentagem de Cd lixiviado nas etapas de S1 a S7, frações biodisponível (Bio) e residual (Res) para o solo RQo, na microbacia Entre Rios, Angatuba, São Paulo.

Para as amostras de sedimentos de fundo ITA1 e ITA10, 38 e $44 \%$ foram encontrados na fração residual (Figura 58). Os 62\% referentes à fração lábil da amostra ITA1, estavam associados em 19\% à matéria orgânica (S7), 12 \% aos óxidos de ferro cristalinos (S6) e aos óxidos de ferro amorfo (S5), 9\% aos trocáveis (S2), 7\% aos ácidos solúveis (S3) e 3\% aos óxidos de Mn (S4) e 1\% dissolvidos em água (S1). Para a amostra ITA10, nos 56\% da fração lábil, a distribuição das fases teve a contribuição de $16 \%$ da fração ligada à matéria orgânica (S7), 12\% aos ácidos solúveis (S3), 10\% aos óxidos de ferro amorfo (S5), 9\% aos óxidos de ferro cristalinos (S6), 5\% aos óxidos de manganês (S4) e 4\% aos trocáveis (S2). 


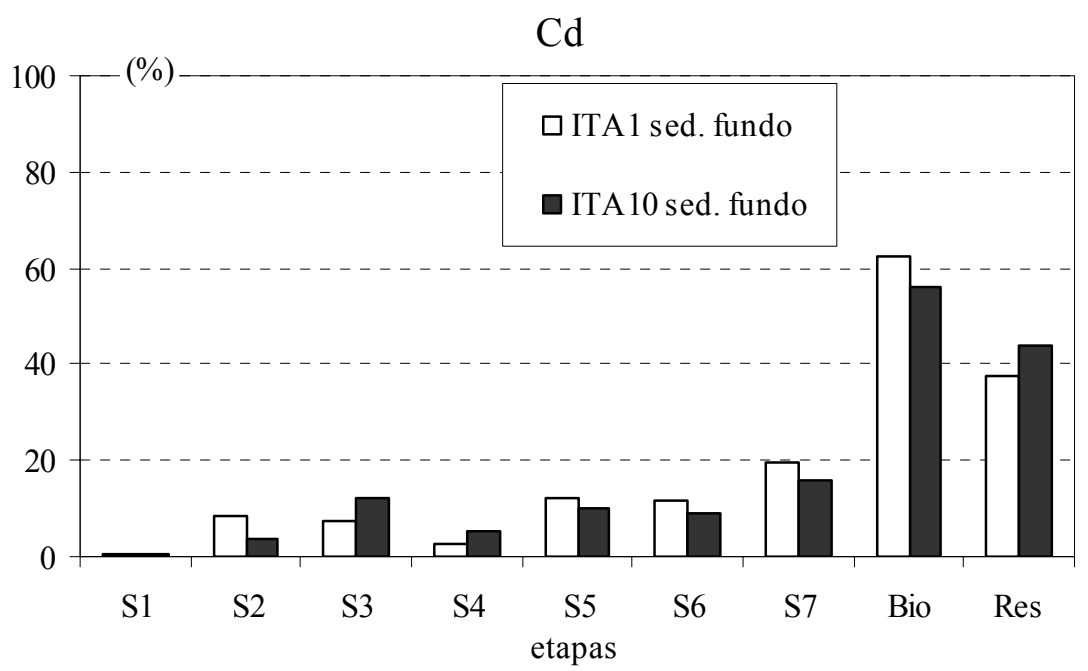

Figura 58. Porcentagem de Cd lixiviado nas etapas de S1 a S7, frações biodisponível (Bio) e residual (Res) para as amostras de sedimentos de fundo ITA1 e ITA10 coletadas no período chuvoso e seco, respectivamente, na microbacia Entre Rios, Angatuba, São Paulo.

De maneira geral, foi observado que o $\mathrm{Cd}$ teve maiores porcentagens das frações biodisponíveis nas amostras do solo LVd e sedimentos de fundo da microbacia de drenagem principalmente ligados aos óxidos de ferro cristalino (S6) e matéria orgânica (S7), respectivamente.

Para o elemento $\mathrm{Pb}$, resultados significativos foram observados apenas nas amostras de LVd, sendo suas frações residuais, nas profundidades de 0-10, 10-20 e 20-40 cm, de 63, 66 e 98\%, respectivamente (Figura 59). Para a profundidade de $0-10 \mathrm{~cm}$, os $37 \%$ da fração biodisponível esteve associado em $23 \%$ aos óxidos de ferro cristalinos (S6) e $14 \%$ na fase ligada aos óxidos de ferro amorfo (S5). Na profundidade de 10-20 cm, 34\% da fração lábil ou biodisponível teve $15 \%$ de contribuição associada aos óxidos de ferro cristalino (S6), 11\% ligada aos óxidos de ferro amorfo (S5) e 8\% ligado aos óxidos de manganês (S4). Para a profundidade de 20-40 cm, os 2\% da fração lábil estavam associados aos óxidos de ferro cristalinos (S6). 


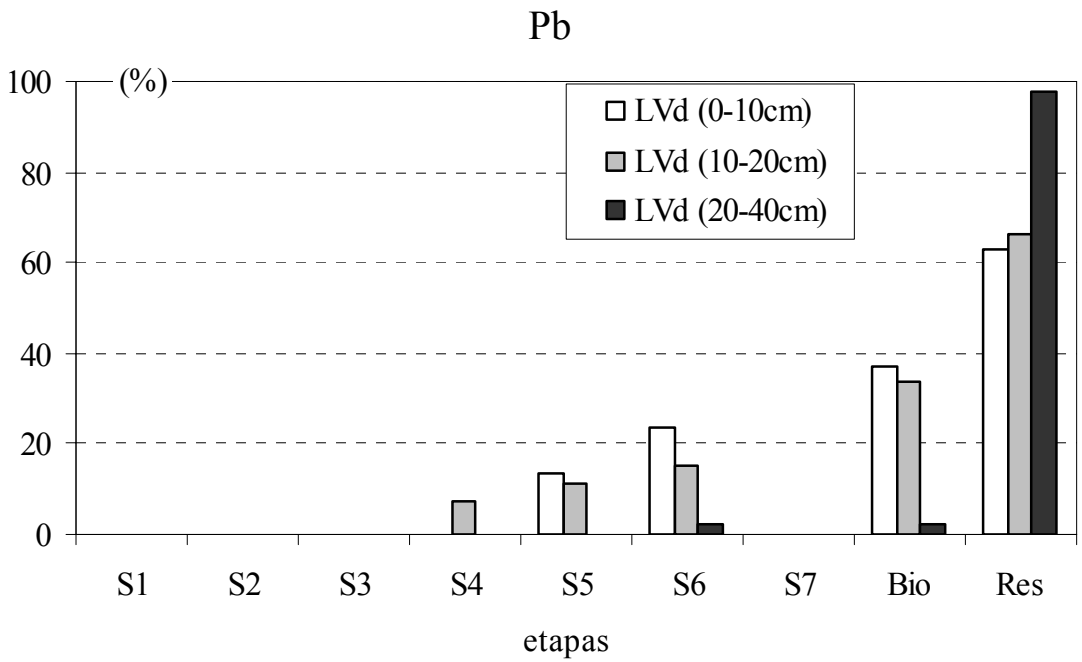

Figura 59. Porcentagem de $\mathrm{Pb}$ lixiviado nas etapas de $\mathrm{S} 1$ a $\mathrm{S} 7$, frações biodisponível (Bio) e residual (Res) para o solo LVd, na microbacia Entre Rios, Angatuba, São Paulo.

De maneira geral, foi observado que o $\mathrm{Pb}$ teve maiores porcentagens das frações biodisponíveis nas amostras do solo LVd para as profundidades de 0-10 e 10-20 $\mathrm{cm}$ na microbacia de drenagem principalmente ligados aos óxidos de ferro cristalino (S6).

Para o elemento $\mathrm{Ni}$, resultados significativos foram observados também apenas para o LVd, sendo suas frações residuais, nas profundidades de 0-10, 10-20 e 20-40 cm, com 92, 83 e $81 \%$, respectivamente (Figura 60). Para a profundidade de $0-10 \mathrm{~cm}$, a fração lábil, cerca de $8 \%$, estava 4\% associado aos óxidos de ferro amorfo (S5), 2\% aos óxidos de manganês (S4) e à matéria orgânica (S7). Na profundidade $10-20 \mathrm{~cm}$ os $17 \%$ da fração biodisponível estavam distribuídos em $9 \%$ à matéria orgânica (S7), 3\% aos ácidos solúveis (S3), 2\% óxidos de manganês (S4) e óxidos de ferro amorfo (S5) e 1\% aos trocáveis (S2). Na profundidade de 20-40 cm os 19\% se distribuíram em 13\% à matéria orgânica (S7), 3\% aos óxidos de manganês (S4), 2\% aos óxidos de ferro amorfo (S5) e 1\% aos trocáveis (S2). 


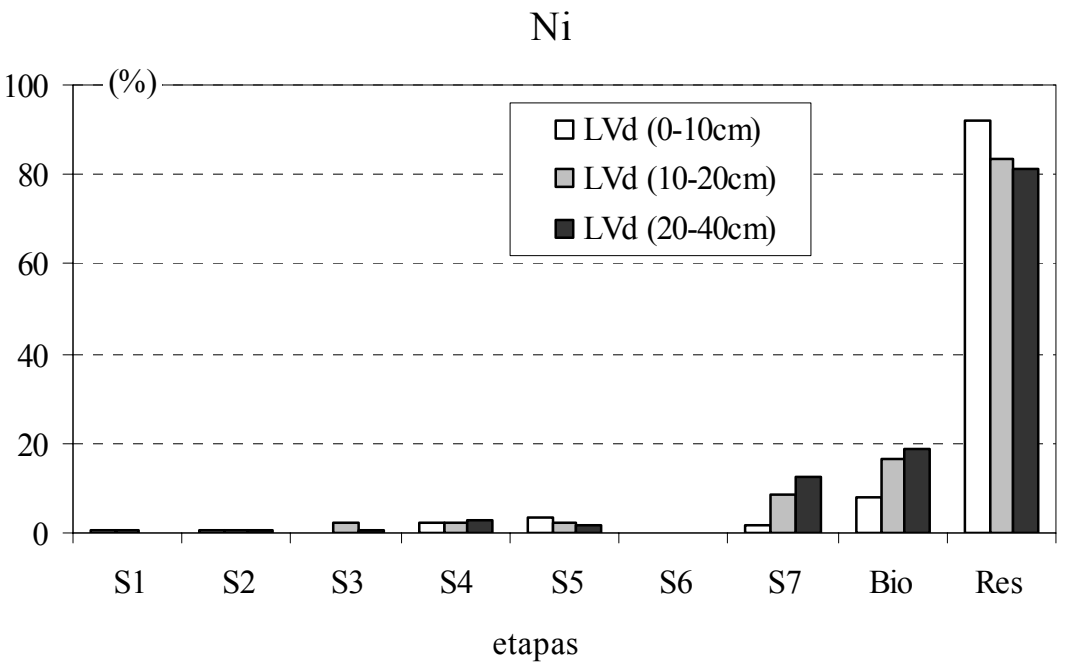

Figura 60. Porcentagem de Ni lixiviado nas etapas de S1 a S7, frações biodisponível (Bio) e residual (Res) para o solo LVd, na microbacia Entre Rios, Angatuba, São Paulo.

De maneira geral, foi observado que o Ni teve maior porcentagem da fração biodisponível na amostra do solo LVd, profundidade de $20-40 \mathrm{~cm}$ da microbacia de drenagem principalmente ligado a matéria orgânica (S7).

O Co no solo CXbd, apresentou na fração residual 81\% nas profundidades 0-10 e 20-40 cm e $90 \%$ na profundidade de $10-20 \mathrm{~cm}$ (Figura 61 ). Na profundidade de $0-10 \mathrm{~cm}$, os $19 \%$ referentes à fração biodisponível foram distribuídos em aproximadamente $8 \%$ aos óxidos de ferro cristalino (S6), 3\% aos trocáveis (S2), ácidos solúveis $(\mathrm{S} 3)$ e óxidos de ferro amorfo (S5) e 2\% à matéria orgânica (S7). Na profundidade de 10-20 cm, dos $10 \%$ referentes à fração lábil, cerca de $6 \%$ estavam associados aos óxidos de ferro cristalino (S6) e 2\% aos trocáveis $(\mathrm{S} 2)$ e ligados à matéria orgânica (S7). Na camada de 20-40 cm, dos 19\% correspondentes à fração lábil, $6 \%$ estavam associados aos óxidos de ferro cristalino (S6), 4\% à matéria orgânica (S7), 3\% aos trocáveis (S2) e aos óxidos de ferro amorfo (S5) e 1\% aos ácidos solúveis (S3), óxidos de manganês (S4) e dissolvidos em água $(\mathrm{S} 1)$. 
Co

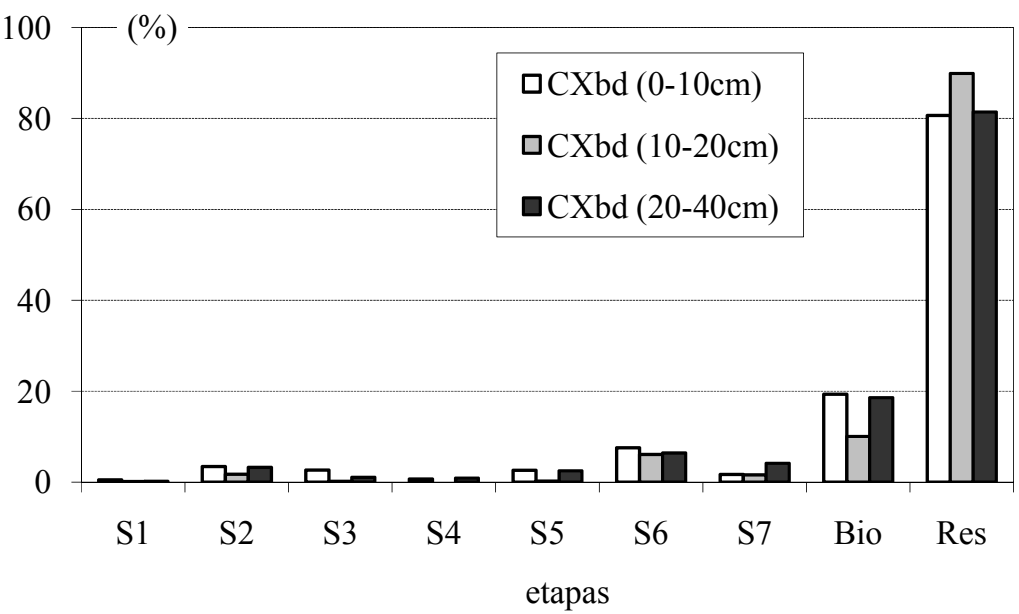

Figura 61. Porcentagem de Co lixiviado nas etapas de S1 a S7, frações biodisponível (Bio) e residual (Res) para o solo CXbd, na microbacia Entre Rios, Angatuba, São Paulo.

No LVAd as frações residuais foram de 89, 91 e 92\% para as profundidades de 0-10, 10 20 e 20-40 cm, respectivamente (Figura 62). Na profundidade de $0-10 \mathrm{~cm}$, os $11 \%$ referentes à fração lábil estavam distribuídos em cerca de 6\% à matéria orgânica (S7), 3\% aos óxidos de ferro cristalino (S6) e $2 \%$ aos óxidos de manganês (S4). Na profundidade de 10-20 cm, dos 9\% referentes à fração lábil, cerca de 7\% estavam associados aos óxidos de ferro cristalino (S6) e 2\% à matéria orgânica $(\mathrm{S} 7)$. Na camada de $20-40 \mathrm{~cm}$, os cerca de $8 \%$ correspondentes à fração lábil, cerca de 3\% estavam associados aos óxidos de ferro cristalino (S6) e 2\% à matéria orgânica (S7) e 1\% aos óxidos de ferro amorfo (S5), óxidos de manganês (S4) e ácidos solúveis (S3). 


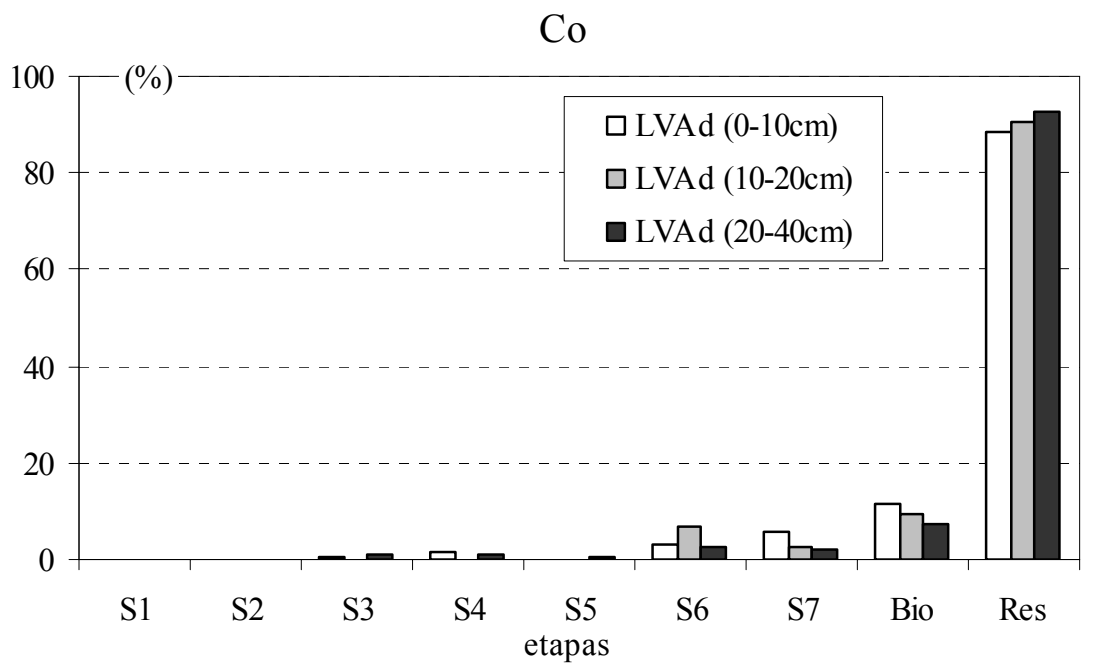

Figura 62. Porcentagem de Co lixiviado nas etapas de S1 a S7, frações biodisponível (Bio) e residual (Res) para o solo LVAd, na microbacia Entre Rios, Angatuba, São Paulo.

O solo LVd teve $89 \%$ da fração residual nas profundidades de 0-10 e 20-40 cm, respectivamente, e $90 \%$ na profundidade de $10-20 \mathrm{~cm}$ (Figura 63). Na profundidade de $0-10 \mathrm{~cm}$, cerca dos $11 \%$ referentes à fração lábil, estavam associados em $4 \%$ aos óxidos de ferro amorfo (S5), 2\% aos trocáveis (S2) e matéria orgânica (S7), 1\% associadas aos ácidos solúveis (S3), óxidos de ferro cristalino (S6) e aos óxidos de manganês (S4). Na profundidade de 10-20 cm, os $10 \%$ da fração biodisponível foram distribuídos em $3 \%$ associados aos óxidos de ferro amorfo (S5), 2\% matéria orgânica (S7), aos óxidos de ferro cristalino (S6) e 1\% aos ácidos solúveis (S3), trocáveis (S2) e aos óxidos de manganês (S4). Na profundidade de $20-40 \mathrm{~cm}$, a contribuição dos $11 \%$ da fração lábil foi distribuída em $3 \%$ à matéria orgânica (S7), $2 \%$ aos óxidos de ferro amorfo (S5), óxidos de ferro cristalino (S6) e aos ácidos solúveis (S3) e 1\% trocáveis (S2) e aos óxidos de manganês (S4). 


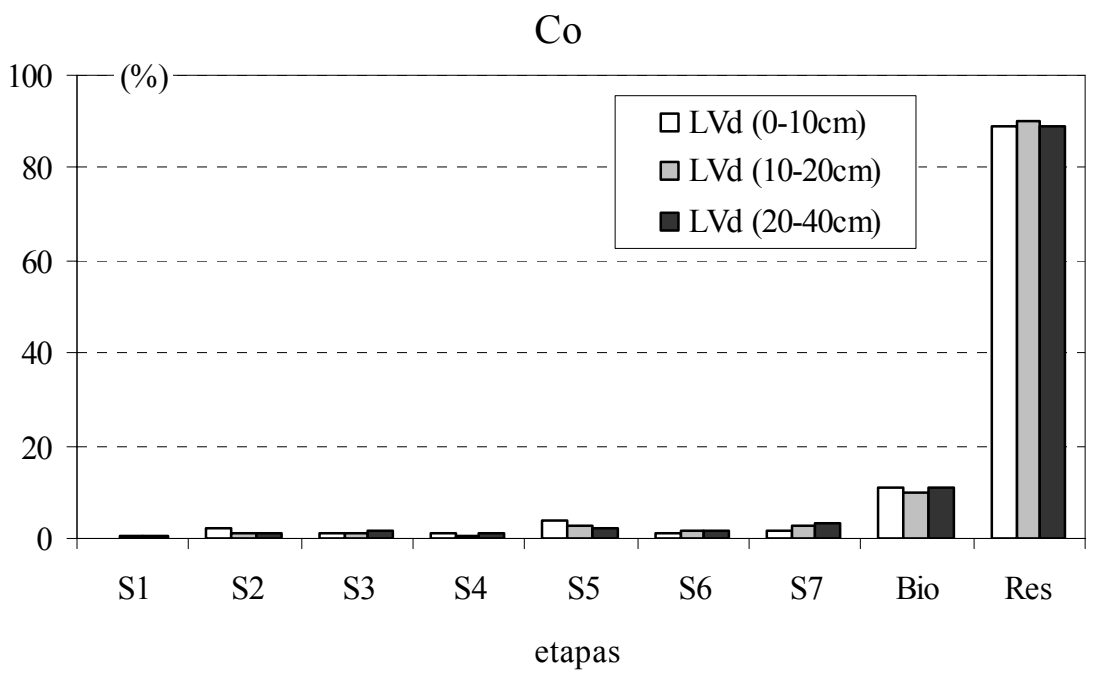

Figura 63. Porcentagem de Co lixiviado nas etapas de S1 a S7, frações biodisponível (Bio) e residual (Res) para o solo LVd, na microbacia Entre Rios, Angatuba, São Paulo.

Nas amostras de solo RQo, 58, 43 e 82\% estavam na fração residual para as profundidades de $0-10,10-20$ e $20-40 \mathrm{~cm}$, respectivamente (Figura 64 ). Na profundidade de $0-10$ cm, os 42\% referentes à fração lábil, se distribuíram em 19\% à matéria orgânica (S7), 13\% aos óxidos de ferro cristalino (S6), $6 \%$ aos óxidos de ferro amorfo (S5), 3\% aos óxidos de manganês (S4) e $1 \%$ dissolvidos em água (S1). Na profundidade de $10-20 \mathrm{~cm}$, a contribuição dos $57 \%$ da fração lábil estava associada em 17\% à matéria orgânica (S7), 16\% aos óxidos de ferro cristalino (S6), 10\% aos óxidos de ferro amorfo (S5), 9\% aos óxidos de manganês (S4), 4\% aos ácidos solúveis (S3) e 1\% dissolvidos em água (S1). Na profundidade de 20-40 cm, a contribuição dos $18 \%$ da fração lábil foi distribuída em 7\% aos óxidos de ferro amorfo (S5) e aos óxidos de ferro cristalinos (S6), 3\% ligados à matéria orgânica (S7) e 1\% aos ácidos solúveis (S3). 


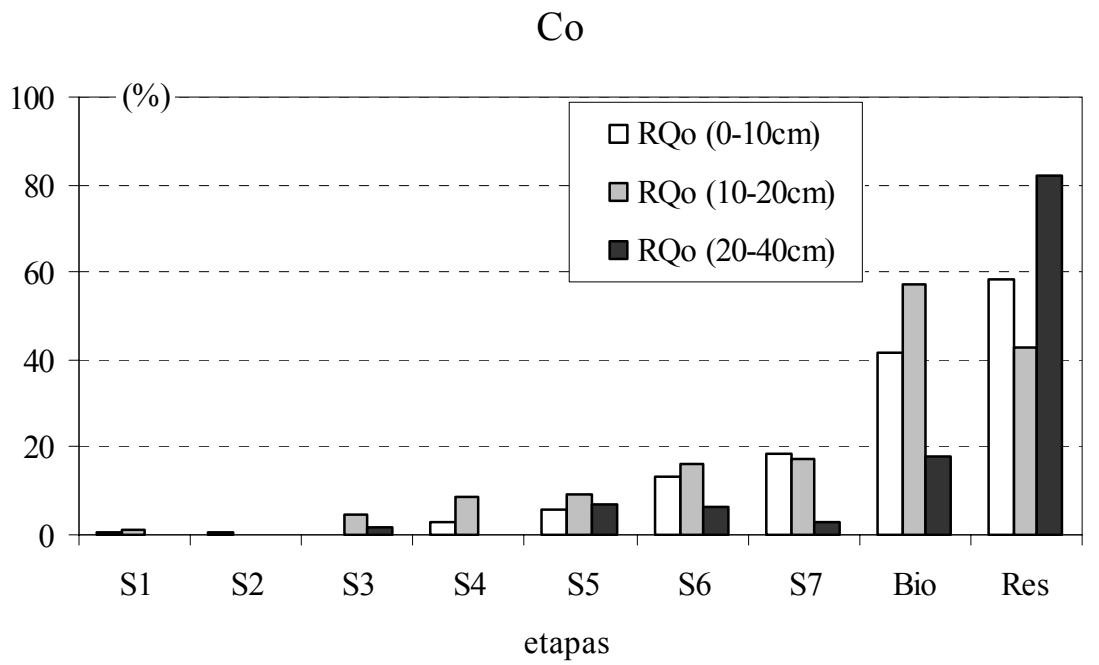

Figura 64. Porcentagem de Co lixiviado nas etapas de S1 a S7, frações biodisponível (Bio) e residual (Res) para o solo RQo, na microbacia Entre Rios, Angatuba, São Paulo.

As frações residuais para as amostras de sedimentos ITA1 e ITA10 foram de 68 e $76 \%$ respectivamente (Figura 65). Na ITA1, os 32\% da fração lábil ou biodisponível distribuíram-se em 11, 8, 6, 5 e 2\% nas frações óxidos de ferro amorfo (S5), ácidos solúveis (S3), óxidos de ferro cristalinos (S6), trocáveis (S2) e à matéria orgânica (S7), respectivamente. Na ITA10, a fração lábil (24\%) distribuiu-se em 10\% associadas óxidos de ferro amorfo (S5), 5\% aos ácidos solúveis (S3), 3\% aos trocáveis (S2), aos óxidos de ferro cristalinos (S6) e à matéria orgânica (S7). 


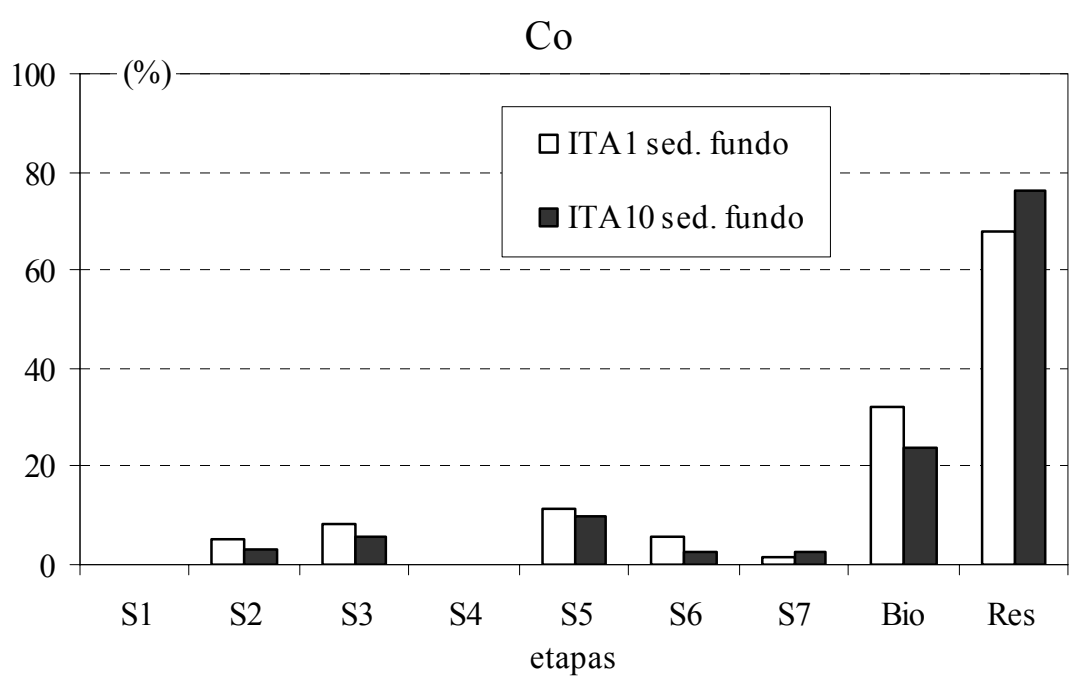

Figura 65. Porcentagem de Co lixiviado nas etapas de S1 a S7, frações biodisponível (Bio) e residual (Res) para as amostras de sedimentos de fundo ITA1 e ITA10 coletadas no período chuvoso e seco, respectivamente, na microbacia Entre Rios, Angatuba, São Paulo.

De maneira geral, foi observado que o Co teve maiores porcentagens das frações biodisponíveis nas amostras do solo RQo para as profundidades de 0-10 e 10-20 cm da microbacia de drenagem principalmente ligados a matéria orgânica (S7).

$\mathrm{O} \mathrm{Cu}$ apresentou para amostragem do solo CXbd, uma contribuição de 85,84 e $87 \%$ da fração residual nas profundidades de 0-10, 10-20 e 20-40 cm (Figura 66). Na profundidade de 0$10 \mathrm{~cm}$, dos $15 \%$ da fração lábil, $11 \%$ estavam associados aos óxidos de ferro amorfo (S5), 3\% aos óxidos de ferro cristalino (S6) e 1\% à matéria orgânica (S7). Na profundidade de $10-20 \mathrm{~cm}$, os $16 \%$ da fração lábil distribuíram-se em $11 \%$ associados aos óxidos de ferro amorfo (S5), 4\% aos óxidos de ferro amorfo e cristalino (S6) e 1\% ligados à matéria orgânica (S7), respectivamente. Na profundidade de $20-40 \mathrm{~cm}$, os $13 \%$ referentes à fração biodisponível, cerca de 12\% estavam associados aos óxidos de ferro amorfo (S5) e 1\% aos ácidos solúveis (S3). 


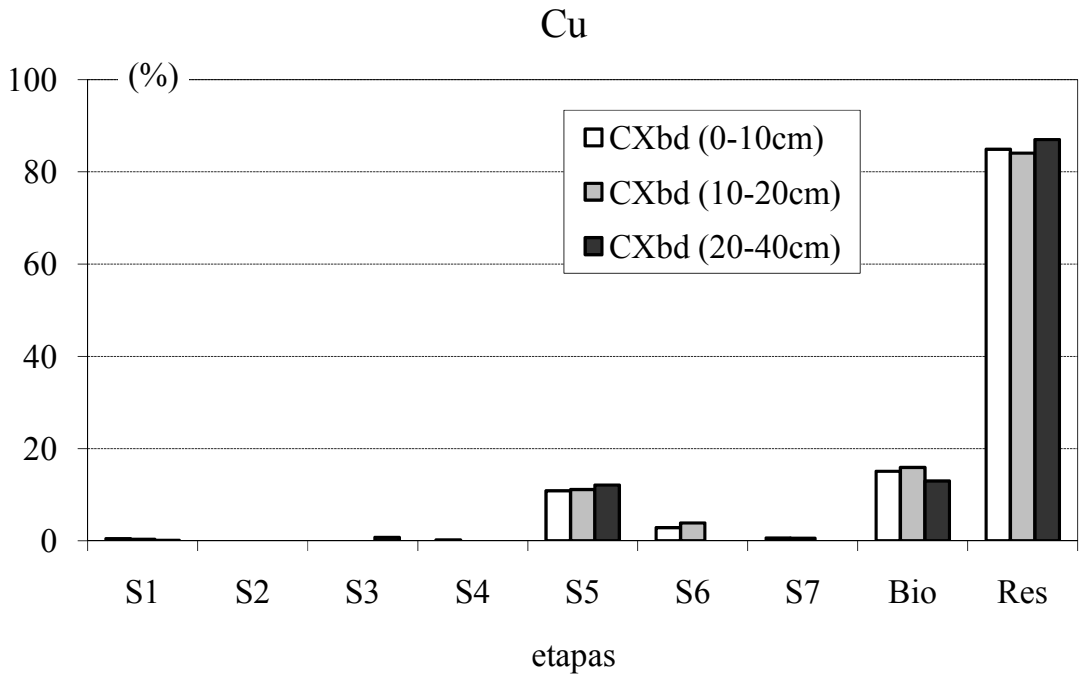

Figura 66. Porcentagem de $\mathrm{Cu}$ lixiviado nas etapas de $\mathrm{S} 1$ a S7, frações biodisponível (Bio) e residual (Res) para o solo CXbd, na microbacia Entre Rios, Angatuba, São Paulo.

Para o LVAd, a fração residual obtida na profundidade de $0-10 \mathrm{~cm}$ foi de $97 \%$, e nas profundidades de 10-20 e 20-40 $\mathrm{cm}$ foram de 92\% (Figura 67). Em 0-10 cm, cerca de 3\% da fração biodisponível estavam associados aos óxidos de ferro amorfo (S5). Na profundidade de 10-20 cm, 8\% da fração biodisponível, estavam associadas também aos óxidos de ferro amorfo (S5). Na profundidade de $20-40 \mathrm{~cm}$, dos $8 \%$ referentes à fração biodisponível, $7 \%$ aos óxidos de ferro amorfo (S5) e 1\% estava associado aos ácidos solúveis (S3). 


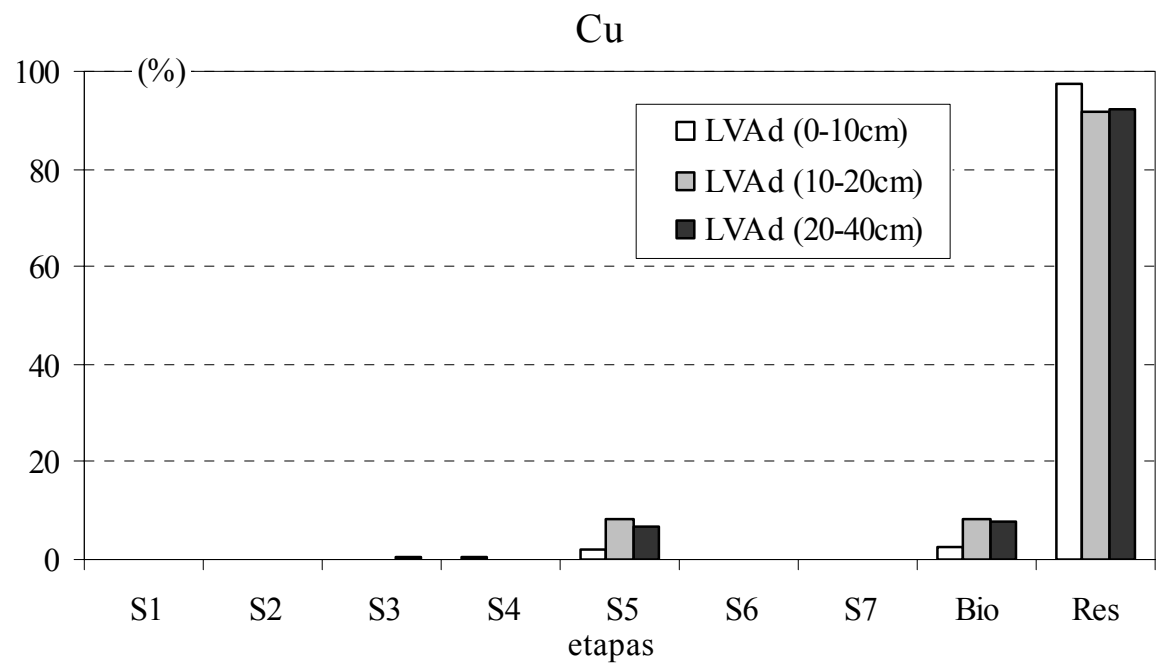

Figura 67. Porcentagem de $\mathrm{Cu}$ lixiviado nas etapas de $\mathrm{S} 1$ a S7, frações biodisponível (Bio) e residual (Res) para o solo LVAd, na microbacia Entre Rios, Angatuba, São Paulo.

No LVd, de $86 \%$ do Cu estava associado à fração residual na camada de $0-10 \mathrm{~cm}$ e $14 \%$ da fração lábil estava distribuído em $7 \%$ aos óxidos de ferro amorfo (S5), 5\% associados à matéria orgânica (S7) e 2\% aos trocáveis (S3) (Figura 68). Na profundidade de 10-20 cm, a fração residual correspondeu a $74 \%$, enquanto que a lábil ou biodisponível foi de $26 \%$. Dessa fração, $12 \%$ estavam associados aos óxidos de ferro cristalinos (S6), 6\% óxidos de ferro amorfo (S5) e a matéria orgânica (S7) e 2\% aos ácidos solúveis (S3). Na profundidade de 20-40 cm, a fração residual correspondeu a 77 e $23 \%$ a fração biodisponível, sendo $10 \%$ associados à matéria orgânica (S7), 7\% aos óxidos de ferro cristalinos (S6), 5\% óxidos de ferro amorfo (S5) e 1\% aos ácidos solúveis $(\mathrm{S} 3)$. 


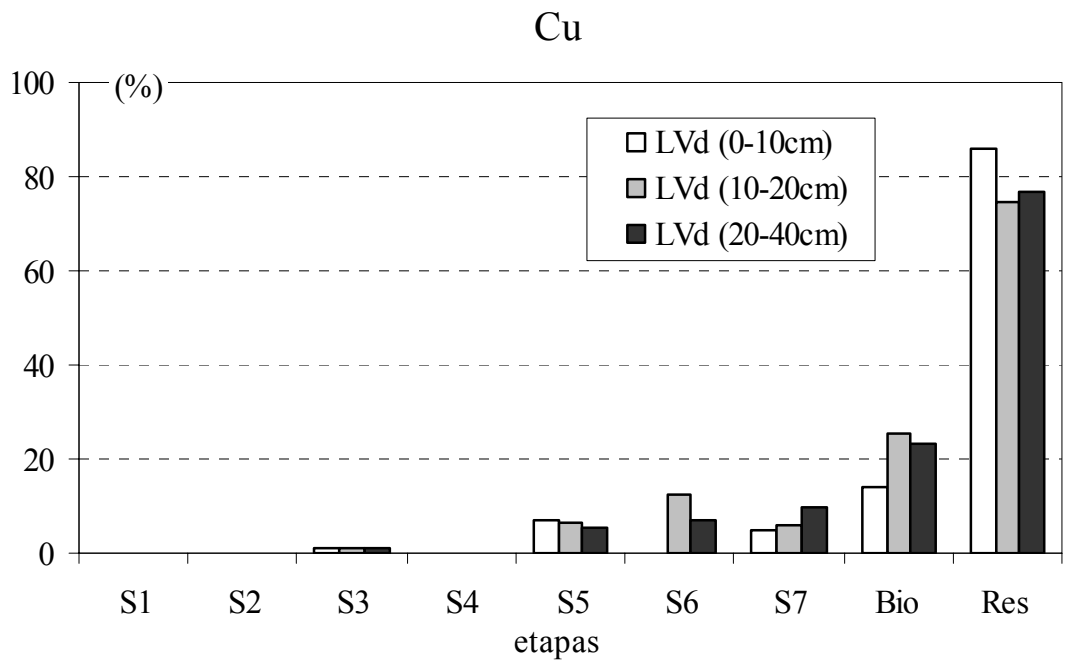

Figura 68. Porcentagem de $\mathrm{Cu}$ lixiviado nas etapas de $\mathrm{S} 1$ a S7, frações biodisponível (Bio) e residual (Res) para o solo LVd, na microbacia Entre Rios, Angatuba, São Paulo.

$\mathrm{Na}$ amostra de solo RQo na profundidade de $0-10 \mathrm{~cm}$ foi encontrado 86 e 14\%, respectivamente na fração residual e lábil (Figura 69). Na fração lábil ou biodisponível, 8\% estavam associados aos óxidos de ferro amorfo (S5), 4\% aos trocáveis (S2) e 2\% aos ácidos solúveis (S3). Na profundidade de 10-20 cm, 97\% estavam associadas à fração residual e dos 3\% da fração biodisponível que estavam ligados aos óxidos de ferro amorfo (S5). Na profundidade de $20-40 \mathrm{~cm}$, os $68 \%$ de $\mathrm{Cu}$ foram encontrados na fração residual e os restantes $32 \%$ encontrados na fração lábil foram distribuídos em $26 \%$ associados aos óxidos de ferro amorfo (S5), $4 \%$ à matéria orgânica (S7) e 2\% aos óxidos de manganês (S4). 


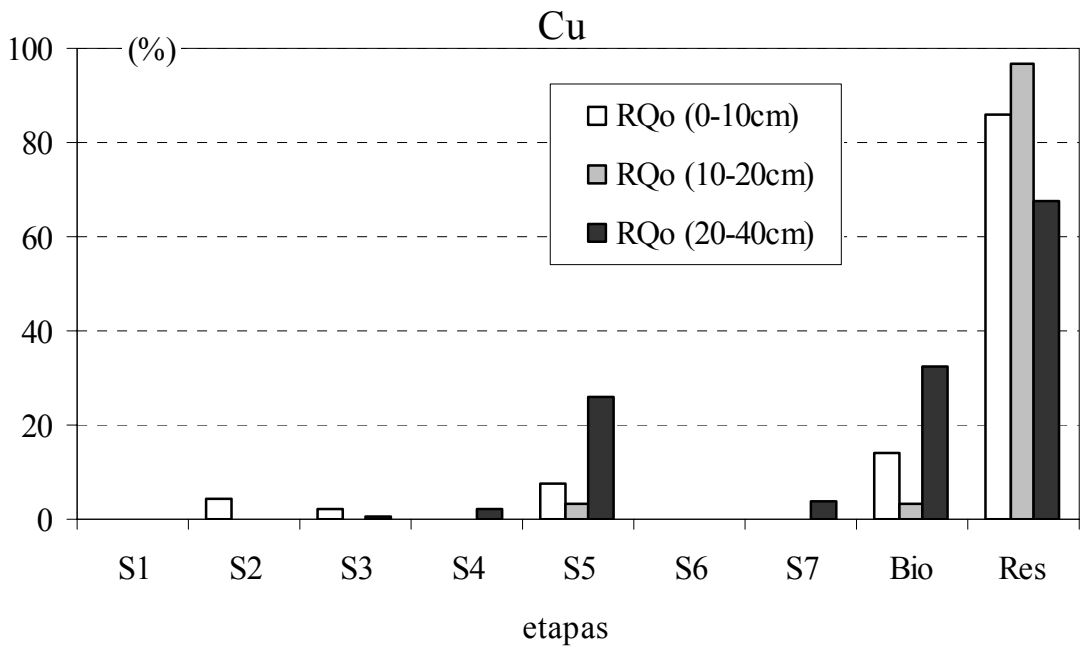

Figura 69. Porcentagem de $\mathrm{Cu}$ lixiviado nas etapas de $\mathrm{S} 1$ a S7, frações biodisponível (Bio) e residual (Res) para o solo RQo, na microbacia Entre Rios, Angatuba, São Paulo.

$\mathrm{Na}$ amostra de sedimentos ITA1 e ITA10, a fração residual correspondeu a 70 e $83 \%$ respectivamente (Figura 70). Da fração lábil em ITA1, dos cerca de 30\%, 14\% estavam associadas aos óxidos de ferro amorfo (S5) e 11\% aos óxidos de ferro cristalinos (S6), 3\% associados à matéria orgânica (S7) e 1\% aos óxidos de manganês (S4) e aos trocáveis (S3). Na ITA10, cerca dos $17 \%$ da fração biodisponível foram distribuídos em $8 \%$ na fase óxidos de ferro amorfo (S5), 5\% nos óxidos de ferro cristalinos (S6), 3\% à matéria orgânica (S7) e 1\% nos óxidos de manganês (S4). 


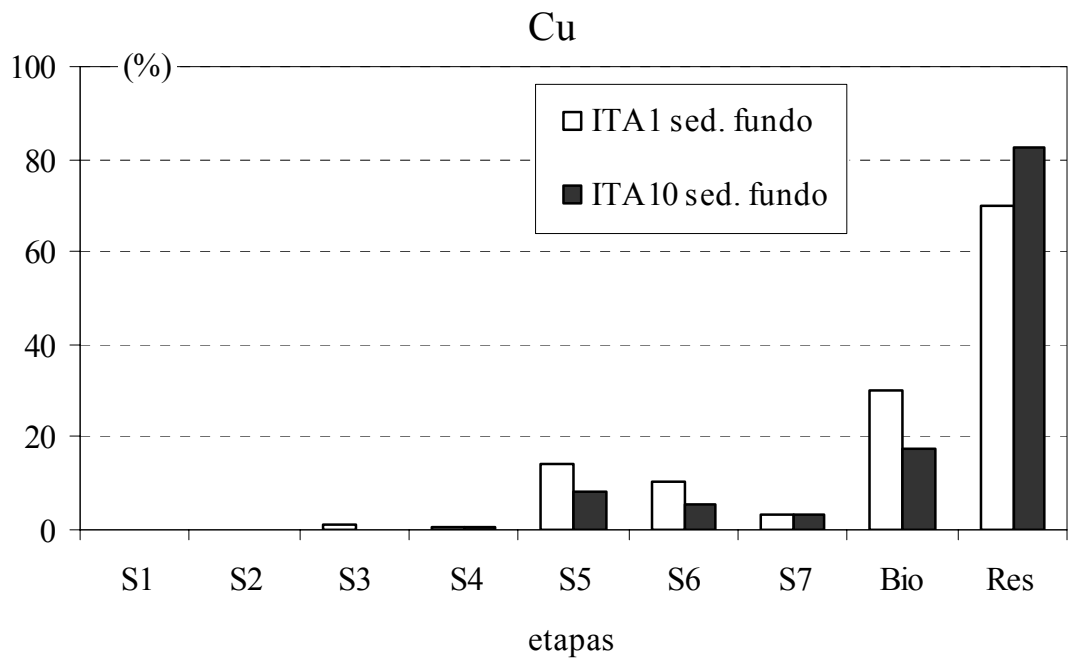

Figura 70. Porcentagem de $\mathrm{Cu}$ lixiviado nas etapas de S1 a S7, frações biodisponível (Bio) e residual (Res) para as amostras de sedimentos de fundo ITA1 e ITA10 coletadas no período chuvoso e seco, respectivamente, na microbacia Entre Rios, Angatuba, São Paulo.

De maneira geral, foi observado que o $\mathrm{Cu}$ teve maiores porcentagens das frações biodisponíveis nas amostras dos solos e sedimentos da microbacia de drenagem principalmente ligados aos óxidos de ferro amorfo (S5).

O Zn na amostra do solo CXbd apresentou frações residuais de 61, 68 e 96\% para as profundidades de 0-10, 10-20 e 20-40 cm, respectivamente (Figura 71). Nas profundidades de 010 e 10-20 os 39 e 32\% da fração lábil, estavam associados somente aos óxidos de ferro cristalino (S5). Na camada de 20-40 cm, os 4\% da fração lábil se encontrava associado aos ácidos solúveis (S3). 


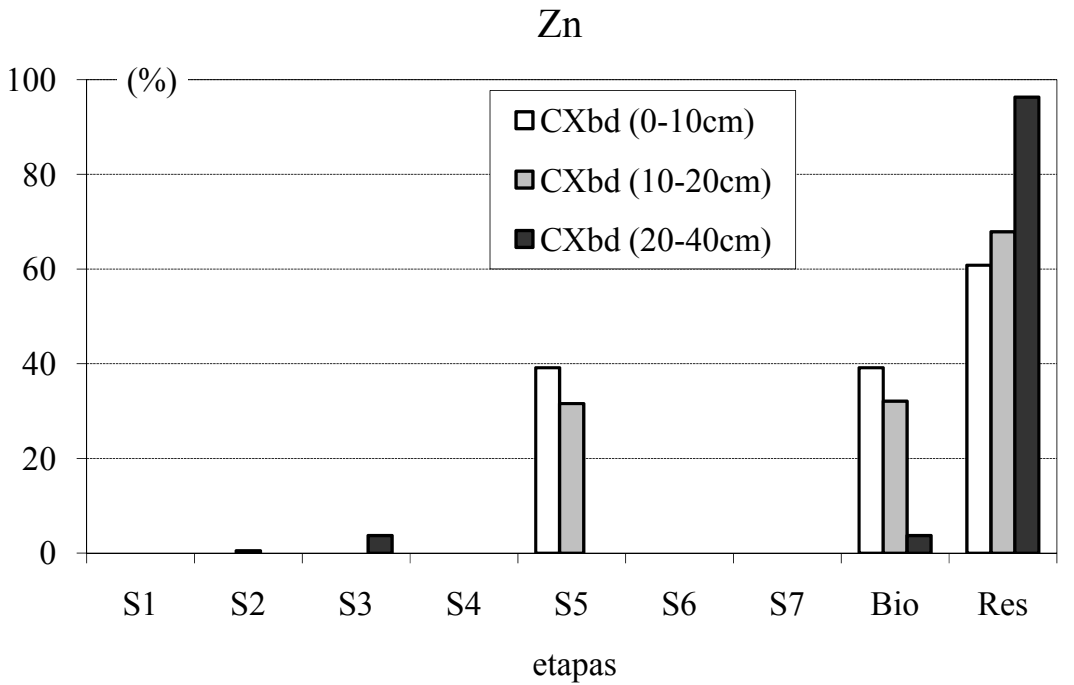

Figura 71. Porcentagem de Zn lixiviado nas etapas de S1 a S7, frações biodisponível (Bio) e residual (Res) para o solo CXbd, na microbacia Entre Rios, Angatuba, São Paulo.

Para o LVAd, na profundidade de 0-10 cm, a fração residual foi $87 \%$ (Figura 72). Os 13\% da fração lábil esteve associada aos ácidos solúveis (S3). Na profundidade de 10-20 $\mathrm{cm}$ foram distribuídos $87 \%$ na fração residual e $13 \%$ na fração lábil. Da fração lábil, os $13 \%$ estavam associados aos ácidos solúveis (S3). Na profundidade de 20-40 cm, 83\% do elemento Zn estavam na fração residual e o restante, cerca de $17 \%$ da fração lábil, foi distribuída em $9 \%$ aos óxidos de ferro amorfo (S5), 4\% aos óxidos de ferro cristalinos (S6), 2\% aos ácidos solúveis (S3) e 1\% associados aos dissolvidos (S1) e à matéria orgânica (S7). 


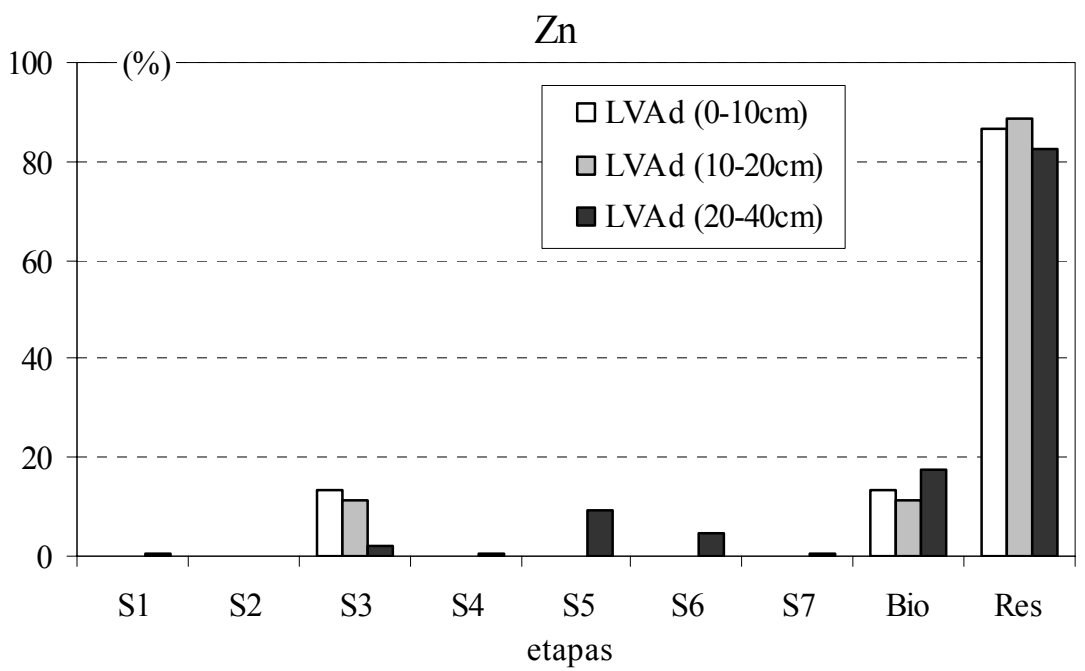

Figura 72. Porcentagem de Zn lixiviado nas etapas de S1 a S7, frações biodisponível (Bio) e residual (Res) para o solo LVAd, na microbacia Entre Rios, Angatuba, São Paulo.

Para o LVd, na profundidade de $0-10 \mathrm{~cm}, 41 \%$ foram encontrados na fração residual e $59 \%$ na fração lábil (Figura 73). Na fração lábil, cerca de $22 \%$ estava associado à matéria orgânica (S7), 16\% aos óxidos de ferro amorfo (S5), 13\% aos óxidos de ferro cristalinos (S6) e $8 \%$ aos óxidos de manganês (S4). Na profundidade de 10-20, dos $86 \%$ da fração lábil, $40 \%$ estavam associados à matéria orgânica (S7), 22\% aos óxidos de ferro cristalinos (S6), 17\% aos óxidos de ferro amorfo (S5), 6\% aos óxidos de manganês (S4) e 1\% dissolvidos em água (S1). Na profundidade de $20-40 \mathrm{~cm}$, os $86 \%$ referentes à fração lábil foi distribuída em $48 \%$ associados à matéria orgânica (S7), 20\% aos óxidos de ferro cristalinos (S6), 11\% aos óxidos de ferro amorfo (S5), 6\% aos óxidos de manganês (S4) e 1\% dissolvidos em água (S1). 


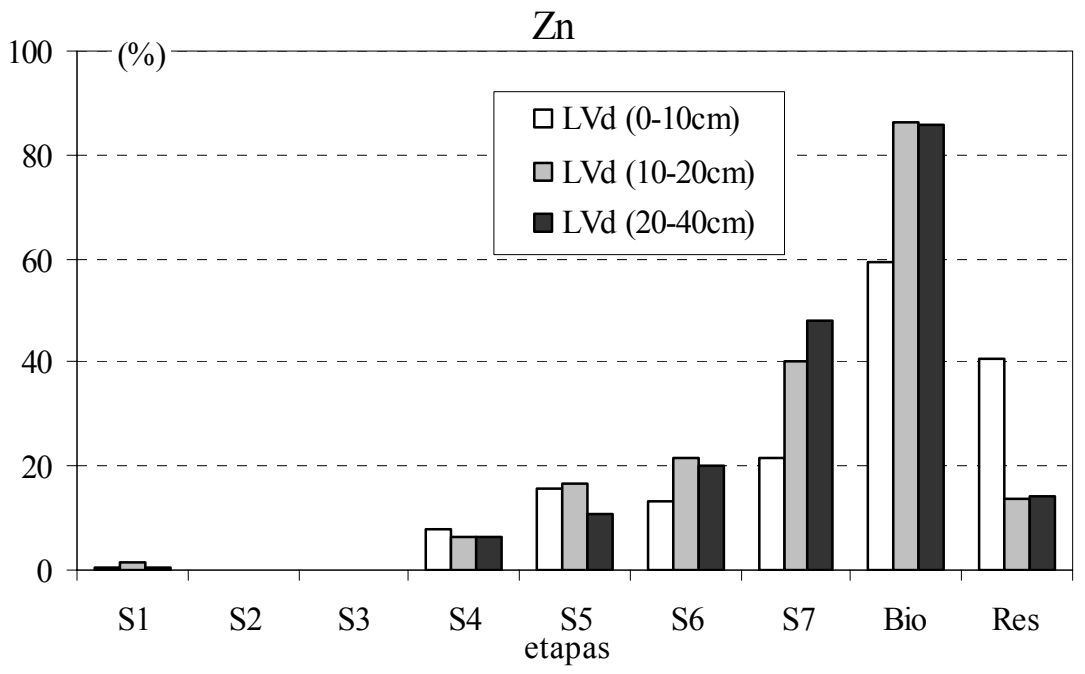

Figura 73. Porcentagem de Zn lixiviado nas etapas de S1 a S7, frações biodisponível (Bio) e residual (Res) para o solo LVd, na microbacia Entre Rios, Angatuba, São Paulo.

Para as amostras do solo RQo o teor do elemento Zn não foi encontrado, pois estava abaixo do limite de detecção do aparelho. Para a amostragem de sedimento de fundo ITA1, 75\% estavam associados à fração residual (Figura 74). Na fração lábil, dos 25\%, 18\% estavam associados aos óxidos de ferro amorfo (S5) e 7\% aos ácidos solúveis (S3). Para a amostragem de sedimento de fundo ITA10, 93\% estavam associados à fração residual e apenas $7 \%$ na fração lábil. Todos os 7\% estavam associados aos óxidos de ferro amorfo (S5). 


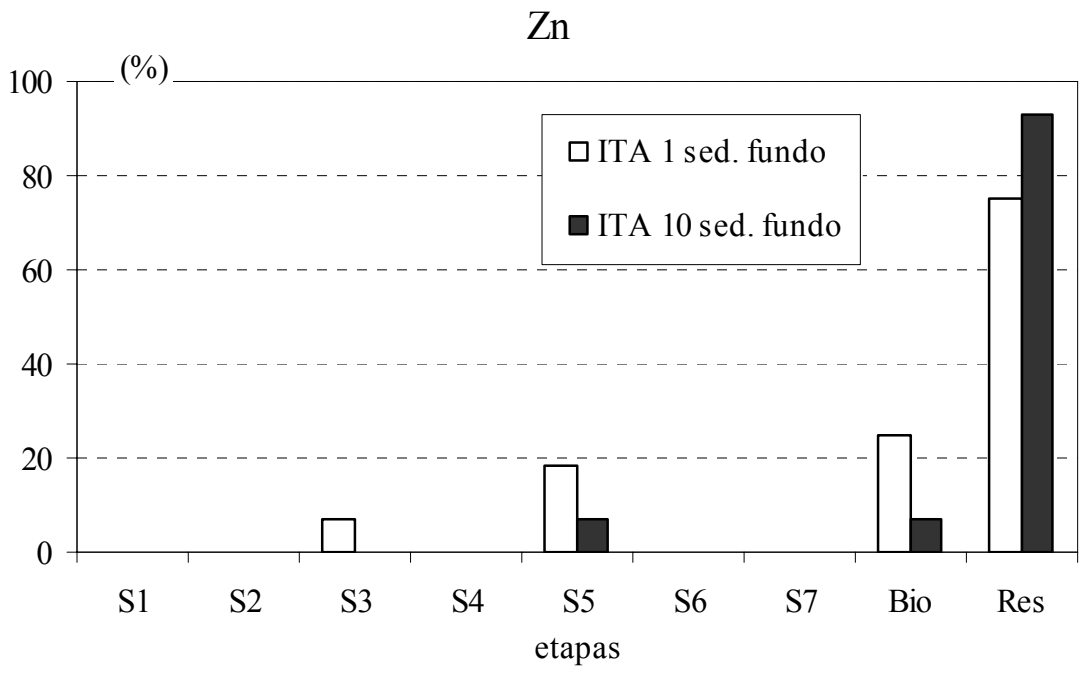

Figura 74. Porcentagem de Zn lixiviado nas etapas de S1 a S7, frações biodisponível (Bio) e residual (Res) para as amostras de sedimentos de fundo ITA1 e ITA10 coletadas no período chuvoso e seco, respectivamente, na microbacia Entre Rios, Angatuba, São Paulo.

De maneira geral, foi observado que o $\mathrm{Zn}$ teve maiores porcentagens das frações biodisponíveis nas amostras do solo LVd da microbacia de drenagem principalmente ligados a matéria orgânica (S7). Nas amostras do solo RQo para as profundidades estudadas as concentrações de Zn estavam abaixo do limite de deteç̧ão $\left(0,030 \mathrm{mg} \mathrm{L}^{-1}\right)$, e portanto não foram reportadas.

O elemento Sc nas amostras do solo CXbd, cerca de 69 e 31\% estavam na fração residual e lábil na profundidade de 0-10 cm, respectivamente (Figura 75). Na fração lábil, 25\% estavam associados aos óxidos de ferro cristalinos (S6), 3\% aos ácidos solúveis (S3) e 1\% à matéria orgânica (S7), dissolvidas em água (S1) e trocáveis (S2). Na profundidade de 10-20 cm, apenas $23 \%$ de Sc foram encontrados na fração residual. O restante, cerca de $77 \%$ referentes à fração lábil, distribuíram-se em 40, 23 e 10\% associados aos óxidos de ferro amorfo (S5), óxidos de ferro cristalinos (S6) e aos ácidos solúveis (S3), respectivamente. Houve contribuição de aproximadamente $2 \%$ à matéria orgânica (S7) e 1\% dissolvidas em água (S1) e aos trocáveis 
(S2). Na profundidade de $20-40 \mathrm{~cm}$, os $66 \%$ da fração lábil foram distribuídos em 33, 16, 13, 2 e 1\%, associados aos óxidos de ferro amorfo (S5) e cristalinos (S6), ácidos solúveis (S3), matéria orgânica (S7), dissolvidos em água (S1) e trocáveis (S2), respectivamente.

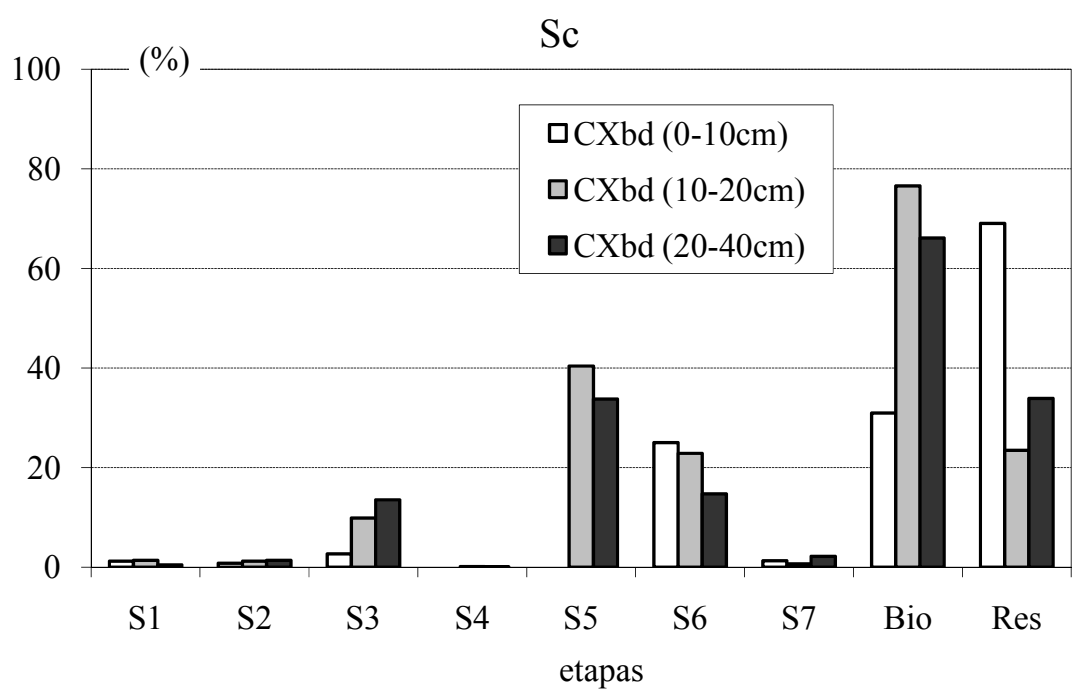

Figura 75. Porcentagem de Sc lixiviado nas etapas de S1 a S7, frações biodisponível (Bio) e residual (Res) para o solo CXbd, na microbacia Entre Rios, Angatuba, São Paulo.

No LVAd, houve contribuição na fração residual de 37,21 e 52\% nas profundidades $0-10$, 10-20 e 20-40 cm, respectivamente (Figura 76). Na profundidade de 0-10 cm, os 63\% da fração lábil foram distribuídos em 31, 21, 8 e 1\%, associados aos óxidos de ferro amorfo (S5), óxidos de ferro cristalinos (S6) e aos ácidos solúveis (S3) e dissolvidos em água (S1), trocáveis (S2) e à matéria orgânica (S7), respectivamente. Na profundidade de $10-20 \mathrm{~cm}$, dos $79 \%$ da fração biodisponível, cerca de 40, 20, 16, 2 e 1\% estavam associados aos óxidos de ferro amorfo (S5), óxidos de ferro cristalinos (S6) e aos ácidos solúveis (S3), trocáveis (S2), dissolvidos (S1) e ligados à matéria orgânica (S7), respectivamente. Na profundidade de 20-40 cm, houve contribuição de $48 \%$ na fração biodisponível que se distribuiu em 26, 13, 7 e 1\% associados 
respectivamente aos óxidos de ferro amorfo (S5), aos ácidos solúveis (S3), óxidos de ferro cristalinos (S6) e trocáveis (S2) e à matéria orgânica (S7).

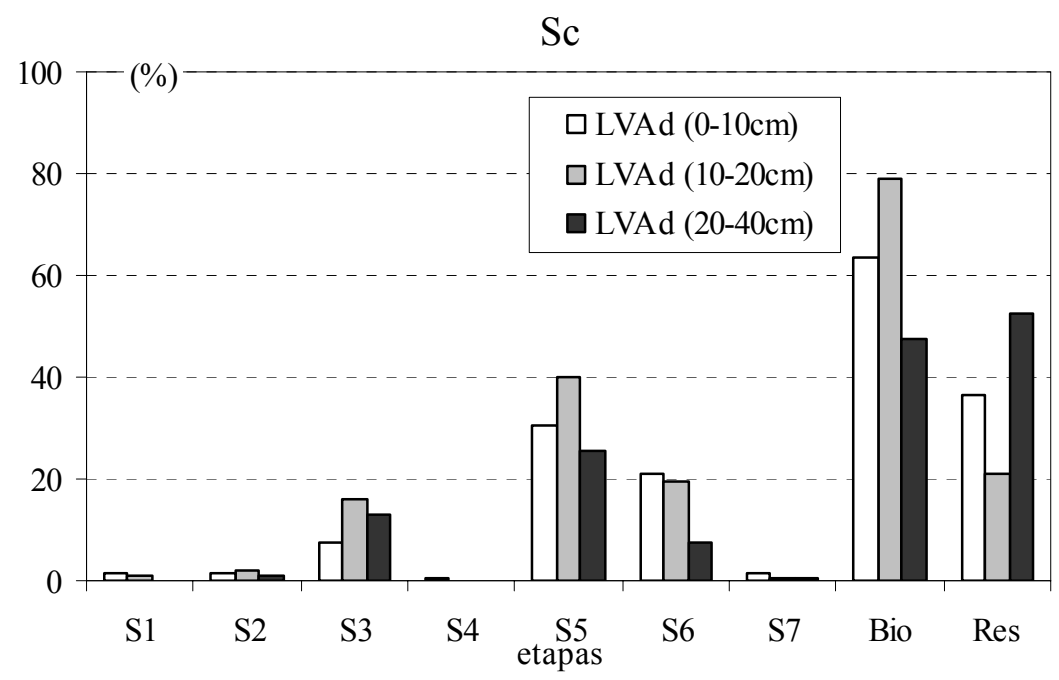

Figura 76. Porcentagem de Sc lixiviado nas etapas de S1 a S7, frações biodisponível (Bio) e residual (Res) para o solo LVAd, na microbacia Entre Rios, Angatuba, São Paulo.

Para o LVd, houve distribuição em 69, 70 e 60\% da fração residual e 31, 30 e 40\% da fração biodisponível nas profundidades de 0-10, 10-20 e 20-40 cm (Figura 77). As contribuições da fração lábil para a profundidade de $0-10 \mathrm{~cm}$ foram de $15 \%$ associados aos óxidos de ferro cristalinos (S6), 13\% aos óxidos de ferro amorfo (S5) e 3\% aos ácidos solúveis (S3). Na profundidade de 10-20 cm, houve contribuição para a fração lábil em 17\% associados aos óxidos de ferro cristalinos (S6), 11\% aos óxidos de ferro amorfo (S5) e 2\% aos ácidos solúveis (S3). Na profundidade de $20-40 \mathrm{~cm}$, houve contribuição para a fração lábil em $20 \%$ associados aos óxidos de ferro cristalinos (S6), 14\% aos óxidos de ferro amorfo (S5), 4\% aos ácidos solúveis (S3) e 2\% à matéria orgânica $(\mathrm{S} 7)$. 


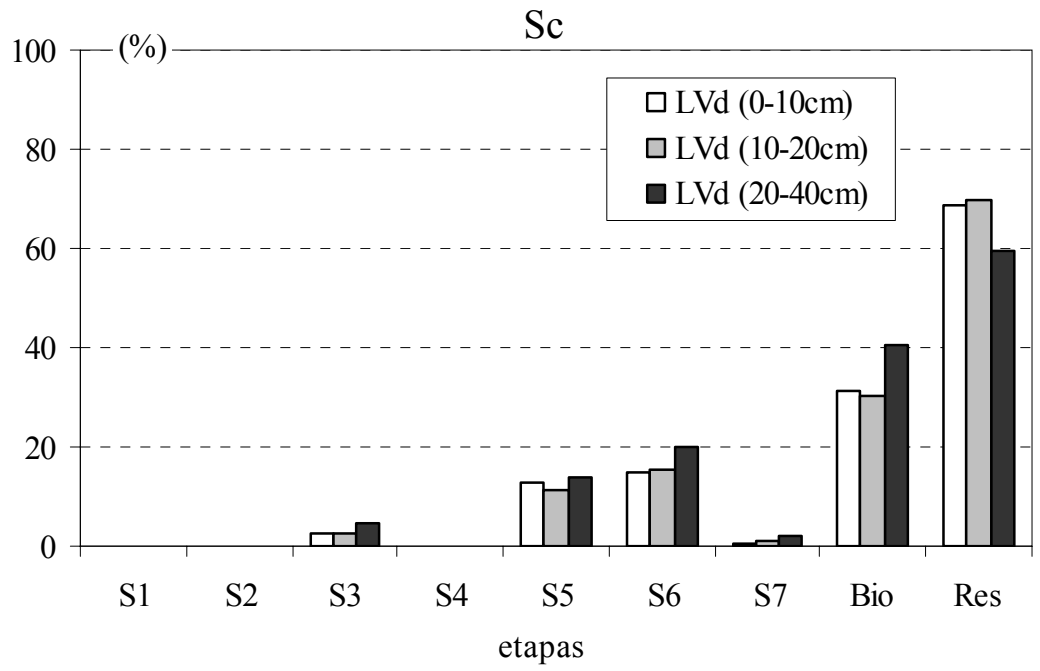

Figura 77. Porcentagem de Sc lixiviado nas etapas de S1 a S7, frações biodisponível (Bio) e residual (Res) para o solo LVd, na microbacia Entre Rios, Angatuba, São Paulo.

Para o RQo, na profundidade de $0-10 \mathrm{~cm}$ a fração residual foi de 47\% (Figura 78). Na fração biodisponível, os 53\% distribuíram-se em 29,15, 6, 2 e 1\%, associados aos óxidos de ferro amorfo (S5), óxidos de ferro cristalino (S6), ácidos solúveis (S3), à matéria orgânica (S7) e dissolvidas em água (S1), respectivamente. Na profundidade de 10-20 cm, a fração residual contemplou 32\%. Os $68 \%$ da fração lábil, distribuíram-se em 35, 16, 14 e 1\%, associados aos óxidos de ferro amorfo (S5), óxidos de ferro cristalino (S6), ácidos solúveis (S3), trocáveis (S2), dissolvidas em água (S1) e à matéria orgânica (S7), respectivamente. Na profundidade de 20-40 cm, a contribuição dos 77\% referentes à fração biodisponível se distribuiu em 46, 16, 14 e 1\%, associados respectivamente aos óxidos de ferro amorfo (S5), ácidos solúveis (S3), óxidos de ferro cristalinos (S6) e trocáveis (S2). 


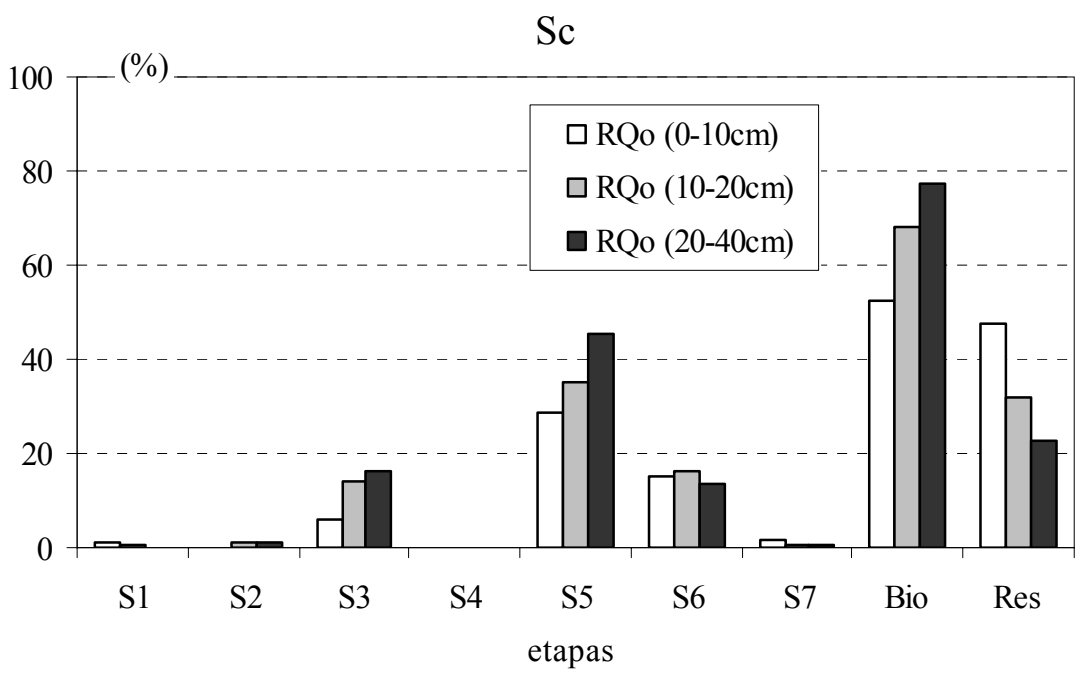

Figura 78. Porcentagem de Sc lixiviado nas etapas de S1 a S7, frações biodisponível (Bio) e residual (Res) para o solo RQo, na microbacia Entre Rios, Angatuba, São Paulo.

Para as amostras de sedimentos ITA1 e ITA10, as frações residuais foram de 64 e $79 \%$, respectivamente (Figura 79). As contribuições para a fração lábil em ambas as amostras (36 e $21 \%$ ) ocorreram nas frações associadas aos óxidos de ferro amorfo (S5) com 19 e 10\%, óxidos de ferro cristalinos (S6) com 10 e 6\%, ácidos solúveis (S3) com 6 e 3\% e matéria orgânica (S7) com 1 e $2 \%$, respectivamente.

De maneira geral, foi observado que o Sc teve maiores porcentagens das frações biodisponíveis nas amostras dos solos e sedimentos da microbacia de drenagem principalmente ligados aos óxidos de ferro amorfo (S5) e ferro cristalino (S6). 


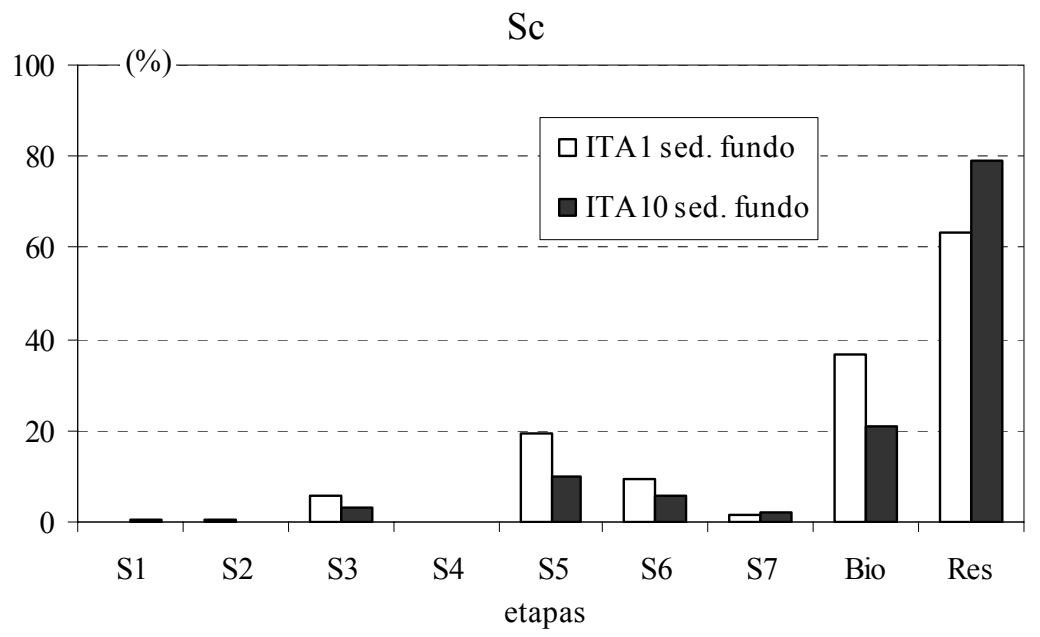

Figura 79. Porcentagem de Sc lixiviado nas etapas de S1 a S7, frações biodisponível (Bio) e residual (Res) para as amostras de sedimentos de fundo ITA1 e ITA10 coletadas no período chuvoso e seco, respectivamente, na microbacia Entre Rios, Angatuba, São Paulo.

\subsection{Fundo geoquímico natural e fator de enriquecimento (EF)}

O fundo geoquímico natural da microbacia Entre Rios foi calculado a partir das amostras dos solos nas profundidades de 20-40 cm, conforme item 4.8., com concentrações para $\mathrm{Cr}, \mathrm{Cd}$, $\mathrm{Co}, \mathrm{Cu}$ e $\mathrm{Zn}$, respectivamente de 26,$30 ; 2,29 ; 6,72 ; 11,93 ; 22,50$ e $5,38 \mu \mathrm{g} \mathrm{g}^{-1}$ para o CXbd, 23,$48 ; 2,25 ; 13,04 ; 10,06 ; 34,18$ e $6,84 \mu \mathrm{g} \mathrm{g}{ }^{-1}$ para o LVAd, 26,$25 ; 2,11 ; 4,34 ; 6,87$ e $5,03 \mu \mathrm{g} \mathrm{g}^{-1}$ para o ROo e para $\mathrm{Cr}, \mathrm{Cd}, \mathrm{Pb}, \mathrm{Ni}, \mathrm{Co}, \mathrm{Cu}$ e $\mathrm{Zn}$ concentrações de 89,50; 3,80; 24,23; 48,62; 178,$54 ; 205,73 ; 145,10$ e 40,70 $\mu \mathrm{g} \mathrm{g}^{-1}$ para o LVd. Em termos comparativos, foram utilizados os resultados médios das concentrações de $\mathrm{Cr}, \mathrm{Cd}, \mathrm{Pb}, \mathrm{Ni}, \mathrm{Co}, \mathrm{Cu}$ e $\mathrm{Zn}$ presentes na crosta terrestre de acordo com Taylor e McLennan (1985) com concentrações médias de 35; 0,1; 20; 20; 10; 25 e 71 , respectivamente.

A Tabela 20 apresenta os resultados das possíveis anomalias de $\mathrm{Cu}, \mathrm{Cd}$ e $\mathrm{Co}$ nas amostras de solos da camada de 0-10 $\mathrm{cm}$, expressas de acordo com o fator de enriquecimento (EF) 
calculado tendo o Sc como elemento normalizador, considerando o fundo geoquímico natural da microbacia de drenagem e a composição média da crosta terrestre.

Tabela 20. Fatores de enriquecimento para os principais solos da microbacia de drenagem Entre Rios na profundidade de $0-10 \mathrm{~cm}$.

\begin{tabular}{|c|c|c|c|c|c|c|c|}
\hline \multirow{2}{*}{ solos } & $\mathrm{Cu}$ & $\mathrm{Cr}$ & $\mathrm{Cd}$ & $\mathrm{Ni}$ & $\mathrm{Pb}$ & Co & $\mathrm{Zn}$ \\
\hline & \multicolumn{7}{|c|}{ fator de enriquecimento (fundo geoquímico natural) } \\
\hline $\operatorname{Cxbd}(0-10 \mathrm{~cm})$ & 2,2 & 1,1 & 1,2 & & & 1,6 & 1,7 \\
\hline LVAd $(0-10 \mathrm{~cm})$ & 8,4 & 2,2 & 2,0 & & & 2,6 & 2,3 \\
\hline $\operatorname{LVd}(0-10 \mathrm{~cm})$ & 1,0 & 1,0 & 1,1 & 1,0 & 0,9 & 1,0 & 1,2 \\
\hline \multirow[t]{2}{*}{ RQo $(0-10 \mathrm{~cm})$} & 2,1 & 1,5 & 1,2 & & & 1,2 & 1,3 \\
\hline & \multicolumn{7}{|c|}{ fator de enriquecimento (crosta continental terrestre) } \\
\hline Cxbd $(0-10 \mathrm{~cm})$ & 2,2 & 1,6 & 55,4 & & & 2,2 & 1,1 \\
\hline $\operatorname{LVAd}(0-10 \mathrm{~cm})$ & 5,5 & 2,4 & 72,2 & & & 5,4 & 1,8 \\
\hline $\operatorname{LVd}(0-10 \mathrm{~cm})$ & 2,2 & 0,7 & 11,5 & 0,6 & 0,3 & 5,0 & 0,6 \\
\hline RQo $(0-10 \mathrm{~cm})$ & 1,3 & 2,5 & 55,2 & & & 1,2 & 0,8 \\
\hline
\end{tabular}

De maneira geral pode ser verificado que os resultados obtidos de EF foram semelhantes tanto com a utilização do fundo geoquímico natural ou com a composição média da crosta terrestre, exceto para Co nos latossolos e Cd. Os altos valores de EF observados para o Cd podem ser devido à presença de solos lateríticos na região da microbacia de drenagem.

De acordo com Sposito (1989), valores de EF entre 0,5 e 2 podem ser considerados dentro da variabilidade natural, o que ocorreu para a maioria dos solos estudados, com exceção ao Cu e Co que apresentaram valores de 8,4 e 5,4 para o solo LVAd e 5,0 para o LVd.

De qualquer maneira, os resultados de EF apresentados para os solos da camada de 0-10 $\mathrm{cm}$ da microbacia de drenagem se mostraram de origem natural. $\mathrm{O} \mathrm{Cu}$ foi o elemento com valor de EF cerca de 8 vezes o fundo geoquímico natural e poderia apresentar preocupação com o 
ambiente de estudo, porém conforme observado na extração seqüencial seletiva, apenas $3 \%$ se mostrou concentrado na fração biodisponível e principalmente ligado aos óxidos de ferro amorfo.

Para a microbacia de drenagem, foi observado que os metais pesados nas amostras de solos e sedimentos, exceto $\mathrm{Cu}$ no LVAd $(0-10 \mathrm{~cm})$ com fatores de enriquecimento considerados de origem natural (menores do que 2) tiveram as mais significativas porcentagens das frações biodisponíveis associadas aos óxidos de ferro amorfo, óxidos de ferro cristalino e matéria orgânica, e, portanto de difícil alteração do pH em condições naturais. 


\section{CONCLUSÕES}

O monitoramento hidrogeoquímico realizado na microbacia de drenagem Entre Rios, através da dinâmica do material particulado e dissolvido transportados fluvialmente, considerando-se os aportes de origem atmosférica e antrópica, bem como as flutuações hidroclimáticas locais permitiram a utilização de modelos de diluição proposta para bacias de grande e médio porte. A realização de duas amostragens intensivas das águas fluviais da microbacia de drenagem durante os eventos chuvosos foram fundamentais para a validação dos modelos de diluição propostos para as espécies químicas de interesse, para verificar contribuições de aportes difusos na microbacia anterior e posterior a colheita da madeira e para observar a contribuição do escoamento superficial e subterrâneo nos aportes fluviais da microbacia de drenagem.

Não houve desequilíbrio iônico, verificado pela qualidade analítica das amostras de águas fluviais coletadas na microbacia do córrego Entre Rios em função do princípio da neutralidade química. O erro analítico obtido menor do que $10 \%$ foi critério necessário e suficiente para atestar a boa qualidade dos resultados segundo o procedimento adotado.

As características hidroquímicas das águas fluviais da microbacia de drenagem do córrego

Entre Rios mostraram que as espécies químicas $\mathrm{SiO}_{2}, \mathrm{HCO}_{3}^{-}, \mathrm{Ca}^{2+}, \mathrm{Mg}^{2+}, \mathrm{Na}^{+}$, e TDS apresentaram uma tendência de diluição de acordo com o modelo bilogarítmo ou de potência. Os relacionamentos concentração/vazão obtidos para $\mathrm{SiO}_{2}$ e $\mathrm{HCO}_{3}^{-}$em comparação com suas respectivas curvas de diluição teórica indicaram a influência de aportes difusos na microbacia associados aos processos de alterações de minerais silicatados existentes na microbacia e aos aportes pluviais decorridos ao longo do período estudado.

A partir das análises realizadas com as variabilidades temporais e do relacionamento 
concentração/vazão para as espécies químicas de interesse, os resultados da segunda amostragem intensiva de águas fluviais, posterior a colheita de madeira, evidenciaram anomalias de $\mathrm{K}^{+} \mathrm{e} \mathrm{Cl}^{-}$ nas cargas dissolvidas que apresentaram padrões de aumento de suas concentrações em relação ao aumento das respectivas vazões. A aplicação de insumos agrícolas foi a principal via de entrada destas espécies dissolvidas, aumentando a concentração destes íons na carga fluvial dissolvida.

Os resultados de porcentagem das principais espécies químicas dissolvidas no córrego Entre Rios em função dos sólidos dissolvidos totais, nas amostragens extensivas e intensivas 1 e 2, evidenciaram que as espécies mais representativas foram o $\mathrm{SiO}_{2}(40,1 ; 42,9$ e $34,1 \%), \mathrm{HCO}_{3}{ }^{-}$ $(34,8 ; 31,4$ e $27,6 \%), \mathrm{Ca}^{2+}(6,8 ; 6,5$ e $6,9 \%), \mathrm{K}^{+}(6,5 ; 7,8$ e $12,0 \%)$ e $\mathrm{Cl}^{-}(4,1 ; 3,4$ e $8,5 \%)$.

Foi observado maior valor do transporte específico de TDS na amostragem intensiva 1 (anterior à colheita), em relação à amostragem intensiva 2 (posterior à colheita) pelo método

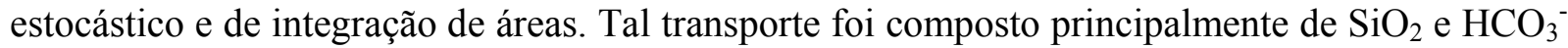
e a origem destas espécies, como mencionado anteriormente, estiveram associadas à alterações de rochas e aportes atmosféricos totais. Não houve diferenças significativas $(\alpha=0,05)$ ao compararem-se os métodos estocástico e de integração de áreas no cálculo de transporte das amostragens intensivas, de acordo com a aplicação do teste t de Student.

O relacionamento concentração/vazão de MPS permitiu verificar aumento da concentração em função da vazão, ou seja, maior arraste deste material nas maiores vazões, especialmente nas duas amostragens intensivas de acordo com os modelos clássicos observados para rios de pequeno porte. O transporte específico na amostragem intensiva 1 foi maior do que as demais, fato esse atribuído a maior precipitação ocorrida no dia da amostragem e as maiores condições de saturação do solo nos dias que antecederam a coleta de amostras. Em ambas as amostragens intensivas foi possível observar a ocorrência dos processos de remobilização e 
sedimentação da carga particulada.

A erosão mecânica mostrou-se com uma taxa de dedradação física dos solos da microbacia de $8,7 \mathrm{~m} \mathrm{Ma}^{-1}$. Esse resultado indica uma grande importância da área cultivada com eucaliptos para a erosão mecânica e para possíveis alterações de manejo.

Em relação aos aportes atmosféricos, $\mathrm{o} \mathrm{Ca}^{2+} \mathrm{e} \mathrm{o} \mathrm{Na}^{+}$foram os cátions que apresentaram valores mais significativos nas amostras de água de chuva, enquanto que para os ânions, os mais representativos foram o $\mathrm{HCO}_{3}{ }^{-}, \mathrm{NO}_{3}{ }^{-}$e $\mathrm{SO}_{4}{ }^{2-}$. O transporte específico das principais espécies químicas precipitadas nas águas da chuva (TDS) foi de $4,10 \mathrm{t} \mathrm{km}^{-2} \mathrm{a}^{-1}$. Os resultados das razões entre $\mathrm{Ca}^{2+}, \mathrm{Mg}^{2+}, \mathrm{Na}^{+}, \mathrm{K}^{+}$e $\mathrm{SO}_{4}{ }^{2-}$ com o $\mathrm{Cl}^{-}$mostraram que não houve contribuições provindas desses íons da chuva marinha nos aportes pluviais da microbacia Entre Rios, sendo originadas principalmente de emissões terrestres. De maneira geral, houve domínio da química da água da chuva sobre a química da água do córrego Entre Rios observados pelas razões entre os resultados dos transportes totais de águas pluviais e fluviais.

O estudo da mineralogia dos solos evidenciou que na microbacia de drenagem há predomínio de quartzo $\left(\mathrm{SiO}_{2}\right)$ nos solos e sedimentos, e presença de hematita $\left(\mathrm{Fe}_{2} \mathrm{O}_{3}\right)$ e caulinita $\left(\mathrm{Al}_{2} \mathrm{Si}_{2} \mathrm{O}_{5}(\mathrm{OH})_{4}\right)$ no solo LVd. Os resultados da composição química nas amostras de sedimentos de fundo e solos nas profundidades 0-10, 10-20 e 20-40 cm (CXbd, LVAd, LVd e RQo) mostraram predominância dos óxidos de $\mathrm{SiO}_{2}, \mathrm{Al}_{2} \mathrm{O}_{3}$ e $\mathrm{Fe}_{2} \mathrm{O}_{3}$ na microbacia de drenagem Entre Rios. A predominância de $\mathrm{SiO}_{2}(>80 \%)$ nos solos CXbd, LVAd e RQo da microbacia Entre Rios deveu-se à sua constituição mineralógica composta de quartzo. O LVd de textura argilosa teve menor contribuição de $\mathrm{SiO}_{2}(27 \%)$.

Em termos de extração total os metais pesados $\mathrm{Cr}, \mathrm{Cd}, \mathrm{Co}, \mathrm{Cu}, \mathrm{Zn}$ e $\mathrm{Sc}$ foram os que apresentaram concentrações mais elevadas no solo LVd que contempla $17,2 \%$ da área total da microbacia de drenagem em relação aos demais solos estudados. As características intrínsecas do 
solo LVd como textura argilosa e elevado grau de alteração de rochas podem justificar esses elevados teores.

A especiação química dos solos e sedimentos revelou que os metais pesados com maior representatividade em termos de biodisponibilidade na microbacia de drenagem foram o $\mathrm{Cd}$ e $\mathrm{Zn}$ no solo LVd com valores maiores do que 80 \% da fração biodisponível e Sc nos solos CXbd, LVAd e RQo com contribuições maiores do que 70 \% da fração lábil. Esses solos representam mais de $50 \%$ da área total da microbacia. Para os sedimentos de fundo o Cd foi o metal pesado que teve a contribuição mais significativa (56 \% ) da fração biodisponível e os demais elementos a contribuição foi menor do que $45 \%$. Na fração biodisponível os metais pesados $\mathrm{Cr}, \mathrm{Cd}$ e $\mathrm{Pb}$ indicaram ligações principalmente associadas à fase óxido de ferro cristalino. Ni e Zn estiveram ligadas principalmente à fase matéria orgânica, enquanto Sc à fase óxido de ferro amorfo.

Os resultados de EF apresentados para os solos da camada de 0-10 $\mathrm{cm}$ da microbacia de drenagem não evidenciaram influência antrópica causada pelos tratos culturais realizadas na área de estudo, exceto pelo $\mathrm{Cu}$ no solo LVAd. Entretanto, apenas 3\% desse elemento se encontraram na fração biodisponível e principalmente ligado aos óxidos de ferro amorfo. 


\section{REFERÊNCIAS}

AMIOTTE-SUCHET, P. Cycle du carbone, érosion chimique des continents et transferts vers les oceans. Strasbourg, 1995. 156 f. Thèse (Doctor) - Centre de Géochimie de la Surface, Université Louis Pasteur.

ARCOVA, F.C.S.; CICCO, V. Qualidade da água de microbacias com diferentes usos do solo na região de Cunha, Estado de São Paulo. Scientia Forestalis, Piracicaba, v. 56, p. 125-134, 1999.

ARCOVA, F.C.S.; CICCO, V.; LIMA, W.P. Balanço dos nutrientes $\mathrm{Ca}^{2+}, \mathrm{Mg}^{2+}, \mathrm{Na}^{+}, \mathrm{K}^{+} \mathrm{e}$ $\mathrm{NO}_{3}{ }^{-}$em bacia hidrográfica experimental com vegetação natural do Parque Estadual da Serra do Mar - Núcleo Cunha - SP. IPEF, Piracicaba, v. 31, p. 61-67, 1985.

BERNER, R.A.; LASAGA, A.C.; GARRELS, R.M. The carbonate silicate geochemical cycle and its effect on atmospheric carbon dioxide over the past 100 millions years. American Journal of Science, Stanford, v. 283, p. 641-683, 1983.

BIBIAN, J.P.R. Caracterização hidrogeoquímica da microbacia de drenagem do córrego Barra Bonita, São Paulo. Piracicaba, 2007. 194 f. Dissertação (Mestrado) - Centro de Energia Nuclear na Agricultura, Universidade de São Paulo.

BOEGLIN, J.I.; MORTATTI, J.; TARDY, Y. Erosion chimique et mécanique sur le bassin amont du Niger (Guiné, Mali). Bilan géochimique de l'álteration en milieu tropical. Comptes Rendus de l’Academie de Science de Paris. Paris, v. 325, p. 185-191, 1997.

BOEGLIN, J.L.; PROBST, J.L. Physical and chemical weathering rates ad $\mathrm{CO}_{2}$ consumption in a tropical lateritic environment: the upper Niger basin. Chemical Geology, Amsterdam, v. 148, p. 137-156, 1998.

BORTOLETTO JÚNIOR, M.J. Características hidrogeoquímicas e processos erosivos mecânicos e químicos nas bacias de drenagem dos rios Tietê e Piracicaba. Piracicaba, 2004. 202 f. Tese (Doutorado) - Centro de Energia Nuclear na Agricultura, Universidade de São Paulo, 2004.

BORTOLETTO JÚNIOR, M.J.; MORTATTI, J.; PROBST J.L. Erosão química na bacia hidrográfica do rio Corumbataí (SP). Geochimica Brasiliensis, Rio de Janeiro, v. 16, n. 1, p. 99-111, 2002.

BORTOLETTO JÚNIOR. M.J. Balanço de alteração e erosão química na bacia hidrográfica do rio Corumbataí. Piracicaba, 1999. 95 f. Dissertação (Mestrado) - Centro de Energia Nuclear na Agricultura, Universidade de São Paulo.

BOS, M.G. Discharge Measurement Structures. Wageningen, ILRI, 1976. 464p.

BROOKS, K.N.; FFOLLIOTT, P.F. GREGERSEN, H.M.; THAMES, J.L. Hydrology and the Management of Watersheds. Ames: Iowa State University Press, 1991. 391p. 
CÂMARA, C.D.; LIMA, W.P. Corte raso de uma plantação de Eucalyptus saligna de 50 anos: impactos sobre o balanço hídrico e a qualidade da água em uma microbacia experimental. Scientia Forestalis, Piracicaba, v. 56, p. 41-58, 1999.

CÂMARA, C.D.; LIMA, W.P.; VIEIRA, S.A. Corte raso de uma plantação de Eucalyptus saligna de 50 anos: impactos sobre a ciclagem de nutrientes em uma microbacia experimental. Scientia Forestalis, Piracicaba, v. 57, p. 99-109, 2000.

COSTA, C. das N. Biodisponibilidade de metais pesados em solos do Rio Grande do Sul. Porto Alegre, 2005. 110 f. Tese (Doutorado) - Faculdade de Agronomia, Universidade Federal do Rio Grande do Sul.

CRUCIANI, D.E. Hidráulica, equações, tabelas, gráficos. Centro Acadêmico "Luiz de Queiroz”, Departamento Editorial, 1993. 129p.

EDMOND, J.M. High precision determination of titration alkalinity and total carbon dioxide content of seawater by potentiometric titration. Deep-Sea Research. Part I: Oceanographic Research Papers, Oxford, v. 17, n. 4, p. 737-750, 1970.

EMBRAPA. Determinação da textura pelo método do densímetro simplificado. Centro Nacional de Pesquisas de solos, 1997. Disponível em: www.embrapa.br/solos/paqlf. Acesso em: 28 ago. 2008.

EMBRAPA. Sistema brasileiro de classificação de solos. $2^{a}$ ed. Brasília: Embrapa, 2006. 306p.

FERNANDES, A.M. Comportamento do $\mathbf{N}$ inorgânico dissolvido em águas superficiais e sub-superficiais em área com cultivo de cana-de-açúcar. Piracicaba, 2008. $133 \mathrm{f}$. Dissertação (Mestrado) - Centro de Energia Nuclear na Agricultura, Universidade de São Paulo.

FILGUEIRAS, A.V.; LAVILLA, I.; BENDICHO, C. Chemical sequential extration form metal partitioning in environmental solid samples. Journal of Environmental Monitoring, Cambridge, v. 4. p. 823-857, 2002.

GARCIA-ESTEVES J.; LUDWIG, W.; KERHERVÉ , P.; PROBST, J.L.; LESPINAS, F. Predicting the impact of land use on the major element and nutrient fluxes in coastal Mediterranean rivers: the case of the Têt River (Southern France). Applied Geochemistry, Oxford, v. 22, p. 230-248. 2007.

GARRELS, R.M.; MACKENZIE, F.T. Evolutions of sedimentary rocks. New York: Norton, 1971. 397p.

GAVA, J.L. Relações entre atributos do solo e qualidade da madeira de clone de Eucaliptus grandis para produção de celulose. Piracicaba, 2005. 54 f. Dissertação (Mestrado) - Escola Superior de Agricultura Luiz de Queiroz, Universidade de São Paulo.

GLEYZES, C.; TELLIER, S.; ASTRUC, M. Fractionation studies of trace elements in contaminated soils and sediments: A review of sequential extraction procedures. Trends Analytical Chemistry, Amsterdam, v. 21, p. 451-467, 2002. 
GOMES, P.C. Fracionamento e biodisponibilidade de metais pesados por calagem e concentrações de metais em Latossolo Vermelho-amarelo. Viçosa, 1996. 161p. Tese (Doutorado) - Universidade Federal de Viçosa.

GRESENS, R. L. Composition-volume relationships of metasomatism. Chemical Geology, Amsterdam, v. 2, p. 47-55, 1967.

HEN, J. D. Study and interpretation of the chemical characteristics of natural water. Washington, United States Government Printing Office, 1970. 383 p.

HINO, M.; HASEBE, M. Identification and Prediction of Nonlinear Hydrologic Systems by the Filter-Separation Autoregressive (AR) Method: Extension to Hourly Hydrologic Data. Journal of Hydrology, Amsterdam, v. 68, p. 181-210. 1984.

HLAVAY, J.; PROHASKA, T.; WEISZ, M.; WENZEL , W.W.; STINGEDER, G.J. Determination of trace elements bound to soils and sediment fractions. (IUPAC Technical Report). Pure and Applied Chemistry, Prague, v. 76, n. 2, p. 415-442. 2004.

HO, M.D.; EVANS, G.J. Sequential extraction of metal contaminated soils with radiochemical assessment of readsorption effects. Environmental Science \& Technology, Iowa, v. 34. p. 1030-1035. 2000.

HOPMANS, P.; FLINN, D.W.; FARREL, P.W. Nutrient dynamics of forested catchments in southeasterm Australia and changes in water quality and nutrient exports following clearing. Forest Ecology and Management, Amsterdam, v. 20, n. 34, p. 209-231, 1987.

HORNBECK, J. W.; KROPELIN, W. Nutrient removal and leaching from a whole-tree harvest of northerm hardwoods. Journal of Envrironental Quality, Madison, v. 11, n. 2, p. 309-316, 1982.

INSTITUTO DE PESQUISAS TECNOLÓGICAS DE SÃO PAULO - IPT. Mapa Geológico do Estado de São Paulo. São Paulo, v. 1, 126p. 1981.

JENKINS, A.; PETERS, N.E.; RHODE, A. Hydrology. In: MOLDAN, B.; CERNY, J. Biogeochemistry of small catchments: A tool for environmental research. Chichester: John Wiley \& Sons, 1994.

KABALA, C.; SINGH, B. R. Fractionation and mobility of copper, lead, and zinc in soil profiles in the vicinity of a copper smelter. Journal of Environmental Quality, Madison, v. 30, p. 485-492, 2001.

KATTAN, Z. Géochimie et hydrologie dês eaix fluviales dês bassins de la moselle et de la Mossig. Transports dissous et particulaires. Cycles biogeochimiques dês éléments. Strasbourg, 1989, 220 f. Thèse (Doctor) - Centre de Géochimie de la Surfaze, Université Louis Pasteur.

KER, J.C. Latossolos do Brasil: uma revisão. Geonomos, Belo Horizonte, v. 5, p. 17-40, 1997. 
LELEYTER L. Spéciation chimique des éléments majeurs, traces et des terres rares dans les matières en suspension et dans les sédiments de fond des cours d'eau: Application aux fleuves de Patagonie (Argentine), à la Piracicaba (Brésil), à l'oued Sebou (Maroc) et à l'Ill (France). Strasbourg, 1998. 297 f. Thèse (Doctor) - Centre de Géochimie de la Surface, Université Louis Pasteur.

LIMA, W.P. Escoamento superficial, perdas de solo e de nutrientes em microparcelas reflorestadas com eucalipto em solos arenosos no município de São Simão (SP). Scientia Florestalis, Piracicaba, v. 38, p. 5-16, 1988.

LIMA, W.P.; ZAKIA, M.J.B. Indicadores Hidrológicos Em Áreas Florestais. Série Técnica IPEF, Piracicaba, v. 12, n. 31, p. 53-64, 1998.

MARTINELLI, L. A. DEVOL, A. H.; FORSBERG, B. R.; VICTORIA, R. L.; RICHEY, J. E. Descarga de sólidos dissolvidos totais do rio Amazonas e seus principais tributários. Geochimica Brasiliensis, Rio de Janeiro, v. 3, p. 141-148, 1989.

McLENNAN, S.M. Sediments and soils: chemistry and abundances. In: Rock Physics and Phase Relations, a hand book of physical constants. A.G.U. reference shelf-3. American Geophysical Union, v. 34, p. 8-19, 1995.

MESSAITFA, A. Transfert d'eau, des sediments et de polluants associes sur le bassin de l'Ill: cas de mercure. Strasbourg, 1997. 209 f. Thèse (Doctor) - Centre de Géochimie de la Surface, Université Louis Pasteur.

MEYBECK, M. Bilan hydrochímique et géochimique du Lac Léman. Paris, 1970. $245 \mathrm{f}$. Thèse (Doctor) - C.R.G. Thonon les Bains, Université des Sciences.

MEYBECK, M. Composition chimique des ruisseaux non pollués de France. Science. Geology, Bulletin, Strasbourg, v. 39, n.1, p. 3-77, 1987.

MEYBECK, M. Total minerals dissolved transport by world major rivers. Hydrological Sciences Journal, Oxford, v. 21, p. 265-84, 1976.

MORTATTI, J. ; OLIVEIRA, H.; BIBIAN, J. P. R.; LOPES, R. A.; BONASSI, J. A.; PROBST, J. L. Origem do carbono inorgânico dissolvido no rio Tietê (São Paulo): Reações de equilíbrio e variabilidade temporal. Geochimica Brasiliensis, Rio de Janeiro, v. 20, p. 267-277, 2006.

MORTATTI, J. Erosão na Amazônia: processos, modelos e balanço. Piracicaba. 1995. 155 f. Tese (Livre-Docência) - Escola Superior de Agricultura “Luiz de Queiroz”, Universidade de São Paulo.

MORTATTI, J.; BERNARDES, M.C., PROBST, J.L.; LELEYTER-REINERT, L. Composição química dos sedimentos fluviais em suspensão na bacia do rio Piracicaba: extração seletiva de elementos traço. Geochimica Brasiliensis, Rio de Janeiro, v. 16, n. 2, p. 123-141, 2002.

MORTATTI, J.; BORTOLETTO JUNIOR, M J ; MILDE, L C E. ; PROBST, J L. Hidrologia dos rios Tietê e Piracicaba: séries temporais de vazão e hidrogramas de cheia. Ciência e Tecnologia, Piracicaba, v. 12, n. 23, p. 55-67, 2004. 
MORTATTI, J.; PROBST J.L.; BORTOLETTO JUNIOR, M.J. Piracicaba river basin: mechanical and chemical erosions. Geociências, São Paulo, v. 22, n. 1, p. 75-81, 2003.

MORTATTI, J.; PROBST, J. L. Silicate weathering and atmospheric/soil $\mathrm{CO}_{2}$ uptake in the Amazon basin estimated from river water geochemistry: seasonal and spatial variations. Chemical Geology, Amsterdam, v. 197, p. 177-196, 2003.

MORTATTI, J.; PROBST, J.L.; FERREIRA, J.R. . Hydrological And Geochemical Characteristics Of The Jamari An Jiparana River Basins (Rondonia, Brazil). Geojournal, Dordrecht, v. 26, n. 3, p. 287-296, 1992.

MORTATTI, J.; RODRIGUES, J.R.; MARTINELLI, L.A. Balanço da erosão na bacia do rio Piracicaba: resultados preliminares. In: WORKSHOP DO PROJETO PIRACENA, 2., 1996, Nazaré Paulista. A bacia hidrográfica como unidade de estudo: estrutura e processos; anais. Piracicaba: CENA/USP, 1996. p. 137-139.

MORTATTI, J.; VICTORIA, R.L.; TARDY, Y. Balanço de Alteração e Erosão Química na Bacia Amazônica. Geochimica Brasiliensis, Rio de Janeiro, v. 11, n. 1, p. 2-13, 1997.

MOUKOLO, N.; LARAQUE, A.; OLIVRY, J.C.; BRICQUET, J. P. Transport en solution et en suspension par le fleuve Congo (Zaire) et ses principaux affluents de rive droite. Hidrological Science Journal, Oxford, v. 38, p. 133-145, 1993.

NIREL, P.M.V.; MOREL, F.M.M. Pitfalls of sequential extractions. Water Research, Amsterdam, v. 24. p. 1055-1056, 1990.

NKOUNKOU R.R.; PROBST J.L. Hydrology and Geochemistry of the Congo River System. Hamburg: Mitt.Geol.-Paliont. Institute; Univ. Sonderb, 1987. p. 483-508. (SCOPE, $64)$.

ODUM, E. Ecologia. Rio de Janeiro: Ed. Guanabara, 1988. 434 p.

PERAY, N. Composition chimique des eaux e l'Ill à Strasbourg: variations saisonnières des flux de matières et bilan de l'erosion chimique. Strasbourg, 1998. ULP - Centre de Géochimie de la Surface.

PROBST, J. L. Dissolved and suspended matter transported by the Girou River (France): mechanical e chemical erosion rates in a calcareous molasse basin. Hidrological Sciences Journal, Oxford, v. 31, p. 61-79, 1986.

PROBST, J. L.; BAZERBACHI, A. Transports en solution et en suspension par la Garonne supérieure. Science Géologiques Bulletin, Strasbourg, v. 1, p. 79-98, 1986.

PROBST, J.L. Géochimie et Hydrologie de l’Érosion Continentale. Mécanisms, Bilan Global Actuel et Fluctuations au Cours des 500 Derniers millions d'annés. Sciencie Geology, Strasbourg, 1992. 161p.

PROBST, J.L. Hydrologie du bassin de la Garonne. Modèles de mélanges. Bilan de l'erosion. Exportation des phosphates et des nitrates. Toulouse, 1983. 148 f. Thèse (Doctor) - Université Paul Sabatier. 
PROBST, J.L.; MORTATTI, J.; TARDY, Y. Carbon river fluxes and global weathering $\mathrm{CO}_{2}$ consumption in the Congo and Amazon river basins. Applied Geochemistry, Oxford, v. 9, p. 1-13, 1994.

PROBST, J.L.; NKOUNKOU, R.R.; KREMPP, G.; BRICQUET, J.P.; THIÉBAUX, J.P.; OLIVRY, J.C. Dissolved major elements exported by the Congo and the Ubangi rivers during the period 1987-1989. Journal of Hydrology, Amsterdam, v. 135, p. 237-257, 1992.

RANZINI, M.; LIMA, W.P. Comportamento hidrológico, balanço de nutrientes e perdas de solo em duas microbacias reflorestadas com Eucalyptus, no Vale do Paraíba (SP). Scientia Forestalis, Piracicaba, v. 61, p. 144-159, 2002.

RANZINI, M.; RIGHETTO, A.M.; LIMA, W.P.; GUANDIQUE, M.E.G.; ARCOVA, F.C.S.; CICCO, V. Processos hidrológicos de uma microbacia com Mata Atlântica, na região da Serra do Mar (SP). Scientia Forestalis, Piracicaba, v. 65, p. 108-119, 2004.

SAMUEL J.; ROUAULT R. Analyse multiélémentaire standardisée des matériaux géologiques en spectrométrie d'émission par plasma a couplage inductif. Analusis, v. 13, p. 312-317, 1985.

SASTRE, I.; VICENTE, M.A.; LOBO, M.C. Behavior of cadmium and nickel in a soil amended with sewage sludge. Land Degradation and Development, Baltimore, v. 12, p. 2733, 2001.

SCARDUA, F.P. Caracterização hidrológica de uma microbacia hidrográfica da estação experimental de Ciências Florestais de Itatinga (SP). Piracicaba, 1994. 94 f. Dissertação (Mestrado) - Escola Superior de Agricultura Luiz de Queiroz, Universidade de São Paulo.

SEMHI, K. et al. Dissolved silica in the Garonne river waters: changes in the weathering dynamics. Environmental Geology, Heidelberg, v. 40, n. 1-2, p. 19-26, 2000.

SILVA, I.S.; ABATE, G.; LICHTIG, J.; MASINI, J.C. Heavy metal distribution in recent sediments of the Tietê-Pinheiros system in São Paulo State, Brazil. Applied Geochemistry, Oxford, v. 17, p. 105-116, 2002.

SMOLDERS A.J.P.; HUDSON-EDWARDS K.A.; VAN DER VELDE G.; ROELOFS J.G. M. Controls on water chemistry of the Pilcomayo river (Bolivia, South-America). Applied Geochemistry, Oxford, v. 19, p. 1745-1758, 2004.

SPOSITO, G. The Chemistry of Soils. New York: Oxford University Press, 1989. 277 p.

SPOSITO, G.; LUND, L.J.; CHANG, A. C. Trace metal chemistry in arid zone field soils amended with sewage sludge: fractionation of $\mathrm{Ni}, \mathrm{Cu}, \mathrm{Zn}, \mathrm{Cd}$ and $\mathrm{Pb}$ in solid phases. Soil Science Society America Journal, Madison, v. 46, p. 260-264, 1982.

STALLARD, R. F.; EDMOND, J. M. Geochemistry of the Amazon basin. 2. The influence of the geology and weathering environment on the dissolved load. Journal of the Geophysical Research, Washington, v. 88, p. 9671-9688, 1983. 
STALLARD, R.F.; EDMOND, J.M. Precipitacion chemistry and marine contribution to the dissolved load at the time of peak discharge. Journal of Geophysical Research. Serie C, Washington, v. 86, p. 9844-9858, 1981.

STEVENS, P.A; NORRIS, A.D.; WILLIAMS, T.G. Nutrient losses after clearfelling in Bedgelert Forest: a comparison of the effects of conventional and whole-tree harvest on soil water chemistry. Forestry, Oxford, v. 68, p. 115-131, 1995.

SUGIMOTO, S.; NAKAMURA, F.; ITO, A. Heat budget and statistical analysis of the relationship between stream temperature and riparian forest in the Toikanbetsu river basin, Northern Japan. Journal of Forest Research, Tokyo, v. 2, p. 103-107, 1997.

SWAMI, M.; MATTOS, A. Hidrologia Aplicada. São Paulo: Mcgraw-Hill do Brasil, 1975. 233p.

SWIFT JR, L.W.; MESSER, J.B. Forest cuttings raise temperatures of small streams in the southern Appalachians. Journal of soil and water conservation, v.26, n.3, p. 111-117, 1971.

TARDY, Y. Characterization of the principal weathering types by the geochemistry of Waters from some european and african crystalline massifs. Chemical Geology, Amsterdam, v.7, p. 253-271, 1971.

TARDY, Y. Une méthode de détermination dês types d'altération actuels par l'étude dês eaux em pays granitiques et gneissiques. Comptes Rendus de l'Academie des Sciences. Serie D, Paris, v. 267, p. 579-582, 1968.

TAYLOR, S.R.; McLENNAN, S.M. The continental crust: Its composition and evolution. Blackwell: Oxford University Press, 1985. 312 p.

TESSIER, A.; CAMPBELL, P. G. C.; BISSON, M. Sequential extraction procedure for the speciation of particulate trace metals. Environmental Technology, London, v. 51, p. 844851, 1979.

URE, A.M. QUEVAUVILlER, P. H.; MUNTAU, H.; GRIEPINK, B. Speciation of heavy metals in soils and sediments. An account of the improvement and harmonization of extraction techniques undertaken under the auspices of the BCR of the Commission of the European Communities. International Journal of Environmental Analytical Chemistry, Oxon, v. 51, p. 133-151, 1993.

VIETS, F. G. Chemistry and availability of micronutrient in soils. Journal of Agricultural and Food Chemistry, Washington, v. 10 p. 174-178, 1962.

VITAL, A.R.T.; LIMA, W.P.; CAMARGO, F.R.A. Efeitos do corte raso de plantação de Eucalyptus sobre o balanço hídrico, a qualidade da água e as perdas de solo e de nutrientes em uma microbacia no Vale do Paraíba (SP). Scientia Forestalis, Piracicaba, v. 55, p. 5-16, 1999.

WALLING D. E. Water in the catchment ecosystem. In: GOWER, A. M. Water quality in the catchment ecosystems. Chichester: John Wiley \& Sons, p. 1-47, 1980. 
YOHO, N.S. Forest management and sediment production in the south; a review. Southern Journal of Applied Forestry, Washington, v. 4, p. 27-36, 1980. 
Apêndice 1 
Tabela 1A. Atividades desenvolvidas na área da microbacia de drenagem Entre Rios, desde o preparo até a colheita da madeira de eucaliptos.

\begin{tabular}{|c|c|c|c|c|c|c|}
\hline \multirow{2}{*}{ Talhão } & \multirow{2}{*}{$\begin{array}{l}\text { Área } \\
\text { (ha) }\end{array}$} & \multirow{2}{*}{ Atividade } & \multicolumn{2}{|c|}{ Data } & \multirow{2}{*}{ Adubação } & \multirow{2}{*}{$\begin{array}{c}\text { Quantidade } \\
\left(\mathrm{kg} \mathrm{ha}^{-1}\right)\end{array}$} \\
\hline & & & início & fim & & \\
\hline \multirow{8}{*}{30} & \multirow{8}{*}{3,9} & ADUBAÇAO DE PLANTIO & $22 / 03 / 05$ & $22 / 03 / 05$ & CINZA & $2.228,53$ \\
\hline & & SUBSOLAGEM & $22 / 07 / 05$ & $27 / 07 / 05$ & & \\
\hline & & ADUBAÇAO DE PLANTIO & $22 / 07 / 05$ & $27 / 07 / 05$ & $\begin{array}{l}\text { NPK 06-30-10 + } \\
0,3 \% \text { B }\end{array}$ & 291,15 \\
\hline & & PLANTIO & $27 / 07 / 05$ & $29 / 07 / 05$ & & \\
\hline & & ADUBAÇAO DE PLANTIO & $12 / 11 / 05$ & $13 / 11 / 05$ & $\begin{array}{l}\text { NPK 14-00-15 + } \\
0,5 \% \text { B + 16,8\% S }\end{array}$ & 168,94 \\
\hline & & ADUBAÇAO DE PLANTIO & 01/06/06 & 04/06/06 & $\begin{array}{l}\text { NPK 14-00-15 + } \\
0,5 \% \text { B + 16,8\% S }\end{array}$ & 301,93 \\
\hline & & $\begin{array}{l}\text { ADUBAÇAO DE } \\
\text { COBERTURA } 4\end{array}$ & 02/03/07 & 02/03/07 & $\begin{array}{l}\text { NPK 00-00-54 + } \\
1 \% \text { B }\end{array}$ & 161,25 \\
\hline & & $\begin{array}{l}\text { ADUBAÇAO DE } \\
\text { COBERTURA } 4\end{array}$ & $04 / 04 / 07$ & 05/04/07 & $\begin{array}{l}\text { NPK 20-00-00 + } \\
\text { 24\% S (SULFATO } \\
\text { DE AMONIO) }\end{array}$ & 395,38 \\
\hline \multirow{5}{*}{31 e 33} & \multirow{5}{*}{16,4} & $\begin{array}{l}\text { ADUBAÇAO PRÉ - } \\
\text { PLANTIO } 1\end{array}$ & 20/11/07 & $22 / 11 / 07$ & CINZA & $2.089,65$ \\
\hline & & SUBSOLAGEM & $01 / 12 / 07$ & $11 / 12 / 07$ & & \\
\hline & & ADUBAÇAO DE PLANTIO & 01/12/07 & $12 / 12 / 07$ & $\begin{array}{l}\text { NPK 06-30-10 + } \\
0,3 \% \text { B }\end{array}$ & 261,21 \\
\hline & & PLANTIO & $06 / 12 / 07$ & $22 / 12 / 07$ & & \\
\hline & & $\begin{array}{l}\text { ADUBAÇAO DE } \\
\text { COBERTURA } 1\end{array}$ & 05/03/08 & $17 / 03 / 08$ & $\begin{array}{l}\text { NPK 14-00-15 + } \\
0,5 \% \text { B + 16,8\% S }\end{array}$ & 149,98 \\
\hline \multirow{5}{*}{32} & \multirow{5}{*}{47,3} & ADUBAÇAO DE PLANTIO & $22 / 02 / 04$ & $22 / 02 / 04$ & CINZA & $2.921,03$ \\
\hline & & PLANTIO & $04 / 03 / 04$ & $10 / 03 / 04$ & & \\
\hline & & ADUBAÇAO DE PLANTIO & $10 / 03 / 04$ & $10 / 03 / 04$ & $\begin{array}{l}\text { NPK 06-30-10 + } \\
0,3 \% \text { B }\end{array}$ & 254,52 \\
\hline & & SUBSOLAGEM & $10 / 03 / 04$ & $10 / 03 / 04$ & & \\
\hline & & ADUBAÇAO DE PLANTIO & $26 / 05 / 04$ & $26 / 05 / 04$ & $\begin{array}{l}\text { NPK 14-00-15 + } \\
0,5 \% \text { B + 16,8\% S }\end{array}$ & 146,29 \\
\hline
\end{tabular}

Continua... 
Tabela 1A. Atividades desenvolvidas na área da microbacia de drenagem Entre Rios, desde o preparo até a colheita da madeira de eucaliptos (continuação).

\begin{tabular}{|c|c|c|c|c|c|c|}
\hline & & $\begin{array}{l}\text { ADUBAÇAO DE } \\
\text { COBERTURA }\end{array}$ & 23/03/06 & $24 / 03 / 06$ & $\begin{array}{l}\text { NPK 00-00-54 + } \\
1 \% \text { B }\end{array}$ & 149,86 \\
\hline & & $\begin{array}{l}\text { ADUBAÇAO DE } \\
\text { COBERTURA }\end{array}$ & 24/03/06 & 26/03/06 & $\begin{array}{l}\text { NPK 14-00-15 + } \\
0,5 \% \text { B + 16,8\% S }\end{array}$ & 349,67 \\
\hline \multirow{15}{*}{222} & \multirow{15}{*}{14,2} & ADUBAÇAO DE PLANTIO & $15 / 05 / 02$ & $19 / 06 / 02$ & $\begin{array}{l}\text { NPK 06-30-10 + } \\
0,6 \% \text { B }\end{array}$ & 260,99 \\
\hline & & ADUBAÇAO DE PLANTIO & $19 / 05 / 02$ & $22 / 05 / 02$ & CINZA & $1.180,00$ \\
\hline & & SULCAMENTO & $22 / 05 / 02$ & $19 / 06 / 02$ & & \\
\hline & & PLANTIO & $22 / 05 / 02$ & $19 / 06 / 02$ & & \\
\hline & & ADUBAÇAO DE PLANTIO & 18/06/02 & 18/06/02 & $\begin{array}{l}\text { CALCARIO } \\
\text { DOLOMITICO }\end{array}$ & $1.503,60$ \\
\hline & & $\begin{array}{l}\text { ADUBAÇAO DE } \\
\text { COBERTURA }\end{array}$ & $27 / 08 / 02$ & 28/08/02 & $\begin{array}{l}\text { NPK 15-00-20 + } \\
0,6 \% \text { B + 9,6\% S }\end{array}$ & 120,33 \\
\hline & & $\begin{array}{l}\text { ADUBAÇAO DE } \\
\text { COBERTURA }\end{array}$ & 06/09/03 & 06/09/03 & NPK 16-00-32 & 252,76 \\
\hline & & $\begin{array}{l}\text { ADUBAÇAO DE } \\
\text { COBERTURA }\end{array}$ & $13 / 09 / 03$ & $13 / 09 / 03$ & $\begin{array}{l}\text { NPK 00-00-54 + } \\
1 \% \text { B }\end{array}$ & 152,01 \\
\hline & & $\begin{array}{l}\text { ADUBAÇAO DE } \\
\text { COBERTURA }\end{array}$ & $20 / 07 / 04$ & $22 / 07 / 04$ & $\begin{array}{l}\text { NPK 00-00-54 + } \\
1 \% \text { B }\end{array}$ & 152,85 \\
\hline & & $\begin{array}{l}\text { ADUBAÇAO DE } \\
\text { COBERTURA }\end{array}$ & $20 / 07 / 04$ & $22 / 07 / 04$ & $\begin{array}{l}\text { NPK 20-00-00 + } \\
\text { 24\% S (SULFATO } \\
\text { DE AMONIO) }\end{array}$ & 304,48 \\
\hline & & $\begin{array}{l}\text { ADUBAÇAO DE } \\
\text { COBERTURA }\end{array}$ & 06/04/05 & 09/04/05 & $\begin{array}{l}\text { NPK 20-00-00 + } \\
24 \% \text { S (SULFATO } \\
\text { DE AMONIO) }\end{array}$ & 302,03 \\
\hline & & $\begin{array}{l}\text { ADUBAÇAO DE } \\
\text { COBERTURA }\end{array}$ & 09/09/03 & 09/09/03 & $\begin{array}{l}\text { NPK 16-00-32+ 1\% } \\
\text { B }\end{array}$ & 250,13 \\
\hline & & $\begin{array}{l}\text { ADUBAÇAO DE } \\
\text { COBERTURA }\end{array}$ & $11 / 09 / 03$ & $11 / 09 / 03$ & $\begin{array}{l}\text { NPK 00-00-54 + } \\
1 \% \text { B }\end{array}$ & 150,38 \\
\hline & & $\begin{array}{l}\text { ADUBAÇAO DE } \\
\text { COBERTURA }\end{array}$ & $16 / 07 / 04$ & $27 / 07 / 04$ & $\begin{array}{l}\text { NPK 00-00-54 + } \\
1 \% \text { B }\end{array}$ & 145,16 \\
\hline & & $\begin{array}{l}\text { ADUBAÇAO DE } \\
\text { COBERTURA }\end{array}$ & $16 / 07 / 04$ & $27 / 07 / 04$ & $\begin{array}{l}\text { NPK 20-00-00 + } \\
24 \% \text { S (SULFATO } \\
\text { DE AMONIO) }\end{array}$ & 301,2 \\
\hline
\end{tabular}


Tabela 1A. Atividades desenvolvidas na área da microbacia de drenagem Entre Rios, desde o preparo até a colheita da madeira de eucaliptos (conclusão).

\begin{tabular}{|c|c|c|c|c|c|c|}
\hline \multirow{10}{*}{223} & \multirow{10}{*}{28,1} & ADUBAÇAO DE PLANTIO & $19 / 05 / 02$ & $28 / 05 / 02$ & CINZA & $1.046,33$ \\
\hline & & ADUBAÇAO DE PLANTIO & $25 / 05 / 02$ & $25 / 06 / 02$ & $\begin{array}{l}\text { NPK 06-30-10 + } \\
0,6 \% \text { B }\end{array}$ & 259,94 \\
\hline & & PLANTIO & $28 / 05 / 02$ & $25 / 06 / 02$ & & \\
\hline & & SULCAMENTO & $28 / 05 / 02$ & $25 / 06 / 02$ & & \\
\hline & & ADUBAÇAO DE PLANTIO & $10 / 06 / 02$ & 13/06/02 & $\begin{array}{l}\text { CALCARIO } \\
\text { DOLOMITICO }\end{array}$ & $1.475,75$ \\
\hline & & $\begin{array}{l}\text { ADUBAÇAO DE } \\
\text { COBERTURA }\end{array}$ & 30/08/02 & 19/12/02 & $\begin{array}{l}\text { NPK 15-00-20 + } \\
0,6 \% \text { B + 9,6\% S }\end{array}$ & 123,42 \\
\hline & & $\begin{array}{l}\text { ADUBAÇAO DE } \\
\text { COBERTURA }\end{array}$ & 09/09/03 & 09/09/03 & $\begin{array}{l}\text { NPK 16-00-32+ 1\% } \\
\text { B }\end{array}$ & 250,13 \\
\hline & & $\begin{array}{l}\text { ADUBAÇAO DE } \\
\text { COBERTURA }\end{array}$ & $11 / 09 / 03$ & 11/09/03 & $\begin{array}{l}\text { NPK 00-00-54+ } \\
1 \% \text { B }\end{array}$ & 150,38 \\
\hline & & $\begin{array}{l}\text { ADUBAÇAO DE } \\
\text { COBERTURA }\end{array}$ & $16 / 07 / 04$ & $27 / 07 / 04$ & $\begin{array}{l}\text { NPK 00-00-54+ } \\
1 \% \text { B }\end{array}$ & 145,16 \\
\hline & & $\begin{array}{l}\text { ADUBAÇAO DE } \\
\text { COBERTURA }\end{array}$ & $16 / 07 / 04$ & $27 / 07 / 04$ & $\begin{array}{l}\text { NPK 20-00-00 + } \\
\text { 24\% S (SULFATO } \\
\text { DE AMONIO) }\end{array}$ & 301,2 \\
\hline
\end{tabular}


Apêndice 2 
Tabela 1B. Transportes parciais dos cátions principais e $\mathrm{SiO}_{2}$ referente ao hidrograma da amostragem intensiva 1 ocorrida em 17/03/2007 na microbacia Entre Rios, calculados pelo método de integração de áreas.

\begin{tabular}{ccccc}
\hline $\mathbf{C a}^{2+}$ & $\mathbf{t}_{\mathbf{a c u m}}(\mathbf{h})$ & $\begin{array}{c}\text { Volume } \\
(\mathbf{L})\end{array}$ & $\mathbf{C}_{\mathbf{M N Q}}\left(\mathbf{m g ~ L}^{-\mathbf{1}}\right)$ & $\mathbf{T} \mathbf{~ ( k g ~ h}^{-\mathbf{1}} \mathbf{)}$ \\
\hline $\mathrm{A}_{0-1}$ & 0,58 & 26603 & 1,74 & 0,079 \\
$\mathrm{~A}_{1-2}$ & 1,10 & 42890 & 1,66 & 0,065 \\
$\mathrm{~A}_{2-3}$ & 1,30 & 30533 & 1,35 & 0,032 \\
$\mathrm{~A}_{3-4}$ & 1,72 & 86274 & 1,09 & 0,055 \\
$\mathrm{~A}_{4-5}$ & 3,13 & 285600 & 1,14 & 0,104 \\
$\mathrm{~A}_{5-6}$ & 5,08 & 293503 & 1,31 & 0,076 \\
$\mathrm{~A}_{6-7}$ & 9,53 & 423437 & 1,38 & 0,061 \\
$\mathrm{~A}_{7-8}$ & 16,17 & 414640 & 1,58 & 0,040 \\
\hline
\end{tabular}

\begin{tabular}{ccccc}
\hline $\mathbf{M g}^{2+}$ & $\mathbf{t}_{\text {acum }}(\mathbf{h})$ & $\begin{array}{c}\text { Volume } \\
(\mathbf{L})\end{array}$ & $\mathbf{C}_{\mathbf{M N Q}}\left(\mathbf{m g ~ L}^{-\mathbf{1}}\right)$ & $\left.\mathbf{T} \mathbf{~ ( k g ~ h}^{-\mathbf{1}}\right)$ \\
\hline $\mathrm{A}_{0-1}$ & 0,58 & 26603 & 0,45 & 0,021 \\
$\mathrm{~A}_{1-2}$ & 1,10 & 42890 & 0,42 & 0,016 \\
$\mathrm{~A}_{2-3}$ & 1,30 & 30533 & 0,34 & 0,008 \\
$\mathrm{~A}_{3-4}$ & 1,72 & 86274 & 0,30 & 0,015 \\
$\mathrm{~A}_{4-5}$ & 3,13 & 285600 & 0,28 & 0,025 \\
$\mathrm{~A}_{5-6}$ & 5,08 & 293503 & 0,32 & 0,019 \\
$\mathrm{~A}_{6-7}$ & 9,53 & 423437 & 0,44 & 0,019 \\
$\mathrm{~A}_{7-8}$ & 16,17 & 414640 & 0,45 & 0,012 \\
\hline
\end{tabular}

\begin{tabular}{ccccc}
\hline $\mathbf{N a}^{+}$ & $\mathbf{t}_{\mathbf{a c u m}} \mathbf{( h )}$ & $\begin{array}{c}\text { Volume } \\
(\mathbf{L})\end{array}$ & $\mathbf{C}_{\mathbf{M N Q}}\left(\mathbf{m g ~ L} \mathbf{~}^{-\mathbf{1}}\right)$ & $\mathbf{T} \mathbf{~ ( k g ~ h}^{\mathbf{- 1}} \mathbf{)}$ \\
\hline $\mathrm{A}_{0-1}$ & 0,58 & 26603 & 0,51 & 0,023 \\
$\mathrm{~A}_{1-2}$ & 1,10 & 42890 & 0,42 & 0,016 \\
$\mathrm{~A}_{2-3}$ & 1,30 & 30533 & 0,34 & 0,008 \\
$\mathrm{~A}_{3-4}$ & 1,72 & 86274 & 0,33 & 0,016 \\
$\mathrm{~A}_{4-5}$ & 3,13 & 285600 & 0,38 & 0,035 \\
$\mathrm{~A}_{5-6}$ & 5,08 & 293503 & 0,43 & 0,025 \\
$\mathrm{~A}_{6-7}$ & 9,53 & 423437 & 0,44 & 0,020 \\
$\mathrm{~A}_{7-8}$ & 16,17 & 414640 & 0,47 & 0,012 \\
\hline
\end{tabular}

\begin{tabular}{ccccc}
\hline $\mathbf{N H}_{\mathbf{4}}{ }^{+}$ & $\mathbf{t}_{\text {acum }}(\mathbf{h})$ & $\begin{array}{c}\text { Volume } \\
(\mathbf{L})\end{array}$ & $\mathbf{C}_{\mathbf{M N Q}}\left(\mathbf{m g ~ L}^{-\mathbf{1}}\right)$ & $\left.\mathbf{T ~ ( k g ~ h}^{-\mathbf{1}}\right)$ \\
\hline $\mathrm{A}_{0-1}$ & 0,58 & 26603 & 0,04 & 0,002 \\
$\mathrm{~A}_{1-2}$ & 1,10 & 42890 & 0,04 & 0,002 \\
$\mathrm{~A}_{2-3}$ & 1,30 & 30533 & 0,03 & 0,001 \\
$\mathrm{~A}_{3-4}$ & 1,72 & 86274 & 0,02 & 0,001 \\
$\mathrm{~A}_{4-5}$ & 3,13 & 285600 & 0,02 & 0,002 \\
$\mathrm{~A}_{5-6}$ & 5,08 & 293503 & 0,02 & 0,001 \\
$\mathrm{~A}_{6-7}$ & 9,53 & 423437 & 0,01 & 0,000 \\
$\mathrm{~A}_{7-8}$ & 16,17 & 414640 & 0,02 & 0,000 \\
\hline
\end{tabular}

\begin{tabular}{ccccc}
\hline $\mathbf{K}^{+}$ & $\mathbf{t}_{\mathbf{a c u m}} \mathbf{( h )}$ & $\begin{array}{c}\text { Volume } \\
(\mathbf{L})\end{array}$ & $\mathbf{C}_{\mathbf{M N Q}}\left(\mathbf{m g ~ L}^{\mathbf{- 1}}\right)$ & $\mathbf{T} \mathbf{( \mathbf { k g ~ h } ^ { - \mathbf { 1 } } )}$ \\
\hline $\mathrm{A}_{0-1}$ & 0,58 & 26603 & 1,73 & 0,079 \\
$\mathrm{~A}_{1-2}$ & 1,10 & 42890 & 1,72 & 0,067 \\
$\mathrm{~A}_{2-3}$ & 1,30 & 30533 & 1,58 & 0,037 \\
$\mathrm{~A}_{3-4}$ & 1,72 & 86274 & 1,50 & 0,075 \\
$\mathrm{~A}_{4-5}$ & 3,13 & 285600 & 1,55 & 0,142 \\
$\mathrm{~A}_{5-6}$ & 5,08 & 293503 & 1,61 & 0,093 \\
$\mathrm{~A}_{6-7}$ & 9,53 & 423437 & 1,58 & 0,070 \\
$\mathrm{~A}_{7-8}$ & 16,17 & 414640 & 1,75 & 0,045 \\
\hline
\end{tabular}

\begin{tabular}{ccccc}
\hline $\mathbf{S i O}_{2}$ & $\mathbf{t}_{\mathbf{a c u m}}(\mathbf{h})$ & $\begin{array}{c}\text { Volume } \\
(\mathbf{L})\end{array}$ & $\mathbf{C}_{\mathbf{M N Q}}\left(\mathbf{m g ~ L}^{\mathbf{- 1}}\right)$ & $\left.\mathbf{T} \mathbf{~ ( k ~ h ~ h}^{-\mathbf{1}}\right)$ \\
\hline $\mathrm{A}_{0-1}$ & 0,58 & 26603 & 10,21 & 0,466 \\
$\mathrm{~A}_{1-2}$ & 1,10 & 42890 & 9,41 & 0,367 \\
$\mathrm{~A}_{2-3}$ & 1,30 & 30533 & 9,02 & 0,212 \\
$\mathrm{~A}_{3-4}$ & 1,72 & 86274 & 8,31 & 0,417 \\
$\mathrm{~A}_{4-5}$ & 3,13 & 285600 & 8,11 & 0,739 \\
$\mathrm{~A}_{5-6}$ & 5,08 & 293503 & 8,61 & 0,497 \\
$\mathrm{~A}_{6-7}$ & 9,53 & 423437 & 9,02 & 0,401 \\
$\mathrm{~A}_{7-8}$ & 16,17 & 414640 & 9,69 & 0,249 \\
\hline
\end{tabular}


Tabela 2B. Transportes parciais dos ânions principais e TDS referente ao hidrograma da amostragem intensiva 1 ocorrida em 17/03/2007 na microbacia Entre Rios, calculados pelo método de integração de áreas.

\begin{tabular}{ccccc}
\hline $\mathbf{H C O}_{3}^{-}$ & $\mathbf{t}_{\text {acum }}(\mathbf{h})$ & $\begin{array}{c}\text { Volume } \\
(\mathbf{L})\end{array}$ & $\left.\mathbf{C}_{\mathbf{M N Q}} \mathbf{( m g ~ L}^{-\mathbf{1}}\right)$ & $\left.\mathbf{T} \mathbf{~ ( k g ~ h}^{-\mathbf{1}}\right)$ \\
\hline $\mathrm{A}_{0-1}$ & 0,58 & 26603 & 8,26 & 0,377 \\
$\mathrm{~A}_{1-2}$ & 1,10 & 42890 & 7,58 & 0,296 \\
$\mathrm{~A}_{2-3}$ & 1,30 & 30533 & 6,59 & 0,155 \\
$\mathrm{~A}_{3-4}$ & 1,72 & 86274 & 5,71 & 0,287 \\
$\mathrm{~A}_{4-5}$ & 3,13 & 285600 & 5,57 & 0,508 \\
$\mathrm{~A}_{5-6}$ & 5,08 & 293503 & 6,27 & 0,362 \\
$\mathrm{~A}_{6-7}$ & 9,53 & 423437 & 6,92 & 0,307 \\
$\mathrm{~A}_{7-8}$ & 16,17 & 414640 & 7,32 & 0,188 \\
\hline
\end{tabular}

\begin{tabular}{ccccc}
\hline $\mathbf{C l}^{-}$ & $\mathbf{t}_{\text {acum }}(\mathbf{h})$ & $\begin{array}{c}\text { Volume } \\
(\mathbf{L})\end{array}$ & $\mathbf{C}_{\mathbf{M N Q}}\left(\mathbf{m g ~ L}^{-\mathbf{1}}\right)$ & $\mathbf{T}\left(\mathbf{k g ~ h}^{\mathbf{- 1}}\right)$ \\
\hline $\mathrm{A}_{0-1}$ & 0,58 & 26603 & 0,90 & 0,041 \\
$\mathrm{~A}_{1-2}$ & 1,10 & 42890 & 0,90 & 0,035 \\
$\mathrm{~A}_{2-3}$ & 1,30 & 30533 & 0,66 & 0,015 \\
$\mathrm{~A}_{3-4}$ & 1,72 & 86274 & 0,58 & 0,029 \\
$\mathrm{~A}_{4-5}$ & 3,13 & 285600 & 0,64 & 0,059 \\
$\mathrm{~A}_{5-6}$ & 5,08 & 293503 & 0,61 & 0,035 \\
$\mathrm{~A}_{6-7}$ & 9,53 & 423437 & 0,65 & 0,029 \\
$\mathrm{~A}_{7-8}$ & 16,17 & 414640 & 1,02 & 0,026 \\
\hline
\end{tabular}

\begin{tabular}{|c|c|c|c|c|}
\hline $\mathrm{SO}_{4}{ }^{2-}$ & $t_{\text {acum }}(\mathbf{h})$ & $\begin{array}{c}\text { Volume } \\
(\mathrm{L})\end{array}$ & $\mathrm{C}_{\mathrm{MNQ}}\left(\mathrm{mg} \mathrm{L}^{-1}\right)$ & $\mathrm{T}\left(\mathrm{kg} \mathrm{h}^{-1}\right)$ \\
\hline$A_{0-1}$ & 0,58 & 26603 & 0,36 & 0,016 \\
\hline $\mathrm{A}_{1-2}$ & 1,10 & 42890 & 0,41 & 0,016 \\
\hline $\mathrm{A}_{2-3}$ & 1,30 & 30533 & 0,31 & 0,007 \\
\hline $\mathrm{A}_{3-4}$ & 1,72 & 86274 & 0,29 & 0,015 \\
\hline $\mathrm{A}_{4-5}$ & 3,13 & 285600 & 0,36 & 0,033 \\
\hline$A_{5-6}$ & 5,08 & 293503 & 0,38 & 0,022 \\
\hline$A_{6-7}$ & 9,53 & 423437 & 0,43 & 0,019 \\
\hline $\mathrm{A}_{7-8}$ & 16,17 & 414640 & 0,63 & 0,016 \\
\hline
\end{tabular}

\begin{tabular}{ccccc}
\hline $\mathbf{P O}_{4}{ }^{3-}$ & $\mathbf{t}_{\text {acum }}(\mathbf{h})$ & $\begin{array}{c}\text { Volume } \\
(\mathbf{L})\end{array}$ & $\mathbf{C}_{\mathbf{M N Q}}\left(\mathbf{m g ~ L}^{-\mathbf{1}}\right)$ & $\mathbf{T}\left(\mathbf{k g ~ h}^{\mathbf{- 1}}\right)$ \\
\hline $\mathrm{A}_{0-1}$ & 0,58 & 26603 & 0,09 & 0,004 \\
$\mathrm{~A}_{1-2}$ & 1,10 & 42890 & 0,06 & 0,002 \\
$\mathrm{~A}_{2-3}$ & 1,30 & 30533 & 0,04 & 0,001 \\
$\mathrm{~A}_{3-4}$ & 1,72 & 86274 & 0,03 & 0,001 \\
$\mathrm{~A}_{4-5}$ & 3,13 & 285600 & 0,03 & 0,003 \\
$\mathrm{~A}_{5-6}$ & 5,08 & 293503 & 0,09 & 0,005 \\
$\mathrm{~A}_{6-7}$ & 9,53 & 423437 & 0,06 & 0,003 \\
$\mathrm{~A}_{7-8}$ & 16,17 & 414640 & 0,00 & 0,000 \\
\hline
\end{tabular}

\begin{tabular}{ccccc}
\hline $\mathbf{N O}_{3}^{-}$ & $\mathbf{t}_{\mathbf{a c u m}} \mathbf{( h )}$ & $\begin{array}{c}\text { Volume } \\
(\mathbf{L})\end{array}$ & $\mathbf{C}_{\mathbf{M N Q}}\left(\mathbf{m g ~ L}^{-\mathbf{1}}\right)$ & $\left.\mathbf{T ~ ( k g ~ h}^{-\mathbf{1}}\right)$ \\
\hline $\mathrm{A}_{0-1}$ & 0,58 & 26603 & 0,39 & 0,018 \\
$\mathrm{~A}_{1-2}$ & 1,10 & 42890 & 0,39 & 0,015 \\
$\mathrm{~A}_{2-3}$ & 1,30 & 30533 & 0,37 & 0,009 \\
$\mathrm{~A}_{3-4}$ & 1,72 & 86274 & 0,37 & 0,018 \\
$\mathrm{~A}_{4-5}$ & 3,13 & 285600 & 0,43 & 0,039 \\
$\mathrm{~A}_{5-6}$ & 5,08 & 293503 & 0,52 & 0,030 \\
$\mathrm{~A}_{6-7}$ & 9,53 & 423437 & 0,57 & 0,025 \\
$\mathrm{~A}_{7-8}$ & 16,17 & 414640 & 0,53 & 0,014 \\
\hline
\end{tabular}

\begin{tabular}{ccccc}
\hline TDS & $\mathbf{t}_{\mathbf{a c u m}}(\mathbf{h})$ & $\begin{array}{c}\text { Volume } \\
(\mathbf{L})\end{array}$ & $\mathbf{C}_{\mathbf{M N Q}}\left(\mathbf{m g ~ L}^{\mathbf{- 1}}\right)$ & $\left.\mathbf{T ~ ( k g ~ h}^{-\mathbf{1}}\right)$ \\
\hline $\mathrm{A}_{0-1}$ & 0,58 & 26603 & 24,68 & 1,126 \\
$\mathrm{~A}_{1-2}$ & 1,10 & 42890 & 23,00 & 0,897 \\
$\mathrm{~A}_{2-3}$ & 1,30 & 30533 & 20,63 & 0,485 \\
$\mathrm{~A}_{3-4}$ & 1,72 & 86274 & 18,53 & 0,931 \\
$\mathrm{~A}_{4-5}$ & 3,13 & 285600 & 18,52 & 1,688 \\
$\mathrm{~A}_{5-6}$ & 5,08 & 293503 & 20,17 & 1,165 \\
$\mathrm{~A}_{6-7}$ & 9,53 & 423437 & 21,49 & 0,955 \\
$\mathrm{~A}_{7-8}$ & 16,17 & 414640 & 23,47 & 0,602 \\
\hline
\end{tabular}


Tabela 3B. Transportes parciais dos cátions principais e $\mathrm{SiO}_{2}$ referente ao hidrograma da amostragem intensiva 2 ocorrida em 05/12/2007 na microbacia Entre Rios, calculados pelo método de integração de áreas.

\begin{tabular}{ccccc}
\hline $\mathbf{C a}^{2+}$ & $\mathbf{t}_{\mathbf{a c u m}}(\mathbf{h})$ & $\begin{array}{c}\text { Volume } \\
(\mathbf{L})\end{array}$ & $\mathbf{C}_{\mathbf{M N Q}}\left(\mathbf{m g ~ L}^{-\mathbf{1}}\right)$ & $\mathbf{T}\left(\mathbf{k g ~ h}^{-\mathbf{1}}\right)$ \\
\hline $\mathrm{A}_{0-1}$ & 0,75 & 23608 & 1,55 & 0,049 \\
$\mathrm{~A}_{1-2}$ & 1,12 & 19235 & 1,71 & 0,029 \\
$\mathrm{~A}_{2-3}$ & 1,55 & 55330 & 1,45 & 0,052 \\
$\mathrm{~A}_{3-4}$ & 2,28 & 116844 & 1,32 & 0,067 \\
$\mathrm{~A}_{4-5}$ & 3,28 & 106247 & 1,40 & 0,045 \\
$\mathrm{~A}_{5-6}$ & 4,90 & 113462 & 1,65 & 0,038 \\
$\mathrm{~A}_{6-7}$ & 6,93 & 93266 & 1,81 & 0,024 \\
$\mathrm{~A}_{7-8}$ & 13,42 & 210060 & 1,65 & 0,026 \\
\hline
\end{tabular}

\begin{tabular}{ccccc}
\hline $\mathbf{M g}^{2+}$ & $\mathbf{t}_{\text {acum }}(\mathbf{h})$ & $\begin{array}{c}\text { Volume } \\
(\mathbf{L})\end{array}$ & $\mathbf{C}_{\mathbf{M N Q}}\left(\mathbf{m g ~ L}^{-\mathbf{1}}\right)$ & $\left.\mathbf{T} \mathbf{~ ( k g ~ h}^{-\mathbf{1}}\right)$ \\
\hline $\mathrm{A}_{0-1}$ & 0,75 & 23608 & 0,40 & 0,012 \\
$\mathrm{~A}_{1-2}$ & 1,12 & 19235 & 0,45 & 0,008 \\
$\mathrm{~A}_{2-3}$ & 1,55 & 55330 & 0,39 & 0,014 \\
$\mathrm{~A}_{3-4}$ & 2,28 & 116844 & 0,36 & 0,018 \\
$\mathrm{~A}_{4-5}$ & 3,28 & 106247 & 0,40 & 0,013 \\
$\mathrm{~A}_{5-6}$ & 4,90 & 113462 & 0,43 & 0,010 \\
$\mathrm{~A}_{6-7}$ & 6,93 & 93266 & 0,45 & 0,006 \\
$\mathrm{~A}_{7-8}$ & 13,42 & 210060 & 0,53 & 0,008 \\
\hline
\end{tabular}

\begin{tabular}{ccccc}
\hline $\mathbf{N a}^{+}$ & $\mathbf{t}_{\mathbf{a c u m}} \mathbf{( h )}$ & $\begin{array}{c}\text { Volume } \\
(\mathbf{L})\end{array}$ & $\mathbf{C}_{\mathbf{M N Q}}\left(\mathbf{m g ~ L}^{-\mathbf{1}}\right)$ & $\left.\mathbf{T} \mathbf{~ ( k g ~ h}^{-\mathbf{1}}\right)$ \\
\hline $\mathrm{A}_{0-1}$ & 0,75 & 23608 & 0,50 & 0,016 \\
$\mathrm{~A}_{1-2}$ & 1,12 & 19235 & 0,46 & 0,008 \\
$\mathrm{~A}_{2-3}$ & 1,55 & 55330 & 0,35 & 0,012 \\
$\mathrm{~A}_{3-4}$ & 2,28 & 116844 & 0,32 & 0,016 \\
$\mathrm{~A}_{4-5}$ & 3,28 & 106247 & 0,33 & 0,011 \\
$\mathrm{~A}_{5-6}$ & 4,90 & 113462 & 0,42 & 0,010 \\
$\mathrm{~A}_{6-7}$ & 6,93 & 93266 & 0,55 & 0,007 \\
$\mathrm{~A}_{7-8}$ & 13,42 & 210060 & 0,58 & 0,009 \\
\hline
\end{tabular}

\begin{tabular}{ccccc}
\hline $\mathbf{K}^{+}$ & $\mathbf{t}_{\text {acum }} \mathbf{( h )}$ & $\begin{array}{c}\text { Volume } \\
(\mathbf{L})\end{array}$ & $\mathbf{C}_{\mathbf{M N Q}}\left(\mathbf{m g ~ L}^{\mathbf{- 1}}\right)$ & $\mathbf{T}\left(\mathbf{k g ~ h}^{\mathbf{- 1}}\right)$ \\
\hline $\mathrm{A}_{0-1}$ & 0,75 & 23608 & 1,79 & 0,056 \\
$\mathrm{~A}_{1-2}$ & 1,12 & 19235 & 3,01 & 0,052 \\
$\mathrm{~A}_{2-3}$ & 1,55 & 55330 & 2,91 & 0,104 \\
$\mathrm{~A}_{3-4}$ & 2,28 & 116844 & 2,70 & 0,138 \\
$\mathrm{~A}_{4-5}$ & 3,28 & 106247 & 2,69 & 0,087 \\
$\mathrm{~A}_{5-6}$ & 4,90 & 113462 & 2,67 & 0,062 \\
$\mathrm{~A}_{6-7}$ & 6,93 & 93266 & 2,24 & 0,030 \\
$\mathrm{~A}_{7-8}$ & 13,42 & 210060 & 1,72 & 0,027 \\
\hline
\end{tabular}

\begin{tabular}{ccccc}
\hline $\mathbf{N H}_{\mathbf{4}}{ }^{+}$ & $\mathbf{t}_{\mathbf{a c u m}} \mathbf{( h )}$ & $\begin{array}{c}\text { Volume } \\
(\mathbf{L})\end{array}$ & $\mathbf{C}_{\mathbf{M N Q}}\left(\mathbf{m g ~ \mathbf { L } ^ { - 1 }}\right)$ & $\left.\mathbf{T} \mathbf{~ k g ~ h}^{-\mathbf{1}}\right)$ \\
\hline $\mathrm{A}_{0-1}$ & 0,75 & 23608 & 0,00 & 0,000 \\
$\mathrm{~A}_{1-2}$ & 1,12 & 19235 & 0,00 & 0,000 \\
$\mathrm{~A}_{2-3}$ & 1,55 & 55330 & 0,00 & 0,000 \\
$\mathrm{~A}_{3-4}$ & 2,28 & 116844 & 0,00 & 0,000 \\
$\mathrm{~A}_{4-5}$ & 3,28 & 106247 & 0,00 & 0,000 \\
$\mathrm{~A}_{5-6}$ & 4,90 & 113462 & 0,00 & 0,000 \\
$\mathrm{~A}_{6-7}$ & 6,93 & 93266 & 0,00 & 0,000 \\
$\mathrm{~A}_{7-8}$ & 13,42 & 210060 & 0,00 & 0,000 \\
\hline
\end{tabular}

\begin{tabular}{ccccc}
\hline $\mathrm{SiO}_{2}$ & $\mathbf{t}_{\mathbf{a c u m}}(\mathbf{h})$ & $\begin{array}{c}\text { Volume } \\
(\mathbf{L})\end{array}$ & $\mathbf{C}_{\mathbf{M N Q}}\left(\mathbf{m g ~ L}^{-\mathbf{1}}\right)$ & $\mathbf{T}\left(\mathbf{k g ~ h}^{-\mathbf{1}}\right)$ \\
\hline $\mathrm{A}_{0-1}$ & 0,75 & 23608 & 8,28 & 0,261 \\
$\mathrm{~A}_{1-2}$ & 1,12 & 19235 & 9,11 & 0,157 \\
$\mathrm{~A}_{2-3}$ & 1,55 & 55330 & 7,68 & 0,274 \\
$\mathrm{~A}_{3-4}$ & 2,28 & 116844 & 6,53 & 0,334 \\
$\mathrm{~A}_{4-5}$ & 3,28 & 106247 & 6,39 & 0,207 \\
$\mathrm{~A}_{5-6}$ & 4,90 & 113462 & 7,62 & 0,176 \\
$\mathrm{~A}_{6-7}$ & 6,93 & 93266 & 7,97 & 0,107 \\
$\mathrm{~A}_{7-8}$ & 13,42 & 210060 & 7,81 & 0,122 \\
\hline
\end{tabular}


Tabela 4B. Transportes parciais dos ânions principais e TDS referente ao hidrograma da amostragem intensiva 2 ocorrida em 05/12/2007 na microbacia Entre Rios, calculados pelo método de integração de áreas.

\begin{tabular}{ccccc}
\hline $\mathbf{H C O}_{\mathbf{3}}{ }^{-}$ & $\mathbf{t}_{\mathbf{a c u m}} \mathbf{( h )}$ & $\begin{array}{c}\text { Volume } \\
(\mathbf{L})\end{array}$ & $\mathbf{C}_{\mathbf{M N Q}}\left(\mathbf{m g ~ L}^{\mathbf{- 1}}\right)$ & $\left.\mathbf{T} \mathbf{~ k g ~ h}^{\mathbf{- 1}}\right)$ \\
\hline $\mathrm{A}_{0-1}$ & 0,75 & 23608 & 7,25 & 0,228 \\
$\mathrm{~A}_{1-2}$ & 1,12 & 19235 & 7,38 & 0,127 \\
$\mathrm{~A}_{2-3}$ & 1,55 & 55330 & 5,69 & 0,203 \\
$\mathrm{~A}_{3-4}$ & 2,28 & 116844 & 5,07 & 0,259 \\
$\mathrm{~A}_{4-5}$ & 3,28 & 106247 & 5,33 & 0,172 \\
$\mathrm{~A}_{5-6}$ & 4,90 & 113462 & 5,99 & 0,139 \\
$\mathrm{~A}_{6-7}$ & 6,93 & 93266 & 6,95 & 0,093 \\
$\mathrm{~A}_{7-8}$ & 13,42 & 210060 & 7,50 & 0,117 \\
\hline
\end{tabular}

\begin{tabular}{ccccc}
\hline $\mathbf{C l}^{-}$ & $\mathbf{t}_{\mathbf{a c u m}} \mathbf{( h )}$ & $\begin{array}{c}\text { Volume } \\
(\mathbf{L})\end{array}$ & $\mathbf{C}_{\mathbf{M N Q}}\left(\mathbf{m g ~ L}^{\mathbf{- 1}}\right)$ & $\mathbf{T} \mathbf{~ ( k g ~ h}^{-\mathbf{1}} \mathbf{)}$ \\
\hline $\mathrm{A}_{0-1}$ & 0,75 & 23608 & 1,24 & 0,039 \\
$\mathrm{~A}_{1-2}$ & 1,12 & 19235 & 1,91 & 0,033 \\
$\mathrm{~A}_{2-3}$ & 1,55 & 55330 & 1,82 & 0,065 \\
$\mathrm{~A}_{3-4}$ & 2,28 & 116844 & 2,01 & 0,103 \\
$\mathrm{~A}_{4-5}$ & 3,28 & 106247 & 2,26 & 0,073 \\
$\mathrm{~A}_{5-6}$ & 4,90 & 113462 & 1,96 & 0,045 \\
$\mathrm{~A}_{6-7}$ & 6,93 & 93266 & 1,54 & 0,021 \\
$\mathrm{~A}_{7-8}$ & 13,42 & 210060 & 1,03 & 0,016 \\
\hline
\end{tabular}

\begin{tabular}{|c|c|c|c|c|}
\hline $\mathrm{SO}_{4}{ }^{2-}$ & $\mathbf{t}_{\mathrm{acum}}(\mathbf{h})$ & $\begin{array}{c}\text { Volume } \\
\text { (L) }\end{array}$ & $\mathrm{C}_{\mathrm{MNQ}}\left(\mathrm{mg} \mathrm{L}^{-1}\right)$ & $T\left(\operatorname{kg~h}^{-1}\right)$ \\
\hline$A_{0-1}$ & 0,75 & 23608 & 0,49 & 0,016 \\
\hline$A_{1-2}$ & 1,12 & 19235 & 0,79 & 0,014 \\
\hline $\mathrm{A}_{2-3}$ & 1,55 & 55330 & 0,93 & 0,033 \\
\hline $\mathrm{A}_{3-4}$ & 2,28 & 116844 & 0,83 & 0,043 \\
\hline $\mathrm{A}_{4-5}$ & 3,28 & 106247 & 0,77 & 0,025 \\
\hline$A_{5-6}$ & 4,90 & 113462 & 0,90 & 0,021 \\
\hline $\mathrm{A}_{6-7}$ & 6,93 & 93266 & 1,03 & 0,014 \\
\hline $\mathrm{A}_{7-8}$ & 13,42 & 210060 & 1,09 & 0,017 \\
\hline
\end{tabular}

\begin{tabular}{ccccc}
\hline $\mathbf{N O}_{3}{ }^{-}$ & $\mathbf{t}_{\mathbf{a c u m}} \mathbf{( h )}$ & $\begin{array}{c}\text { Volume } \\
(\mathbf{L})\end{array}$ & $\mathbf{C}_{\mathbf{M N Q}}\left(\mathbf{m g ~ L}^{-\mathbf{1}}\right)$ & $\mathbf{T} \mathbf{~} \mathbf{k g ~ h}^{\mathbf{- 1}} \mathbf{)}$ \\
\hline $\mathrm{A}_{0-1}$ & 0,75 & 23608 & 0,34 & 0,011 \\
$\mathrm{~A}_{1-2}$ & 1,12 & 19235 & 1,05 & 0,018 \\
$\mathrm{~A}_{2-3}$ & 1,55 & 55330 & 0,84 & 0,030 \\
$\mathrm{~A}_{3-4}$ & 2,28 & 116844 & 0,57 & 0,029 \\
$\mathrm{~A}_{4-5}$ & 3,28 & 106247 & 0,52 & 0,017 \\
$\mathrm{~A}_{5-6}$ & 4,90 & 113462 & 0,72 & 0,017 \\
$\mathrm{~A}_{6-7}$ & 6,93 & 93266 & 0,73 & 0,010 \\
$\mathrm{~A}_{7-8}$ & 13,42 & 210060 & 0,40 & 0,006 \\
\hline & & & &
\end{tabular}

\begin{tabular}{ccccc}
\hline $\mathbf{P O}_{4}{ }^{3-}$ & $\mathbf{t}_{\text {acum }}(\mathbf{h})$ & $\begin{array}{c}\text { Volume } \\
(\mathbf{L})\end{array}$ & $\mathbf{C}_{\mathbf{M N Q}}\left(\mathbf{m g ~ L}^{-\mathbf{1}}\right)$ & $\left.\mathbf{T ~ ( k g ~ h}^{-\mathbf{1}}\right)$ \\
\hline $\mathrm{A}_{0-1}$ & 0,75 & 23608 & 0,06 & 0,002 \\
$\mathrm{~A}_{1-2}$ & 1,12 & 19235 & 0,10 & 0,002 \\
$\mathrm{~A}_{2-3}$ & 1,55 & 55330 & 0,03 & 0,001 \\
$\mathrm{~A}_{3-4}$ & 2,28 & 116844 & 0,00 & 0,000 \\
$\mathrm{~A}_{4-5}$ & 3,28 & 106247 & 0,00 & 0,000 \\
$\mathrm{~A}_{5-6}$ & 4,90 & 113462 & 0,07 & 0,002 \\
$\mathrm{~A}_{6-7}$ & 6,93 & 93266 & 0,10 & 0,001 \\
$\mathrm{~A}_{7-8}$ & 13,42 & 210060 & 0,00 & 0,000 \\
\hline
\end{tabular}

\begin{tabular}{ccccc}
\hline TDS & $\mathbf{t}_{\text {acum }}(\mathbf{h})$ & $\begin{array}{c}\text { Volume } \\
(\mathbf{L})\end{array}$ & $\mathbf{C}_{\mathbf{M N Q}}\left(\mathbf{m g ~ L}^{-\mathbf{1}}\right)$ & $\mathbf{T}\left(\mathbf{k g ~ h}^{-\mathbf{1}}\right)$ \\
\hline $\mathrm{A}_{0-1}$ & 0,75 & 23608 & 21,89 & 0,689 \\
$\mathrm{~A}_{1-2}$ & 1,12 & 19235 & 25,99 & 0,448 \\
$\mathrm{~A}_{2-3}$ & 1,55 & 55330 & 22,09 & 0,788 \\
$\mathrm{~A}_{3-4}$ & 2,28 & 116844 & 19,69 & 1,008 \\
$\mathrm{~A}_{4-5}$ & 3,28 & 106247 & 20,09 & 0,650 \\
$\mathrm{~A}_{5-6}$ & 4,90 & 113462 & 22,42 & 0,519 \\
$\mathrm{~A}_{6-7}$ & 6,93 & 93266 & 23,37 & 0,314 \\
$\mathrm{~A}_{7-8}$ & 13,42 & 210060 & 22,31 & 0,349 \\
\hline
\end{tabular}


Apêndice 3 
Tabela 1C. Resultado das análises das amostras de água de chuva, com a concentração para os ânions e cátions majoritários, soma de ânions $\left(\Sigma^{+}\right)$e soma de cátions $\left(\Sigma^{-}\right)$, em meq $\mathrm{L}^{-1}$, para o período de 13/10/2006 a 17/02/2008.

\begin{tabular}{|c|c|c|c|c|c|c|c|c|c|c|c|c|c|}
\hline Data & $\mathrm{Ca}^{2+}$ & $\mathrm{Mg}^{2+}$ & $\mathrm{Na}^{+}$ & $\mathbf{K}^{+}$ & $\mathrm{NH}_{4}^{+}$ & $\mathrm{HCO}_{3}^{-}$ & $\begin{array}{c}\mathrm{Cl}^{-} \\
\left(\mathrm{meq} \mathrm{L}^{-1}\right)\end{array}$ & $\mathrm{SO}_{4}{ }^{2-}$ & $\mathrm{NO}_{3}^{-}$ & $\mathrm{PO}_{4}^{3-}$ & $\Sigma^{+}$ & $\Sigma$ & $\Delta(\%)$ \\
\hline $13 / 10 / 06$ & 0,026 & 0,006 & 0,005 & 0,001 & 0,003 & 0,023 & 0,003 & 0,006 & 0,006 & 0,000 & 0,040 & 0,038 & 6,875 \\
\hline $20 / 11 / 06$ & 0,023 & 0,007 & 0,006 & 0,001 & 0,015 & 0,015 & 0,008 & 0,009 & 0,015 & 0,000 & 0,051 & 0,048 & 5,940 \\
\hline $29 / 11 / 06$ & 0,011 & 0,004 & 0,005 & 0,001 & 0,017 & 0,013 & 0,003 & 0,005 & 0,009 & 0,004 & 0,038 & 0,034 & 9,897 \\
\hline $04 / 12 / 06$ & 0,010 & 0,006 & 0,005 & 0,003 & 0,011 & 0,011 & 0,006 & 0,008 & 0,004 & 0,003 & 0,035 & 0,032 & 7,870 \\
\hline $06 / 12 / 06$ & 0,014 & 0,004 & 0,006 & 0,002 & 0,028 & 0,037 & 0,003 & 0,005 & 0,010 & 0,002 & 0,054 & 0,057 & $-5,780$ \\
\hline $07 / 12 / 06$ & 0,025 & 0,007 & 0,015 & 0,003 & 0,009 & 0,036 & 0,009 & 0,006 & 0,000 & 0,003 & 0,059 & 0,054 & 8,696 \\
\hline $09 / 12 / 06$ & 0,018 & 0,006 & 0,008 & 0,001 & 0,007 & 0,020 & 0,005 & 0,009 & 0,006 & 0,004 & 0,040 & 0,043 & $-7,222$ \\
\hline $21 / 12 / 06$ & 0,034 & 0,004 & 0,006 & 0,001 & 0,001 & 0,030 & 0,003 & 0,005 & 0,002 & 0,002 & 0,046 & 0,041 & 11,125 \\
\hline $22 / 12 / 06$ & 0,023 & 0,004 & 0,005 & 0,001 & 0,000 & 0,010 & 0,006 & 0,013 & 0,001 & 0,000 & 0,032 & 0,029 & 11,062 \\
\hline $23 / 12 / 06$ & 0,014 & 0,003 & 0,011 & 0,001 & 0,002 & 0,020 & 0,004 & 0,003 & 0,003 & 0,000 & 0,031 & 0,030 & 4,709 \\
\hline $25 / 12 / 06$ & 0,014 & 0,003 & 0,005 & 0,000 & 0,011 & 0,016 & 0,003 & 0,008 & 0,006 & 0,002 & 0,034 & 0,036 & $-5,585$ \\
\hline $26 / 12 / 06$ & 0,028 & 0,005 & 0,007 & 0,001 & 0,007 & 0,023 & 0,001 & 0,006 & 0,005 & 0,013 & 0,048 & 0,049 & $-1,598$ \\
\hline $31 / 12 / 06$ & 0,032 & 0,007 & 0,008 & 0,001 & 0,009 & 0,023 & 0,004 & 0,011 & 0,011 & 0,002 & 0,057 & 0,051 & 10,445 \\
\hline $01 / 01 / 07$ & 0,019 & 0,004 & 0,004 & 0,001 & 0,000 & 0,025 & 0,000 & 0,003 & 0,002 & 0,001 & 0,028 & 0,031 & $-7,872$ \\
\hline $02 / 01 / 07$ & 0,018 & 0,004 & 0,004 & 0,000 & 0,000 & 0,023 & 0,000 & 0,000 & 0,002 & 0,000 & 0,026 & 0,026 & 0,198 \\
\hline $05 / 01 / 07$ & 0,016 & 0,003 & 0,005 & 0,000 & 0,001 & 0,018 & 0,002 & 0,001 & 0,002 & 0,000 & 0,025 & 0,023 & 11,458 \\
\hline $06 / 01 / 07$ & 0,014 & 0,003 & 0,004 & 0,000 & 0,000 & 0,015 & 0,002 & 0,002 & 0,001 & 0,000 & 0,021 & 0,021 & 2,350 \\
\hline $07 / 01 / 07$ & 0,016 & 0,003 & 0,003 & 0,000 & 0,000 & 0,021 & 0,001 & 0,002 & 0,000 & 0,002 & 0,024 & 0,026 & $-10,031$ \\
\hline $08 / 01 / 07$ & 0,018 & 0,003 & 0,006 & 0,001 & 0,002 & 0,018 & 0,002 & 0,002 & 0,002 & 0,003 & 0,030 & 0,028 & 7,264 \\
\hline $18 / 01 / 07$ & 0,013 & 0,004 & 0,005 & 0,001 & 0,002 & 0,010 & 0,002 & 0,008 & 0,004 & 0,002 & 0,025 & 0,026 & $-2,036$ \\
\hline $20 / 01 / 07$ & 0,019 & 0,003 & 0,005 & 0,001 & 0,005 & 0,016 & 0,003 & 0,003 & 0,005 & 0,003 & 0,033 & 0,030 & 10,315 \\
\hline $21 / 01 / 07$ & 0,013 & 0,003 & 0,003 & 0,000 & 0,000 & 0,009 & 0,001 & 0,002 & 0,003 & 0,002 & 0,019 & 0,017 & 8,388 \\
\hline $27 / 01 / 07$ & 0,012 & 0,004 & 0,004 & 0,001 & 0,006 & 0,016 & 0,002 & 0,006 & 0,003 & 0,000 & 0,027 & 0,026 & 3,640 \\
\hline $28 / 01 / 07$ & 0,011 & 0,003 & 0,005 & 0,003 & 0,016 & 0,016 & 0,005 & 0,009 & 0,004 & 0,000 & 0,037 & 0,034 & 7,564 \\
\hline $29 / 01 / 07$ & 0,014 & 0,004 & 0,007 & 0,002 & 0,008 & 0,025 & 0,004 & 0,004 & 0,004 & 0,000 & 0,034 & 0,036 & $-3,765$ \\
\hline $06 / 02 / 07$ & 0,015 & 0,005 & 0,005 & 0,001 & 0,017 & 0,020 & 0,003 & 0,011 & 0,006 & 0,000 & 0,042 & 0,039 & 7,131 \\
\hline $10 / 02 / 07$ & 0,010 & 0,004 & 0,007 & 0,001 & 0,023 & 0,016 & 0,003 & 0,009 & 0,012 & 0,001 & 0,045 & 0,041 & 8,736 \\
\hline $11 / 02 / 07$ & 0,011 & 0,004 & 0,005 & 0,000 & 0,002 & 0,010 & 0,003 & 0,003 & 0,006 & 0,000 & 0,022 & 0,022 & $-3,130$ \\
\hline $28 / 02 / 07$ & 0,030 & 0,006 & 0,012 & 0,002 & 0,005 & 0,020 & 0,017 & 0,013 & 0,003 & 0,000 & 0,055 & 0,052 & 5,864 \\
\hline $02 / 03 / 07$ & 0,036 & 0,009 & 0,012 & 0,003 & 0,011 & 0,032 & 0,008 & 0,015 & 0,009 & 0,003 & 0,072 & 0,066 & 8,403 \\
\hline 09/03/07 & 0,033 & 0,007 & 0,007 & 0,001 & 0,017 & 0,033 & 0,007 & 0,011 & 0,009 & 0,000 & 0,064 & 0,059 & 7,643 \\
\hline $10 / 03 / 07$ & 0,029 & 0,007 & 0,009 & 0,001 & 0,007 & 0,015 & 0,011 & 0,013 & 0,010 & 0,000 & 0,053 & 0,048 & 10,230 \\
\hline $13 / 03 / 07$ & 0,013 & 0,004 & 0,007 & 0,001 & 0,017 & 0,013 & 0,006 & 0,012 & 0,006 & 0,002 & 0,041 & 0,040 & 3,642 \\
\hline $15 / 03 / 07$ & 0,029 & 0,005 & 0,008 & 0,001 & 0,005 & 0,023 & 0,006 & 0,008 & 0,007 & 0,000 & 0,049 & 0,045 & 8,603 \\
\hline $16 / 03 / 07$ & 0,034 & 0,008 & 0,009 & 0,003 & 0,007 & 0,034 & 0,008 & 0,006 & 0,010 & 0,000 & 0,061 & 0,058 & 4,999 \\
\hline $18 / 03 / 07$ & 0,012 & 0,003 & 0,006 & 0,012 & 0,001 & 0,002 & 0,013 & 0,008 & 0,007 & 0,000 & 0,034 & 0,031 & 9,786 \\
\hline $13 / 04 / 07$ & 0,025 & 0,012 & 0,008 & 0,001 & 0,001 & 0,020 & 0,009 & 0,010 & 0,004 & 0,001 & 0,047 & 0,043 & 7,374 \\
\hline $12 / 05 / 07$ & 0,022 & 0,003 & 0,008 & 0,004 & 0,005 & 0,013 & 0,007 & 0,006 & 0,009 & 0,004 & 0,042 & 0,039 & 8,357 \\
\hline $22 / 05 / 07$ & 0,030 & 0,006 & 0,010 & 0,003 & 0,000 & 0,016 & 0,011 & 0,010 & 0,006 & 0,000 & 0,048 & 0,044 & 9,610 \\
\hline $23 / 05 / 07$ & 0,029 & 0,008 & 0,006 & 0,001 & 0,000 & 0,020 & 0,008 & 0,013 & 0,000 & 0,000 & 0,043 & 0,041 & 6,239 \\
\hline $02 / 06 / 07$ & 0,036 & 0,008 & 0,012 & 0,002 & 0,000 & 0,026 & 0,014 & 0,014 & 0,000 & 0,000 & 0,059 & 0,054 & 8,140 \\
\hline 03/06/07 & 0,033 & 0,007 & 0,012 & 0,005 & 0,000 & 0,034 & 0,009 & 0,006 & 0,010 & 0,003 & 0,057 & 0,062 & $-9,428$ \\
\hline $17 / 07 / 07$ & 0,018 & 0,004 & 0,003 & 0,002 & 0,008 & 0,020 & 0,002 & 0,004 & 0,004 & 0,002 & 0,034 & 0,031 & 9,513 \\
\hline $18 / 07 / 07$ & 0,005 & 0,001 & 0,001 & 0,000 & 0,000 & 0,002 & 0,000 & 0,002 & 0,001 & 0,002 & 0,007 & 0,007 & $-0,151$ \\
\hline $23 / 07 / 07$ & 0,008 & 0,002 & 0,002 & 0,001 & 0,012 & 0,014 & 0,002 & 0,003 & 0,004 & 0,002 & 0,026 & 0,025 & 3,322 \\
\hline $25 / 07 / 07$ & 0,006 & 0,002 & 0,001 & 0,000 & 0,001 & 0,005 & 0,001 & 0,001 & 0,002 & 0,001 & 0,010 & 0,010 & 1,033 \\
\hline $24 / 10 / 07$ & 0,039 & 0,008 & 0,006 & 0,007 & 0,007 & 0,030 & 0,012 & 0,015 & 0,013 & 0,001 & 0,067 & 0,071 & $-5,799$ \\
\hline $30 / 10 / 07$ & 0,019 & 0,004 & 0,005 & 0,005 & 0,028 & 0,030 & 0,008 & 0,015 & 0,013 & 0,002 & 0,060 & 0,067 & $-10,755$ \\
\hline $02 / 11 / 07$ & 0,021 & 0,003 & 0,006 & 0,004 & 0,003 & 0,010 & 0,008 & 0,010 & 0,008 & 0,000 & 0,036 & 0,037 & $-0,767$ \\
\hline $03 / 11 / 07$ & 0,020 & 0,005 & 0,009 & 0,001 & 0,002 & 0,002 & 0,004 & 0,017 & 0,014 & 0,000 & 0,037 & 0,037 & 1,102 \\
\hline $04 / 11 / 07$ & 0,018 & 0,004 & 0,008 & 0,003 & 0,024 & 0,026 & 0,004 & 0,014 & 0,014 & 0,000 & 0,057 & 0,058 & $-2,125$ \\
\hline $11 / 11 / 07$ & 0,007 & 0,002 & 0,005 & 0,001 & 0,001 & 0,004 & 0,002 & 0,004 & 0,005 & 0,000 & 0,015 & 0,015 & 5,255 \\
\hline $05 / 12 / 07$ & 0,022 & 0,003 & 0,008 & 0,004 & 0,005 & 0,012 & 0,007 & 0,006 & 0,009 & 0,005 & 0,042 & 0,039 & 7,145 \\
\hline $11 / 12 / 07$ & 0,017 & 0,006 & 0,007 & 0,005 & 0,016 & 0,005 & 0,006 & 0,023 & 0,011 & 0,000 & 0,051 & 0,046 & 10,877 \\
\hline $12 / 12 / 07$ & 0,011 & 0,002 & 0,003 & 0,000 & 0,005 & 0,012 & 0,001 & 0,005 & 0,005 & 0,000 & 0,022 & 0,024 & $-10,887$ \\
\hline $21 / 12 / 07$ & 0,018 & 0,003 & 0,015 & 0,004 & 0,011 & 0,016 & 0,011 & 0,008 & 0,016 & 0,005 & 0,051 & 0,056 & $-8,465$ \\
\hline 05/01/08 & 0,019 & 0,008 & 0,020 & 0,003 & 0,009 & 0,020 & 0,019 & 0,007 & 0,015 & 0,000 & 0,059 & 0,061 & $-4,032$ \\
\hline $13 / 01 / 08$ & 0,020 & 0,004 & 0,007 & 0,001 & 0,012 & 0,030 & 0,002 & 0,002 & 0,007 & 0,000 & 0,044 & 0,041 & 7,385 \\
\hline $15 / 01 / 08$ & 0,014 & 0,003 & 0,007 & 0,006 & 0,002 & 0,004 & 0,007 & 0,009 & 0,014 & 0,000 & 0,031 & 0,034 & $-6,795$ \\
\hline $18 / 01 / 08$ & 0,014 & 0,004 & 0,007 & 0,004 & 0,000 & 0,014 & 0,007 & 0,007 & 0,003 & 0,000 & 0,028 & 0,030 & $-6,949$ \\
\hline $19 / 01 / 08$ & 0,015 & 0,003 & 0,004 & 0,000 & 0,003 & 0,020 & 0,001 & 0,001 & 0,003 & 0,000 & 0,026 & 0,025 & 3,955 \\
\hline $20 / 01 / 08$ & 0,013 & 0,003 & 0,009 & 0,002 & 0,005 & 0,015 & 0,007 & 0,004 & 0,010 & 0,000 & 0,033 & 0,036 & $-9,654$ \\
\hline $29 / 01 / 08$ & 0,016 & 0,008 & 0,015 & 0,003 & 0,000 & 0,012 & 0,012 & 0,008 & 0,012 & 0,000 & 0,041 & 0,045 & $-8,271$ \\
\hline $08 / 02 / 08$ & 0,019 & 0,008 & 0,015 & 0,000 & 0,000 & 0,021 & 0,009 & 0,008 & 0,006 & 0,000 & 0,042 & 0,044 & $-6,607$ \\
\hline $11 / 02 / 08$ & 0,017 & 0,003 & 0,011 & 0,001 & 0,001 & 0,018 & 0,009 & 0,006 & 0,003 & 0,000 & 0,034 & 0,036 & $-6,910$ \\
\hline $16 / 02 / 08$ & 0,016 & 0,003 & 0,009 & 0,000 & 0,008 & 0,005 & 0,008 & 0,013 & 0,010 & 0,000 & 0,036 & 0,035 & 2,833 \\
\hline $17 / 02 / 08$ & 0,015 & 0,008 & 0,011 & 0,001 & 0,011 & 0,012 & 0,011 & 0,013 & 0,014 & 0,000 & 0,045 & 0,049 & $-8,139$ \\
\hline
\end{tabular}


Apêndice 4 
Tabela 1 D. Composição química ( $\mu \mathrm{g} \mathrm{g}^{-1}$ ) de Cr nas distintas etapas de S1 a S7, frações biodisponível (Bio), residual (R) e total (T) para as amostras de terra dos solos CXbd, LVAd, LVd, RQo nas profundidades de 0-10, 10-20 e 20-40 cm e sedimentos de fundo ITA1 e ITA10 na microbacia Entre Rios, Angatuba, São Paulo.

\begin{tabular}{|c|c|c|c|c|c|c|c|c|c|c|c|c|c|c|}
\hline \multirow{2}{*}{ etapas } & \multicolumn{3}{|c|}{ CXbd } & \multicolumn{3}{|c|}{ LVAd } & \multicolumn{3}{|c|}{ LVd } & \multicolumn{3}{|c|}{ RQo } & \multicolumn{2}{|c|}{ Sedimentos de fundo } \\
\hline & $0-10 \mathrm{~cm}$ & $10-20 \mathrm{~cm}$ & $20-40 \mathrm{~cm}$ & $0-10 \mathrm{~cm}$ & $10-20 \mathrm{~cm}$ & $20-40 \mathrm{~cm}$ & $0-10 \mathrm{~cm}$ & $10-20 \mathrm{~cm}$ & $20-40 \mathrm{~cm}$ & $0-10 \mathrm{~cm}$ & $10-20 \mathrm{~cm}$ & $20-40 \mathrm{~cm}$ & ITA1 & ITA10 \\
\hline S1 & 0,044 & 0,040 & 0,009 & 0,017 & 0,003 & 0,000 & 0,000 & 0,021 & 0,000 & 0,020 & 0,018 & 0,010 & 0,052 & 0,085 \\
\hline S2 & 3,577 & 3,329 & 2,572 & 3,146 & 2,644 & 2,846 & 2,846 & 2,677 & 2,375 & 2,807 & 1,891 & 2,162 & 2,486 & 2,241 \\
\hline S3 & 0,121 & 0,297 & 0,316 & 0,074 & 0,269 & 0,248 & 0,361 & 0,143 & 0,008 & 0,075 & 0,489 & 0,256 & 0,315 & 0,381 \\
\hline S4 & 0,056 & 0,003 & 0,000 & 0,000 & 0,000 & 0,000 & 0,000 & 0,000 & 0,000 & 0,000 & 0,000 & 0,127 & 0,062 & 0,099 \\
\hline S5 & 0,726 & 0,674 & 0,772 & 0,735 & 1,400 & 0,517 & 3,322 & 2,439 & 1,591 & 0,479 & 0,374 & 0,635 & 2,241 & 1,300 \\
\hline S6 & 7,305 & 6,213 & 5,196 & 5,634 & 6,285 & 3,175 & 15,602 & 17,704 & 18,308 & 5,121 & 4,957 & 3,576 & 5,740 & 3,325 \\
\hline S7 & 2,161 & 1,859 & 2,366 & 2,623 & 1,504 & 2,301 & 3,223 & 0,757 & 2,091 & 2,622 & 1,118 & 2,378 & 2,896 & 2,158 \\
\hline Bio & 13,991 & 12,416 & 11,231 & 12,229 & 12,104 & 9,087 & 25,353 & 23,742 & 24,373 & 11,123 & 8,847 & 9,143 & 13,792 & 9,589 \\
\hline $\mathrm{R}$ & 13,654 & 16,365 & 15,071 & 12,096 & 12,167 & 14,389 & 65,332 & 64,160 & 65,127 & 26,867 & 15,971 & 17,110 & 19,175 & 21,977 \\
\hline $\mathrm{T}$ & 27,645 & 28,781 & 26,301 & 24,325 & 24,272 & 23,477 & 90,685 & 87,902 & 89,500 & 37,990 & 24,817 & 26,254 & 32,967 & 31,565 \\
\hline
\end{tabular}


Tabela 2 D. Composição química $\left(\mu \mathrm{g} \mathrm{g}^{-1}\right.$ ) de Cd lixiviado nas distintas etapas de S1 a S7, frações biodisponível (Bio), residual (R) e total (T) para as amostras de terra dos solos CXbd, LVAd, LVd, RQo nas profundidades de 0-10, 10-20 e 20-40 cm e sedimentos de fundo ITA1 e ITA10 na microbacia Entre Rios, Angatuba, São Paulo.

\begin{tabular}{|c|c|c|c|c|c|c|c|c|c|c|c|c|c|c|}
\hline \multirow{2}{*}{ etapas } & \multicolumn{3}{|c|}{ CXbd } & \multicolumn{3}{|c|}{ LVAd } & \multicolumn{3}{|c|}{ LVd } & \multicolumn{3}{|c|}{ RQo } & \multicolumn{2}{|c|}{ Sedimentos de fundo } \\
\hline & $0-10 \mathrm{~cm}$ & $10-20 \mathrm{~cm}$ & $20-40 \mathrm{~cm}$ & $0-10 \mathrm{~cm}$ & $10-20 \mathrm{~cm}$ & $20-40 \mathrm{~cm}$ & $0-10 \mathrm{~cm}$ & $10-20 \mathrm{~cm}$ & $20-40 \mathrm{~cm}$ & $0-10 \mathrm{~cm}$ & $10-20 \mathrm{~cm}$ & $20-40 \mathrm{~cm}$ & ITA1 & ITA10 \\
\hline S1 & 0,014 & 0,002 & 0,007 & 0,006 & 0,003 & 0,000 & 0,000 & 0,000 & 0,000 & 0,000 & 0,000 & 0,008 & 0,018 & 0,012 \\
\hline S2 & 0,175 & 0,067 & 0,022 & 0,250 & 0,158 & 0,109 & 0,226 & 0,116 & 0,163 & 0,155 & 0,193 & 0,214 & 0,258 & 0,102 \\
\hline S3 & 0,000 & 0,069 & 0,129 & 0,083 & 0,136 & 0,000 & 0,231 & 0,357 & 0,000 & 0,057 & 0,143 & 0,180 & 0,216 & 0,344 \\
\hline S4 & 0,033 & 0,025 & 0,058 & 0,031 & 0,070 & 0,000 & 0,020 & 0,000 & 0,000 & 0,000 & 0,000 & 0,090 & 0,078 & 0,153 \\
\hline S5 & 0,083 & 0,022 & 0,023 & 0,057 & 0,147 & 0,000 & 0,535 & 0,390 & 0,137 & 0,000 & 0,000 & 0,109 & 0,367 & 0,278 \\
\hline S6 & 0,564 & 0,365 & 0,265 & 0,333 & 0,428 & 0,119 & 3,159 & 1,912 & 2,866 & 0,167 & 0,153 & 0,471 & 0,349 & 0,248 \\
\hline S7 & 0,036 & 0,149 & 0,088 & 0,127 & 0,000 & 0,000 & 0,126 & 0,430 & 0,601 & 0,000 & 0,014 & 0,263 & 0,577 & 0,440 \\
\hline Bio & 0,904 & 0,699 & 0,592 & 0,886 & 0,941 & 0,228 & 4,298 & 3,205 & 3,766 & 0,379 & 0,503 & 1,334 & 1,863 & 1,577 \\
\hline $\mathrm{R}$ & 1,760 & 1,609 & 1,697 & 1,183 & 1,532 & 2,018 & 0,007 & 0,391 & 0,034 & 2,009 & 1,521 & 0,776 & 1,124 & 1,225 \\
\hline $\mathrm{T}$ & 2,665 & 2,308 & 2,290 & 2,069 & 2,473 & 2,246 & 4,305 & 3,596 & 3,800 & 2,388 & 2,024 & 2,110 & 2,987 & 2,802 \\
\hline
\end{tabular}


Tabela 3 D. Composição química $\left(\mu \mathrm{g} \mathrm{g}^{-1}\right.$ ) de Pb lixiviado nas distintas etapas de S1 a S7, frações biodisponível (Bio), residual (R) e total (T) para as amostras de terra dos solos CXbd, LVAd, LVd, RQo nas profundidades de 0-10, 10-20 e 20-40 cm e sedimentos de fundo ITA1 e ITA10 na microbacia Entre Rios, Angatuba, São Paulo.

\begin{tabular}{cccc}
\hline \multirow{2}{*}{ etapas } & \multicolumn{3}{c}{ LVd } \\
\cline { 2 - 4 } & $0-10 \mathrm{~cm}$ & $10-20 \mathrm{~cm}$ & $20-40 \mathrm{~cm}$ \\
\hline S1 & 0,000 & 0,000 & 0,000 \\
S2 & 0,000 & 0,000 & 0,000 \\
S3 & 0,000 & 0,000 & 0,065 \\
S4 & 0,000 & 1,446 & 0,000 \\
S5 & 3,133 & 2,234 & 0,000 \\
S6 & 5,409 & 3,007 & 0,511 \\
S7 & 0,000 & 0,000 & 0,000 \\
Bio & 8,542 & 6,687 & 0,576 \\
R & 14,638 & 13,153 & 23,654 \\
T & 23,180 & 19,840 & 24,230 \\
\hline
\end{tabular}


Tabela 4 D. Composição química $\left(\mu \mathrm{g} \mathrm{g}^{-1}\right)$ de Ni lixiviado nas distintas etapas de S1 a S7, frações biodisponível (Bio), residual (R) e total (T) para as amostras de terra dos solos CXbd, LVAd, LVd, RQo nas profundidades de 0-10, 10-20 e 20-40 cm e sedimentos de fundo ITA1 e ITA10 na microbacia Entre Rios, Angatuba, São Paulo.

\begin{tabular}{cccc}
\hline \multirow{2}{*}{ etapas } & \multicolumn{3}{c}{$\mathrm{LVd}$} \\
\cline { 2 - 4 } & $0-10 \mathrm{~cm}$ & $10-20 \mathrm{~cm}$ & $20-40 \mathrm{~cm}$ \\
\hline S1 & 0,144 & 0,187 & 0,120 \\
S2 & 0,274 & 0,416 & 0,362 \\
S3 & 0,000 & 1,234 & 0,181 \\
S4 & 1,003 & 1,105 & 1,519 \\
S5 & 1,656 & 1,060 & 0,769 \\
S6 & 0,000 & 0,000 & 0,000 \\
S7 & 0,836 & 4,261 & 6,071 \\
Bio & 3,913 & 8,264 & 9,022 \\
R & 43,719 & 41,057 & 39,598 \\
T & 47,632 & 49,321 & 48,620 \\
\hline
\end{tabular}


Tabela 5 D. Composição química $\left(\mu \mathrm{g} \mathrm{g}^{-1}\right)$ de Co lixiviado nas distintas etapas de S1 a S7, frações biodisponível (Bio), residual (R) e total (T) para as amostras de terra dos solos CXbd, LVAd, LVd, RQo nas profundidades de 0-10, 10-20 e 20-40 cm e sedimentos de fundo ITA1 e ITA10 na microbacia Entre Rios, Angatuba, São Paulo.

\begin{tabular}{|c|c|c|c|c|c|c|c|c|c|c|c|c|c|c|}
\hline \multirow{2}{*}{ etapas } & \multicolumn{3}{|c|}{ CXbd } & \multicolumn{3}{|c|}{ LVAd } & \multicolumn{3}{|c|}{ LVd } & \multicolumn{3}{|c|}{ RQo } & \multicolumn{2}{|c|}{ Sedimentos de fundo } \\
\hline & $0-10 \mathrm{~cm}$ & $10-20 \mathrm{~cm}$ & $20-40 \mathrm{~cm}$ & $0-10 \mathrm{~cm}$ & $10-20 \mathrm{~cm}$ & $20-40 \mathrm{~cm}$ & $0-10 \mathrm{~cm}$ & $10-20 \mathrm{~cm}$ & $20-40 \mathrm{~cm}$ & $0-10 \mathrm{~cm}$ & $10-20 \mathrm{~cm}$ & $20-40 \mathrm{~cm}$ & ITA1 & ITA10 \\
\hline S1 & 0,057 & 0,014 & 0,014 & 0,007 & 0,001 & 0,016 & 0,211 & 0,649 & 0,496 & 0,031 & 0,036 & 0,000 & 0,032 & 0,028 \\
\hline S2 & 0,361 & 0,179 & 0,220 & 0,000 & 0,028 & 0,000 & 3,600 & 2,081 & 2,077 & 0,015 & 0,011 & 0,000 & 0,926 & 0,538 \\
\hline S3 & 0,285 & 0,020 & 0,072 & 0,068 & 0,000 & 0,116 & 2,527 & 2,206 & 2,673 & 0,000 & 0,171 & 0,063 & 1,457 & 0,945 \\
\hline S4 & 0,076 & 0,000 & 0,062 & 0,214 & 0,000 & 0,125 & 1,559 & 0,958 & 1,482 & 0,158 & 0,346 & 0,000 & 0,000 & 0,000 \\
\hline S5 & 0,278 & 0,026 & 0,169 & 0,029 & 0,005 & 0,076 & 6,935 & 5,006 & 4,276 & 0,290 & 0,373 & 0,305 & 1,982 & 1,718 \\
\hline S6 & 0,799 & 0,628 & 0,433 & 0,516 & 0,903 & 0,368 & 2,412 & 3,308 & 3,007 & 0,652 & 0,627 & 0,283 & 0,970 & 0,445 \\
\hline S7 & 0,183 & 0,167 & 0,279 & 0,912 & 0,324 & 0,240 & 3,360 & 4,635 & 6,067 & 0,934 & 0,678 & 0,124 & 0,278 & 0,435 \\
\hline Bio & 2,039 & 1,034 & 1,249 & 1,745 & 1,262 & 0,942 & 20,604 & 18,844 & 20,079 & 2,080 & 2,242 & 0,775 & 5,646 & 4,107 \\
\hline $\mathrm{R}$ & 8,500 & 9,196 & 5,473 & 13,644 & 12,189 & 12,095 & 165,854 & 168,369 & 158,461 & 2,901 & 1,687 & 3,562 & 11,976 & 13,211 \\
\hline $\mathrm{T}$ & 10,539 & 10,230 & 6,722 & 15,389 & 13,451 & 13,037 & 186,458 & 187,213 & 178,540 & 4,981 & 3,929 & 4,337 & 17,622 & 17,318 \\
\hline
\end{tabular}


Tabela 6 D. Composição química $\left(\mu \mathrm{g} \mathrm{g}^{-1}\right)$ de Cu lixiviado nas distintas etapas de S1 a S7, frações biodisponível (Bio), residual (R) e total (T) para as amostras de terra dos solos CXbd, LVAd, LVd, RQo nas profundidades de 0-10, 10-20 e 20-40 cm e sedimentos de fundo ITA1 e ITA10 na microbacia Entre Rios, Angatuba, São Paulo.

\begin{tabular}{|c|c|c|c|c|c|c|c|c|c|c|c|c|c|c|}
\hline \multirow{2}{*}{ etapas } & \multicolumn{3}{|c|}{ CXbd } & \multicolumn{3}{|c|}{ LVAd } & \multicolumn{3}{|c|}{ LVd } & \multicolumn{3}{|c|}{ RQo } & \multicolumn{2}{|c|}{ Sedimentos de fundo } \\
\hline & $0-10 \mathrm{~cm}$ & $10-20 \mathrm{~cm}$ & $20-40 \mathrm{~cm}$ & $0-10 \mathrm{~cm}$ & $10-20 \mathrm{~cm}$ & $20-40 \mathrm{~cm}$ & $0-10 \mathrm{~cm}$ & $10-20 \mathrm{~cm}$ & $20-40 \mathrm{~cm}$ & $0-10 \mathrm{~cm}$ & $10-20 \mathrm{~cm}$ & $20-40 \mathrm{~cm}$ & ITA1 & ITA10 \\
\hline S1 & 0,126 & 0,052 & 0,013 & 0,006 & 0,007 & 0,000 & 0,000 & 0,017 & 0,000 & 0,013 & 0,000 & 0,013 & 0,037 & 0,039 \\
\hline S2 & 0,000 & 0,000 & 0,000 & 0,000 & 0,000 & 0,000 & 0,349 & 0,486 & 0,451 & 0,583 & 0,003 & 0,000 & 0,000 & 0,000 \\
\hline S3 & 0,000 & 0,000 & 0,093 & 0,049 & 0,021 & 0,078 & 2,743 & 2,012 & 2,258 & 0,297 & 0,005 & 0,033 & 0,236 & 0,000 \\
\hline S4 & 0,054 & 0,000 & 0,000 & 0,136 & 0,000 & 0,000 & 0,000 & 0,000 & 0,000 & 0,000 & 0,000 & 0,144 & 0,082 & 0,088 \\
\hline S5 & 2,819 & 1,810 & 1,445 & 0,906 & 1,007 & 0,684 & 15,162 & 13,365 & 10,688 & 1,031 & 0,433 & 1,769 & 2,508 & 1,395 \\
\hline S6 & 0,747 & 0,632 & 0,000 & 0,000 & 0,000 & 0,000 & 0,370 & 25,414 & 14,062 & 0,000 & 0,000 & 0,000 & 1,888 & 0,911 \\
\hline S7 & 0,166 & 0,095 & 0,000 & 0,000 & 0,000 & 0,000 & 10,052 & 11,911 & 20,171 & 0,000 & 0,000 & 0,258 & 0,610 & 0,619 \\
\hline Bio & 3,912 & 2,589 & 1,551 & 1,097 & 1,034 & 0,762 & 28,677 & 53,205 & 47,630 & 1,924 & 0,441 & 2,218 & 5,361 & 3,052 \\
\hline $\mathrm{R}$ & 22,026 & 13,665 & 10,377 & 37,997 & 11,136 & 9,296 & 179,161 & 154,018 & 158,100 & 11,726 & 12,235 & 4,655 & 12,561 & 14,395 \\
\hline $\mathrm{T}$ & 25,938 & 16,254 & 11,928 & 39,094 & 12,170 & 10,059 & 207,838 & 207,223 & 205,730 & 13,650 & 12,675 & 6,873 & 17,922 & 17,448 \\
\hline
\end{tabular}


Tabela 7 D. Composição química $\left(\mu \mathrm{g} \mathrm{g}^{-1}\right.$ ) de Zn lixiviado nas distintas etapas de S1 a S7, frações biodisponível (Bio), residual (R) e total (T) para as amostras de terra dos solos CXbd, LVAd, LVd, RQo nas profundidades de 0-10, 10-20 e 20-40 cm e sedimentos de fundo ITA1 e ITA10 na microbacia Entre Rios, Angatuba, São Paulo.

\begin{tabular}{|c|c|c|c|c|c|c|c|c|c|c|c|}
\hline \multirow{2}{*}{ etapas } & \multicolumn{3}{|c|}{ CXbd } & \multicolumn{3}{|c|}{ LVAd } & \multicolumn{3}{|c|}{$\mathrm{LVd}$} & \multicolumn{2}{|c|}{ Sedimentos de fundo } \\
\hline & $0-10 \mathrm{~cm}$ & $10-20 \mathrm{~cm}$ & $20-40 \mathrm{~cm}$ & $0-10 \mathrm{~cm}$ & $10-20 \mathrm{~cm}$ & $20-40 \mathrm{~cm}$ & $0-10 \mathrm{~cm}$ & $10-20 \mathrm{~cm}$ & $20-40 \mathrm{~cm}$ & ITA1 & ITA10 \\
\hline S1 & 0,000 & 0,000 & 0,000 & 0,000 & 0,000 & 0,198 & 1,134 & 2,579 & 0,645 & 0,000 & 0,000 \\
\hline S2 & 0,000 & 0,123 & 0,000 & 0,000 & 0,000 & 0,000 & 0,000 & 0,000 & 0,000 & 0,000 & 0,000 \\
\hline S4 & 0,000 & 0,000 & 0,000 & 0,000 & 0,000 & 0,127 & 13,401 & 9,768 & 9,118 & 0,000 & 0,000 \\
\hline S5 & 14,456 & 7,540 & 0,000 & 0,000 & 0,000 & 3,117 & 26,657 & 25,396 & 15,625 & 6,309 & 3,015 \\
\hline S6 & 0,000 & 0,000 & 0,000 & 0,000 & 0,000 & 1,507 & 22,882 & 32,959 & 29,510 & 0,000 & 0,000 \\
\hline S7 & 0,000 & 0,000 & 0,000 & 0,000 & 0,000 & 0,196 & 37,129 & 61,395 & 69,791 & 0,000 & 0,000 \\
\hline Bio & 14,456 & 7,663 & 0,836 & 4,860 & 4,108 & 5,911 & 101,204 & 132,097 & 124,690 & 8,678 & 3,015 \\
\hline $\mathrm{R}$ & 22,440 & 16,194 & 21,669 & 31,771 & 31,620 & 28,269 & 69,149 & 21,339 & 20,410 & 26,127 & 40,196 \\
\hline $\mathrm{T}$ & 36,896 & 23,856 & 22,505 & 36,631 & 35,728 & 34,180 & 170,352 & 153,437 & 145,100 & 34,805 & 43,210 \\
\hline
\end{tabular}


Tabela 8 D. Composição química $\left(\mu \mathrm{g} \mathrm{g}^{-1}\right.$ ) de Sc lixiviado nas distintas etapas de S1 a S7, frações biodisponível (Bio), residual (R) e total (T) para as amostras de terra dos solos CXbd, LVAd, LVd, RQo nas profundidades de 0-10, 10-20 e 20-40 cm e sedimentos de fundo ITA1 e ITA10 na microbacia Entre Rios, Angatuba, São Paulo.

\begin{tabular}{|c|c|c|c|c|c|c|c|c|c|c|c|c|c|c|}
\hline \multirow{2}{*}{ etapas } & \multicolumn{3}{|c|}{ CXbd } & \multicolumn{3}{|c|}{ LVAd } & \multicolumn{3}{|c|}{$\mathrm{LVd}$} & \multicolumn{3}{|c|}{ RQo } & \multicolumn{2}{|c|}{ Sedimentos de fundo } \\
\hline & $0-10 \mathrm{~cm}$ & $10-20 \mathrm{~cm}$ & $20-40 \mathrm{~cm}$ & $0-10 \mathrm{~cm}$ & $10-20 \mathrm{~cm}$ & $20-40 \mathrm{~cm}$ & $0-10 \mathrm{~cm}$ & $10-20 \mathrm{~cm}$ & $20-40 \mathrm{~cm}$ & $0-10 \mathrm{~cm}$ & $10-20 \mathrm{~cm}$ & $20-40 \mathrm{~cm}$ & ITA1 & ITA10 \\
\hline S1 & 0,063 & 0,071 & 0,024 & 0,040 & 0,033 & 0,017 & 0,010 & 0,006 & 0,003 & 0,042 & 0,040 & 0,010 & 0,007 & 0,008 \\
\hline S2 & 0,042 & 0,061 & 0,073 & 0,043 & 0,087 & 0,061 & 0,051 & 0,071 & 0,055 & 0,000 & 0,071 & 0,052 & 0,015 & 0,002 \\
\hline S3 & 0,141 & 0,504 & 0,729 & 0,239 & 0,692 & 0,904 & 1,109 & 1,195 & 1,831 & 0,288 & 0,766 & 0,825 & 0,175 & 0,096 \\
\hline S4 & 0,000 & 0,008 & 0,006 & 0,012 & 0,007 & 0,002 & 0,000 & 0,000 & 0,002 & 0,006 & 0,004 & 0,002 & 0,000 & 0,000 \\
\hline S5 & 0,000 & 2,057 & 1,816 & 0,961 & 1,711 & 1,751 & 5,291 & 5,506 & 5,711 & 1,373 & 1,897 & 2,296 & 0,597 & 0,308 \\
\hline S6 & 1,323 & 1,164 & 0,792 & 0,658 & 0,847 & 0,507 & 6,193 & 7,762 & 8,036 & 0,716 & 0,889 & 0,688 & 0,293 & 0,170 \\
\hline S7 & 0,069 & 0,034 & 0,117 & 0,045 & 0,022 & 0,017 & 0,297 & 0,546 & 0,836 & 0,080 & 0,024 & 0,022 & 0,042 & 0,062 \\
\hline Bio & 1,638 & 3,900 & 3,558 & 1,999 & 3,399 & 3,260 & 12,951 & 15,087 & 16,475 & 2,505 & 3,692 & 3,896 & 1,129 & 0,646 \\
\hline $\mathrm{R}$ & 3,652 & 1,195 & 1,824 & 1,154 & 0,902 & 3,576 & 28,439 & 34,663 & 24,225 & 2,252 & 1,737 & 1,138 & 1,968 & 2,444 \\
\hline $\mathrm{T}$ & 5,289 & 5,095 & 5,382 & 3,153 & 4,301 & 6,836 & 41,389 & 49,750 & 40,700 & 4,757 & 5,429 & 5,034 & 3,097 & 3,091 \\
\hline
\end{tabular}

